\title{
WHAT DRIVES CAR USE? \\ MODELLING PSYCHOLOGICAL \\ ANTECEDENTS OF TRAVEL \\ MODE CHOICE
}

\author{
Benjamin David Gardner \\ Doctor of Philosophy (DPhil), Social Psychology \\ University of Sussex \\ March 2008
}


I hereby declare that this thesis has not been and will not be, submitted in whole or in part to another University for the award of any other degree.

Signature. 


\section{Acknowledgements}

Thanks to:

Charles Abraham for his help, encouragement, support, and laptop;

everybody who gave their time to participate in my studies;

Steve Weeks, O Fasoul, Stewart Holmes, Graham McDonald, Kev Grimwood, Heather Finch, and Maureen O'Reilly for allowing me access to employees for studies 1 and 2 and accepting very little in return;

Henk Aarts, Christy Collins, Sonja Forward, Jörgen Garvill, Maria Johansson, Maria

Vredin Johansson, Florian Kaiser, Christian Klöckner, Ellen Matthies, Annika

Nordlund, Merritt Polk, Henk Staats, and Bas Verplanken, for responding to my requests for information for the meta-analysis in study 3 ;

Stuart Croucher, Dean Spears, Charlotte Welch and the Transport Planning Department at Brighton and Hove Council for allowing me to send questionnaires for free to local residents for study 4 ;

Gjalt-Jorn Peters, Dirk Franssens, Rob Ruiter and everyone else in the Work and Organisational department at Maastricht University who made me feel so welcome and supported me through my data collection for study 7 , and who taught me the Dutch for 'three beers please';

Neelam, for her kindness, generosity, and rotia;

my family - and especially Mum, who thought of random words to filter out irrelevant papers for the systematic search for study 3, and Dad, who not only read the publication of study 1 but also made notes and put ticks in the margin as teachers are wont to do;

and

Poonam, for love, happiness, and making it all worthwhile. 


\title{
UNIVERSITY OF SUSSEX
}

\section{BENJAMIN DAVID GARDNER \\ DOCTOR OF PHILOSOPHY (DPHIL), SOCIAL PSYCHOLOGY}

\section{WHAT DRIVES CAR USE? MODELLING PSYCHOLOGICAL ANTECEDENTS OF TRAVEL MODE CHOICE}

\begin{abstract}
Car emissions have significant detrimental environmental and health impacts, and many journeys could be undertaken using alternative transport. Effective transport policy necessitates identification of potentially modifiable determinants of driving. This thesis identified psychological underpinnings of decisions to drive. Study 1 used qualitative 'grounded theory' analysis to detail commuters' reasons for driving, and highlighted misconceptions and biases underpinning these motives. In study 2, we developed quantitative measures of the concepts identified in study 1 , and tested these as determinants of decisions to commute by public transport alongside variables from the Theory of Planned Behaviour (TPB; Ajzen, 1991). Results showed that the inductive concepts were best modelled as determinants of attitude and control perceptions, and demonstrated the superiority of established deductive concepts. A meta-analysis of the extant literature (study 3 ) showed a dearth of available evidence of correlates of driving. Strong associations with behaviour were found for intention and habit, and TPB cognitions relating to not driving showed stronger effects on intentions than did TPB variables relating to driving. There were also effects for descriptive and personal norms. Using an extended TPB model, study 4 demonstrated that the motivation to make local journeys by car was informed by cognitions relating to car and to non-car travel, and descriptive and personal norms. Environmental beliefs informed personal norms and attitudes to non-car travel. Studies 5-7 explored habit in commuting mode choice: study 5 developed a new self-report habit measure, which in studies 6 and 7 was used in comparison with existing habit indices to predict car and bicycle commuting among UK and Dutch samples respectively. Findings revealed the superiority of an existing habit measure, and pointed to the habitual nature of commuting mode choice. The seven studies highlighted motivational and volitional determinants of driving, and suggest various intervention strategies to reduce car use.
\end{abstract}




\section{Table of contents}

Declaration $\quad$ ii

Acknowledgements

Abstract iv

Table of contents

Figures $x i$

Tables

Chapter 1. Introduction 1

1.1. Structural driving reduction strategies: 'Carrots' and 'sticks' 2

1.2. Psychological and behavioural strategies 3

1.3. What drives car use? 6

1.4. The theory of planned behaviour $\quad 7$

1.5. Antecedents of TPB cognitions 9

1.6. Potential additional determinants of intentions and behaviour 11

$\begin{array}{ll}\text { 1.6.1. Cognitions towards alternatives } & 11\end{array}$

$\begin{array}{ll}\text { 1.6.2. Willingness to reduce car use } & 12\end{array}$

$\begin{array}{lll}\text { 1.6.3. } & \text { Car use as a social dilemma } & 13\end{array}$

$\begin{array}{lll}\text { 1.6.4. Personal norms and the TPB } & 13\end{array}$

1.6.5. The theory of interpersonal behaviour: affect and habit 14

1.7. Work reported in this thesis 16

Chapter 2. Study 1: A grounded theory analysis of commuters' reasons for driving

2.1. Abstract 19

2.2. Literature review 19

2.2.1. The present study 21

2.3. Method 21

2.3.1. Participants 21

2.3.2. Procedure and interview schedule 22

2.3.3. Grounded theory 22 
2.4. Results 23

2.4.1. Journey time concerns and journey-based affect 23

2.4.2. Effort minimisation 27

2.4.3. Personal space concerns 28

2.4.4. Monetary cost concerns 29

2.4.5. Desire for control 30

2.4.6. Views on transport policies: Consequences for whom? 32

2.5. Discussion 34

Chapter 3. Study 2: Predicting travel mode choice among regular car commuters: Comparing and integrating the Theory of Planned Behaviour and inductive concepts

3.1. Abstract 39

3.2. Literature review 39

3.2.1. The present study 42

3.3. Method 43

3.3.1. Pilot study 43

3.3.2. Main study 45

3.3.2.1. Participants and procedure 45

3.3.2.2. Measures 46

3.4. Results 49

3.4.1. Descriptives and correlations 49

3.4.2. Regressions 50

3.4.2.1. Modelling T2 behaviour 53

3.4.2.2. Modelling T1 intentions to commute by

3.4.2.3. Modelling T1 attitudes towards PT 54

3.4.2.4. Modelling T1 PBC 55

3.4.3. Constructing a structural model of travel mode choice 55

3.4.4. Post-hoc analyses: Modelling T1 affect 58

3.5. Discussion 58

Chapter 4. Study 3: A meta-analysis of potentially modifiable psychological correlates of car use

4.1. Abstract 65

4.2. Literature review 65

4.3. Method 69

4.3.1. Literature searches and inclusion criteria 69 
$\begin{array}{lll}\text { 4.3.2. } & \text { Data extraction } & 71\end{array}$

4.3.3. Study characteristics and measures 71

4.3.4. Meta-analytic strategy 75

$\begin{array}{lll}\text { 4.3.4.1. } & \text { Specificity } & 75\end{array}$

4.3.4.2. $\quad$ Multiple measures $\quad 75$

$\begin{array}{lll}\text { 4.3.4.3. } & \text { Effect size analyses } & 75\end{array}$

4.3.4.4. Failsafe N 75

4.3.4.5. Heterogeneity analyses 76

4.4. Results 76

4.4.1. Correlates of behaviour $\quad 77$

4.4.1.1. $\quad$ TPB and associated variables 77

$\begin{array}{lll}\text { 4.4.1.1.1. } & \text { Intention to (not) use a car } & 77\end{array}$

4.4.1.1.2. Attitudes 77

4.4.1.1.3. $\quad$ Perceived behavioural control (PBC) 77

$\begin{array}{lll}\text { 4.4.1.1.4. } & \text { Subjective norms } & 79\end{array}$

4.4.1.1.5. Other normative variables $\quad 79$

$\begin{array}{lll}\text { 4.4.1.2. } & \text { Car use habit } & 79\end{array}$

4.4.1.3. Environmental variables 80

4.4.2. Correlates of intention and preference $\quad 81$

$\begin{array}{lll}\text { 4.4.2.1. } & \text { TPB variables } & 81\end{array}$

4.4.2.1.1. $\quad$ Attitudes $\quad 81$

4.4.2.1.2. PBC $\quad 81$

4.4.2.1.3. $\quad$ Subjective norms 81

4.4.2.2. Car use habit $\quad 81$

4.4.2.3. Travel concerns $\quad 83$

4.4.2.4. Social value orientation $\quad 83$

4.4.3. Correlates of willingness to reduce car use 83

$\begin{array}{lll}\text { 4.4.3.1. } & \text { Environmental variables } & 83\end{array}$

4.4.3.2. Self-transcendent values $\quad 85$

4.5. Discussion $\quad 85$

Chapter 5. Study 4: Going green? Modelling the impact of environmental concerns and perceptions of transport alternatives on decisions to drive 90

$\begin{array}{llr}\text { 5.1. } & \text { Abstract } & 90\end{array}$

5.2. Literature review 90

5.2.1. The theory of planned behaviour 91

5.2.2. Environmental considerations and personal moral norms 91

$\begin{array}{lll}\text { 5.2.3 Descriptive norms } & 92\end{array}$

5.2.4. Cognitions towards non-car use 93

$\begin{array}{lll}\text { 5.2.5. The present study } & 93\end{array}$ 
$\begin{array}{lll}\text { 5.3. } & 94\end{array}$

$\begin{array}{lll}\text { 5.3.1. } & \text { Procedure and participants } & 94\end{array}$

5.3.2. Measures 95

5.4. Results 97

5.4.1. Sample homogeneity 97

$\begin{array}{lll}\text { 5.4.2. Descriptive statistics and correlations } & 97\end{array}$

5.4.3. Modelling car use: A path analysis 99

$\begin{array}{ll}\text { 5.5. Discussion } & 104\end{array}$

Chapter 6. Studies 5-7: Is travel mode choice an automatic decision? 109

6.1. Abstract 109

$\begin{array}{ll}\text { 6.2. } & 109\end{array}$

6.2.1. Habits in travel mode choice 110

6.2.2. Habit measurement 112

6.2.2.1. Past behaviour 112

6.2.2.2. Response-frequency measure 113

$\begin{array}{lll}\text { 6.2.2.3. } & 114\end{array}$

$\begin{array}{ll}\text { 6.2.3. Developing a new measure of automaticity } & 115\end{array}$

6.3. Study 5: Developing an automaticity measure 115

$\begin{array}{lll}\text { 6.3.1. Method } & 115\end{array}$

$\begin{array}{lll}\text { 6.3.2. Results } & 115\end{array}$

$\begin{array}{ll}\text { 6.3.3. Discussion } & 116\end{array}$

6.4. Study 6: Car use as a habitual behaviour 121

$\begin{array}{lll}\text { 6.4.1. Method } & 122\end{array}$

6.4.1.1. Participants and procedure 122

6.4.1.2. Measures 122

$\begin{array}{lll}\text { 6.4.2. Results } & 125\end{array}$

$\begin{array}{lll}\text { 6.4.2.1. } & \text { Skewness } & 125\end{array}$

$\begin{array}{ll}\text { 6.4.2.2. } & 125\end{array}$

6.4.2.3. Habit as a moderator of the intention-behaviour relation 127

$\begin{array}{ll}\text { 6.4.3. Discussion } & 132 \\ 6.5 . & 133\end{array}$

6.5. Study 7: Bicycle use as a habitual behaviour 133

$\begin{array}{lll}\text { 6.5.1. Method } & 134\end{array}$

$\begin{array}{lll}\text { 6.5.1.1. } & 134\end{array}$

$\begin{array}{lll}\text { 6.5.1.2. } & 134 \\ 6.5 .2 . & \text { Measures }\end{array}$

$\begin{array}{lll}\text { 6.5.2. Results } & 135\end{array}$

$\begin{array}{lll}\text { 6.5.2.1. } & 135\end{array}$

$\begin{array}{lll}\text { 6.5.2.2. } & 135\end{array}$

6.5.2.3. Habit as a moderator of the intention-behaviour relation 136

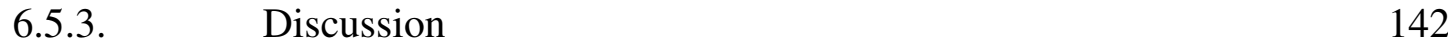


6.6. General discussion of studies 5, 6 and 7

$\begin{array}{lll}\text { 6.6.1. Habit measurement } & 144\end{array}$

$\begin{array}{lll}\text { 6.6.2. } & \text { Is travel mode choice habitual? } & 146\end{array}$

6.6.3. How can habits be broken? 147

$\begin{array}{lll}\text { 6.6.4. } & 148\end{array}$

$\begin{array}{lll}\text { 6.6.5. Conclusion } & 149\end{array}$

$\begin{array}{ll}\text { Chapter 7. Discussion } & 150\end{array}$

$\begin{array}{ll}\text { 7.1. Overview } & 150\end{array}$

$\begin{array}{lll}\text { 7.2. } & \text { The present findings } & 150\end{array}$

7.3. Theoretical implications: Towards an integrative model of car use 153

7.3.1. Determinants of intentions to drive 154

7.3.2. Beliefs underlying pre-intention cognitions 156

7.3.3. Barriers to the transition of intention into action 157

$\begin{array}{lll}\text { 7.4. } & \text { Transport policy implications } & 158\end{array}$

$\begin{array}{lll}\text { 7.5. } & \text { Directions for future research } & 159\end{array}$

$\begin{array}{lll}\text { 7.6. Conclusion } & 161\end{array}$

$\begin{array}{ll}\text { References } & 162\end{array}$

$\begin{array}{ll}\text { Appendices } & 186\end{array}$

A.2.1. Study 1 recruitment email to employers

A.2.2. Study 1 interview schedule

A.2.3. Debrief for study 1

A.3.1. Study 2 pilot study questionnaire

A.3.2. Study 2 main study recruitment email sent to employers

A.3.3. Study 2 main study recruitment email sent to employees

A.3.4. Study 2 main study Time 1 questionnaire

A.3.5. Study 2 main study Time 2 recruitment email

A.3.6. Study 2 main study Time 2 reminder email

A.3.7. Study 2 main study Time 2 questionnaire

A.3.8. Debrief for study 2 main study

A.4.1. Online search details for study 3

A.4.2. Data extraction form and author request form for study 3

A.4.3. Study characteristics and effect sizes for studies and variables entered into study 3 meta-analysis

A.4.4. Study characteristics and effect sizes from studies excluded from study 3 meta-analysis

A.5.1. Recruitment letter sent to participants in study 4 postal group

A.5.2. Recruitment email sent to participants in study 4 online group

A.5.3. Study 4 questionnaire

A.5.4. Debrief for study 4 online participants 
A.6.1. Study 5 recruitment email

A.6.2. Study 5 questionnaire

A.6.3. Study 5 debrief

A.6.4. Study 6 recruitment email

A.6.5. Study 6 recruitment poster

A.6.6. Study 6 questionnaire

A.6.7. Study 6 Time 2 email and questionnaire

A.6.8. Study 6 Time 2 reminder email

A.6.9. Study 6 debrief

A.6.10.Study 7 recruitment poster

A.6.11.Study 7 questionnaire

A.6.12.Study 7 Time 2 email and questionnaire

A.6.13.Study 7 Time 2 reminder email

A.6.14.Study 7 debrief 
Figures

Chapter 3. Study 2: Predicting travel mode choice among regular car commuters: Comparing and integrating the Theory of Planned Behaviour and inductive concepts

3.1. Hypothesised structural model of PT versus car commuting with standardised path coefficients and explained variance in $\mathrm{T} 1$ attitude, T1 PBC, T1 intention and T2 behaviour

Chapter 5. Study 4: Going green? Modelling the impact of environmental concerns and perceptions of transport alternatives on decisions to drive

5.1. Non-car use attitude as moderator of car use PBC-intention relation 102

5.2. PCE as moderator of car use PBC-intention relation 103

5.3. Path model with standardised regression coefficients and explained variances

Chapter 6. Studies 5-7: Is travel mode choice an automatic decision?

6.1. RFM as moderator of intention-behaviour relation (study 6)

6.2. SRHI as moderator of intention-behaviour relation (study 6)

6.3. Modified-SRHI as moderator of intention-behaviour relation (study 6)

6.4. SRHI as moderator of intention-behaviour relation (study 7)

6.5. Modified-SRHI as moderator of intention-behaviour relation (study 7) 


\section{Tables}

Chapter 3. Study 2: Predicting travel mode choice among regular car commuters: Comparing and integrating the Theory of Planned Behaviour and inductive concepts

3.1. Pilot questionnaire items with reliability coefficients 44

3.2. Intercorrelations and descriptive statistics 51

3.3. Regression of $\mathrm{T} 1$ intention on significant correlates $(N=222)$

Chapter 4. Study 3: A meta-analysis of potentially modifiable psychological correlates of car use

$\begin{array}{lll}\text { 4.1. } & \text { Screening process } & 70\end{array}$

4.2. Behaviour measures employed in studies featuring car use correlates 73

4.3. Intention and willingness measures employed in studies featuring car use correlates

$\begin{array}{lll}\text { 4.4. } & \text { Correlates of driving } & 78\end{array}$

4.5. Correlates of intention to drive 82

4.6. Correlates of willingness to reduce driving 84

Chapter 5. Study 4: Going green? Modelling the impact of environmental concerns and perceptions of transport alternatives on decisions to drive

5.1. Intercorrelations and descriptive statistics

5.2. Trimmed regression of intention including interaction terms $(N=187) \quad 100$

\section{Chapter 6. Studies 5-7: Is travel mode choice an automatic decision?}

6.1. Study 5: Intercorrelations between piloted automaticity items 117

6.2. Study 5: Automaticity scale items and factor loadings 120

6.3. Study 6: Descriptive statistics and correlations 126

6.4. Study 6: Principal component analyses for behaviour, intention, SRHI and automaticity items 128

6.5. Study 6: RFM as moderator of intention-behaviour relationship $(N=105) 129$

6.6. Study 6: SRHI as moderator of intention-behaviour relationship $(N=107) 130$

6.7. Study 6: Modified SRHI as moderator of intention-behaviour relationship $(N=107) \quad 131$

6.8. Study 6: AM as moderator of intention-behaviour relationship $(N=107) 132$

6.9. Study 7: Descriptive statistics and correlations 137 
6.10. Study 7: Principal component analyses for behaviour, intention,

SRHI and automaticity items

6.11. Study 7: RFM as moderator of intention-behaviour relationship $(N=99) 139$

6.12. Study 7: SRHI as moderator of intention-behaviour relationship $(N=102) 139$

6.13. Study 7: Modified-SRHI as moderator of intention-behaviour relationship $(N=102)$

6.14. Study 7: AM as moderator of intention-behaviour relationship $(N=102) 142$ 


\section{Chapter 1. Introduction}

Traffic emissions, which are predominantly attributable to private car use (Berntsen, 2004), contribute to climate change (Oskamp, 2000) and cardiovascular and respiratory diseases (Peters \& Pope, 2002; Peters et al., 2004; UK National Air Quality Information Archive [UKNAQIA], undated), and are thus implicated in the deaths of over 24,000 people in the UK each year (Department for the Environment, Transport and the Regions [DETR], 2000). Yet levels of private car use continue to increase (Department for Transport [DfT], 2006a): mileage travelled by car within the UK increased by $75 \%$ between 1980 and 2005, and car journeys now account for $80 \%$ of all UK road travel (DfT, 2006a). Environmental health risks are likely to become more acute unless levels of private car use are significantly reduced (Department of Health, 1998; Goodwin, 1997; Stern, 1992). This is a realistic target because $25 \%$ of all UK car journeys cover distances of less than 2 miles (Institution of Civil Engineers, 2005; DETR, 2000), which in most cases could be undertaken using alternative transport (Goodwin, 1997).

However, while many drivers acknowledge the necessity of reduced car use (e.g. Commission for Integrated Transport [CfIT], 2002), few are switching to non-car transport (e.g. Steg \& Sievers, 2000; Stradling, Meadows \& Beatty, 2000).

Transport demand management (TDM) schemes seek to provide sustainable solutions to congestion and pollution problems by reducing traffic levels and managing traffic flow. Although originally designed to optimise the efficiency of urban transportation systems, growing concerns over air pollution and energy conservation have led to TDM schemes being harnessed primarily to reduce private car use (Meyer, 1999). Fujii and colleagues (Fujii, Gärling \& Kitamura, 2001; Taniguchi, Hara, Takano, Kagaya \& Fujii, 2003) have classified TDM initiatives into two categories.

Modifications of the physical and/or legislative structures that regulate travel behaviour (e.g. bus priority lanes, road pricing, pedestrianisation schemes; cf. Steg, 2003) aim to decrease the attractiveness of and opportunities for car travel and offer incentives for use of non-car transport (Gärling \& Schuitema, 2007), whereas psychological and behavioural interventions seek to change attitudes, beliefs and perceptions and thereby engender voluntary mode switch (Taylor \& Ampt, 2003). 


\subsection{Structural driving reduction strategies: 'Carrots' and 'sticks'}

Structural TDM strategies can be further divided into 'carrot' and 'stick' policies, which respectively seek to promote and/or enhance benefits of non-car travel (e.g. improving public transport services), and decrease the attractiveness of car use via punitive measures or reduced opportunities to drive (e.g. restricting car access to city centre areas; Meyer, 1999).

TDM measures which are unpopular with the general public are less politically manageable and less likely to be effective (Gärling \& Schuitema, 2007; Saleh, 2007; Schade \& Schlag, 2003). Transport users recognise the necessity and likely effectiveness of driving reduction programmes (CfIT, 2002), and judge 'carrot' policies more favourably than 'sticks' (Thorpe, Hills \& Jaensirisak, 2000). Thorpe et al. (2000), for example, found that, among 650 members of the general public, $80 \%$ thought public transport improvements were 'totally acceptable', but 50\% judged parking charges and restricted city centre access for private cars to be 'unacceptable'. Many drivers cite poor public transport facilities as a reason for driving (e.g. Mackett, 2003), but enhancements to public transport services may be insufficient to prompt drivers to switch to alternative transport. In one study for example, a bus service introduced in response to local drivers' concerns that non-car transport was unavailable was withdrawn after four months due to lack of demand (Going for Green, 1999).

Structural 'carrot' strategies are based on the assumption that, acting rationally, drivers will seek to maximise expected utility (Winterton \& Sheate, 2003). Unfortunately this approach neglects the complex systems of beliefs, attitudes and affective experiences which underpin travel mode choice (Mann \& Abraham, 2006). Psychological research has shown that drivers often hold unrealistically negative perceptions of the attractiveness and feasibility of public transport, tending to for example overestimate travel times (Fujii \& Kitamura, 2003), anticipate negative affective experiences (Mann \& Abraham, 2006), and generalise from atypical isolated public transport experiences or 'worst-case scenarios' (Guiver, 2007). Public transport enhancements alone may therefore be ineffective in promoting mode switching because they fail to address biased perceptions of public transportation (Fujii \& Kitamura, 2003). Although policymakers continue to promote public transport via improved services and infrastructure (DfT, 2005a; Kingham, Dickinson \& Copsey, 2001), costly structural modifications may be unnecessary, because cognition change might be a more 
effective route to behaviour change among drivers (Fujii \& Kitamura, 2003; cf. Marinelli \& Roth, 2002).

In the past decade, policy attention has shifted towards the implementation of 'stick' measures, and in particular, road pricing schemes, which provide financial incentives for car use reduction (Saleh, 2007; Thorpe et al., 2000). In 2003, London implemented a congestion charge, a form of road pricing whereby drivers were charged $£ 5$ (now £8) for driving in the centre of the city during peak hours. Transport for London (2007) estimate that the scheme has reduced congestion within the zone by 20 to 30 per cent. Road pricing has been shown to be the most effective means of reducing congestion (e.g. Saleh, 2007), but there is considerable opposition to punitive financial schemes: following announcements in February 2007 that the UK government was considering nationwide per-mile road charges, an opinion poll revealed $74 \%$ of respondents were opposed to the initiative and a petition against the scheme attracted $1.8 \mathrm{~m}$ signatories, approximating $6 \%$ of the UK driving population (BBC News Online, 2007).

Structural changes may meet with disapproval from drivers because they fail to target motivations underlying travel mode choice (Green \& Stone, 2004; Thorpe et al., 2000; cf. Triandis, 1977): car users may continue to be motivated to drive but feel frustrated in attempts to do so (cf. Collins \& Chambers, 2005; Gärling \& Schuitema, 2007). Failure to change the cognitions that support driving means that such strategies are unlikely to produce behaviour change that generalises to other situations (e.g. Gärling \& Schuitema, 2007), and there are concerns that structural changes merely redistribute rather than reduce traffic (Parkhurst, 2000; Whitelegg, 2003). Effective longer-term driving reduction interventions will depend on identifying and modifying the cognitive antecedents of car use (e.g. Bartholomew, Parcel, Kok \& Gottlieb, 2006).

\subsection{Psychological and behavioural strategies}

Psychological and behavioural strategies aim to promote voluntary behaviour change via modification of attitudes towards and beliefs about transport choices (Rose \& Ampt, 2001). These strategies are less costly and more publicly acceptable than structural interventions (Emmerink, Nijkamp \& Rietveld, 1995; Tisato \& Robinson, 1999). Hertfordshire County Council (1993) established one of the first psychological initiatives aimed at decreasing car use ('TravelWise'; see too Hampshire County Council, 1993), which sought to raise awareness of the environmental impacts of 
driving via persuasive information highlighting congestion and pollution problems and promoting more sustainable travel solutions. The campaign was underpinned by the assumption that enhanced awareness of environmental issues surrounding transport mode decisions would change attitudes, and thus behaviour (Ciaburro, Jones, \& Haigh, 1994; Hertfordshire County Council, 1993; Rose \& Ampt, 2001).

More recent psychological initiatives have sought to not only change attitudes, but also to provide drivers with personalised information to enhance the knowledge required to use environmentally-friendly transport (e.g. Brög, 1998). These 'travel feedback programmes' (TFPs) involve the provision of personally tailored information designed to change behaviour in light of each participant's reported transport patterns (Ampt \& Rooney, 1998; Brög, 1998; Marinelli \& Roth, 2002; Rose \& Ampt, 2001; Taniguchi et al., 2003). Several TFP subtypes exist (Fujii \& Taniguchi, 2005a): Individualised Marketing (Brög, 1998), for example, involves participants in choosing which personally relevant information (e.g. bus timetables, route maps) to receive and also provides passes which allow free or subsidised use of local public transport. Travel Blending (Ampt \& Rooney, 1998; Rose \& Ampt, 2001) requires participants to complete 7-day personal travel diaries, on the basis of which participants are sent information suggesting alternative transport modes, routes and methods for consolidating multiple journeys as customised to personal travel patterns (e.g. Hensher \& Reyes, 2000; Taniguchi et al., 2003). Participants also receive feedback relating to their personal transport emissions, and the personal and environmental benefits of noncar travel.

Evidence of behaviour change arising from TFPs is weak, and the field lacks rigorous evaluation studies (e.g. James, 1998; Rose \& Ampt, 2001; but see Fujii \& Taniguchi, 2005b). For example, James (1998) reported that an Individualised Marketing programme run with 383 households significantly reduced car mileage and daily car trips. However, the failure to employ a suitable control group means that it unclear whether observed changes in travel behaviour can reliably be attributed to intervention success, or to unmeasured external factors (e.g. road closures). Taniguchi et al. (2003) employed a control group for evaluation of TFP effects on the behaviour of Year 6 children and their families, but pre-treatment behaviour measures were not taken. Hence, while the TFP group exhibited 1\% less car use than did the control group, it is unclear whether this represented a significant change relative to pre-intervention behaviour. 
Both public awareness campaigns and TFPs are based on assumptions regarding the underpinnings of driving which are not well supported by the extant research literature. Firstly, these initiatives assume that attitudes may be changed via increased awareness of environmental impacts of personal travel emissions (Ciaburro, Jones \& Haigh, 1994; Rose \& Ampt, 2001). However, attitudes towards transport modes incorporate a variety of different beliefs, which may include environmental concerns (Mann, 2004), but more often incorporate personal utility concerns regarding the efficacy of each available transport mode for meeting journey time, financial cost, and convenience needs (e.g. Bamberg \& Schmidt, 2003; van Vugt, Meertens \& van Lange, 1995). A driver might therefore be aware of the ecological issues surrounding car transport, but continue to drive because she perceives driving to be quicker and more convenient than public transport (e.g. van Vugt et al., 1995). Where personal benefits are thus prioritised over environmental costs, persuasive messages relating to environmental damage are unlikely to influence attitudes (Ajzen \& Fishbein, 1980). Attitudinal change is therefore likely to depend on a priori identification and targeting of the beliefs underpinning the favourability of different transport modes among the target population (Ajzen \& Fishbein, 1980).

Secondly, public awareness campaigns tacitly assume that attitude change is sufficient to change motivations, which in turn will inform behaviour change (e.g. Taniguchi et al., 2003). TFPs also acknowledge the importance of knowledge and skills as a prerequisite for confidence in using non-car travel (i.e. self-efficacy; Bandura, 1997), but evidence shows that motivations to drive may be determined not only by attitudes and self-efficacy, but also by, for example, social norms of conduct and anticipated affective experiences (Bamberg \& Schmidt, 2003). For example, a driver may hold positive attitudes towards public transport use and feel confident in using public transport, but view car use as more befitting of his perceived social status (Bamberg \& Schmidt, 2003; Triandis, 1977). Furthermore, ingrained transport habits may interfere with the transition of motivation into behaviour (Verplanken, Aarts, van Knippenberg \& van Knippenberg, 1994).

Aside from limited empirical support then, existing psychological strategies do not appear to have been developed in accordance with evidence regarding why people choose to drive (Bamberg \& Schmidt, 2003). This not only constrains potential effectiveness (Bartholomew et al., 2006), but also precludes exploration of the cognitive processes through which such interventions operate, and how these processes can be 
changed. Identifying and measuring the cognitive mechanisms underpinning behaviour maintenance is likely to be important in forecasting expected change, and improving interventions. Where behaviour is changed but cognitions are not measured, the cognitive mechanisms underpinning these changes remain unclear, and conversely, if an intervention does not have desired behavioural effects, it is difficult to pinpoint the underlying cognitions precluding change. For example, while Taniguchi et al. (2003) concluded that a TFP changed behaviour among Year 6 children and their families, no changes in any of the measured cognitions (awareness of environmental consequences of behaviour, perceived moral obligations, habits, and intentions to drive) were found, and so the reasons for observed behavioural change were unclear. Similarly, Fujii and Taniguchi (2005a) found that a TFP administered to Year 6 children ironically appeared to increase car use, but a failure to measure cognitions also meant reasons for these results were not apparent.

Psychological and behavioural strategies to date have been neither designed nor evaluated in light of evidence regarding the psychological antecedents of car use (cf. Mann, 2004). Perhaps consequently, there is only weak support for their effectiveness (Fujii \& Taniguchi, 2005a; Marinelli \& Roth, 2002; Taniguchi et al., 2003; Tertoolen, van Kreveld \& Verstraten, 1998). Social psychological insights into the causes of travel mode choice are likely to contribute significantly to the design, implementation and evaluation of both structural and psychological interventions, and may be useful in helping to forecast the acceptability and effectiveness of such schemes, as well as identifying the psychological reasons for change. The development of effective car use reduction interventions will therefore depend on understanding the determinants of driving (Bartholomew et al., 2006).

\subsection{What drives car use?}

Traditional economic analyses have modelled travel mode choice on objective attributes of each travel mode (e.g. financial costs, travel times; see Koppelman, 1980), and have represented traveller characteristics via socio-demographic and socioeconomic variables (e.g. gender, age, income; Curtis \& Headicar, 1997). While these models may be useful in predicting transport use (Steg, Geurs \& Ras, 2001), such analyses are limited because demographic variables do not readily explain why, for example, males may tend to drive more than females (Polk, 2004; Steg, Geurs \& Ras, 2001). Consequently, how interventions might reduce car use among men is unclear. 
Economic models are therefore unlikely to provide bases for developing and evaluating effective psychological and behavioural driving reduction strategies.

Social cognition theories suggest that demographic influences on behaviour are mediated by cognitions, and that cognitions are the most proximal determinants of behaviour (e.g. Ajzen, 1991; Fishbein \& Ajzen, 1975; Schwartz, 1977; Triandis, 1977); men may, for example, tend to believe driving is more consonant with their perceived social role than do women, and these beliefs may increase motivation to drive, in turn translating into more car use (Bamberg \& Schmidt, 2003; Triandis, 1977). Variation in the favourability of cognitions towards driving may also explain important differences in transport behaviour within socio-demographic and socio-economic groups. Cognitions therefore offer mechanisms which not only predict but also explain driving behaviour. Moreover, cognitions may be modified so as to motivate drivers to voluntarily reduce their car use (e.g. Beale \& Bonsall, 2007; Fujii \& Kitamura, 2003). Identifying and targeting potentially modifiable cognitive antecedents of driving is therefore an important prerequisite to designing effective psychological car use reduction strategies (Bartholomew et al., 2006).

\subsection{The theory of planned behaviour}

The best supported social cognitive model to have been applied to the prediction of car use is Ajzen's (1991) Theory of Planned Behaviour (TPB; Bamberg, Ajzen \& Schmidt, 2003; Bamberg, Rölle \& Weber, 2003; Bamberg \& Schmidt, 1998, 1999, 2001, 2003; Forward, 1998a, 1998b, 2004; Harland, Staats \& Wilke, 1999; Kaiser \& Gutscher, 2003; Mann, 2004; Staats, Harland \& Wilke, 2004). The TPB suggests that behaviour is most closely determined by an intention to act. Intention summates motivational influences, which are represented in the TPB via three components: attitudes, subjective norms, and perceived behavioural control (PBC). Attitude represents the perceived overall favourability of salient expected outcomes of an action, subjective norms refer to perceived social approval for the action, and PBC refers to the perceived ease or difficulty of performing the action. To the extent that perceptions of control accurately reflect actual control, PBC will influence behaviour directly, because individuals have a greater tendency to perform behaviours over which they have control (e.g. Bandura, 1997).

The TPB uses an expectancy-value framework to model relationships between beliefs and attitudinal, normative, and control perceptions (e.g. Conner \& Sparks, 1996, 
2005). Subjective norms thus combine perceptions of significant others' preferences and the actor's motivation to comply with these expectations. Attitude represents a combination of the various salient expected consequences of the action and the evaluation of these outcomes. PBC refers to the perceived internal and external facilitators and barriers to action as combined with the perceived power of these to facilitate or inhibit performance of the behaviour. Where subjective norms are thus predominantly driven by the perceived social climate, attitude and PBC capture salient beliefs regarding the favourability of and opportunities afforded by the focal behaviour. Although beliefs are distal predictors of behaviour, intervention at this level is necessary to modify drivers' beliefs surrounding car and non-car transport (Ajzen \& Fishbein, 1980), and thus change attitudinal and control perceptions, so as to enhance non-car use motivation. Utilising the TPB to promote behaviour change among drivers thus requires identifying and targeting the salient beliefs that underpin attitudes and PBC towards travel mode options (Ajzen \& Fishbein, 1980).

Evidence supports the TPB as a predictive model of car use (Bamberg, Ajzen \& Schmidt, 2003; Bamberg \& Schmidt, 1998, 1999, 2003; Harland, Staats \& Wilke, 1999; Kaiser \& Gutscher, 2003). For example, Bamberg and Schmidt (1999) found that attitudes, subjective norms and PBC predicted $68 \%$ of variance in intentions to drive, and intentions and PBC explained $70 \%$ of variance in car use. Elsewhere, Bamberg and Schmidt (2003) found that the TPB predicted $60 \%$ of variance in intentions to drive, and $45 \%$ of variance in car use. However, the theory is not exhaustive, and Ajzen (1991) has invited augmentation with additional cognitions where predictive utility may be enhanced. For example, a revision of the model (Ajzen \& Fishbein, 2005) incorporates a measure of descriptive norm - i.e., perceptions of the extent to which significant others engage in the focal behaviour (Cialdini, Kallgren \& Reno, 1991), and Heath and Gifford (2002) have shown that a measure of descriptive norm contributed unique variance over and above TPB cognitions in both intentions to use buses and bus use.

Although the TPB is a nomothetic theory, it offers two key areas for development of a behaviour-specific predictive model of car use. Firstly, salient beliefs held by drivers can be modelled as potential antecedents of attitudes and PBC (Ajzen \& Fishbein, 1980; Bamberg \& Schmidt, 2003), and thus as distal predictors of car use. Secondly, theoretical constructs not captured by TPB cognitions can be incorporated to enhance the utility of the model for predicting driving (Ajzen, 1991; Bamberg \& Schmidt, 2003; Heath \& Gifford, 2002). 


\subsection{Antecedents of TPB cognitions}

Beliefs underpinning decisions to drive may be broadly classified into two types: those focused on maximising personal, goal-directed utility, and those relating more to concerns for maximising positive (and minimising negative) affect (e.g. Steg, Vlek \& Slotegraaf, 2001; Wardman, Hine \& Stradling, 2001).

Personally-relevant utility-based factors that have been found to be associated with travel mode choices include financial cost concerns, travel time, reliability, travel time variability, convenience, flexibility, and physical exertion (Anable \& Gatersleben, 2005; Bamberg \& Schmidt, 1998, 2001; Gärling \& Sandberg, 1997; Heath \& Gifford, 2002; Jakobsson, Fujii \& Gärling, 2002; Joireman, van Lange, Kuhlman, van Vugt \& Shelley, 1997; Loukopoulos \& Gärling, 2005; Mackett, 2003; Reibstein, Lovelock \& Dobson, 1980; Steg, 2003; Stradling et al., 2000; Tertoolen et al., 1998; van Lange, van Vugt, Meertens \& Ruiter, 1998; van Vugt et al., 1995; van Vugt, van Lange, \& Meertens, 1996; Verplanken, Aarts \& van Knippenberg, 1997; Wardman et al., 2001). For example, Loukopoulos and Gärling (2005) found that perceptions of the physical effort necessary to walk 3 kilometres significantly positively correlated with selfreported levels of car use for all trips, and van Vugt et al. (1995) reported that preferences for driving over public transport use in a hypothetical commuting scenario were strongly positively correlated with convenience and flexibility concerns in commuting journeys.

Elsewhere, environmentally-focused and thus collectively-oriented utilitarian outcomes have been found to impinge on travel mode choices. van Vugt et al. (1995) showed that reported concern for the environment had a strong negative impact on preferences for car use over public transport use, and Nilsson and Küller (2000) reported a significant negative correlation between levels of awareness of the environmental damage caused by car use and reported driving distance over the previous year. Driving preferences and behaviour have also been variously associated with: consideration of environmental problems (Collins \& Chambers, 2005); perceived individual, societal and biospheric threats arising from environmental damage (Baldassare \& Katz, 1992; Collins \& Chambers, 2005); perceived severity of environmental damage caused by driving (Tanner, 1999); and the perceived usefulness of car use reduction as a means of lessening these problems (Steg \& Sievers, 2000).

Steg, Vlek and Slotegraaf (2001) have suggested that utilitarian beliefs may be overrepresented in transport research, and that driving may be more closely associated 
with concerns for maximising affective outcomes and arousal (Steg, 2003, 2004, 2005). Steg (2005) demonstrated that concerns for conveying personality, social status, power and prestige, and experiencing enjoyment and freedom when driving were stronger among participants who drove more than 25,000 kilometres per year than for participants who drove less. Steg (2003) has also showed that frequent drivers judge public transport to offer less independence, fun and empowerment experiences than do infrequent drivers. Elsewhere, drivers have reported public transport to be stressful, boring and involve risks inherent in exposure to fellow transport users due to personal space intrusions, whereas car use is often associated with experiences of comfort, safety, excitement, autonomy and independence (Bamberg \& Schmidt, 1998, 2001; Ellaway, Macintyre \& Hiscock, 2003; Guiver, 2007; Hiscock, Macintyre, Ellaway \& Kearns, 2002; Mann \& Abraham, 2006; Stradling et al., 2000). Furthermore, some drivers may simply enjoy driving (Ory \& Mokhtarian, 2005).

The TPB suggests that utility and affect-based beliefs are important determinants of attitudes and PBC (Ajzen, 1991; Fishbein \& Ajzen, 1975), yet few attempts have been made to systematically model relationships between salient beliefs and TPB cognitions (Bamberg \& Schmidt, 1998, 1999). In a rare example, Bamberg and Schmidt $(1998,1999)$ reported that a combination of utilitarian and affect-based beliefs - relating to the utility of car use for achieving comfort, flexibility, lack of stress, rapid journey times, and low financial costs - predicted $88 \%$ of variance in attitudes towards car commuting, while reported car ownership and access to a car accounted for $79 \%$ of variance in car commuting PBC. Bamberg and Schmidt's analysis is also significant because the beliefs chosen to represent predictors of attitudes and PBC were identified using free elicitation (Ajzen \& Fishbein, 1980), whereby a sub-sample of a target population is asked to list advantages and disadvantages of, and any other beliefs associated with the behavioural object. Ajzen and Fishbein argue that such elicitation research is an important step in identifying salient beliefs antecedent to attitudinal and control perceptions within the population.

However, free elicitation may be limited as an appeal to identifying important beliefs, for a number of reasons. Firstly, the method is open to self-presentation biases (e.g. Paulhus, 1986): participants may not wish to disclose certain beliefs which are nonetheless important behavioural determinants. Indeed, Steg, Vlek \& Slotegraaf (2001) have shown that where the research purpose is evident, individuals are less likely to report motives for driving that may be incongruent with desired self-presentation, 
such as affect-based motives, and are more likely to rationalise their decisions by appeals to instrumental, utility-oriented factors. Secondly, drivers may be unaware of beliefs that influence their attitudes and perceptions of control (e.g. Wegner, 2002). Thirdly, even if freely elicited beliefs are accurate representations of drivers' perceptions, the method often does not permit sufficient depth of analysis to clarify the detailed structure of such beliefs and how they might be formed and maintained, and reveal how they may be targeted to reduce driving.

Guiver (2007) conducted qualitative analysis of focus group data from transport users, and found that, while concerns for, for example, costs, safety, comfort and convenience were raised by participants (cf. Bamberg \& Schmidt, 1998, 1999), discussions of the utility of public transport for meeting these needs highlighted participants' generalisations from isolated, worst-case scenarios (cf. Mann \& Abraham, 2006). Similarly, using semi-structured interviews with car commuters Mann and Abraham (2006) found that not only were costs an important concern, but drivers made biased comparisons between car and public transport costs, possibly because car costs were equated with petrol costs only. Mann and Abraham's analytic methods revealed beliefs and perceptions that drivers may be unwilling to disclose in simple self-report questionnaire responses (Steg, Vlek \& Slotegraaf, 2001). Thus, qualitative analysis is an important tool for highlighting and exploring important beliefs and perceptions that influence decisions to drive and thus present targets for behaviour change interventions.

\subsection{Potential additional determinants of intentions and behaviour}

\subsubsection{Cognitions towards alternatives. Behavioural decisions often entail selection} among goal-directed options (Sheppard, Hartwick \& Warshaw, 1988). Where travel decisions are motivated by journey needs (e.g. Bamberg \& Schmidt, 2003; but see Ory \& Mokhtarian, 2005) and alternative transport is available, car use is likely to represent one of several competing options. Real-world transport decisions are likely to be informed by choice between available options (Abraham \& Sheeran, 2003), but applications of the TPB to travel mode choice have tended to model intentions and behaviour on the attractiveness of one particular behavioural option (e.g. Bamberg, Ajzen \& Schmidt, 2003; Bamberg \& Schmidt, 1998, 1999; Forward, 2004; Kaiser \& Gutscher, 2003). For example, Bamberg, Ajzen and Schmidt (2003) obtained measures of TPB cognitions relating to car use and matched measures relating to bus use, but 
modelled these separately as determinants of car and bus use respectively (see too Forward, 2004). Such analyses presume that TPB measures relating to a particular behavioural option encapsulate consideration of the favourability of alternative options (Fishbein \& Ajzen, 1975). However, there is no evidence to support this assumption, and Mann (2004) found that a TPB model of public transport use was significantly enhanced by a measure of PBC over car use. Taking account of beliefs about alternatives may therefore enhance the predictive utility of the TPB, but little evidence is available to assess the relative contributions of TPB cognitions relating to car use and to non-car transport (Mann, 2004).

\subsubsection{Willingness to reduce car use. A number of studies have treated drivers'} willingness to reduce car use as an outcome of behavioural significance (Beale \& Bonsall, 2007; Garvill, 1999; Nordlund \& Garvill, 2003; Polk, 2003, 2004; Steg \& Vlek, 1997), but its meaning has not been clearly defined in this domain. These studies appear to assume that willingness is important because it represents openness to use of alternative transport even when the individual continues to drive (e.g. Beale and Bonsall, 2007). Gibbons, Gerrard, Blanton and Russell (1998a, 1998b) suggest that, whereas intention pertains to premeditated action, willingness involves a relative lack of forethought and reflects an unplanned behavioural reaction to unforeseen circumstances conducive to action. Although intention and willingness may be traced back to the same cognitive antecedents (Gibbons et al., 1998a), where behaviours are socially unattractive and/or involve risk, behaviour may be better informed by willingness, which may therefore provide a potentially useful alternative indicator of motivation to intention (Gibbons et al., 1998a, 1998b). Drivers willing to reduce their car use may respond more positively to psychological driving reduction interventions (Beale \& Bonsall, 2007), but there is little available evidence to evaluate effects of willingness to reduce car use on behaviour in the absence of intervention.

Aside from TPB cognitions and willingness, social cognitive variables that may influence car use decisions have been derived mainly from three theoretical frameworks (Bamberg \& Schmidt, 2003): the social dilemma paradigm (Gärling \& Sandberg, 1997; van Lange et al., 1998; van Vugt, Meertens \& van Lange, 1994, 1995; van Vugt, van Lange \& Meertens, 1996), a norm activation model (Hunecke, Blöbaum, Matthies \& Höger, 2001; Klöckner \& Matthies, 2004; Matthies, Klöckner \& Preißner, 2006; 
Schwartz, 1977), and Triandis's (1977) theory of interpersonal behaviour (TIB; e.g. Verplanken et al., 1994; Verplanken, Aarts, van Knippenberg \& Moonen, 1998).

1.6.3. Car use as a social dilemma. van Vugt and colleagues (e.g. van Vugt et al., 1995) have suggested that car use represents an example of a social dilemma (Hardin, 1968): drivers are faced with the dilemma of driving, which maximises short-term personal utility outcomes but incurs considerable long-term collective costs via environmental damage, or using public transport, which is less personally gratifying but has less environmental detriment and so is of greater long-term benefit for the collective (van Lange, van Vugt \& de Cremer, 2000; van Lange et al., 1998; van Vugt et al., 1995; van Vugt, van Lange \& Meertens, 1996; see too Gärling \& Sandberg, 1997). This analysis has suggested roles for trust in others - i.e. that others are honest and trustworthy (Yamagishi, 1986) and will choose pro-environment options (e.g. van Lange et al., 1998) - and social value orientation - i.e. general preferences for self- versus collectively-oriented outcomes. For example, van Lange et al. (1998) found that higher levels of trust in the likely pro-environment behaviour of others were associated with greater public transport choices in a hypothetical car versus public transport commuting scenario. In a similar hypothetical scenario, van Vugt et al. (1995) found that participants of a pro-social value orientation were more likely to choose to use public transport over car use than were 'pro-selves'. However, evidence for the role of social value orientation is mixed: van Lange et al. (1998) found no significant differences in the transport mode preferences of pro-social versus 'pro-self' participants. Moreover, the hypothetical settings in which these variables have been tested may not generalise to real-world settings, and the little evidence available suggests driving is not experienced as a social dilemma by drivers making everyday transport mode choices (see e.g. van Vugt, van Lange, Meertens \& Joireman, 1996).

\subsubsection{Personal norms and the TPB. Given the environmental impact of driving,} Matthies and colleagues (Hunecke et al., 2001; Klöckner \& Matthies, 2004; Matthies et al., 2006) have characterised travel mode decisions as morally guided behaviour. Hunecke et al. (2001) propose that awareness of environmental problems associated with car use and one's responsibility for remedial action arouses a perceived moral obligation to act to reduce the environmental threat - or personal moral norm - which is the most proximal determinant of transport behaviour (Schwartz, 1977; see too Matthies 
et al., 2006). Indeed, Bamberg and Schmidt (2003) found that perceived severity of consequences and self-ascribed responsibility accounted for $46 \%$ of variance in personal norm. However, evidence suggests that the direct effect of personal norm on behaviour is small: Bamberg and Schmidt (2003) reported that personal norm predicted 14\% of variance in car use, with greater personal norms informing less car use, and Klöckner and Matthies (2004) found that a measure of personal norm predicted 20\% of variance in decisions to drive or use public transport. Harland et al. (1999) have shown that personal norm can alternatively be modelled as an independent predictor of intention over and above TPB cognitions (see too Mann, 2004; but see Bamberg \& Schmidt, 2003). The TPB predicts that environmental beliefs are encompassed by attitudes, subjective norms and/or PBC, but evidence linking environmental cognitions with TPB variables in models of car use is scant and inconsistent (Bamberg \& Schmidt, 2003; Mann, 2004): Bamberg and Schmidt (2003) found that anticipated environmental consequences could be modelled as determinants of subjective norms, and Mann (2004) reported that both personal norm and attitude were determined by environmental problem awareness.

1.6.5. The theory of interpersonal behaviour: affect and habit. Triandis's (1977) theory of interpersonal behaviour (TIB) concurs with the TPB in positing intention as a proximal determinant of behaviour, but includes affect as a predictor of intention. Whereas the TPB assumes that affect-based outcome expectations are cognitively represented as a component of attitude (Fishbein \& Ajzen, 1975), the TIB presents affect as an independent predictor of intention over and above attitude (Triandis, 1977). As previously illustrated, there is a wealth of evidence for the role for affective considerations in driving choices, but no study has modelled affect as an independent predictor of intentions to drive, or its relationship with attitudes, intentions, and behaviour. This is likely to be because, although a number of conceptually independent affect-based predictors of behaviour have been identified (e.g. Steg, 2003, 2004, 2005; Steg, Vlek \& Slotegraaf, 2001), there is as yet no standardised self-report measure of affect that summates the influence of specific affective concerns.

The TIB also suggests that the relationship between intention and behaviour is moderated by habit (Triandis, 1977). Habits are learned, goal-directed behaviours which are initiated automatically (Aarts, Verplanken \& van Knippenberg, 1997; Verplanken \& Aarts, 1999; Verplanken et al., 1997). Habit theorists suggest that performance of 
behaviour in novel settings is regulated by conscious goal-directed deliberation (as depicted by the TPB), but when behaviours have been frequently performed and satisfactorily experienced in unchanging contexts, the goal-behaviour association becomes reinforced such that when the goal is activated, the behaviour follows automatically in the absence of deliberation (Aarts, Verplanken \& van Knippenberg, 1998). Habit effects may be concealed where habitual and intended behaviours concur, but where habits and intentions conflict, the TIB predicts that habit will have the greater influence on subsequent behavioural outcomes (Triandis, 1977). Aarts et al. (1998) suggest that travel mode choice exemplifies habitual behaviour, and indeed, Verplanken et al. (1998) found that villagers' intentions not to drive to a nearby city were more strongly predictive of travel mode choice where driving habits were weak. Conversely, where car use habits were strong, there was no effect of intention on behaviour (see too Klöckner, Matthies \& Hunecke, 2003; Møller \& Thøgersen, 2003; Verplanken et al., 1994; but see Bamberg, Ajzen \& Schmidt, 2003).

Theorising habit in travel mode choice is however limited by problems of operationalisation (e.g. Eagly \& Chaiken, 1993). Traditional treatments used past behaviour as a proxy measure of habit, because frequently performed behaviours are more likely to become habituated (Ouellette \& Wood, 1998), but past behaviour has no explanatory value: strong past and future behaviour correlations indicate stability of behaviour, and where behaviour is stable, past behaviour simply summarises the continued influence of unmeasured factors, which may not include habit (Ajzen, 2002a). Verplanken et al. (1994) devised a response-frequency measure (RFM) of travel mode habits, whereby participants are presented with a series of hypothetical travel scenarios characterised by minimal information, and are asked to indicate as quickly as possible which mode of transport they would choose to use for each scenario. Assuming habitual responses are more cognitively accessible and that minimal information and imposed time pressure preclude deliberation, car use habit is indexed as the number or proportion of car use choices (Klöckner et al., 2003; Verplanken et al., 1994). Verplanken and colleagues (Verplanken et al., 1994; Verplanken et al., 1998) found that higher car habit RFM scores were associated with greater car use and weaker correlations between noncar use intentions and behaviour, but Bamberg, Ajzen and Schmidt (2003) found no relationship between RFM habit scores and car use. These inconsistencies may have arisen from Bamberg, Ajzen and Schmidt's (2003) use of an RFM in a questionnaire design in which time pressure is not imposed (Verplanken, Myrbakk \& Rudi, 2005; but 
see Klöckner et al., 2003). Verplanken and Orbell (2003) have devised a 12-item selfreport habit index (SRHI) which requires participants to reflect upon the extent to which they perform behaviours automatically in the absence of deliberation. The SRHI has been found to perform in accordance with the TIB's moderation hypothesis for a variety of behaviours (see Verplanken, 2006), but there is as yet no available evidence on the utility of the SRHI for predicting car use choices (but see Verplanken et al., 2005, for an examination of the construct and convergent validity of the SRHI as applied to travel mode choice). Habit presents an additional cognitive barrier to action and is thus likely to present a boundary condition for the predictive utility of the TPB (Verplanken, 2006), because strong habits are likely to diminish the predictive power of intentions (Triandis, 1977). Habitual car use has important implications for intervention design, because changing drivers' motivations may have little behavioural impact where driving habits remain unbroken.

\subsection{Work reported in this thesis}

The studies reported in this thesis tested the proposal that the TPB represents the best available model of car use (Bamberg \& Schmidt, 2003), and attempted to identify determinants of car use. Primary empirical work was carried out in cities with excellent public transport infrastructure to support bus, train and cycle use as alternatives to driving, so that it could be assumed that use of non-car transport was feasible for the majority of our participants.

Two strands of inquiry were followed. The first study (reported in chapter 2) used a qualitative 'grounded theory' analysis (e.g. Strauss \& Corbin, 1990, 1998) of interviews with regular car commuters to inductively derive concepts that explain decisions to drive in the presence of high-quality alternatives. Our analysis revealed

concerns for journey time, effort and monetary cost minimisation, maximising personal space, and attaining positive affect or minimising negative affect, which were based on a fundamental desire for control over the transport experience and journey progression. We also documented important misconceptions and systematic biases underpinning drivers' motives, and identified an additional set of beliefs linking transport policy acceptance to perceived self- and identity-relevant consequences.

The second study (chapter 3 ) built upon the preceding study by developing quantitative measures of the beliefs and concerns identified in study 1 . These were modelled in relation to both car and public transport use using longitudinal survey data 
from a large sample of car commuters. We also measured TPB variables relating to public transport use. We firstly entered the inductively derived concepts as predictors of behaviour independently of the TPB, but these variables were not found to predict behaviour or intentions directly. Integrating the inductive concepts into the TPB produced the optimal model, in which inductively-derived beliefs were modelled as predictors of attitude and PBC towards public transport. We concluded that our inductively-derived measures were less predictive than deductively-derived TPBspecified concepts.

The second, more deductive strand (studies 3-7) aimed to evaluate and develop the TPB as a model of car use. Our third study (chapter 4) used meta-analysis of the extant literature to identify and synthesise correlates of car use, intentions to drive, and willingness to reduce car use. Strong effects were found for intention and habit on behaviour. With the exception of subjective norms, the utility of TPB cognitions relating to car use on intentions to drive was supported, but stronger correlations with intentions and behaviour were observed for TPB cognitions towards not driving than for cognitions relating to driving. There were also medium sized effects of personal and descriptive norms on behaviour. Environment-related cognitions had relatively small effects on behaviour and have not been explored in relation to intentions. No evidence was available on the relationship between willingness and behaviour. This study highlighted the dearth of available evidence linking cognitions to driving (and nondriving) intentions and behaviour.

The fourth study (chapter 5) constructed a TPB model of car use as extended to include cognitions relating to non-car use, personal and descriptive norms, and proenvironment beliefs. Cross-sectional questionnaire data (justified on the basis of high behavioural stability over time) showed that self-reported behaviour over the preceding week was explained by intention and participant age, while intention was predicted by a combination of car use and non-car use cognitions, and descriptive and personal norms. Non-car cognitions generally had greater influence on intention than did car cognitions. Perceived control over environmental problem reduction and environmental concern had effects on intention that were mediated by both non-car use attitude and personal norm. We concluded that driving was primarily the result of unfavourable perceptions of non-car transport, rather than the appeal of car use.

Study 4 implicitly assumed travel mode choice is a reasoned action, but the predictive utility of the TPB may be constrained by habit (e.g. Verplanken et al., 1998), 
and so studies 5-7 (chapter 6) explored the role of habit and concomitant nondeliberation in transport choice. We argue that the current state-of-the-art habit measure (Verplanken and Orbell's [2003] self-report habit index [SRHI]) is limited because it potentially conflates behavioural aspects of habit (i.e. repetition) with its cognitive component (automaticity), and so study 5 sought to develop a new, reliable self-report measure of automaticity using a sample of 56 university-based drivers. The factor structure of the new measure, its convergent validity relative to existing habit measures, and the role of new and existing habit measures as potential moderators of the intentionbehaviour relationship were explored in a prospective study of the travel behaviour of regular car commuters (study 6). Principal component and moderation analyses demonstrated the conceptual and predictive superiority of the SRHI. A replication study which focused on habitual bicycle use in the Netherlands (study 7) produced nearidentical results to study 6. It was concluded, therefore, that the SRHI represented the best available measure of habit. Moreover, although we observed that a reasoned action explanation would be sufficient in both studies 6 and 7, the data pointed to the strong habitual nature of commuter transport choice. 


\section{Chapter 2. Study 1: A grounded theory analysis of commuters' reasons for driving*}

\subsection{Abstract}

A grounded theory analysis of reasons for driving to work was undertaken following semi-structured interviews with nineteen regular private car commuters in a small English city. Five core motives were identified: journey time concerns; journey-based affect; effort minimisation; personal space concerns; and monetary costs. An underlying desire for control underpinned many of these motives. The analysis revealed misconceptions regarding journey times and control in relation to car and public transport use, systematic underestimation of car-related monetary costs, and the importance of self- and identity-relevant consequences in relation to transport policy acceptance. Drivers' motives and misconceptions are discussed in light of transport demand management policies.

\subsection{Literature review}

Car ownership and the number of car journeys are rising steadily in the UK (Department of the Environment, Transport and the Regions [DETR], 2000). Traffic emissions contribute to climate change (Oskamp, 2000) and are the primary cause of air pollution in Britain (UK National Air Quality Informative Archive [UKNAQIA], undated). Exposure to air pollution causes respiratory disease onset as well as exacerbation of existing health problems and is implicated in more than 24,000 deaths annually in the UK (DETR, 2000). Increasing car use has cancelled out gains made from economic incentives for the use of reduced-emission vehicles, and infrastructure changes designed to reduce urban congestion often relocate rather than reduce pollution problems (Whitelegg, 2003). Hence reductions in emissions will depend on decreasing car use (Stern, 1992). Commuting transport mode choice represents a key intervention target because $70 \%$ of UK commuter journeys are driven (Department for Transport [DfT], 2005b).

As argued in chapter 1 (pp.2-3), driving reduction programmes designed to bring about psychological change, such as travel feedback programmes (e.g., Ampt,

\footnotetext{
* A version of this chapter has been published as Gardner, B., \& Abraham, C. (2007) What drives car use? A grounded theory analysis of commuters' reasons for driving. Transportation Research Part F, 10, 187-200.
} 
1999; Brög, 1998) are less expensive and more publicly acceptable than infrastructure modifications such as bus priority lanes and road pricing (Emmerink, Nijkamp, \& Rietveld, 1995; Fujii, Gärling, \& Kitamura, 2001) but developing optimally effective psychological interventions depends upon identification of key beliefs and attitudes that underpin driving decisions in the context of available alternatives. Models of psychological antecedents of driving decisions are often based on nomothetic theory and research. For example, the Theories of Reasoned Action (Fishbein \& Ajzen, 1975) and Planned Behaviour (TPB; Ajzen, 1991; e.g. Bamberg \& Schmidt, 2003); the Norm Activation Model (Schwartz, 1977; e.g. Klöckner \& Matthies, 2004); and Triandis's (1977) Theory of Interpersonal Behaviour (e.g. Verplanken, Aarts, van Knippenberg, \& van Knippenberg, 1994) have all been applied to driving motivation. While providing useful general models of cognitive antecedents of driving, such approaches can be developed by qualitative approaches which adopt an idiographic perspective on individual understanding, explanation and decision making. Such an individual-level focus can identify strands of meaning which underpin correlations observed in nomothetic research and, thereby, help target persuasive efforts more precisely.

As outlined previously (chapter 1, pp.9-10), research has highlighted two broad categories of driving motivation. Instrumental or utilitarian motives include financial costs, travel time, convenience, flexibility, physical effort or exertion (e.g. Tertoolen, van Kreveld \& Verstraten, 1998; van Lange, van Vugt, Meertens, \& Ruiter, 1998; van Vugt, Meertens, \& van Lange, 1995; van Vugt, van Lange, \& Meertens, 1996; Wardman, Hine \& Stradling, 2001). These motives are underpinned by a desire to maximise the expected utility of available transport modes in the context of current goals (Steg, Vlek, \& Slotegraaf, 2001; Steg, 2005). For example, van Vugt et al. (1996) found that preferences for public transport over car use increased as expected public transport journey time decreased, and other experimental research has shown that imposing financial disincentives can reduce private car use (e.g. Jakobsson, Fujii, \& Gärling, 2002). By contrast, affective motives (Steg, Vlek \& Slotegraaf, 2001; Steg, 2005) are based on the experience of driving and perceived stress, excitement, uncertainty, safety, enjoyment and autonomy have all been found to correlate with travel mode choice (e.g., Anable \& Gatersleben, 2005; Bamberg \& Schmidt, 2001; Ellaway, Macintyre, Hiscock, \& Kearns 2003; Mann \& Abraham, 2006; Ory \& Mokhtarian, 2005; Stradling, Meadows, \& Beatty, 1998, 2001; Wardman et al., 2001). 
Stradling et al. (2001), for example, demonstrated that drivers who derived most autonomy from driving intended to drive more and use public transport less.

Many researchers have treated utilitarian and affective motives as independent (Steg, Vlek \& Slotegraaf, 2001; Steg, 2005; Wardman et al., 2001) but this separation may not be salient to drivers themselves (Mann \& Abraham, 2006; Reibstein, Lovelock, \& Dobson, 1980). For example, apparently utilitarian factors such as time and reliability can be important precisely because of their affective consequences, such as frustration, and stress. In such cases motives are primary affect-based but the decision is nevertheless justified in utilitarian terms. Drivers may also feel that utilitarian rationales for driving are more socially acceptable, which may mask the importance of affective motives in driving research (Paulhus, 1986; Steg, Vlek \& Slotegraaf, 2001). Analysis of interviews in which individuals speak at length about various car and transport issues may overcome such self-presentational biases and reveal the complexity of motivational structures. Yet such analyses are rare (although see Hiscock, Macintyre, Kearns, \& Ellaway, 2002, and Mann \& Abraham, 2006, for illustrations).

\subsubsection{The present study}

Our study was designed to: (1) explore driving decisions from the driver's perspective; (2) investigate relationships between utilitarian and affective motives; and (3) relate drivers' motivations to travel demand management (TDM) policy making.

\subsection{Method}

\subsubsection{Participants}

Interviewees were nineteen regular private car commuters (10 women and 9 men, aged between 22 and 58 years, mean 35.3 years) employed at one of four major organisations located in central Brighton and Hove: a life assurance organisation $(N=$ $9)$, a college of further education $(N=4)$, a utility company $(N=4)$, and a banking corporation $(N=2)$. We focused on car commuters in the city centre because the city is heavily polluted by road traffic despite having excellent public transport and infrastructure to support use of non-car travel. For example, participants' workplaces are served by frequent bus services and cycle paths, and the latter three organisations are based close to train stations served by intra- and inter-city routes. All participants lived within reach of an hourly or better bus service to the city centre, and none had physical impairments necessitating car use. Income ranged from $£ 10,000$ to $£ 60,000$ 
(mean $£ 24,342$ ). Eighteen participants were in sole or joint ownership of at least one car, and one participant (P6) was renting a car.

\subsubsection{Procedure and interview schedule}

Interviews lasted between 30 and 45 minutes, and took place at the participant's workplace. Interviews were semi-structured, covering a range of topics including monetary costs; driving experiences; motives for purchasing a car; public transport experiences; and attitudes towards various existing, proposed or hypothetical TDM initiatives. The extent to which each issue was explored was dependent upon its importance to the participant. Interviews were taped and transcribed verbatim. Following the interview, participants provided age, income and occupation details and received a debriefing sheet.

Participants were encouraged to talk spontaneously, and follow-up questions were used to facilitate further discussion of salient issues. Interviews opened with a question relating to willingness to switch to alternative transport when commuting to work. Where participants provided a negative response, the question was repeated at the close of the interview. This allowed for detection of possible intervention effects of the interview. Only one participant displayed inconsistency in her two responses. Hence, while prompting reflection, the interview did not appear to change participants' transport mode preferences.

\subsubsection{Grounded theory}

Grounded theory analysis was undertaken using the constant comparative method (Glaser \& Strauss, 1967; Willig, 2001), following guidelines provided by Strauss and Corbin (1990, 1998). Initial (or “open”) coding involves assigning conceptual labels to topics, which are refined through repeated inspection. Secondary (or "axial") coding involves examination of relationships between conceptual labels and overarching categories. Further inspection of the data (i.e., 'selective' coding) generates an understanding of how categories are inter-related. The analysis is data-driven and reflects topics raised in a particular dataset. However, where interviewees are representative of a wider group such analyses can provide insights into patterns of perception and reasoning which can subsequently be tested with larger samples. The method has been successfully applied to a variety of psychological understandings and experiences (e.g. Johnston \& Abraham, 2000; Sherrard, 1998; Tweed \& Salter, 2000). 
Transcripts were read and reread, and pertinent excerpts assigned provisional conceptual codes. For example, when asked about the cost of keeping a car, Participant 5 (P5) responded:

"[My car costs me] petrol wise, probably about sixty pounds a month. And then there's obviously car tax, which for me is a hundred and ten a year, and insurance which is about twenty quid a month."

Open coding deconstructed this excerpt into several provisional concepts: primacy of petrol cost, uncertainty about costs, omitted costs, and cognitive timescale of costs (e.g., monthly versus yearly). Further open and axial coding resulted in refinement of initial concepts and development of a set of overarching categories (Strauss \& Corbin, 1990, 1998). Finally, selective coding procedures allowed identification of a 'central category' according to criteria set out by Strauss and Corbin (1998, p.147).

\subsection{Results}

Six overarching categories were extracted from transcripts. Five of these represented motives for car use: journey time concerns and journey-based affect; minimising effort; personal space concerns; minimising monetary costs; and a desire for control. These motives arose spontaneously, independently of our interview schedule. A sixth category linked consequences for self and identity to TDM policy acceptance.

Conflict between motives was rare. Car use was commonly perceived to optimise positive affect, personal space, and control, whilst minimising journey time, negative affect, effort, and costs.

\subsubsection{Journey time concerns and journey-based affect}

Seventeen participants expressed concern regarding travel time and meeting planned arrival times.

P1: "If I'm looking at spending time with my daughter I'd rather pay [additional parking charges] than just take that time away from her really, because I see (her) little enough during the week..."

Travel time standards were frequently anchored to journey times attainable only by car, and so participants perceived public transport as relatively slow. Travel time was often 
seen as 'dead time', reducing time available to pursue personal goals, and emphasising the importance of faster journeys.

P5: "I can get to work in twenty minutes by car. It's an hour by bus. So time at home asleep, or time sat on the bus. [...]. I hate getting up much earlier than I need to."

Participants tended to neglect the potential for journey time to be used productively, and travelling by public transport was frequently seen as boring.

P5: "The possibility of [...] an hour, over an hour's journey, just [doesn't] appeal. [...] It's the length of time, the boredom of sitting on the bus [...] I just don't enjoy it."

However, when participants focused on traffic congestion and their ability to perform other activities on public transport, driving could be viewed as boring and public transport use a means to recover wasted travel time.

P3: "I don't like sitting in traffic [...] it's boring. [...] That's why I used to come on the bus when I used to live at Mile Oak. [...] The buses sit in traffic, but at least I can read or something."

These quotes illustrate the close connections between utilitarian and affective motives and highlight the possibility of marketing public transport as preferable to car use, in terms of using journey time effectively and enhancing affective experiences (i.e., less boredom and frustration and more time to do other things such as read).

Yet, for most participants, this potential was undermined by their tendency to estimate journey times on the basis of congestion-free roads. Delays were presented as unusual and drivers expected to be able to circumvent problems encountered en route by using alternative routes.

P3: "That's one of the advantages of a car, you can just go, 'Oh, I'll be home in twenty minutes'."

Conversely, public transport journey time estimates accounted for structural and service deficiencies. Public transport was expected to involve delays, not run to schedule and/or break down. 
P18: "[Using the train] is frustrating, because of the delays. There's nothing you can do about it at all [...] you're stuck there."

Thus public transport was problematised while driving was idealised with participants expressing strong protests in relation to uncontrollable and apparently unexpected delays while driving.

P18: "If there's accidents on the road, I can be late [for work]... [...] I don't like it. It gets me [...] stressed out [...] I'll just text my boss and tell him 'I'm in traffic, I'll be late', just to try and get rid of the frustration..."

Given the reality of city congestion, this idealised view of driving could be challenged.

Journey-based affect was also linked to other motives. For example, an evening shift worker (P4) linked autonomy over departure times to feelings of security:

P4: "I don't have to hang around, wait for the bus to turn up, literally leave when I want, come home when I want, no lingering about. In that respect it's safer..."

Affect concerns in relation to functional journeys, such as commuting to work, frequently centred on avoidance of negative affect, rather than attainment of positive affect, and, for most interviewees public transport elicited indifference at best.

P9: "[W] hen I was [...] travelling by train [...] there wasn't any sense of enjoyment. It was very, very functional, getting on the train."

Furthermore, strong negative affective reactions arising from particular public transport experiences appeared to discourage subsequent use:

P16: "My worst [public transport experience] was [...] a long time ago [...] I didn't know there was a bus strike, and [by] process of elimination I worked it out [...] It put me off basically.”

[...]

Int: "What kind of emotions, feeling and experiences come to mind when you think of public transport?"

P16: "Frustration [...] you get a feeling of unreliability..." 
Participants appeared to generalise disproportionately from particular negative experiences. Hence, P6's negative views of his local bus service were largely influenced by two experiences of poor service:

P6: "[O]ne time I did try and use [the bus] recently was when I was going into town [...] and the thing didn't turn up. So I was left stranded, had to go back home and ring a taxi. [...] I hadn't used [this bus service] for a while, I thought 'right, I'll give it another go', and on the one time I did try and give it a go, it didn't turn up."

In contrast to functional journeys, travel time was less important than affect when interviewees focused on leisure-related journeys, so emphasising that different concerns may underpin the decision to drive in relation to different journey types.

Int: "What's your most memorable experience of driving?"

P6: "Probably about three years ago, driving through France and Spain, a sort of driving holiday..."

Int: "What makes it memorable?"

P6: "The scenery, the company, and I guess the roads were so good. It just made it really easy and pleasurable..."

Mastery experiences may also contribute to positive affective consequences of driving, especially for younger drivers:

P9: "Coming to driving so late, I just still really really enjoy it. So if I can [drive] it's something I'll do. [...] Mainly because I've only just been driving for less than a year, I still get huge enjoyment out of it."

This contrasts with, for example, P11, a driver of over twenty years, who focused on utilitarian concerns.

P11: "I'm not out there for the buzz of driving, but it is a means of getting from A to $B . "$

Thus, if new drivers' experiences are more affectively rooted, it may be easier to persuade long-time drivers (for whom driving appears to be primarily goal-oriented) to consider public transport. 


\subsubsection{Effort minimisation}

Sixteen participants expressed a wish to minimise physical and cognitive effort expenditure, particularly on functional journeys. Some participants emphasised the contrast between the perceived effort involved in car use and that entailed by public transport use. The preparation involved in public transport use was judged to be effortful, and unattractive:

P15: "If I have the car as an option, I would always take the car. [...] It's the simplicity. I walk out the door, it's like, outside my house [...]. I have to walk a lot further to get the bus, then I have to wait around, they're not always on time, then I have to change buses, take two buses [...] if I'm going to catch the train [or] catch the bus, you have to plan, sometimes prepare by buying tickets..."

The expenditure of extra effort was viewed as unnecessary 'hassle':

P14: "[Having your own car] is easy, you know step outside your house, step in your car [...] [With car clubs] you have to phone up for the car, then pay per hour. It just seems more hassle..."

The desire to minimise effort represented a barrier to use of public transport because some drivers were unwilling to expend additional effort. Participants tended to neglect potential health benefits of physical exertion involved in using non-car transports for functional journeys:

P14: "It's a fifteen-minute walk to the train station, you have to wait, you get off and you have to walk again. It's laziness really..."

Effort concerns also influenced participants' policy views; initiatives imposing greater effort on car use were viewed negatively:

P7: "The voucher parking, you see that's a pain because you have to go in [to vendors], get the voucher."

However, participants' comments also indicated that policy initiatives focusing on the impact of congestion could help redress the relatively effortless perception of car use. 
P13: "Noticing how clogged up it can get in Brighton and Hove over the weekend, I just wouldn't elect to use my car [at such times], it is easier by bus.”

\subsubsection{Personal space concerns}

Eleven participants talked about how they valued the personal space offered by driving, including protection from contact with undesirable others and personal safety as well as freedom from observation when, for example, "singing loudly".

P5: "[When] it's dark and dingy outside [...] especially in that time of year [winter], the car is, you know, sort of my little zone away from the weather, and you know, the darkness outside..."

This contrasted with a loss of personal space and consequent vulnerability on public transport.

P15: "There's always a lot of (strange) people [on the bus]. [...] You just want to get off as quick as possible."

Solitary personal space was positively experienced, providing opportunities for relaxation and quiet contemplation. This was particularly important when commuting home:

P18: "[My car journey provides] time to unwind before I get home. It's just time [...] literally to myself. I can just think about [the workday], get everything out of my head."

Moreover, some participants commented on how their cars could be used to host social interaction:

P19: "If you get sort of three or four people together in the car and they're all your friends you can [...] use it as an opportunity to have decent conversations..."

These concerns highlight the challenge of portraying social aspects of public transport as positive and safe while also emphasising opportunities to create semisolitary space on public transport (e.g., by using personal stereos). 


\subsubsection{Monetary cost concerns ${ }^{1}$}

All participants wanted to minimise transport costs, regardless of income level. Both the highest-earning participant (P6) and the lowest-earner (P4) used cost as a rationale for transport mode choice:

P6 (£55-60,000) $)^{2}$ : I never park in the city centre any more [...] it's very expensive."

P4 (£10-15,000): “[I drive to work] basically because of the cost ... it’s cheaper than to, to get the buses..."

Private car use involves numerous financial costs: petrol; road tax; insurance; MOT costs; potential parking, servicing and/or road pricing charges ${ }^{3}$; and the cost of purchasing or leasing the car. Additionally, the vehicle depreciates in value. However, where asked to indicate total car use costs (on both monthly and annual timescales), participants indicated that they did not know or consider many of these costs.

Participants instead offered impromptu estimates but were uncertain:

P1 (£15-20,000): “I don’t know. I suppose, pie in the sky, eighty quid [per month], seventy quid, something like that."

Costs appeared to be cognitively represented according to the timescale in which they are encountered. For example, road tax is paid annually and, for many participants not easily accessible as a monthly cost. Unsurprisingly, less frequent costs were less salient. Thus perceived costs did not map accurately onto the real cumulative costs of driving.

P14 (£15-20,000): “[You] pay your [road] tax and get on with it...”

P17 (£15-20,000): "Well, the insurance is thirty-odd a month, so that's about four hundred and fifty quid [per year], um, tax another hundred, and petrol, say, two hundred and forty."

\footnotetext{
${ }^{1}$ Whilst monetary cost issues were part of our interview schedule, cost concerns were commonly cited by participants prior to cost-related questions, and were also evident in responses to non-cost-oriented questions. Thus, cost concerns arose spontaneously and independently of the interview schedule.

${ }^{2}$ Values denote participants' annual income.

${ }^{3}$ Road pricing charges do not currently apply within Brighton and Hove, and no participants indicated that they incur road pricing charges elsewhere. Potential road pricing costs are not discussed further in this section.
} 
Moreover, the cost of a single car journey tended to be conceived of solely in terms of fuel, and was therefore systematically underestimated:

P4 (£10-15,000): “My car doesn’t really cost that much to run, so to pay [...] a pound twenty or something one way [on the bus], it wouldn't cost me that in petrol to get there."

By contrast, public transport involves an explicit cost, typically encountered on a daily or per-journey basis. Public transport cost appraisals were therefore generally accurate so that comparisons with driving were biased in favour of car use. This suggests that per-journey charging on public transport emphasises its relative expense to drivers.

P18 (£15-20,000): "I compared the cost of getting here, literally the cost of getting here petrol-wise, to the train costs [...] so I went for the car."

Cost minimisation motives may be guided by consideration of "sunk" cost (Arkes \& Blumer, 1985). Thus costs arising independently of the extent of car use (e.g., purchase cost, insurance, and tax) provide an additional incentive for car use:

P7 (£15-20,000): “I’ve paid for the car now, I want to use it."

Car use reduction campaigns could therefore address drivers' cost concerns by highlighting the real costs typically incurred through car use, including per-journey costs, and providing drivers with readily comprehensible methods for calculating such costs.

Even cost concerns could be subordinate to affective motives, illustrating the willingness of motorists to pay more for a positively-appraised affective journey experience.

P6 (£55-60,000): "Although we had to pay for [...] the toll roads [...] it was worth it because the roads were so uncongested and smooth..."

\subsubsection{Desire for control}

All participants valued car use for its provision of optimal control over journey initiation and progression, and a desire for control appeared to underpin most other 
motives so identifying control as a unifying central category. For example, personal space concerns were based on a desire for control over physical and social environments when commuting. Drivers saw themselves as self-sufficient, able to spontaneously initiate journeys with minimal preparation, and choose new or alternative routes without consultation. Such control was positively experienced.

P2: "[Car use enables you to] go where you want to go at the time that you want to go and it's within my control."

P5: "I enjoy driving [...] it was always quite important to be able to have the freedom [...] I just felt that that was something I wanted to do, to give me, you know, an independence, so I can get out and get where I wanted to. And now, I find driving interesting..."

Greater perceived control translated into more positive affect:

P15: "If you're out on the open road, you've got a clear, maybe a country lane on a nice day, it can be fun [...] you can drive at your own pace, you can drive fast, you can drive slow. [...] I like to drive at my own speed, I don't want to keep stopping and starting because of the traffic in front, or because the people behind me want me to go faster. You can just do your own thing..."

By contrast public transport use was viewed as delegation of control and acceptance of the helplessness experienced in the passenger role:

P9: “There's no sense of control essentially when you're on public transport. You give yourself up to somebody else. And to a certain extent, that's not something I'm particularly comfortable with. I don't like the fact that you get on [the bus] and somebody else is driving for you..."

Retaining control was seen by some participants to override other concerns such as journey time.

P3: "There's always roadworks on the A27 [...] I've gone all round the back ways [previously]. So as long you keep moving it's alright. It might be another five miles but (it's better than) sitting in traffic."

Drivers typically did not consider potential delays and obstacles when driving so simultaneously overestimated the extent of control afforded by the car and underestimated the likelihood of negative journey affect while driving. Occasionally 
however, when focusing on the real obstacles to hassle-free driving, effort minimisation would lead to acknowledgement of positive aspects of public transport use.

P16: "[With buses] you know you're going to get in without any [hassle], it's not down to you to find [parking], that responsibility's taken away."

Hence, car use reduction campaigns could emphasise parking difficulties when driving in city centres and the reduced responsibility for parking when using public transport as well as greater autonomy and positive affect resulting from control of activities while on public transport.

\subsubsection{Views on transport policies: Consequences for whom?}

The desire for autonomy was fundamental to evaluation of policy initiatives.

When TDM policies were seen to restrict control and freedom and increase dependency they evoked negative reactions.

P16: "[I wouldn't join a car-pool because] it's that feeling of, sort of having other people, it's like other influences for me. [...] I like to feel in control of myself."

Unsurprisingly, TDM policies were assessed in terms of expected personal outcomes.

P11: "If [city centre road closures were] going to affect me, then I'll be honest, I wouldn't really want that. If it causes me a problem then [...] I don't want it to happen."

Consequences were typically evaluated according to the extent to which they are perceived to increase transportation costs:

P19: "If it works out that [paying a road tax proportional to car use were] more expensive than it would have been [under the current road tax system], then obviously I'd be annoyed with it. But if it works out cheaper, then I wouldn't be."

Social identity theory (e.g. Tajfel, 1981) posits that individuals define themselves not only in terms of idiosyncratic personal identities, but also in terms of social identities, that is, membership of real or imagined social groupings. Membership entails adoption of group goals and values and, consequently, social identities prescribe particular 
perceptions and beliefs appropriate to group membership. Interviewees' appraisals of consequences were often dependent upon salient social identities. For example, when participants identified as 'motorists', even TDM policies without direct personal consequences evoked negative affect:

P15: "The car driver [...] pays road tax [...] [so] should have the right to go on any road. [...] [Pedestrianisation] probably would annoy me [...] but it probably wouldn't affect my day-to-day driving. [...] They're cutting down on the choice for the motorist."

(emphasis added)

Within this 'motorist' identity, charging for road use was viewed as taxation and only acceptable if accompanied by reductions in other charges:

P14: "If I didn't have to pay to park, then I'd pay the congestion [charge], yeah."

Such 'taxes' were commonly perceived to be an unfair means of enforcing a switch to alternative transports. Participants typically reported intentions to maintain car use but simply change journey routes to avoid such costs. Congestion charging may therefore be effective in reducing city centre traffic:

P7: "[If congestion charging were introduced in Brighton] I'd take the bypass round Brighton. I just wouldn't go in there."

Individuals subscribe to numerous social identities (e.g. Tajfel, 1981), and as identity shifts, so does the perception of self-relevant consequences. Thus, for example, car drivers could also identify as residents and, in this identity, remain open to policies which restrict motorists but yield benefits for residents. This then had implications for perceptions of policy strategists so that, when identifying as a resident, P13 showed affiliation with policymakers and their interests:

P13: "[Bus priority at traffic lights] is another really good idea worth exploring in this whole scheme of [...] the way we're looking at traffic and reducing cars on the road." 
Many participants avoided driving in the central shopping area of the city, and hence, when discussing TDM policies in this area, adopted a 'pedestrian' identity:

P12: “It annoys me when other people don't respect [the no-car zone on Western Road] especially when you're nearly mowed down because you're not expecting a car to come along there. I think it's a good idea. [...] The only way [the closure] has affected me is I enjoy shopping slightly more [...] it's easier to get across the road..."

Similarly, drivers that also reported using public transport were able to identify as public transport users and were therefore more likely to voice positive views towards public transport promotion policies that restrict car use:

P11: "If I'm coming into Brighton['s shopping district], very often I will use another form of transport. [...] [Bus lanes are a] good idea because I think that frees up the buses to move, and they should have priority."

Some participants alternated between identities. Thus, whilst P12's excerpt above demonstrates a 'pedestrian' viewpoint, elsewhere she adopted a 'motorist' perspective:

P12: "If I had to pay five pound to get into Brighton, I'd find it very irritating [...] it seems the government are forever hitting on the motorist..."

Given the importance of shifting social identities, the framing of car use reduction strategies may influence acceptance by drivers. Appeals to more inclusive identities, such as 'residents' - rather than addressing 'motorists' - may minimise drivers' objections.

\subsection{Discussion}

Grounded theory analysis of drivers' views highlighted the importance of five motives in sustaining car use: minimising journey time, and achieving positive and/or avoiding negative journey-based affect; minimising physical and psychological effort; creating personal space; and minimising financial expenditure. These were underpinned by a desire for control over the transport experience. Analyses also revealed the extent to which affective concerns are interwoven with utilitarian considerations and how acceptance of transport management policies depends, in part, on the social identity adopted by drivers. 
In certain respects our participants' utilitarian concerns echo those identified in previous studies (e.g. Collins \& Chambers, 2005; Mann \& Abraham, 2006; Tertoolen et al., 1998; van Vugt et al., 1996). For example, rapidity was the most important aspect of car use for Tertoolen et al.'s (1998) participants, and 17 of our participants (89\%) cited journey time concerns as a determinant of their transport mode decisions.

Our data question the utility of dividing driving decisions into utility- versus affect-based decisions (see too Mann \& Abraham, 2006; Steg, Vlek \& Slotegraaf, 2001; Wardman et al., 2001). This suggests that as well as improving reliability and journey times public transport policy will need to promote public transport as a more positive experience. This seems especially important given the clear discrepancy between positive affective responses to car and generally negative affective responses to public transport.

Negative evaluations of public transport are, at least to some extent, based on drivers' biases and misconceptions (Fujii \& Gärling, 2005). Drivers have distorted perceptions of control, erroneously feeling able to overcome potential barriers to journey progression even in the face of increasing congestion (DfT, 2005b). This optimistic perspective contrasted sharply with perceptions of public transport, which invariably incorporated delays and problems. This is consistent with research showing that even where bus journeys are relatively short in duration, they are often perceived by drivers to be too long (Wardman et al., 2001). Driving reduction campaigns could perhaps emphasise the real problems encountered by drivers and their impact on journey affect. It is encouraging to note that experience of public transport can reduce drivers' negative evaluations (Brown, Werner, \& Kim, 2003; Fujii et al., 2001; Fujii \& Gärling, 2005). One source of such re-evaluation is the realisation that journey time need not be 'dead time' but can be used productively (e.g., working on a train). Brown et al. (2003) studied car commuters forced to reduce their car use due to a temporary reduction of onsite parking spaces. Despite anticipated dissatisfaction, drivers who switched to public transport developed strategies to use journey time productively. These drivers were subsequently found to have greater satisfaction with public transport and were more likely to switch to public transport after parking spaces were restored (cf. Fujii et al., 2001; Fujii \& Gärling, 2005).

The role of perceived costs in travel mode choice has been well documented (e.g. Jakobsson et al., 2002; Meyer, 1999). Drivers frequently fail to appreciate the full costs of their travel and equate running costs with fuel costs only (Mann \& Abraham, 
2006; RAC, 2004; Wardman et al., 2001). This is facilitated by cognitive representation of different costs on different timescales. Car reduction initiatives might therefore help drivers become aware of the real costs of their transport mode choice (e.g. Ampt, 1999; but see Tertoolen et al., 1998) by highlighting monthly and weekly running costs. In addition, changing road tax charges from a sunken yearly cost to a per-journey payment and offering incentives to buy public transport season tickets could help redress biases in the relative cost of driving versus using public transport.

Personal space concerns took two forms: a desire for protection from undesirable social and physical conditions, and a desire for privacy from unwanted intrusions, especially when commuting. Perceived security when driving was particularly important in sustaining car use amongst our female participants, who viewed public transport as unsafe. Ellaway et al. (2003) argue that feelings of protection and security arising from the car as personal space represent important psychosocial benefits (see also Hiscock et al., 2002). Ellaway et al. found that both car users and individuals with no car access rated the car as a safer travelling environment than public transport. However, participants with no car access rated perceived protection on public transport significantly higher than did those with car access. Thus, drivers may exaggerate the reduced security associated with public transport use. Ellaway et al. also found that participants without access to a car believed that they had greater privacy when using public transport than did car users, probably because they had experience of employing strategies such as reading or listening to personal stereos while using public transport (Brown et al., 2003; Hiscock et al., 2002). Nonetheless, provision of security and personal space pose real challenges to car reduction schemes designed to persuade drivers to switch to public transport.

There is scant research focusing on the role of anticipated effort in transport choices (Wardman et al., 2001) although studies have highlighted the importance of perceived convenience (e.g. Steg, 2003; Tertoolen et al., 1998; van Vugt et al., 1995). For our participants, convenience depended on perceived physical and cognitive demands. Season tickets, on-line journey planners and greater integration of public transport systems could reduce travellers' actual and perceived effort.

When people feel able to control their surroundings, they generally enjoy positive affect and wellbeing, whilst reduced control generates negative affect (Reis, Sheldon, Gable, Roscoe, \& Ryan, 2000; Sheldon, Reis, \& Ryan, 1996). Thus the autonomy and empowerment drivers feel can benefit health and wellbeing and access to 
a car is associated with superior physical health, less depression and lower mortality rates (Macintyre, Hiscock, Kearns, \& Ellaway, 2001; Smith \& Harding, 1997).

Policymakers therefore need to enhance perceptions of control over alternative transport modes if they are to persuade commuters to give up this important sense of control. Greater access to service information and more interactive services (e.g., real-time timetable information) may enhance perceptions of control over journey management. Indeed, enhanced information and understanding may, at least in part, explain the effectiveness of car use reduction schemes in which drivers receive personally tailored information regarding alternative transport options (Taniguchi, Hara, Takano, Kagaya, $\&$ Fujii, 2003). Fortunately, public transport users report significantly higher autonomy gains from public transport use than drivers (Ellaway et al., 2003) so early positive experiences could minimise drivers' potential autonomy loss when switching to public transport.

Past treatments of policy attitudes have distinguished between personal versus social outcomes (Dawes, 1980; Schade \& Schlag, 2003). However, we found that strong responses were evoked by TDM strategies expected to yield significant consequences for a personally-important social ingroup even in the absence of direct personal consequences. Social identity theory (e.g. Tajfel, 1981) proposes that individuals may identify with numerous collective groups, which vary in levels of inclusiveness (Turner, 1985). The positive consequences of car reduction policies may, therefore, be more evident to drivers who identify as citizens or residents. For example, pedestrianisation schemes typically benefit local residents via reduced congestion and pollution, while restricting drivers' options. We found that identification as a 'resident' led to policymakers being viewed as advocates for local improvements while identification as a 'motorist' resulted in portrayal of policymakers as antagonists. Experimental investigation could clarify how such identify shifts can be prompted and whether they consistently alter perceptions of driving reduction policies.

Interestingly, our participants did not discuss environmental issues. This may be because they do not consider environmental consequences when making transport decisions, possibly because they do not feel responsible for the negative consequences of high levels of car use (Collins \& Chambers, 2005; Garvill, 1999; Polk, 2004). Thus, morality may not impinge upon day-to-day travel choices (Klöckner \& Matthies, 2004). Alternatively, participants may have been insufficiently aware of the environmental consequences of private car use. Car commuting reduction campaigns might therefore 
aim to increase drivers' awareness of, and perceptions of (partial) responsibility for environmental detriment.

Our methodology precludes exploration of the predictive validity of our findings and our participants do not constitute a sample representative of UK commuters. However, we have no reason to believe that our participants differ significantly in their transport concerns from other UK car commuters. Indeed, correspondence between our results and previous findings suggests that our participants' perceptions match those of other car commuters.

We have employed grounded theory methods, but we do not propose that our findings constitute a 'grounded theory' (e.g. Willig, 2001). Rather, we have generated a series of evidence-based theoretical proposals. Further qualitative and quantitative theory-testing research is required to develop these proposals into a definitive theory.

Nonetheless our results highlight potential targets for future car reduction interventions: misconceptions of car and public transport travel times; perceptions of car journey time as 'dead time' and utilisation of public transport journey time; discrepancies in typical affective responses to the car versus public transport; perceptions of effort involved in driving versus public transport, especially in relation to the management of congestion and parking; experiences of personal space on public transport; underestimation of car costs; sunk cost reasoning sustaining car use; perceptions and experiences of control when driving versus using public transport; and the role of social identity in policy views. 


\section{Chapter 3. Study 2: Predicting travel mode choice among regular car commuters:} Comparing and integrating the Theory of Planned Behaviour and inductive concepts

\subsection{Abstract}

The Theory of Planned Behaviour (TPB) has been successfully applied to travel mode choice, but car use decisions may be better explained using concepts inductively derived from drivers' self-reported experiences. It was hypothesised that a set of behavioural beliefs derived from qualitative analysis of interviews with drivers would either provide superior prediction of commuting mode choices than the TPB or augment prediction achieved by the TPB. Analyses of longitudinal data from 224 regular car commuters employed in a small English city demonstrated that the TPB predicted public transport commuting intentions and behaviour, but explained variances were low. Inductively derived concepts did not predict intentions or behaviour directly and were best modelled as antecedents of attitudes and perceived behavioural control. Results are discussed in terms of potential habit effects and methodological and conceptual limitations.

\subsection{Literature review}

Despite the increasingly urgent need to reduce unnecessary car journeys (e.g. Stern, 1992), there have been few attempts to devise evidence-based car use reduction strategies. This may be due to gaps in understanding of the cognitive underpinnings of car use; developing effective psychological driving reduction schemes necessitates identifying and targeting potentially modifiable antecedents of travel mode choice (Bartholomew, Parcel, Kok \& Gottlieb, 2006; Michie \& Abraham, 2004).

Two broad approaches to modelling behaviour can be identified. A deductive approach imposes concepts derived from a preconceived nomothetic theoretical framework. Alternatively, an inductive approach uses concepts derived from empirical observation of individuals engaged in the focal behaviour and/or their perceptions of it. A theory or set of concepts grounded in and specific to a particular behaviour may therefore be developed in this way.

Deductive methodology dominates research into cognitive antecedents of travel mode choice (e.g. Bamberg \& Schmidt, 2003). The most popular nomothetic theory to have been applied to driving motivation is the Theory of Planned Behaviour (TPB; 
Ajzen, 1991; Ajzen \& Fishbein, 2005; Bamberg \& Schmidt, 2003), which, as detailed in chapter 1 (pp.7-8), posits that behaviour is most closely determined by intention, i.e. conscious motivation to exert effort to perform an action. Intention in turn is determined by attitude, subjective norms, and perceived behavioural control (PBC). Attitude represents a global evaluation of the favourability of performing the focal behaviour. Subjective norms concern perceived social approval from significant others to (not) perform the behaviour, and later revisions of the TPB (e.g. Ajzen \& Fishbein, 2005) have also highlighted a role for descriptive norms, i.e. perceptions of the actual behaviour of significant others. PBC reflects perceived ability to initiate and control behaviour, and comprises behaviour-specific self-efficacy beliefs (Bandura, 1997) together with anticipated situational constraints (Ajzen, 1988). To the extent that PBC represents actual behavioural control, PBC may also have a direct effect on behaviour (Ajzen, 1988).

Applications of the TPB to travel mode choice have been relatively successful (Bamberg, Ajzen, \& Schmidt, 2003; Bamberg \& Schmidt, 1998, 2003; Heath \& Gifford, 2002). For example, Heath and Gifford (2002) found that TPB constructs relating to bus use predicted around $60 \%$ of variance in intentions, and $55 \%$ of variance in bus use, and Bamberg and Schmidt (2003) showed that measures of attitudes, subjective norms and PBC predicted $60 \%$ of intentions to drive, and $45 \%$ of variance in reported car commuting amongst student commuters.

The TPB models behaviour as the outcome of rational utility-maximising, goaloriented deliberative cognitive processes (Ajzen, 1991), but some behaviours may occur in the absence of forethought, as reactions to unanticipated circumstances (e.g. Gibbons, Gerrard, Blanton, \& Russell, 1998a, 1998b). Alternatively, behaviour can be prompted by non-cognitive mechanisms such as affective responses to situational circumstances, which bypass rational cost-benefit analyses (Loewenstein, 1996). Thus, the assumption that transport mode decisions are premeditated and deliberative is open to question (Aarts, Verplanken, \& van Knippenberg, 1998).

Aside from potential conceptual limitations, past applications of the TPB to travel mode choice have also been restrictive from an intervention design perspective. Pre-intention TPB constructs are underpinned by an expectancy-value model of relations with underlying beliefs (Ajzen, 1991): attitude aggregates salient beliefs regarding expected consequences of action, as multiplicatively combined with subjective utility weights assigned to these consequences, and $\mathrm{PBC}$ represents salient 
beliefs surrounding the likelihood of facilitators and inhibitors of action, together with estimates of the facilitatory or inhibitory power of each obstacle. As argued previously (chapter 1, p.10), applications of the TPB to travel choice have tended to neglect relationships between salient beliefs and attitudes and PBC (e.g. Harland, Staats, \& Wilke, 1999; Heath \& Gifford, 2002; Kaiser \& Gutscher, 2003; but see Bamberg \& Schmidt, 1999, 2001), thus failing to identify which particular consequences of mode choice are important when making transport decisions. For example, do people hold favourable attitudes towards driving because they believe that car use will minimise travel time (e.g. van Vugt, Meertens, \& van Lange, 1995), or for some other reason(s)? This is crucial, because attitudes and control perceptions cannot be effectively targeted without identifying underlying modally salient beliefs amongst intervention target populations (Ajzen, 1988; Ajzen \& Fishbein, 1980).

A wealth of research has identified beliefs and concerns relevant to travel mode choice, such as perceptions of financial costs, reliability, travel time variability, and environmental pollution (e.g. Bamberg \& Schmidt, 1998, 2001; Heath \& Gifford, 2002; Jakobsson, Fujii \& Gärling, 2002; Tertoolen, van Kreveld \& Verstraten, 1998; van Vugt et al., 1995; van Vugt, van Lange, \& Meertens, 1996). However, many such variables have been identified using procedures in which participants are presented with researcher-generated lists of potential travel mode attributes, to which subsequent preferences or behavioural decisions are traced back (e.g. van Vugt et al., 1995). This methodology is potentially problematic, because researcher-generated lists may include attributes not salient to drivers when making real-world transport decisions (Ajzen, 1988).

Bamberg and Schmidt (1999, 2001) found that attitudes towards bus use among a student population were determined by beliefs regarding journey speed, comfort, stress, cost, and levels of environmental pollution, whilst PBC was determined by bus departure knowledge, and perceived quality of bus connections. Although these beliefs were identified using free elicitation (Ajzen \& Fishbein, 1980), whereby participants list advantages and disadvantages of, and any other beliefs associated with, the behavioural object, this method is open to self-presentation biases (e.g. Paulhus, 1986): participants may not wish to disclose certain beliefs which are nonetheless important behavioural determinants. Indeed, Steg, Vlek and Slotegraaf (2001) have shown that where the research purpose is evident, individuals are less likely to report motives for driving that may be incongruent with desired self-presentation, such as affect-based motives. 
However, Mann and Abraham (2006) have demonstrated how qualitative analyses of interview data can reveal beliefs and perceptions that individuals may not disclose initially (Steg, Vlek \& Slotegraaf, 2001).

Our previous study (see chapter 2) used grounded theory analyses of interviews with regular car commuters in a small UK city to identify drivers' key beliefs and concerns: journey time beliefs, monetary cost concerns, effort expenditure, in-journey control over journey progression, personal space opportunities and safety, and minimisation of negative affect. Drivers felt car use was the only means of meeting these concerns, as the only perceived alternative - public transport (PT) - was seen to be deficient in all of these areas. To the extent that interviewees in the previous study represented UK car commuters, constructs emergent from this analysis should represent salient beliefs amongst regular UK car commuters (Ajzen \& Fishbein, 1980).

\subsubsection{The present study}

The present study aimed to explore the predictive utility of beliefs inductively derived from a preceding qualitative inductive analysis (see chapter 2), both in competition and conjunction with the TPB, in predicting deviation from usual commuting behaviour amongst regular car commuters.

Given that regular car commuters are likely to intend to continue commuting by car, measures of willingness to use public transport (Gibbons et al., 1998a, 1998b) were also included in the present study. Whereas intention pertains to premeditated action, willingness involves a relative lack of forethought and reflects an unplanned behavioural reaction to a particular unforeseen set of circumstances (Gibbons et al., 1998a). The two concepts have been shown to have discriminant validity (e.g. Gibbons et al., 1998a, 1998b; Gibbons, Gerrard, Ouellette, \& Burzette, 2000; Thornton,

Gibbons, \& Gerrard, 2002), but willingness can be traced back to the same cognitive antecedents as intention as specified in the TPB (Gibbons et al., 1998a). Whilst conceptually independent, intention and willingness are often practically interchangeable as proximal determinants of behaviour within the TPB framework ${ }^{4}$.

The following hypotheses were tested:

\footnotetext{
${ }^{4}$ Where behaviours are socially unattractive, willingness are less likely to be informed by subjective norms than are intentions (Gibbons et al., 2000), but travel mode decisions rarely involve strong social (dis)approval (e.g. Heath \& Gifford, 2002), and hence this distinction is unlikely to be important in the present study.
} 
Hypothesis 1: $\mathrm{PBC}$ and intention (and/or willingness) will predict a statistically significant proportion of variance in commuting mode choice behaviour.

Hypothesis 2: Inductively derived behavioural belief measures will predict a greater proportion of variance than will TPB constructs (as supplemented by willingness) in commuting mode choice behaviour.

Hypothesis 3: Attitude, subjective norm and $\mathrm{PBC}$ will predict a statistically significant proportion of variance in intention (and/or willingness).

Hypothesis 4: Inductively derived behavioural belief measures will predict a greater proportion of variance in intention (and/or willingness) than will pre-intention TPB constructs.

Hypothesis 5: Inductively derived behavioural belief measures will predict a statistically significant proportion of variance in attitude and/or PBC.

\subsection{Method}

\subsubsection{Pilot study}

A set of matched multi-item measures designed to tap inductively derived behavioural beliefs in relation to car use and PT use were piloted in a preliminary study using 62 university-based staff and postgraduate car commuters.

Both car and PT affect scales were internally reliable, but as table 3.1 shows, the reliability of scales comprising matched items differed considerably for other constructs. For example, perceived journey time items relating to PT were reliable (Cronbach's alpha $[\alpha]=.72$; Nunnally, 1978), but a set of identical items pertaining to car use was only marginally reliable $(\alpha=.61)$. The items are therefore likely to have tapped different dimensions of the journey time construct, which may correspond for PT but do not necessarily do so for car use. Similarly, whilst perceived effort items relating to PT use were marginally reliable $(\alpha=.61)$, matched items relating to car use were highly inconsistent $(\alpha=.18$ ), suggesting that ease of use, and perceived effort and necessity of prior planning are experienced by drivers as different concepts, which are more congruent in relation to PT use than car use. 
Table 3.1. Pilot questionnaire items with reliability coefficients

\begin{tabular}{|c|c|c|}
\hline Variable & Items & Cronbach's $\alpha$ \\
\hline Perceived journey time & $\begin{array}{l}\text { 1....provides the quickest way of } \\
\text { getting to work } \\
\text { 2. Using ... to commute is (slow- } \\
\text { fast) } \\
\text { 3. When I use ..., I feel confident } \\
\text { that I will reach my destination } \\
\text { within the planned time }\end{array}$ & $\begin{array}{l}\text { Car scale }=.61 \\
\text { PT scale }=.72\end{array}$ \\
\hline Affect & $\begin{array}{l}\text { I find using ... to commute to and } \\
\text { from work: } \\
\text { 1. unpleasant-pleasant } \\
\text { 2. enjoyable-unenjoyable } \\
\text { 3. unsatisfying-satisfying } \\
\text { 4. frustrating-not at all frustrating }\end{array}$ & $\begin{array}{l}\text { Car scale }=.78 \\
\text { PT scale }=.80\end{array}$ \\
\hline Perceived effort & $\begin{array}{l}\text { 1. How effortful is it for you to use } \\
\text {... to commute? } \\
\text { 2. For me, commuting by ... is easy } \\
\text { 3. If I use ... to commute, I need to } \\
\text { plan my journey in advance }\end{array}$ & $\begin{array}{l}\text { Car scale }=.18 \\
\text { PT scale }=.61\end{array}$ \\
\hline Personal space & $\begin{array}{l}\text { 1. Commuting by ... is (unsafe-safe) } \\
\text { 2. I feel safe when commuting by ... } \\
\text { 3. I feel vulnerable when I commute } \\
\text { by ... }\end{array}$ & $\begin{array}{l}\text { Car scale }=.59 \\
\text { PT scale }=.78\end{array}$ \\
\hline Perceived cost & $\begin{array}{c}\text { 1. For me, using ... to commute is } \\
\text { expensive } \\
\text { 2. To get value for money, I feel I } \\
\text { should use my car for most journeys } \\
\text { (car use only) }\end{array}$ & $\begin{array}{c}\text { Car scale }=.31 \\
(r=.19 \text { n.s. })\end{array}$ \\
\hline $\begin{array}{c}\text { Perceived in-journey } \\
\text { control }\end{array}$ & $\begin{array}{c}\text { 1. When I commute by..., I rarely } \\
\text { encounter delays or obstacles } \\
\text { 2. How much control do you have } \\
\text { over the progression of your journey } \\
\text { when commuting by ...? (No } \\
\text { control-complete control) } \\
\text { 3. When I commute by ..., I am able } \\
\text { to overcome potential obstacles } \\
\text { arising during the journey } \\
\text { 4. Ifeel in control when I commute } \\
\text { by ... }\end{array}$ & $\begin{array}{l}\text { Car scale }=.68 \\
\text { PT scale }=.42\end{array}$ \\
\hline
\end{tabular}

NB - All items measured on 7-point Likert scales. Unless otherwise stated, all responses ranged from strongly agree-strongly disagree. 
Items designed to measure safety aspects of personal space also differed in reliability (PT scale: $\alpha=.78$; car use scale: $\alpha=.59$ ), suggesting that drivers may have interpreted these items to relate both to personal security and also vehicle safety. A single item used to measure perceived PT cost, was supplemented for car costs by an additional item designed to tap desires to obtain value for money and thereby justify 'sunk costs' (Arkes \& Blumer, 1985). The resultant two-item scale was however unreliable $(\alpha=.31 ; r=.19, p=.09)$, demonstrating that running cost perceptions do not necessarily encapsulate sunken costs (see chapter 2, pp.29-30). Items designed to tap perceived in-journey control did not correspond in relation to PT $(\alpha=.42)$, but were generally acceptable for car use $(\alpha=.68)$ : drivers may feel that overcoming in-journey delays does not necessarily correspond with perceptions of control when using PT.

Where pilot scales were unreliable, items were modified, omitted or added (as detailed below) to create matched unidimensional scales in the main questionnaire.

\subsubsection{Main study}

\subsubsection{Participants and Procedure}

A sample of regular car commuters employed in Brighton and Hove was recruited via employers, who circulated an email containing a hyperlink to a questionnaire. Participants completed the questionnaire electronically, and provided email addresses to permit contact two weeks later with a link to a follow-up questionnaire. Participants who did not complete the second questionnaire were sent at most two reminder emails at weekly intervals, which also outlined the particular twoweek period to which responses were to relate. Participants who completed both questionnaires were entered into a cash prize draw (with prizes of $£ 100, £ 50$ and $£ 25$ ).

Participants were employed by organisations in central Brighton and Hove: a life assurance organisation (Time 1 [T1]: $N=248$; Time 2 [T2]: $N=242$ ), a banking corporation (T1: $N=23$; T2: $N=20$ ), an engineering and development consultancy firm (T1: $N=2 ; \mathrm{T} 2: N=2)$, and a software company (T1: $N=1$; T2: $N=1) .29$ participants did not provide data to indicate their employer ${ }^{5}$. All participants' workplaces are served by frequent bus services and located close to train stations served by intra- and inter-city routes.

\footnotetext{
${ }^{5}$ Workplaces were identified from work email addresses provided by participants, but 23 participants gave non-work addresses, and at Time 1, 6 participants did not provide email addresses.
} 
Questionnaires were administered by email invitation including a link to an online questionnaire. 303 participants completed the first questionnaire, of whom 277 (91\%) also completed the near-identical follow-up questionnaire, 2 weeks later. 24 participants did not meet inclusion criteria and were therefore excluded from analysis: 11 participants were infrequent car commuters, only driving to work 'quite often', 'sometimes', or 'hardly ever'; 10 participants were employed at offices based outside of Brighton and Hove; and 3 participants indicated that they had a physical impairment that necessitated car use.

Participants reported one-way commuting distances of 1 to 76 miles $(M=9.29$, $S D=8.66 ;$ median $=7.00)$. Examination of the distribution of commuting distances indicated that participants at or above the 90 percentile of the sample commuted over 20 miles (one-way), and those located between the 75-89 percentiles commuted between 12 and 20 miles. ANOVAs and follow-up contrasts indicated that participants who commuted 20+ miles differed significantly to other participants on three of the twenty study variables (PT affect, PT personal space opportunity, Car in-journey control), with marginally significant differences $(p<.10)$ on a further three variables (Behaviour, Car effort, Car cost). Only two differences were observed at $p<.10$ between participants commuting between 12 and 20 miles and participants commuting less than 12 miles (Car cost, Car in-journey control). Hence, data from 29 participants who commuted 20+ miles were removed from analysis.

This resulted in a final sample of 224 participants, who 'always' or 'most of the time' drove 20 miles or less to workplaces in Brighton and Hove; this sample met statistical power requirements ${ }^{6}$.

146 participants were female and 73 male; 5 participants did not indicate their gender. Participants ranged in age from 18 to 43 years, and the mean age was 36.42 years $(S D=9.31)$.

\subsubsection{Measures}

Time 2 (T2) behaviour. Participants were asked on how many days in the preceding two weeks they had commuted: a) to their usual workplaces; b) using public

\footnotetext{
${ }^{6}$ A priori power analysis was run using G*Power (Faul \& Erdfelder, 1992). Using a multiple regression procedure, with significance set at .05 , and presupposing medium effect sizes for 15 potential predictors of behaviour (willingness, intention, PBC, and the 12 behavioural belief items; e.g. Ajzen, 1991; Bamberg, Ajzen, \& Schmidt, 2003; Bamberg \& Schmidt, 1998, 2003), an N of 139 was sufficient to achieve power at .80 (Cohen, 1992).
} 
transport; and c) by car. This permitted calculation of the percentage of eligible trips made by car and those made by PT at each timepoint. Journeys made using both PT and car, and journeys made using neither PT nor car were excluded from analysis ${ }^{7}$, so that the behaviour measure represented the percentage of commuting trips made by public transport (effectively an inverse of the percentage of car commuting trips), with high scores representing less driving.

Unless otherwise stated, all cognitions were measured at Time 1 (T1) only, and took the form of statements with which participants marked their agreement on sevenpoint scales ranging from 'strongly disagree' to 'strongly agree'.

Willingness. Two items designed to tap willingness to commute by public transport ('I am willing to commute regularly using public transport instead of my car'; 'I can foresee myself commuting regularly by public transport instead of my car in the future') were included at both timepoints, but these were unreliable (T1 $\alpha=.52, r=.35$, $p<.001 ; \mathrm{T} 2 \alpha=.25, r=.15, p=.02)$. The former item was entered into subsequent analyses as a single-item measure due to its greater semantic closeness to the willingness concept.

Behavioural beliefs. Behavioural belief items relating to car use and those relating to public transport use were matched via identical wording. Participants who did not use public transport to commute were asked to imagine commuting by public transport when responding.

Perceived journey time was measured by four items ('For me, ... provides the quickest way of getting to work'; 'When I ... to and from work, I feel highly confidentnot at all confident that I will reach my destination within the planned time' [recoded]; 'When I commute by ..., I get to my destination on time very often-very rarely' [recoded]). A fourth item followed the stem 'For me, commuting by ... is' (very slowvery fast). However, the reliability of the resultant scales was unsatisfactory (car use journey time $\alpha=.59$; PT journey time $\alpha=.55$ ). Reliability for both scales was enhanced by omitting the items 'For me, ... provides the quickest way of getting to work' and 'For me, commuting by ... is very slow-very fast', and the resultant two-item scales (car use journey time: $\alpha=.71, r=.55, p<.001$; PT journey time: $\alpha=.75, r=.61, p<.001$ )

\footnotetext{
${ }^{7}$ To minimise questionnaire length, behaviour and beliefs were measured in relation to only two transport modes (car and public transport). Hence, use of other transport modes or a combination of PT and car were not of interest.
} 
were entered into subsequent analyses. Higher values indicate quicker perceived journey times.

Three affect items followed a stem ('For me, commuting by ... is': very unpleasant-very pleasant; very enjoyable-very unenjoyable [recoded]; very unsatisfying-very satisfying). Both scales were reliable (car affect: $\alpha=.81$; PT affect: .81). Principal component analyses (PCA) confirmed that each scale was underpinned by a single factor, which accounted for $72.79 \%$ of variance in car affect responses, and $72.18 \%$ of PT affect variance. Higher values indicate positive affect, and lower values negative affect.

Three perceived effort items were used. Two of these followed a stem ('For me, commuting by...is'; very difficult-very easy; highly effortful-completely effortless), and the third item was 'For me, commuting by ... requires very little effort'. The effort scale for PT use was satisfactory $(\alpha=.76)$, and the corresponding car use scale was marginally reliable $(\alpha=.66)$. PCA confirmed a unidimensional factor solution, which accounted for $59.67 \%$ variance in car effort, and $67.68 \%$ variance in PT effort. All items were recoded so that higher values indicated greater perceived effort.

Perceived personal space opportunity was measured using two items ${ }^{8}$ ('I have enough personal space when I commute by...'; 'When I commute by ..., I have enough room to myself'), but for car use these were unreliable $(\alpha=.50, r=.32, p<.001)$. The corresponding scale for PT personal space opportunity was reliable $(\alpha=.74, r=.59$, $p<.001)$, and was entered into subsequent analyses, but a single-item car personal space measure ('When I commute by ..., I have enough room to myself') was selected.

Perceived cost was measured using three items ('For me, commuting by ... is affordable' [recoded]; 'Commuting by ... seems expensive to me'; 'For me, commuting by ... is very expensive-very inexpensive' [recoded]). The two scales were reliable (car cost: $\alpha=.82$; PT cost: $\alpha=.76$ ), and PCA confirmed a single factor underpinning the majority of variance in responses (car cost: $73.71 \%$ variance explained; PT cost: $67.70 \%$ variance explained).

Four items were designed to tap perceived in-journey control ('I feel in control when I commute by ...'; 'How much control do you have over the progression of your journey when commuting by... complete control-no control' [recoded]; 'I have little

\footnotetext{
${ }^{8}$ Personal space items in the pilot questionnaire related to personal safety facets of individuals' personal space requirements (see chapter 2, p.28), but were unreliable. Hence, personal space items were reformulated for the main questionnaire, and addressed perceived opportunities for personal space.
} 
control over the progression of my journey when I commute by...' [recoded]; 'When I commute by..., I am able to overcome potential obstacles during the journey'). The car use in-journey control scale was marginally reliable $(\alpha=.68)$ and PCA highlighted a single factor accounting for $52.07 \%$ variance, so this scale was accepted for analyses. The corresponding scale for PT was unreliable $(\alpha=.51)$, and reliability was not improved by omitting items. Hence a single item ('How much control do you have over the progression of your journey when commuting by...') was used to measure PT injourney control on the basis of its semantic match with in-journey control perceptions.

TPB measures. Minimal TPB items derived from Conner and Sparks (1996) were used to minimise questionnaire length.

Two items designed to tap intention ('[I plan to/I intend to] use public transport to commute to work on at least two days over the next two weeks') had excellent reliability $(\alpha=.92, r=.85, p<.001)$.

Attitude was measured using a stem ('Using public transport to commute on at least two days over the next two weeks would be'), followed by three semantic differential items (beneficial-harmful; foolish-wise; bad-good). Reliability was good ( $\alpha$ $=.86)$.

A subjective norm item ('most people who are important to me would want me to use public transport to commute to work on at least two days over the next two weeks') and a descriptive norm item ('most people who are important to me will use public transport to commute to work on at least two days over the next two weeks'; Cialdini, Kallgren, \& Reno, 1991) were included, but a scale combining the two measures was unreliable $(\alpha=.56, r=.39, p<.001)$. Hence, the two norm items were treated as conceptually independent single-item measures.

Perceived behavioural control was measured using two items ("[ I have no control-complete control over/I am able to control] whether I use public transport to commute to work on at least two days over the next two weeks'), which were satisfactorily reliable $(\alpha=.78, r=.64, p<.001)$.

\subsection{Results}

\subsubsection{Descriptives and correlations}

Table 3.2 shows descriptive statistics and intercorrelations between variables at Time 1 as well as measures of willingness and behaviour at Time 2. T2 PT commuting was minimal amongst the sample, with a mean of just $2.93 \%(S D=10.71)$ of eligible 
commuting journeys being undertaken by PT between the measurement points.

Participants were generally unwilling to use PT (T2 willingness: $M=2.12, S D=1.42$;

T1 willingness: $M=2.50, S D=1.69$ ).

Participants typically felt that the car involved a quick journey $(M=5.24, S D=$ 1.01), elicited positive affect $(M=4.58, S D=1.30)$, incurred minimal effort $(M=2.59$, $S D=1.12)$, maximised personal space opportunities $(M=6.28, S D=1.13)$, was relatively inexpensive $(M=3.47, S D=1.46)$, and afforded control over journey progression $(M=5.26, S D=1.22)$. By contrast, $\mathrm{PT}$ was seen to be relatively slow $(M=$ $2.77, S D=1.39)$, effortful $(M=5.50, S D=1.09)$, and expensive $(M=4.76, S D=1.36)$, offering few opportunities for personal space $(M=3.06, S D=1.39)$ and in-journey control $(M=1.82, S D=1.25)$, whilst evoking negative affect $(M=2.82, S D=1.18)$.

Hence, intentions to use PT were typically low $(M=1.59, S D=1.17)$. Overall, attitudes towards PT were negative $(M=3.10, S D=1.32)$, and participants believed PT use was not normative $(M=2.35, S D=1.58)$, nor were significant others perceived to use PT $(M=2.70, S D=1.87)$. However, participants felt that using PT was within their control $(M=4.63, S D=2.16)$.

PT commuting was significantly correlated with intention to use PT $(r=.46$, $p<.001$ ), but not with willingness at either timepoint (T2 willingness: $r=.08, p=.25$; T1 willingness: $r=.08, p=.23)$. Attitude and PBC were also significantly correlated with behaviour (PBC: $r=.18, p=.01$; attitude: $r=.14, p=.049$ ), but normative variables were not (subjective norm: $r=.12, p=.10$; descriptive norm: $r=.05, p=.45$ ). Of behavioural belief measures, only PT journey time $(r=.16, p=.02)$ and PT perceived effort $(r=-.14, p=.047)$ significantly correlated with T2 behaviour.

Intention was significantly correlated with $\mathrm{PBC}(r=.21, p=.001)$, attitude $(r=$ $.34, p<.001)$, and subjective norm $(r=.15, p=.02)$, but not descriptive norm $(r=.07, p=$ .34). Intention was also correlated with both willingness measures (T2 willingness: $r=$ $.29, p<.001$; T1 willingness: $r=.29, p<.001)$. Of behavioural belief measures, only PT $\operatorname{affect}(r=.14, p=.045)$ and PT perceived effort $(r=-.14, p=.04)$ significantly correlated with intention. Hence, the majority of behavioural belief measures are not significantly associated with commuting mode intentions.

\subsubsection{Regressions}

A series of hierarchical multiple regressions were run, entering significant correlates only $(p<.05)$. 
Table 3.2. Intercorrelations and descriptive statistics.

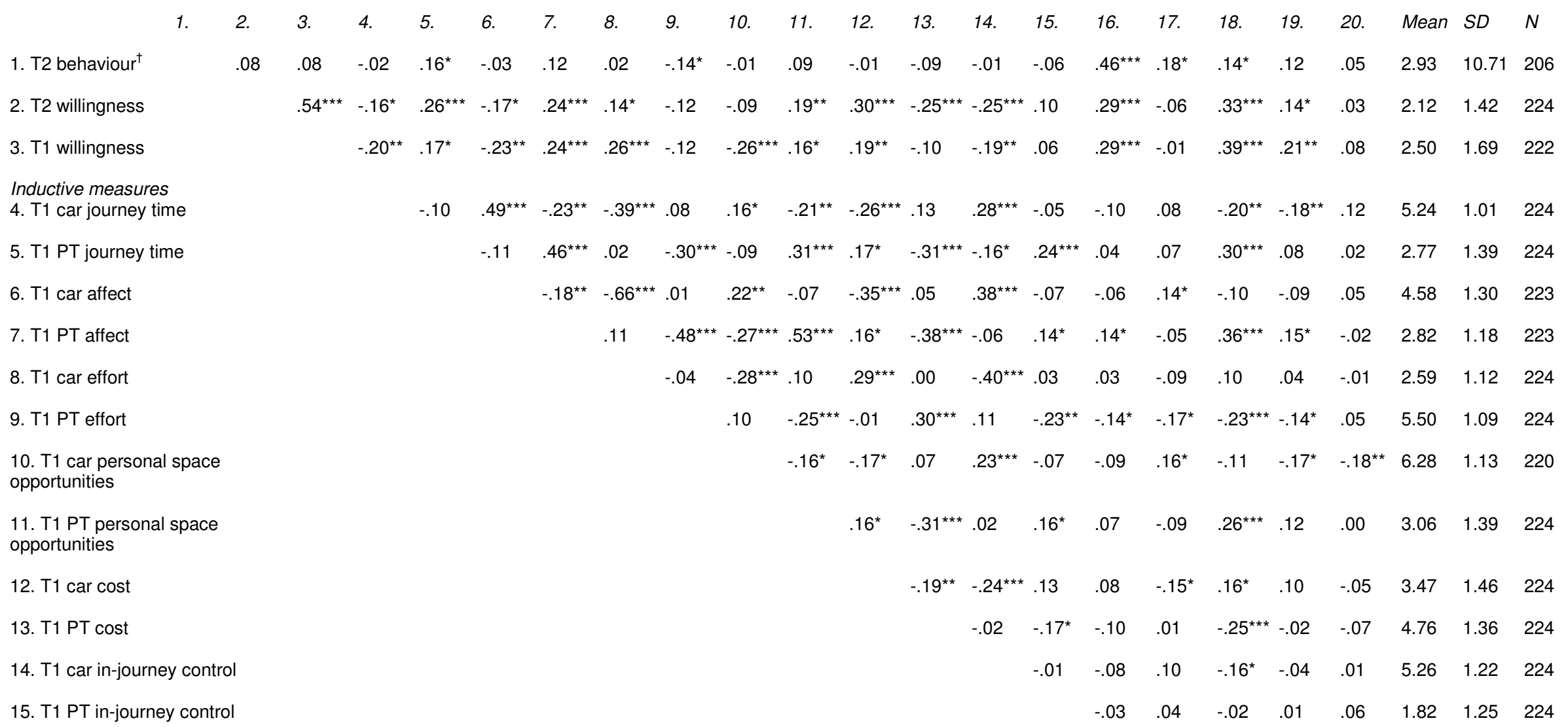


TPB-based measures

16. T1 intention

17. T1 PBC

18. T1 attitude

20. $T 1$ descriptive norm
19. $T 1$ subjective norm

$$
\begin{array}{ccccccc}
\text { 17. } 18 . & 19 . & 20 . & \text { Mean } & S D & N \\
.21^{* *} & .34^{* * *} & .15^{*} & .07 & 1.59 & 1.17 & 223 \\
& .15^{*} & .03 & -.02 & 4.63 & 2.16 & 224 \\
& .24^{* * *} & .00 & 3.10 & 1.32 & 223 \\
& & .40^{* * *} & 2.35 & 1.58 & 224 \\
& & & 2.70 & 1.87 & 223
\end{array}
$$

${ }^{*} p<.05,{ }^{* *} p<.01,{ }^{* * *} p<.001 .{ }^{\dagger} \mathrm{T} 2$ behaviour is measured as a percentage of eligible trips commuted by public transport rather than car; all other variables measured on 7 -point scales. 
3.4.2.1. Modelling T2 behaviour. T2 behaviour scores were highly positively skewed $\left(z_{\text {skewness }}=35.21\right.$; see Field, 2005, p.72), indicating that car commuters rarely used public transport to commute in the time period between the two measurement points.

Redistribution of values using the Base 10 logarithm did not eliminate the problematic positive skew $\left(z_{\text {skewness }}=14.55\right)$, and hence the original $\mathrm{T} 2$ behaviour variable was entered into analyses despite heavy skew.

A three-step hierarchical regression of behaviour was run on TPB variables. Intention at step one accounted for $21 \%$ of variance $($ Model $F[1,202]=53.44, p<.001)$. Entering PBC at step two did not improve the model $\left(\Delta R^{2}=.01, \Delta F=1.42, p=.24\right)$, nor did the addition of attitude and subjective norm at step three $\left(\Delta R^{2}=.01, \Delta F=0.43\right.$, $p=.73)$. Within this model, only intention $(\beta=.44, p=.002)$ was significantly predictive. Thus, intention was able to explain a significant portion of variance in behaviour, partially supporting hypothesis 1 .

A forced-entry regression model of behaviour run on the two significant behavioural belief correlates (PT journey time and PT effort) was statistically significant (Model $F[2,203]=3.69, p=.03)$, but only PT journey time was a marginally significant predictor $(\beta=.13, p=.07)$, whilst PT effort was non-significant $(\beta=-.10, p$ $=.15)$. Furthermore, explained variance was negligible $\left(R^{2}=.04\right)$. Hence, inductivelyderived behavioural beliefs regarding PT commuting did not influence actual public transport commuting, and hypothesis 2 was not supported.

In sum, behavioural beliefs did not successfully explain public transport use over and above TPB measures. PBC, T1 willingness to use PT, and T2 willingness did not influence behaviour, but intention was strongly predictive.

\subsubsection{Modelling T1 intentions to commute by public transport (PT). Heavy positive} skew was observed on T1 intention values $\left(z_{\text {skewness }}=14.84\right)$. A transformation using the Base 10 logarithm failed to sufficiently reduce skew $\left(z_{\text {skewness }}=11.28\right)$, and hence untransformed intention values were entered into analysis.

A two-step cross-sectional regression of intention was run entering PT affect and PT effort together at step one and TPB variables at step two. As table 3.3 shows, the model at the first step was not sufficiently predictive $\left(R^{2}=.03\right.$, Model $F[2,219]=2.77$, $p=.07$ ), and neither of the variables within the model was significantly predictive (PT affect: $\beta=.09, p=.23$; PT effort: $\beta=-.09, p=.23$ ). Entering TPB variables in the second step improved the model considerably $\left(R^{2}=.15\right.$, Model $F[5,216]=7.61$, 
$\left.p<.001 ; \Delta R^{2}=.13, \Delta F=10.60, p<.001\right)$. Within this model, only attitude $(\beta=.29$, $p<.001)$ and $\operatorname{PBC}(\beta=.17, p=.01)$ were significant predictors. Thus hypothesis 4 was not supported.

Table 3.3. Regression of $\mathrm{T} 1$ intention on significant correlates $(N=222)$

Step Variables entered $\quad \beta \quad \beta$

1. T1 PT affect

T1 PT effort

2. T1 attitude

T1 subjective norm

T1 PBC
.09

$-.09$

$R^{2}$

Model $F$

$F$ Change

$10.40 * * *$

${ }^{*} p<.05 ; * * p<.01 ; * * * p<.001$

The model was rerun as a forced entry regression entering only TPB constructs, which explained $15 \%$ of variance (Model $F[3,218]=12.70, p<.001)$. Only attitude $(\beta=$ $.30, p<.001)$ and $\operatorname{PBC}(\beta=.17, p=.01)$ were significant predictors, thereby offering qualified support for hypothesis 3 .

Intentions to commute by PT were therefore best explained by global evaluations of the favourability of PT commuting, together with perceptions of control over the initiation of PT commuting.

3.4.2.3. Modelling T1 attitudes towards PT. A forced entry cross-sectional regression was run to determine if behavioural beliefs underpinned attitudes towards PT commuting. The model, which included only significant correlates of T1 attitudes, was 
significantly predictive $\left(R^{2}=.18\right.$, Model $\left.F[8,213]=6.01, p<.001\right)$. Within the model, PT affect was the only statistically significant predictor $(\beta=.18, p=.03)$, though there was also a marginally significant effect of PT journey time $(\beta=.13, p=.07)$. The regression model was rerun, trimmed to include only half of the potential predictor variables (car journey time, PT journey time, PT affect, PT effort) - chosen on the basis of superior Beta weights in the previous model - to eliminate potential noise. The trimmed model explained $18 \%$ of variance (Model $F[4,218]=11.53, p<.001)$, and PT journey time $(\beta=.15, p=.04)$ and PT affect $(\beta=.23, p=.002)$ were statistically significant predictors. There was also a marginally significant effect of car journey time $(\beta=-.12, p=.06)$.

3.4.2.4. Modelling T1 PBC. A cross-sectional regression was run to determine whether any behavioural beliefs could explain variance in perceived control over using public transport to commute. Negative skew $\left(z_{\text {skewness }}=-2.50\right)$ was sufficiently reduced by squaring values on the $\mathrm{T} 1 \mathrm{PBC}$ scale $\left(z_{\text {skewness }}=0.38\right)$, and the squared values remained closely correlated with the untransformed PBC variable ( $r h o=1.00$, Pearson's $r=.98$, $p<.001)$. Hence, the transformed T1 PBC variable was entered as the dependent variable in the regression.

The four beliefs significantly correlated with T1 PBC were entered in a forced entry regression, and the resultant model was significant (Model $F[4,214]=4.30$, $p=.002$ ), but only explained $7 \%$ of variance in T1 PBC. Within the model, only PT effort reached statistical significance $(\beta=-.16, p=.02)$, though there was also a marginally significant effect of car personal space opportunity $(\beta=.13, p=.06)$.

Hence, five of the twelve inductively-identified behavioural belief items appeared to have distal effects on transport mode choice, informing attitudes and perceptions of control over commuting by PT which in turn appeared to translate into intention, which predicted actual behaviour; hypothesis 5 was therefore supported.

\subsubsection{Constructing a structural model of travel mode choice. On the basis of previous} regression analyses, a structural model of relationships between variables and moderator terms was constructed and submitted to structural equation analyses using EQS 6.0 (Bentler, 2004). This permits hypothesis testing using a modelling method more powerful and robust than a series of multiple regression analyses, whilst also indicating the fit of the specified model to the observed data. Variables found to have no predictive 
value in the previous regression analyses (e.g. subjective norm) were omitted from the model. Cases with missing T2 behaviour data were deleted, resulting in a sample of $N=$ 206. For all other variables, missing values were replaced with means; at most, $2 \%$ of values on a single variable were computed in this way.

Figure 3.1 shows hypothesised relations between variables, with structural model parameters and values of explained variance in each endogenous variable. Debate surrounds which statistics best evaluate the model, and hence fit between the structural model and observed data was evaluated using several indexes: Chi-square $\left(\chi^{2}\right)$; goodness-of-fit (GFI); normed fit (NFI); and the root mean square error of approximation (RMSEA). Non-significant chi-square values indicate satisfactory model fit, but values essentially depend on sample sizes, and therefore the test may require augmenting with alternative fit statistics. The GFI approximates an estimate of total variance explained by the model, whilst the NFI compares the specified model to a null model in which no relationships among variables are assumed. Both GFI and NFI statistics range between 0 and 1, with values of .90 or above indicating satisfactory fit. The RMSEA index measures discrepancy between specified and observed fit for each degree of freedom, thereby accounting for sample size, with values of around .08 or less being considered satisfactory.

The model shown in figure 3.1 adequately fitted the data $\left(\chi^{2}[18]=21.22, p=\right.$ $.27 ; \mathrm{GFI}=.98 ; \mathrm{NFI}=.92 ; \mathrm{RMSEA}=.03$ ). Coefficients for all parameters were statistically significant. Wald tests and Lagrange multiplier tests, performed to determine whether parameters could be eliminated or added to the model respectively to improve fit, failed to recommend any parameter adjustments. The model in figure 3.1 therefore represents the model that best fits the data.

As the model shows, T1 intention was a significant independent predictor of T2 behaviour. Thus, hypothesis 1 was partially supported, but there was no support for hypothesis 2 . Intention was best predicted by attitude and PBC, and so hypothesis 3 thus received partial support, but hypothesis 4 was rejected. Attitudes towards PT commuting were predicted by perceptions of PT and car journey times, and expected affective reactions to commuting by PT. Perceptions of control over initiating and maintaining PT commuting were influenced by perceptions of effort expenditure when using PT, and perceived opportunities for personal space when driving. Hence, hypothesis 5 was supported. The relationship between car personal space opportunity and PBC ran in an unexpected direction, indicating that individuals who perceived 
Figure 3.1. Hypothesised structural model of PT versus car commuting with standardised path coefficients and explained variance in T1 attitude, T1 $\mathrm{PBC}, \mathrm{T} 1$ intention and $\mathrm{T} 2$ behaviour

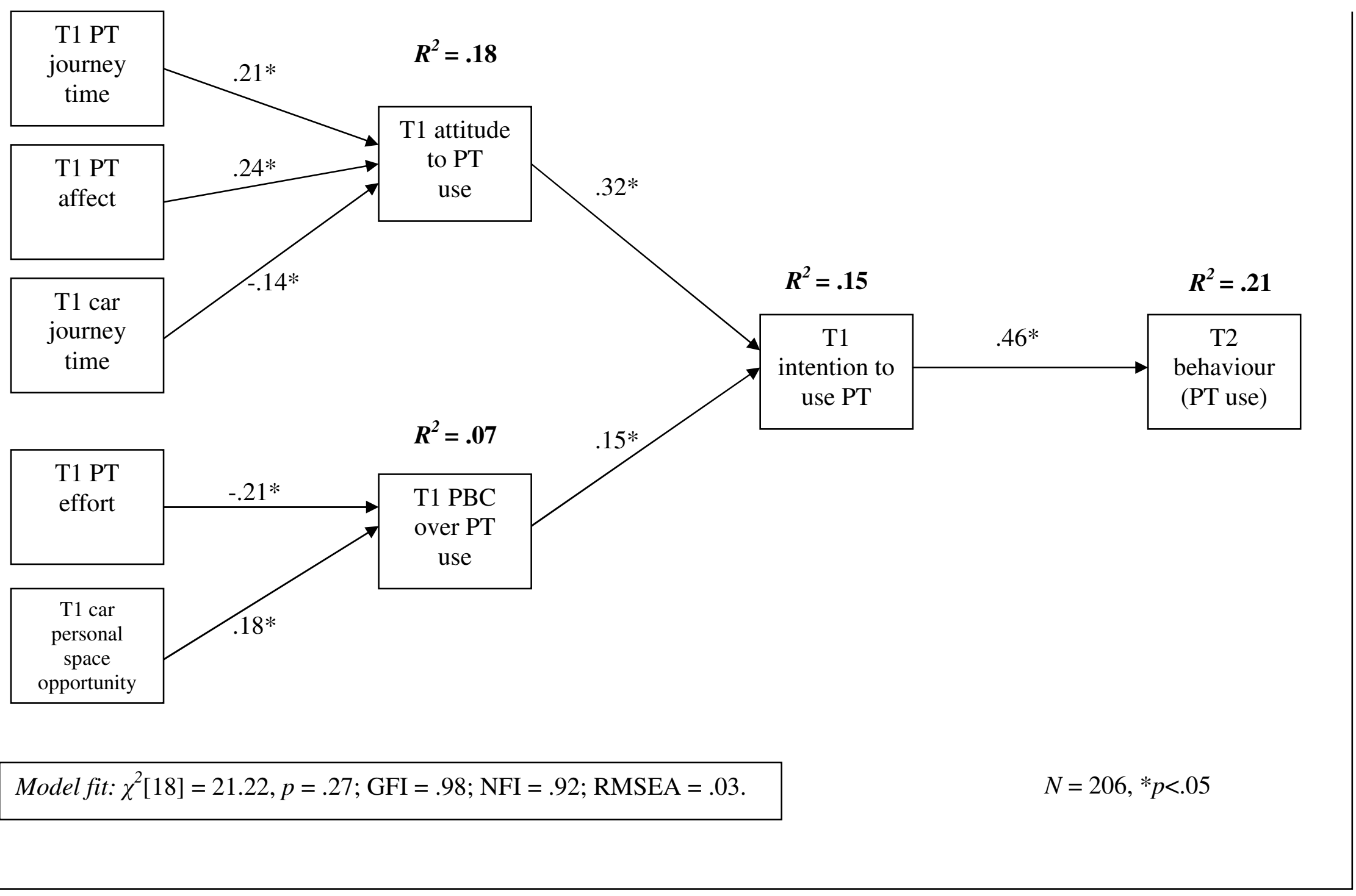


greater opportunities for personal space when driving felt more in control of commuting by PT. However, whilst statistically significant, the magnitude of these relationships was small, with explained variances ranging from $7 \%$ of variance in $\mathrm{PBC}$, to $21 \%$ of the variance in behaviour.

\subsubsection{Post-hoc analyses: Modelling T1 affect. Given the limited role played by} inductively derived behavioural beliefs in intention formation and PT commuting, exploratory regression analyses were performed to investigate whether beliefs could be modelled as determinants of affective experiences of car and PT use. Exploratory forced-entry regressions of $\mathrm{T} 1$ affect measures were run on all behavioural belief constructs significantly correlated with each outcome variable. A model of car affect regressed on to beliefs towards the car regarding journey time expectations, effort, personal space opportunities, costs, and in-journey control explained 53\% of variance in car use affect (Model $F[5,213]=47.08, p<.001)$. Within this model, car effort $(\beta=-.50$, $p<.001)$, car journey time $(\beta=.25, p<.001)$, and perceived car costs $(\beta=-.12, p=.02)$ were significantly predictive.

Similarly, a model including beliefs towards both car and PT in relation to journey time, personal space opportunities, and costs, as supplemented by expected PT effort expenditure and PT in-journey control, explained 51\% of variance in PT affect scores $($ Model $F[8,210]=27.20, p<.001)$. Within this model, beliefs towards PT in regard to personal space opportunities $(\beta=.32, p<.001)$, perceived effort $(\beta=-.29$, $p<.001)$, journey time expectations $(\beta=.24, p<.001)$, and perceived costs $(\beta=-.12$, $p=.03)$ were significant predictors, as was perceived car personal space opportunities $(\beta$ $=-.15, p=.003)$.

Thus, inductively derived behavioural beliefs were better modelled as antecedents of affect experienced during journeys than as predictors of intentions and behaviour.

\subsection{Discussion}

The present study sought to quantify and validate a set of inductively derived behavioural belief measures as predictors of regular car commuters' travel mode choices, in comparison with measures taken from the most popular deductive theory in the field, the TPB. Comparing the predictive utility of behavioural belief items with TPB measures highlighted the superiority of the TPB for predicting intentions to 
commute using PT and reported PT commuting. Behavioural beliefs generally did not correlate with intention or behaviour, but could be integrated into the TPB as antecedents of attitudinal or control judgements of PT commuting. Participants formed positive attitudes towards commuting by PT where they believed that PT journey times were quick and would yield positive affective experiences (or avoid negative affective experiences). Perceptions of control over PT commuting were best predicted by beliefs that PT involves little effort expenditure, and that car use provides personal space. Measures of willingness did not predict PT use, and hence travel mode choice appears to be better regarded as premeditated action than an unforeseen response to situational cues (e.g. Gibbons et al., 1998a, 1998b).

The successful integration of inductively derived behavioural belief measures into the TPB supports the TPB as a theoretical framework which may be augmented via domain-specific behavioural beliefs, and thereby as a means for integrating research findings (e.g. Taylor \& Todd, 1997), while also highlighting the potential for theory generation from interplay between inductive and deductive enquiry. The TPB posits that behavioural beliefs determine attitudinal and control perceptions, and thus have a distal effect on behaviour (Ajzen, 1991), and our findings confirmed these assumptions: rather than having direct effects on preferences or behaviour (Fujii \& Gärling, 2003a), inductively identified beliefs - perceptions of journey time, effort, and personal space opportunities, and affective expectations - were found to operate as antecedents of attitudes towards and perceptions of control over PT commuting. This broadly echoes previous research findings (e.g. Bamberg \& Schmidt, 1999) and emphasises the potentially distinct role of affective and cognitive evaluations (Conner \& Sparks, 2005). Interestingly, attitudes and PBC relating to PT commuting were found to be underpinned by behavioural beliefs relating not only to the focal behavioural object (i.e. PT commuting), but also beliefs regarding the journey time and personal space opportunities offered by the primary behavioural alternative (i.e. car commuting). This suggests that when forming, for example, an attitudinal judgement of a particular behaviour, individuals may take into account the attractiveness of facets of alternative options (Abraham \& Sheeran, 2003).

The role of expected effort expenditure when using PT as a determinant of global perceptions of the ease or difficulty of using PT was unsurprising, and reflects previous findings highlighting the importance of effort minimisation in mode choice (Wardman, Hine \& Stradling, 2001). It remains unclear however to what extent 
expected effort reflects real effort expenditure when using PT, rather than unrealistic expectations. Indeed, Fujii, Gärling, and Kitamura (2001) have shown that drivers who rarely use PT often hold inaccurate negative beliefs concerning the feasibility of using PT, but subsequent experiences of PT can rectify these false beliefs (Fujii \& Kitamura, 2003; see also Brown, Werner \& Kim, 2003).

Contrary to previous research (e.g. Bamberg \& Schmidt, 1999), cost perceptions did not directly influence attitudes, $\mathrm{PBC}$ or intentions. Participants may have accurately perceived their PT and car commuting trips to entail equal financial costs: factoring depreciation in to the cost of short car trips can yield an overall per-journey cost roughly equivalent to typical PT costs (Carplus, 2004). However, this would contradict a persuasive literature that suggests that drivers underestimate car running costs (RAC, 2004; Wardman et al., 2001), neglecting 'hidden' costs such as depreciation and/or infrequently encountered costs (e.g. maintenance; see chapter 2, pp.29-30), and may also overestimate PT costs (chapter 2, p.30). Indeed, post-hoc inspection of our dataset revealed a negatively skewed distribution of perceived PT costs, a positively skewed distribution for car costs, and significantly different mean scores for the two scales $(t[223]=8.88$, one tailed $p<.001)$, possibly reflecting biased judgements of both sets of costs.

Our results highlight the importance of affect in travel mode choice (Mann \& Abraham, 2006; Steg, Vlek \& Slotegraaf, 2001; Steg, 2005). Measures relating to anticipated affect when using PT were found to predict attitudes towards PT commuting, highlighting the importance of measuring cognitive and affective components of attitude separately (Conner \& Sparks, 2005) The role of affect in attitude formation supports previous arguments that travel mode choice is not wholly based upon utility considerations (Mann \& Abraham, 2006; Steg, Vlek \& Slotegraaf, 2001), but suggests that the TPB attitude construct may be sufficient to capture affective influences on motivation.

We measured affect using global indicators and so were unable to identify the underlying specific affective concerns - past research suggests that affective transport experiences may aggregate concerns relating to, for example, stress (e.g. Koslowsky \& Krausz, 1994), enjoyment of travel (e.g. Ory \& Mokhtarian, 2005), and/or personal security (Hiscock et al., 2002; Mann \& Abraham, 2006) - but our results point to important links between utility concerns and affective reactions (cf. Mann \& Abraham, 2006). Post-hoc analyses revealed that affect was predicted by beliefs relating to travel 
time, effort, personal space, cost, and in-journey control. The role of beliefs relating to journey time, personal space, and costs when driving, in predicting affective experiences of PT also highlights the potential interdependence of transport mode judgements, demonstrating that favourable perceptions of car use may influence negative affective experiences of the non-car option (PT). More research is however required to establish the robustness of these findings.

The purpose of the present study was to establish the predictive utility of measures of concerns voiced by a sample of regular car commuters in Brighton and Hove (see chapter 2). The preceding qualitative analysis might thus be viewed as elicitation research for the present study. That is, a subsample of the population reported positive and negative consequences of performing the focal action as a precursor to an exploration of the validity and importance of these concerns among a larger sample of this population (Ajzen \& Fishbein, 1980). The present study thus employed a sample of regular car commuters who intended to drive to work, and made minimal use of PT. While it is exactly this group whose behaviour we most need to change in order to reduce car use (see Department for Transport, 2005b), recruitment of this homogeneous sample meant that there was little variance in PT intentions and behaviour, and scores on both variables were highly positively skewed. The generalisability of our findings may, therefore, be questioned. Indeed, where more heterogeneous samples of commuters are used, explained variance in behaviour and intentions is considerably enhanced: Bamberg and Schmidt (2003), for example, were able to predict $45 \%$ variance in driving behaviour and $60 \%$ in intentions from TPB cognitions measured among a sample of bicycle, PT, car and foot commuters. A TPB model comprising our inductively derived behavioural beliefs might therefore predict considerably greater proportions of variance in car versus PT use among a sample comprising frequent and infrequent car commuters, and PT commuters with car access (cf Harland et al., 1999). Further empirical work on a more heterogeneous sample of commuters is necessary to test this model and the generalisability of the present findings to the wider population of commuters.

Given the lack of variance in intentions and behaviour, two aspects of the results are noteworthy. First, the TPB was able to predict significant proportions of this variance, while behavioural beliefs, modelled as direct predictors of intentions or behaviour, were not. Thus, measures based on our previous qualitative study did not enhance the predictive utility of the TPB. Second, attitudes and (post-transformation) 
PBC scores were normally distributed. This not only demonstrates that attitudinal and control perceptions can vary among a relatively homogenous sample of car commuters, but also that the relationships shown between attitudes and PBC and antecedent behavioural beliefs may be relatively robust. Although grounded analyses are necessarily contextualised and specific to the dataset from which findings emerge (e.g. Glaser \& Strauss, 1967; Strauss \& Corbin, 1998), there is no reason to believe that interviewees in the preceding qualitative analysis differed significantly in their transport concerns from other regular car commuters in Brighton and Hove. The performance of the inductive measures as a stand-alone set of predictive concepts questions the utility of constructing theory solely from grounded analyses, at least in this domain, and suggests that deductive concepts may provide a more reliable conceptual foundation for predicting particular behaviours.

Alternatively, these findings may point to limitations of the prior qualitative analysis. Interviewees might have utilised discourse to justify driving (see Guiver, 2007; Kurz, Donaghue, Rapley, \& Walker, 2005), thereby questioning the realist assumptions of grounded theory. Alternatively, although qualitative analysis of interview data can reveal motives that drivers may wish to conceal (e.g. Mann \& Abraham, 2006; Steg, Vlek \& Slotegraaf, 2001), there may be important behavioural determinants of transport mode choice which were not salient to interviewees. Strauss and Corbin (1998) recommend that setbacks experienced in quantitative validation are investigated further using qualitative methods and future studies could explore whether subsequent qualitative investigations of commuting mode preferences generate similar constructs.

Although the TPB predicted intentions to commute by PT and PT commuting, explained variance in intentions (14\%) and behaviour (21\%) was relatively low (see e.g. Bamberg \& Schmidt, 2003; Heath \& Gifford, 2002). There are several possible reasons for this. First, as outlined previously, there may have been insufficient variance to allow reliable and robust modelling of our dependent variables. Alternatively, there may have been a strong habitual component of participants' transport mode decisions which was inadequately modelled by the TPB (e.g. Aarts et al., 1998; but see Bamberg, Ajzen, \& Schmidt, 2003). Indeed, while the TPB assumes behaviour is the outcome of rational deliberation, a growing literature suggests that transport decisions may occur automatically in the absence of rational forethought, as a result of learned associations between goal (i.e. to get to work) and behaviour (driving to work) in stable decisional contexts (e.g. Aarts et al., 1998; Gärling et al., 2001; Triandis, 1977; Verplanken et al., 
1997). Whilst regular car commuters remain an important policy target group (e.g. Department for Transport, 2005a), future transport modelling research might benefit from recruiting heterogeneous samples of commuters with considerable variation in commuting behaviours, habits, and attitudes.

Explained variance in intention and behaviour may also have been reduced because our behavioural outcome measure - percentage of PT use over a two-week period - was not framed at the same level of specificity as our TPB cognition measures, which addressed PT use on at least two days during the two-week period (Ajzen \& Fishbein, 1980). Similarly, a lack of correspondence between behavioural belief measures, which concerned the global favourability of PT and car use on each attribute, and the contextualised TPB cognition items might have reduced explained variance in attitude and PBC (Ajzen \& Fishbein, 1980).

Also potentially problematic in the present study were the assumptions underlying the conceptualisation of commuting mode choice. Commuters were assumed to make journeys for which public transport was the only feasible alternative transport mode, and hence mode choice was treated as the result of motivational and volitional decision processes. The lack of correspondence between TPB cognitions and behaviour might suggest that this conceptualisation was too simplistic: some participants may have included other trips (e.g. taking children to school) in the journey to and/or from work. Public transport is less likely to offer a suitable alternative to the private car for multitrip journeys (Hensher \& Reyes, 2000), which are thus more likely to be constrained by situational factors such as the (un)availability of suitable modes. TPB cognition effects might have been more pronounced had the sample comprised only commuters making single-trip journeys for which only driving and PT were feasible.

Of course, it is plausible that our results are robust and highlight the relatively poor predictive utility of the TPB where applied to inner-city car commuting. Furthermore, while attitude and PBC were statistically significantly predicted by a group of behavioural belief items, explained variances were low, thus raising the question of what attitude and PBC measures actually tap. Attitudes and PBC may represent judgements made in the absence of deliberation over behavioural beliefs, whereas presenting participants with a list of possible behavioural beliefs may prompt more logical and rational attitude formation which does not influence intentions. This is problematic from an intervention design perspective, because it is unclear which beliefs 
may be targeted to engender change in attitudes and perceptions of control, and hence intentions and behaviour.

The present study was designed as a basis for car use reduction intervention programmes, but results were disappointing from a policy perspective, suggesting that targeting conscious cognitive antecedents of travel mode choice is unlikely to have any significant behavioural impact. Hence, no clear policy recommendations arise from the study. Indeed, our results suggest that interventions targeted at psychological antecedents of car commuting are likely to have limited effects, as deviations from usual commuting patterns amongst drivers are at best only partially regulated by motivational factors. Multi-level interventions which supplement psychological with (infra)structural components and/or legislature modifications to support reduced car use may therefore offer the most promising driving reduction strategies. 


\section{Chapter 4. Study 3: A meta-analysis of potentially modifiable psychological correlates of car use $* *$}

\subsection{Abstract}

Reducing the environmental health threat from driving requires identifying and modifying cognitions which sustain car use. This meta-analysis synthesised quantitative research into psychological correlates of car use, intentions to drive, and willingness to reduce car use. Online psychology and transportation databases were searched, and inclusion criteria applied to potentially relevant records. An ancestry approach was also employed to search selected publications. Meta-analyses of effect size $r$ s were performed on 28 unique study datasets. Results generally supported the predictive utility of variables derived from the Theory of Planned Behaviour, though cognitions towards not driving displayed uniformly larger effects than were observed for car use cognitions. There was also a strong effect of habit on behaviour. No evidence was available to quantify the relationship between willingness and behaviour, and support for effects of pro-environment cognitions on driving was weak. However, a dearth of available evidence limited our findings and precludes development of clear evidencebased recommendations for intervention design. Directions for future research are discussed.

\subsection{Literature review}

Traffic emissions contribute to climate change (Oskamp, 2000) and cardiovascular and respiratory diseases (Peters et al., 2004), and are predominantly attributable to private car use, which can realistically be reduced (Berntsen, 2004; Goodwin, 1997; Stern, 1992). For example, 25\% of UK car journeys cover less than 2 miles (Department of the Environment, Transport and the Regions, 2000) which in most cases could be undertaken using alternative transportation (Goodwin, 1997).

Many drivers acknowledge the necessity of reducing driving (e.g. Commission for Integrated Transport, 2002) but few switch to alternative transport (e.g. Stradling, Meadows \& Beatty, 2000; Steg \& Sievers, 2000). As previously argued (e.g. chapter 1, pp.2-3), infrastructural modifications (e.g. bus priority lanes) and/or legislative policy

\footnotetext{
** A version of this chapter has been accepted for publication as Gardner, B., \& Abraham, C. (in press) Psychological correlates of car use: A meta-analysis. Transportation Research Part F.
} 
measures (e.g. congestion charging) provide incentives for driving reduction (see Fujii, Gärling \& Kitamura, 2001; Taniguchi, Hara, Takano, Kagaya \& Fujii, 2003) but psychological strategies targeting attitudes and perceptions are typically more acceptable and less expensive (Emmerink, Nijkamp \& Rietveld, 1995; Taylor \& Ampt, 2003). Consequently, programmes designed to bring about psychological change offer a promising route to reducing car use and air pollution (Ampt, 1999; Brög, 1998; Steg, 2003; Stern, 1992; Tisato \& Robinson, 1999).

Developing effective, persuasive campaigns or interventions depends upon identifying and targeting potentially modifiable psychological constructs underlying car use (Bartholomew, Parcel, Kok \& Gottlieb, 2006). The previous two studies (chapters 2 and 3) explored the utility of inductively derived concepts for explaining and predicting decisions to drive among car commuters. In study 1 (see chapter 2), a series of motives for driving were derived from qualitative analysis of interviews with a small sample of car commuters, and in study 2 reliable quantified measures of these motives were developed and applied to predicting public transport commuting among a larger sample of car commuters (see chapter 3 ). The inductive concepts were found to have at best a distal effect on behaviour, and were generally inferior as predictors of travel mode choice to measures derived from the Theory of Planned Behaviour (TPB; Ajzen, 1991), an established nomothetic theory (see chapter 3, p.53). These results suggest that concepts derived from feedback from a small sample of drivers may be less useful in predicting mode choice than theory-specified measures which have been successfully applied to large samples over numerous studies (e.g. Bamberg, Ajzen \& Schmidt, 2003; Bamberg \& Schmidt, 2003; Forward, 2004; Harland, Staats \& Wilke, 1999; Kaiser \& Gutscher, 2003). The present study reviews the extant literature to assess the evidence surrounding the predictive utility of TPB cognitions and other deductively derived concepts that have been applied to the prediction of car use motivation and behaviour.

As illustrated previously (e.g. chapter 1, pp.7-8), the TPB is the most popular theoretical framework to have been applied to travel mode choice, and posits that behaviour is determined by intentions, which in turn summate attitudes based on perceptions of the consequences of action, subjective norms (i.e. perceived social approval for the action) and perceived control over action (Ajzen, 1991; Bamberg, Ajzen \& Schmidt, 2003; Bamberg \& Schmidt, 2003; Forward, 2004; Harland, Staats \& Wilke, 1999; Kaiser \& Gutscher, 2003). The model has been developed to include perceptions of how other people act (descriptive norms; Ajzen \& Fishbein, 2005; 
Cialdini, Kallgren \& Reno, 1991; Conner \& Sparks, 2005) and, in the travel choice domain, has also been augmented with attitudes towards behavioural alternatives (Verplanken, Aarts, van Knippenberg, \& van Knippenberg, 1994) and morally guided personal norms of conduct (Harland et al., 1999).

The expectancy-value structure of the TPB corresponds to traditional economic analyses which portray the actor as a rational agent with utility-oriented preferences, which may be observed indirectly via self-report ('stated preference'; Bates, 1982), or directly revealed through action ('revealed preference'; Hensher, 1994). Stated preferences comprise an invariant utility function, which includes the TPB attitude construct and contextual factors (e.g. social pressures and beliefs in one's ability to use a particular transport mode), and are thus conceptually equivalent to behavioural intentions (Fujii \& Gärling, 2003a).

Willingness to reduce car use has also featured as a dependent variable in several transport studies (Garvill, 1999; Nordlund \& Garvill, 2003; Polk, 2003, 2004), but its meaning is not clearly defined. Gibbons, Gerrard, Blanton and Russell (1998) distinguish intention, which is deliberative and premeditated, from willingness, which represents a reaction to unforeseen circumstances (see too Ajzen \& Fishbein, 2005). Willingness is typically a stronger predictor of socially unattractive and/or risk behaviours (e.g. Gibbons et al., 1998) and so provides a potentially useful alternative indicator of motivation to intentions and stated preferences.

As noted in chapter 1 (p.13), elsewhere travel mode choice has been characterised as a social dilemma (Garvill, 1999; van Lange, van Vugt, Meertens, \& Ruiter, 1998; van Vugt, Meertens \& van Lange, 1994, 1995; van Vugt, van Lange \& Meertens, 1996). Where car and non-car modes are readily available and their usage unrestrained (Hardin, 1968), individuals are faced with two choices: to drive and enjoy greater personal benefits (e.g., increased reliability and in-journey flexibility; van Vugt et al., 1995) but incur collective costs (environmental pollution), or to forego individual benefits and act for collective interests by using less polluting modes, such as public transport. This suggests a potential role for social value orientation (i.e. predominant preferences for self versus collectively beneficial outcomes; van Vugt et al., 1995; van Vugt et al., 1996) or otherwise 'self-transcendent' values (preferences for collectively or environmentally beneficial outcomes; Nordlund \& Garvill, 2003), and implies that 
concern for the environmental consequences of car use can be important to driving motivation $^{9}$.

Whilst these approaches assume transport choice is deliberative, some researchers have suggested that car use may be habitual (e.g. Verplanken et al., 1994). As summarised earlier (chapter 1, pp.14-15), Triandis's (1977) Theory of Interpersonal Behaviour (TIB) suggests that where a behavioural pattern has been performed frequently in response to a particular goal (e.g. the need to make a journey), initiation of behaviour is no longer guided by behavioural intentions (Thøgersen, 2006).

Furthermore, when an intention is formed in the context of competing habitual tendencies, behaviour is more likely to be regulated by habit (Triandis, 1977). Aarts, Verplanken and van Knippenberg (1998) argue that travel mode choice often exemplifies habitual behaviour, being performed frequently with minimal cognitive deliberation in stable decisional settings (e.g. Aarts \& Dijksterhuis, 2000a). Habit may therefore act as an independent proximal determinant of behaviour (e.g. Bamberg \& Schmidt, 2003) and as a moderator of the intention-behaviour relationship (Verplanken et al., 1994). Evidence for the former role is mixed: whilst habit has been demonstrated to be an independent direct predictor of behaviour (Verplanken et al., 1994), the TIB and TPB have been found to predict similar proportions of variance in driving intentions and behaviour (Bamberg \& Schmidt, 2003). Hence TPB variables may sufficiently capture direct effects of habit on behaviour (Bamberg, Ajzen \& Schmidt, 2003). However, Verplanken and colleagues have shown the statistical relationship between intentions and behaviour to be inversely proportional to habit strength: weak habits facilitated the transition of intention into behaviour, but strong car use habits weakened the intention-behaviour relation (Verplanken et al., 1994; Verplanken, Aarts, van Knippenberg, \& Moonen, 1998).

Despite a growing literature on psychological correlates of car use, recommendations for targeting modifiable antecedents remain unclear because no systematic review of potentially modifiable psychological correlates of driving is available. We systematically reviewed this literature looking back over more than

\footnotetext{
${ }^{9}$ Two studies using the social dilemma paradigm (Joireman, van Lange, Kuhlman, van Vugt \& Shelley, 1997; van Lange et al., 1998) additionally suggested a role for trust in others, i.e. the belief that others are honest and trustworthy (Yamagishi, 1986) and will choose pro-environment options (e.g. van Lange et al., 1998). As such, this variable relates more to the expected behaviour of others (i.e. descriptive norms), but only in situations acknowledged by drivers as being dilemmatic. There is little evidence to suggest driving is experienced as a social dilemma (see e.g. van Vugt, van Lange, Meertens \& Joireman, 1996), thereby questioning the validity of trust as a correlate of driving preference. Hence, we excluded trust from our analysis.
} 
twenty-five years. A meta-analysis was conducted to: a) identify potentially modifiable constructs associated with car use intentions, behaviour and/or willingness to reduce car use; b) evaluate associations between each of these constructs and driving (and/or driving motivation); and c) offer recommendations for driving reduction programmes.

\subsection{Method}

\subsubsection{Literature searches and inclusion criteria}

Three psychology databases (ScienceDirect, PsycInfo, Web of Science) and three transportation databases (TRIS Online, National Transportation Library [NTL] Catalog, NTL Digital Repository) were searched in August 2006. Search terms were identified by creating lists of synonyms for (1) car use, (2) travel mode choice, (3) environmental behaviour, and (4) motives. A complete list of search strings is given in Appendix A.4.1. Studies were selected for further inspection if they were (a) published (b) after 1979 (c) in English (d) in full-text format (e) in peer-reviewed sources ${ }^{10}$. 12,675 unique records were generated.

Table 4.1 shows the study selection process. Inspection of titles removed 12,019 records unrelated to travel mode choice, leaving 656 potentially relevant references. Papers were then excluded if they did not report primary empirical data, failed to report a relevant disaggregated dependent measure ${ }^{11}$ (i.e., any measure of car use / non-car use, intentions or preferences for car use / non-car use or willingness to reduce car $\mathrm{use}^{12}$ ) or failed to include a measure of a psychological correlate of driving. Psychological correlates were distinguished by subjective measurement (e.g. selfreported comfort) as opposed to objective measures (e.g. actual travel times). Studies were also excluded if they measured intention or behaviour change (e.g. Gärling \& Sandberg, 1997) or if they only reported comparative measures resulting from natural or experimental interventions. Intervention evaluation studies were retained if data could be extracted from pre-intervention baseline measures (Matthies, Klöckner, \& Preißner, 2006) or control groups who did not receive the intervention (Gärling, Gillholm, \& Gärling, 1998). Finally, only studies reporting at least one bivariate statistical

\footnotetext{
${ }^{10}$ Conference presentations were ineligible for inclusion unless subsequently published in an edited compilation of proceedings.

${ }^{11}$ Studies that did not disaggregate car use from other transport modes were excluded because composite measures cannot isolate and quantify effects relating to car use.

${ }^{12}$ Psychological behaviour change strategies aimed at increasing willingness necessitate a focus on willingness to reduce car use under existing conditions. Thus, we excluded analyses of correlates of willingness to reduce car use in hypothetical experimental situations where willingness was conditional upon modification of the decisional environment (e.g. increased petrol costs; Gärling \& Sandberg, 1997).
} 
Table 4.1. Screening process

RETAINED

REMOVED

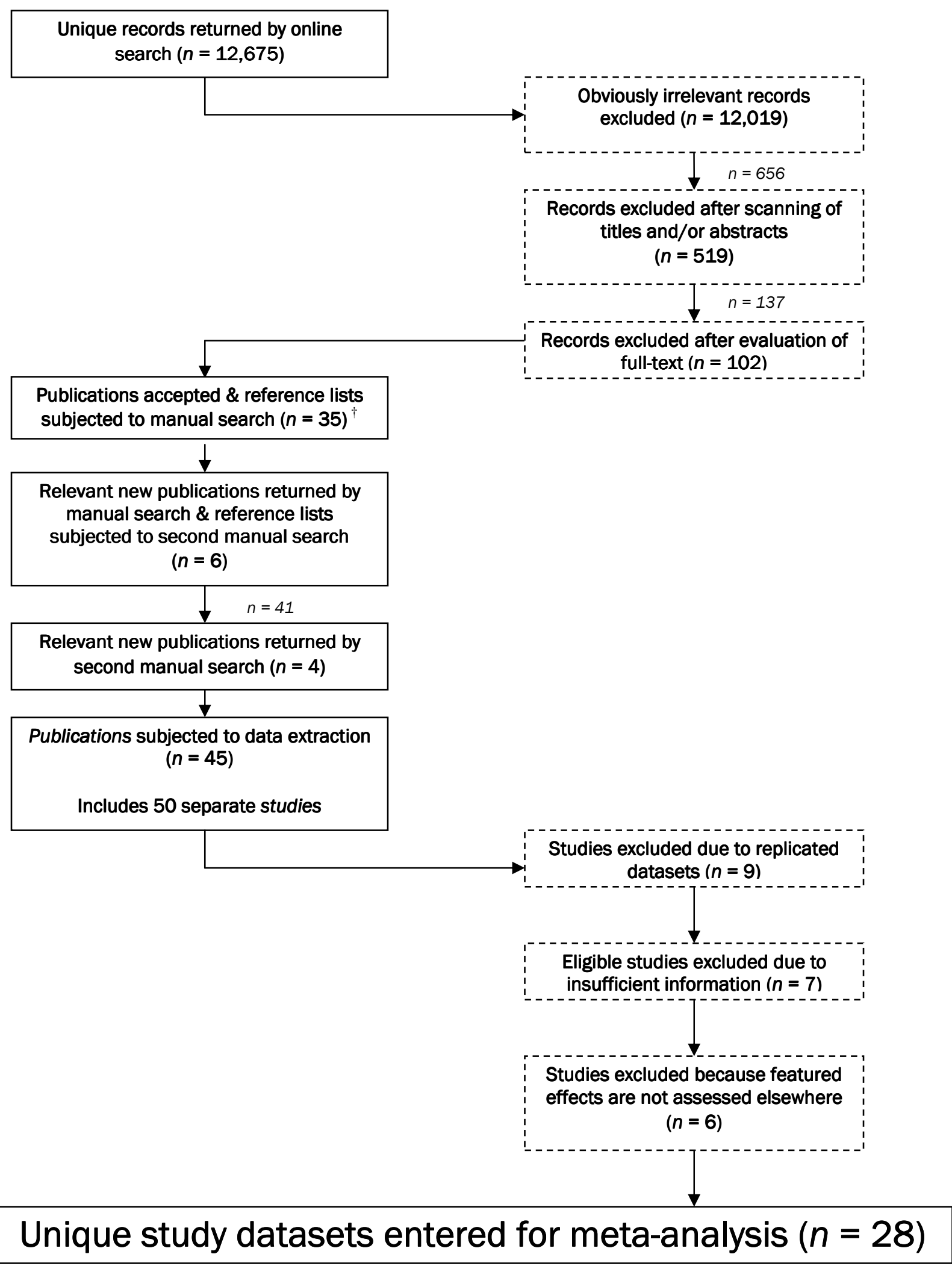

${ }^{\dagger}$ Excludes two qualitative and two associational quantitative studies which were not entered into the metaanalysis but the reference lists of which were manually searched; see Footnote 13 (p.71). 
association between a relevant psychological variable and a relevant dependent variable were retained.

Applying these criteria identified 35 potentially useful publications. The reference lists of these papers were searched manually ${ }^{13}$ using an ancestry approach. Where new records were found, these were also searched until no new citations emerged. This generated 10 further records.

The resulting 45 publications reported 50 relevant studies, which were checked to ensure that they reported data from independent samples. Each set of papers reporting the same dataset were regarded as one study for the purposes of analyses so each variable was only extracted once. This excluded 9 same-data study sets, leaving 41 independent studies.

\subsubsection{Data extraction}

A data extraction form was used to obtain relevant data from each record. Insufficient information led us to contact 16 corresponding authors via email, and again two weeks later where necessary. 4 authors did not provide this data, meaning that 7 otherwise eligible studies had to be excluded from the analyses (marked with superscript "id" [insufficient data] in the references). This left 34 independent studies or study sets from which data was successfully extracted. Six otherwise eligible studies reported data on associations between driving and constructs which were not measured in any other study and so were omitted, leaving a final sample of 28 unique datasets (marked with an asterisk in the references).

Fourteen data segments were extracted from each study dataset. A second postgraduate psychologist reviewed data from 13 studies, and the lowest total percentage agreement was $90 \%$. Disagreements were resolved through discussion.

\subsubsection{Study characteristics and measures}

Of the 28 study datasets accepted for meta-analysis, thirteen studies recruited participants regardless of whether they drove, while 15 studies employed drivers only (i.e. car owners or individuals with a driving licence). 17 studies utilised participants from the general population, of which 8 were driver-only samples. Commuters provided

\footnotetext{
${ }^{13}$ Four publications containing either qualitative (Hiscock, Macintyre, Kearns, \& Ellaway, 2002; Mann \& Abraham, 2006) or associational data (Mackett, 2003; Stradling, Meadows \& Beatty, 2000) were not entered into analysis, but were manually searched for references.
} 
samples for 6 studies; 3 of these were car commuters. Participants in two studies were enrolled on a pro-environment behaviour change intervention programme (run independently of the author). 2 studies recruited student samples of drivers only, and one sample comprised university employee drivers.

The majority of studies (15) focused on car trips made for any purpose, while 5 studies focused specifically on car commuting. Measures in 5 studies related to short car trips, and shopping trips, trips to the city centre, and combined commuting and errand trips were each behavioural outcomes in a single study. Twenty-seven studies were conducted in Europe, and one study (Baldassare \& Katz, 1992) was run in the US. Fifteen of the 27 studies measured behaviour, 13 studies featured intentions or preferences ( 8 and 5 studies respectively), and 4 studies focused on willingness to reduce car use.

Table 4.2 shows the distribution of behavioural measures across the study sample. Two main types of behaviour measure were observed: 'typical' behaviour, which related to participants' self-reported usual car use patterns (e.g. Polk, 2003), featured in 8 studies, and 8 studies focused on reported actual car use over specified time periods (e.g. Verplanken et al., 1994). Of the latter, 6 were retrospective, one was cross-sectional, and one study modelled car use prospectively. Behaviour was most frequently operationalised as self-reported frequency of car use (11 studies), but other measures included whether car or non-car transport was used (3), observed mileage driven (2), and the proportion of journeys made by car (1).

Table 4.3 illustrates the distribution of intention and willingness measures. Intentions were uniformly measured using the conventional self-report Likert scale measure (e.g. Conner \& Sparks, 1996), and related to general car trips in 2 studies, while five other studies focused on intentions to drive short distances, and one study focused on intentions to drive to the city centre. Preference measures focused on car versus public transport (5 studies) in everyday (1) or fictitious hypothetical scenarios (4).

Willingness was operationalised using two measures: levels of self-reported (dis)agreement with statement(s) relating to willingness ( 2 studies), and the extent of reduction in mileage the participant is willing to make (2).

Full details of studies entered for analysis are given in Appendix A.4.3, and Appendix A.4.4 details excluded studies and variables. 
Table 4.2. Behaviour measures employed in studies featuring car use correlates

\begin{tabular}{|c|c|c|c|}
\hline Journey type & $\begin{array}{l}\text { Typical or actual } \\
\text { behaviour }\end{array}$ & $\begin{array}{l}\text { Behaviour } \\
\text { measure }\end{array}$ & $k$ \\
\hline \multirow[t]{6}{*}{ General } & Actual & Car use/driving frequency & 4 \\
\hline & Actual & $\begin{array}{l}\text { Sole use of car vs. at least } \\
\text { one non-car journey }\end{array}$ & 1 \\
\hline & Actual & Mileage driven & 1 \\
\hline & Actual & $\begin{array}{l}\text { Proportion of car vs. } \\
\text { non-car journeys }\end{array}$ & 1 \\
\hline & Typical & Car use/driving frequency & 5 \\
\hline & Typical & Mileage driven & 1 \\
\hline Commuting & Actual & $\begin{array}{l}\text { Whether car or PT used } \\
\text { (dichotomous) }\end{array}$ & 1 \\
\hline $\begin{array}{l}\text { Commuting } \\
\text { and errands }\end{array}$ & Typical & Driving frequency & 1 \\
\hline $\begin{array}{l}\text { City centre } \\
\text { trips }\end{array}$ & Typical & Driving frequency & 1 \\
\hline
\end{tabular}

NB: PT = Public transport

\footnotetext{
${ }^{14}$ Steg \& Sievers (2000) report two behaviour measures (typical mileage driven \& actual proportion of car use relative to other modes).
} 
Table 4.3. Intention and willingness measures employed in studies featuring car use correlates

Journey type

Measure

$k$

Intention $^{15}$

General /

Intention to use car

2

none specified

Intention to drive short

5

distances $(<5 \mathrm{~km})$

Preference for car vs. PT

1

in hypothetical scenarios

City centre trips

Intention to use car

1

Commuting

Preference for car vs. PT

4

in hypothetical scenarios

Total

13

\section{Willingness}

General

Extent of reduction in

mileage participant is

willing to make

Agreement with

statements e.g. 'I am

willing to reduce my

car use'

Total

NB: PT = Public transport

${ }^{15}$ Includes recoded non-car use intentions. 


\subsubsection{Meta-analytic strategy}

4.3.4.1. Specificity. To maximise correspondence between variables (Fishbein \& Ajzen, 1975), pre-intention TPB variables relating to driving were treated as conceptually distinct from TPB variables focusing on restricting driving and/or using non-car transport (e.g. Kaiser \& Gutscher, 2003). However, driving and non-driving intentions and behaviour were collapsed to facilitate comparison of effects of pro- versus antidriving cognitions.

4.3.4.2. Multiple measures. One study (Steg \& Sievers, 2000) derived two behaviour measures from the same sample. A combined effect was computed, and an overall effect size calculated by weighting the correlation by the smaller $N$.

\subsubsection{Effect size analyses. Variables were entered for analysis where $k>1$. Although} meta-analysis is not suitable for summarizing data from only two studies such results are reported here for illustrative purposes. The effect size estimate used was a weighted correlation coefficient, $r$ (range: -1.0 to +1.0 ). Where necessary, alternative test statistics were converted (for formulae see e.g. Hunter \& Schmidt, 1990; but see Field $\&$ Wright, $2006^{16}$ ). Meta-analysis was performed using Schwarzer's (1989a) freeware package. Correlation coefficients were transformed into Fisher's $Z$, weighted by sample size $(N-3)^{17}$, and then backtransformed to provide the weighted average effect, $r_{+}$(e.g. Hedges \& Olkin, 1985). 95\% confidence intervals (CIs) calculated for the population $Z$ were transformed into CIs for each $r_{+}$value (see Hedges \& Olkin, 1985).

We also estimated the 'true' effect ( $\rho$; Hunter \& Schmidt, 1990, 2004), which here represents the weighted average correlation adjusted to account for imperfect variable reliabilities (Schwarzer, 1989a, 1989b).

\subsubsection{Failsafe $N$. The exclusion of unpublished studies and non-peer-reviewed} publications exposes the review to 'publication bias' - non-significant findings are less likely to be published (e.g. Greenwald, 1975; Rosenthal, 1984) - and the 'file drawer problem' (Rosenthal, 1979), which relates to an unknown number of unpublished

\footnotetext{
${ }^{16}$ Field and Wright (2006) argue that F values for two or more groups should not be converted into correlation coefficients because the resultant $r$ value may conceal more complex effects. However, $r$ values converted from $\mathrm{F}$ values for two or more groups are comparable with and no more problematic than $r$ values derived from studies using correlational designs.

${ }^{17}$ Missing values often reduce sample sizes for particular study variables. Where sample sizes for each variable were unavailable, we reduced $\mathrm{N}$ by $5 \%$ for each intra-study correlation prior to weighting.
} 
studies with negligibly sized effects. For both $r_{+}$and $\rho$ we calculated the 'failsafe $N$ ' (Rosenthal, 1984), which estimates the number of studies with null findings necessary to nullify the weighted effect, and thereby indicates the robustness of this effect.

4.3.4.5. Heterogeneity analyses. We performed heterogeneity analyses using chi-square $\left(\chi^{2}\right)$ and proportions of observed variance attributable to sampling error ${ }^{18}$. A nonsignificant chi-square statistic indicates that $r_{+}$adequately represents the population effect size whereas a significant chi-square statistic suggests there is considerable heterogeneity of study effects around the mean. Chi-square is however partially a function of sample size, and hence we also employed Hunter, Schmidt and Jackson's (1982) test, whereby $75 \%$ or more variance in observed effects accounted for by sampling error signifies homogeneity, and less than $75 \%$ indicates heterogeneity (Hunter et al., 1982).

Where appropriate, heterogeneity prompted moderator analyses to identify study characteristics affecting relationships between independent and dependent variables. This involves dividing the dataset into subsets around a variable that appears to account for systematic variation; a moderator is said to have been found where the population effect size varies across subsets, and the residual variance is lower in each subset than for the combined dataset (Hunter et al., 1982). Moderator analysis is inappropriate for small numbers of studies $(k<4)$, because it may be difficult to identify the 'anomalous' finding and/or to isolate the particular characteristic(s) responsible for the irregular finding. In these instances we explored whether heterogeneity could be reduced by removing irregular study effect sizes.

\subsection{Results}

Effects are interpreted in light of Cohen's $(1988,1992)$ guidelines: $r_{+}=.10$ represents a small effect, $r_{+}=.30$ is medium, and $r_{+}=.50$ is large. Unless specified, all weighted average effects were significant at $p \leq .001$.

\footnotetext{
${ }^{18}$ The heterogeneity chi-square index applies only to $r_{+}$, and observed proportions of variance due to sampling error are necessarily identical for $r_{+}$and $\rho$.
} 


\subsubsection{Correlates of behaviour}

\subsubsection{TPB and associated variables}

4.4.1.1.1. Intention to (not) use a car. A strong effect of intentions to use (or not use) a car on behaviour observed from four studies $\left(r_{+}=.53, \rho=.55\right.$; see table 4.4) appeared robust (failsafe $\left.N_{r+}=38, N_{\rho}=41\right)$. Heterogeneity $\left(\chi^{2}=48.10, p<.001 ; 8.32 \%\right.$ ) ${ }^{19}$ could be reduced by omitting an irregularly low study effect (Verplanken et al., 1998; $r=.20)\left(r_{+}\right.$ $=.56,95 \% \mathrm{CI}_{r+}=.52, .59 ; \rho=.58,95 \% \mathrm{CI}_{\rho}=.55, .60 ; p<.001 ; \chi^{2}=4.70, p=.10$; $63.84 \% ; N=2327, k=3)$.

4.4.1.1.2. Attitudes. Four studies produced a moderate weighted effect of attitude to car use on behaviour $\left(r_{+}=.27, \rho=.31\right.$; failsafe $\left.N_{r+}=18, N_{\rho}=21\right)$. Heterogeneity $\left(\chi^{2}=\right.$ $35.45, p<.001 ; 11.28 \%$; residual variance $=0.05)$ prompted moderator analyses which showed smaller effects where behaviour was measured over one week $\left(r_{+}=.08 ; 95 \% \mathrm{CI}\right.$ ${ }_{r+}=.08, .08, \rho=.09,95 \% \mathrm{CI}_{\rho}=.09, .09 ; p=.09 ; \chi^{2}=0.60, p=.44 ; 100 \% ; N=310, k=2$; residual variance $=-0.01$ ) and stronger effects where behaviour was measured over one and two months respectively $\left(r_{+}=.51 ; 95 \% \mathrm{CI}_{r+}=.34, .68, \rho=.58,95 \% \mathrm{CI}_{\rho}=.39, .78\right.$, $N=259, k=2$; residual variance $=0.01$ ).

Attitude to non-car use had a medium to large negative effect on behaviour $\left(r_{+}=\right.$ $-.41, \rho=-.44)$, though there was some evidence that this effect was unreliable due to heterogeneity $\left(\chi^{2}=5.46, p=.07 ; 54.92 \%\right)$. Removing the lowest study effect $(r=-.29$; Verplanken et al., 1994) achieved homogeneity $\left(r_{+}=-.43, \rho=-.46 ; \chi^{2}=0.88, p=.35\right.$; $100 \%)$.

\subsection{Perceived behavioural control (PBC) over non-car use yielded a stronger} average effect $\left(r_{+}=-.51, \rho=-.53\right.$; failsafe $\left.N_{r_{+}}=27, N_{\rho}=29\right)$ than did car use PBC $\left(r_{+}=\right.$ $.31, \rho=.31$; failsafe $\left.N_{r+}=10, N_{\rho}=10\right)$. Heterogeneity observed for non-car use PBC $\left(\chi^{2}\right.$ $=21.05 ; 14.25 \%$; car use PBC: $\chi^{2}=13.83 ; 14.46 \%$ ) was reduced by omitting a study relating to public transport use (Yang-Wallentin, Schmidt, Davidov \& Bamberg, 2004) where two other studies focused on restricting car use (Harland et al., 1999; Kaiser \& Gutscher, 2003: $\left.r_{+}=-.58, \rho=-.61 ; \chi^{2}=0.04, p=.84 ; 100 \%\right)$.

\footnotetext{
${ }^{19}$ Percentages refer to the percentage of observed variance due to sampling error. Values of less than $75 \%$ suggest heterogeneity (Hunter et al., 1982).
} 
Table 4.4. Correlates of driving

\begin{tabular}{|c|c|c|c|c|c|c|c|c|c|c|}
\hline \multirow[b]{2}{*}{ Variable } & \multirow[b]{2}{*}{$N$} & \multirow[b]{2}{*}{$\boldsymbol{k}$} & \multicolumn{3}{|c|}{ Unadjusted effect sizes } & \multicolumn{3}{|c|}{ Adjusted effect sizes } & \multirow{2}{*}{\multicolumn{2}{|c|}{ Heterogeneity indices }} \\
\hline & & & $\boldsymbol{r}_{+}$ & $\left.95 \% C I_{(r+t}\right)$ & Failsafe $N_{r+}$ & $\rho$ & $\left.95 \% C I{ }_{(}\right)$ & Failsafe $N_{\rho}$ & & \\
\hline & & & & & & & & & $\chi^{2}$ & $\begin{array}{l}\text { \% variance } \\
\text { due to } \\
\text { sampling } \\
\text { error }^{20}\end{array}$ \\
\hline \multicolumn{11}{|l|}{ TPB and associated variables } \\
\hline Intention to use car & 2517 & 4 & $.53 * * *$ & {$[.35, .72]$} & 39 & $.55^{* * *}$ & {$[.36, .75]$} & 41 & $48.10 * * *$ & $8.32 *$ \\
\hline Attitude to car use & 569 & 4 & $.27 * * *$ & {$[-.15, .70]$} & 18 & $.31 * * *$ & {$[-.18, .80]$} & 21 & $35.45 * * *$ & $11.28 *$ \\
\hline Attitude to non-car use & 1270 & 3 & $-.41 * * *$ & {$[-.48,-.34]$} & 22 & $-.44 * * *$ & {$[-.51,-.38]$} & 24 & 5.46 & $7.31 *$ \\
\hline $\mathrm{PBC}$ over car use & 324 & 2 & $.31 * * *$ & {$[-.03, .65]$} & 10 & $.31 * * *$ & {$[-.03, .65]$} & 10 & $13.83 * * *$ & $14.46^{*}$ \\
\hline PBC over non-car use & 2334 & 3 & $-.51 * * *$ & {$[-.63,-.38]$} & 27 & $-.53 * * *$ & {$[-.66,-.40]$} & 29 & $21.05 * * *$ & $14.25 *$ \\
\hline Subjective norm for car use & 555 & 2 & -.07 & {$[-.14, .01]$} & 1 & -.08 & {$[-.17, .01]$} & 1 & 2.84 & $70.47 *$ \\
\hline Subjective norm for non-car use & 1069 & 2 & $-.36 * * *$ & {$[-.45,-.27]$} & 12 & $-.36 * * *$ & {$[-.45,-.27]$} & 12 & $4.81 *$ & $41.59 *$ \\
\hline Descriptive norm for car use & 993 & 2 & $.36 * * *$ & {$[.36, .36]$} & 13 & $.46^{* * *}$ & {$[.46, .46]$} & 17 & 0.20 & 100.00 \\
\hline $\begin{array}{l}\text { Personal moral norm for } \\
\text { non-car use }\end{array}$ & 563 & 2 & $-.41 * * *$ & {$[-.70,-.11]$} & 14 & $-.46 * * *$ & {$[-.78,-.13]$} & 16 & $20.04 * * *$ & $9.98 *$ \\
\hline \multicolumn{11}{|l|}{ TIB variable } \\
\hline Car use habit & 934 & 5 & $.50 * * *$ & {$[.21, .79]$} & 45 & $.50 * * *$ & {$[.21, .79]$} & 45 & $41.54 * * *$ & $12.04 *$ \\
\hline \multicolumn{11}{|l|}{ Environmental variables } \\
\hline Problem awareness & 799 & 3 & $-.24 * * *$ & {$[-.33,-.15]$} & 11 & $-.29 * * *$ & {$[-.37,-.20]$} & 14 & 4.90 & $61.24 *$ \\
\hline $\begin{array}{l}\text { Perceived personal threat from } \\
\text { environmental problem }\end{array}$ & 1151 & 2 & $-20 * * *$ & {$[-20-20]$} & 6 & $-22 * * *$ & {$\left[\begin{array}{ll}-22 & -22]\end{array}\right.$} & 7 & 186 & 100.00 \\
\hline Environmental concern & 1462 & 2 & $-.13 * * *$ & {$[-.37, .10]$} & 3 & $-.16^{* * *}$ & {$[-.45, .12]$} & 4 & $24.00 * * *$ & $8.33^{*}$ \\
\hline Perceived responsibility for & & & & & & & & & & \\
\hline problems arising from car use & 403 & 2 & $-.18 * * *$ & {$[-.50, .13]$} & 5 & $-.22 * * *$ & {$[-.60, .16]$} & 7 & $13.11^{* * *}$ & $15.26^{*}$ \\
\hline
\end{tabular}

NB: $* p<.05, * * p<.01, * * * p<.001$. $\rho$ denotes effect corrected for measurement reliabilities. Where $r_{+}$is equal to $\rho$, there was no available measurement reliability data to allow correction.

${ }^{20}$ Values below 75 suggest heterogeneity, hence values of 75 or above signify homogeneity of effects. To aid interpretation, an asterisk (*) is assigned to heterogeneous values $(<75)$. 
Heterogeneity around the effect of car use PBC $\left(\chi^{2}=13.83, p<.001 ; 14.46 \%\right)$ may have been due to problems in combining a conventional PBC measure $(r=.15$; Verplanken et al., 1998) presumed to encompass internal and external constraints (Ajzen, 1991; but see Conner \& Sparks, 2005), with a measure of perceived external barriers ( $r=.53$; Tanner, 1999). Tanner (1999) also measured perceived efficacy (i.e. perceived internal constraints), which yielded a negligible, negative effect on behaviour ( $r=-.06)$. Hence we reran the analysis, combining Tanner's (1999) control variables. Putting aside consistency problems, an average correlation of $r_{+}=.22(\rho=.22)$ was generated, which demonstrated homogeneity $\left(\chi^{2}=2.21, p=.14 ; 90.35 \%\right)$.

4.4.1.1.4. Subjective norms towards car and non-car use were examined in relation to behaviour in two studies respectively. A small unexpectedly negative and nonsignificant effect for car use subjective norm $\left(r_{+}=-.07, \rho=-.08, p=.14\right)$ was highly unreliable (failsafe $N_{r+}=1, N_{\rho}=1$ ). There were stronger bases for the medium sized negative effect for non-car use subjective norm $\left(r_{+}=-.36, \rho=-.36\right.$; failsafe $N_{r+}=12, N_{\rho}$ $=12$ ), but both effects had potential heterogeneity problems (car subjective norm: $\chi^{2}=$ $2.84, p=.09 ; 70.47 \%$; non-car subjective norm: $\left.\chi^{2}=4.81, p=.03 ; 41.59 \%\right)$.

4.4.1.1.5. Other normative variables. Two studies underpinned a homogeneous medium sized effect of descriptive norms on behaviour $\left(r_{+}=.36, \rho=.46 ; \chi^{2}=0.20, p=.65\right.$; $100 \%)$. The average effect on behaviour of personal moral norms $\left(r_{+}=-.41 ; \rho=-.46\right)$ was underpinned by two considerably different effects (Harland et al., 1999: $r=-.62$; Matthies et al., 2006: $r=-.29 ; \chi^{2}=20.04, p<.001 ; 9.98 \%$ ).

\subsubsection{Car use habit}

Five studies explored the effect of car use habit on behaviour using Verplanken et al.'s (1994) response-frequency measure (RFM), which involves presenting participants with a series of travel goals characterised by minimal information (e.g. 'going to the beach'; Verplanken et al., 1994). Participants are required to choose a mode of transport to use in each scenario as quickly as possible, to minimise deliberation and elicit automatic responses (Verplanken et al., 1994). Car use habit is indexed by the frequency of car choices across items.

A strong average effect of habit on behaviour was well-founded $\left(r_{+}=.50, \rho=\right.$ .50 ; failsafe $\left.N_{r+}=45, N_{\rho}=45\right)$, but underlying effects were heterogeneous $\left(\chi^{2}=41.54\right.$, 
$p<.001 ; 12.04 \%)$. The timeframe on which behaviour was measured moderated the habit-behaviour relation (residual variance for whole dataset $=0.02$ ), with a lower average correlation observed where car use was measured over one week (Garvill, Marell \& Nordlund, 2003: $r=.31$; Verplanken et al., 1998: $r=.28 ; r_{+}=.29,95 \% \mathrm{CI}_{r+}$ $=.29, .29 ; \rho=.29,95 \% \mathrm{CI}_{\rho}=.29, .29$; residual variance $\left.=-0.01\right)$, and a larger effect where behaviour was measured over longer time periods $\left(r_{+}=.60,95 \% \mathrm{CI}_{r+}=.50, .71\right.$; $\rho=.60,95 \% \mathrm{CI}_{\rho}=.50, .71$; residual variance $\left.=0.002\right)$. The former statistic was underpinned by homogeneous effects $\left(\chi^{2}=0.08, p=.78 ; 100 \% ; N=310, k=2\right)$, whereas the combined effect size was heterogeneous where behaviour was assessed over two weeks (Matthies et al., 2006), one month (Gärling et al., 2001, study 1), and two months (Verplanken et al., 1994; $\chi^{2}=7.22, p=.03 ; 41.53 \% ; N=624, k=3$ ).

\subsubsection{Environmental variables}

Evidence for effects of four pro-environment variables on driving was surprisingly weak (failsafe $N_{r+}$ range $=3-11, N_{\rho}$ range $=4-14$ ). Unless otherwise specified, each variable was related to behaviour in two studies.

Problem awareness - the extent to which the individual is mindful of the environmental and health impacts of car emissions - was assessed in three studies, yielding a homogeneous small to medium sized negative effect $\left(r_{+}=-.24, \rho=-.29 ; \chi^{2}=\right.$ $4.90, p=.09 ; 61.24 \%)$.

Perceptions of threats to personal health and wellbeing of the environmental problems associated with car use produced a homogeneous small to medium negative effect $\left(r_{+}=-.20, \rho=-.22 ; \chi^{2}=1.86, p=.17 ; 100 \%\right)$.

We also assessed effects of perceived responsibility for environmental problems, which we defined as the extent to which participants feel personally responsible for the detrimental environmental and health impacts of car use (Steg \& Sievers, 2000), and thus feel responsible for reducing such problems (Tanner, 1999). Heterogeneity was observed around a small to medium average effect size $\left(r_{+}=-.18, \rho=-.22 ; \chi^{2}=13.11\right.$, $p<.001 ; 15.26 \%$ ). 


\subsubsection{Correlates of intention and preference}

\subsubsection{TPB variables}

4.4.2.1.1. Attitudes. Six study effects underpinned a strong relationship between attitudes to car use and intention $\left(r_{+}=.44, \rho=.57\right.$; failsafe $N_{r+}=46, N_{\rho}=62$; see table $4.5)$. Observed heterogeneity $\left(\chi^{2}=12.62, p=.03 ; 47.53 \%\right)$ was eliminated by removing an atypically small study effect ( $r=.20$; Forward, 2004, study $1 \mathrm{~b}$ ), generating a revised homogeneous average correlation of $r_{+}=.47\left(95 \% \mathrm{CI}_{r+}=.47, .47 ; \rho=.60 ; 95 \% \mathrm{CI}_{\rho}=\right.$ $\left..60, .60 ; \chi^{2}=3.00, p=.06 ; 100 \% ; N=680, k=5\right)$. The cause of the irregular finding could not be identified. A large homogeneous average effect on intention was observed for non-car use attitudes $\left(r_{+}=-.53, \rho=-.64\right.$; failsafe $N_{r+}=19, N_{\rho}=24 ; \chi^{2}=0.03, p=$ $.86 ; 100 \%)$.

4.4.2.1.2. $P B C$. A strong weighted effect of car use PBC on intention $\left(r_{+}=.52, \rho=.62\right.$; failsafe $N_{r+}=47, N_{\rho}=57$ ) did not adequately represent the five component study effects $\left(\chi^{2}=78.41, p<.001 ; 6.38 \%\right)$. Removing either or both of two irregularly small study effects (Verplanken et al., 1998: $r=.15$; Forward, 2004, study 1b: $r=.47$ ) where remaining studies reported effects around .70, was insufficient to achieve homogeneity (maximum $p$ for $\chi^{2}=.04$ ). Non-car use PBC had a strong effect on intention, $r_{+}=-.67(\rho$ $=-.70$; failsafe $N_{r+}=37, N_{\rho}=39 ; \chi^{2}=3.30, p=.19 ; 91.02 \%$ ).

4.4.2.1.3. Subjective norms towards using cars were found to have a reliable medium sized effect on intentions to drive $\left(r_{+}=.27, \rho=.30 ; \chi^{2}=5.66, p=.23 ; 88.31 \%\right.$; failsafe $\left.N_{r+}=22, N_{\rho}=25\right)$. A strong effect of subjective norms towards not driving was observed $\left(r_{+}=-.49\right.$; failsafe $\left.N_{r+}=17, N_{\rho}=19\right)$ was unstable $\left(\chi^{2}=8.97, p=.003\right.$; $22.28 \%)$.

\subsubsection{Car use habit}

Observed heterogeneity $\left(\chi^{2}=7.65, p=.01 ; 26.13 \%\right.$; failsafe $\left.N_{r+}=9, N_{\rho}=9\right)$ questioned the reliability of the moderate sized effect obtained $\left(r_{+}=.29, \rho=.29\right)$. 
Table 4.5: Correlates of intention to drive

\begin{tabular}{|c|c|c|c|c|c|c|c|c|c|c|}
\hline \multirow[b]{2}{*}{ Variable } & \multirow[b]{2}{*}{$N$} & \multirow[b]{2}{*}{$\boldsymbol{k}$} & \multicolumn{3}{|c|}{ Unadjusted effect sizes } & \multicolumn{3}{|c|}{ Adjusted effect sizes } & & \\
\hline & & & $\boldsymbol{r}_{+}$ & $95 \% C I(r+)$ & Failsafe $N_{r+}$ & $\rho$ & $\left.95 \% C I{ }_{\rho}\right)$ & Failsafe $N_{\rho}$ & \multicolumn{2}{|c|}{ Heterogeneity indices } \\
\hline & & & & & & & & & $\chi^{2}$ & $\begin{array}{l}\% \text { variance } \\
\text { due to } \\
\text { sampling } \\
\text { error }^{21}\end{array}$ \\
\hline \multicolumn{11}{|l|}{ TPB and associated variables } \\
\hline Attitude to car use & 780 & 6 & $.44 * * *$ & {$[.29, .58]$} & 46 & $.57 * * *$ & {$[.42, .72]$} & 62 & $12.62^{*}$ & $47.53 *$ \\
\hline Attitude to non-car use & 1081 & 2 & $-.53 * * *$ & {$[-.53,-.53]$} & 19 & $-.64 * * *$ & {$[-.64,-.64]$} & 24 & 0.03 & 100.00 \\
\hline PBC over car use & 732 & 5 & $.52 * * *$ & {$[.08, .97]$} & 47 & $.62 * * *$ & {$[.10,1.0]$} & 57 & $78.41 * * *$ & $6.38 *$ \\
\hline PBC over non-car use & 1182 & 3 & $-.67 * * *$ & {$[-.69,-.65]$} & 37 & $-.70 * * *$ & {$[-.70,-.70]$} & 39 & 3.30 & 91.02 \\
\hline Subjective norm for car use & 732 & 5 & $.27 * * *$ & {$[.21, .32]$} & 22 & $.30 * * *$ & {$[.24, .36]$} & 25 & 5.66 & 88.31 \\
\hline Subjective norm for non-car use & 1069 & 2 & $-.49 * * *$ & {$[-.61,-.37]$} & 17 & $-.52 * * *$ & {$[-.65,-.39]$} & 19 & $8.97 * *$ & $22.28 *$ \\
\hline \multicolumn{11}{|l|}{ TIB variable } \\
\hline Car use habit & 238 & 2 & $.29 * * *$ & {$[.01, .56]$} & 9 & $.29 * * *$ & {$[.01, .56]$} & 9 & $7.65 * *$ & $26.13^{*}$ \\
\hline \multicolumn{11}{|l|}{ Travel concerns } \\
\hline Importance of travel time & 140 & 2 & $.24 * *$ & {$[.24, .24]$} & 8 & $.24 * *$ & {$[.24, .24]$} & 8 & 0.38 & 100.00 \\
\hline Importance of flexibility & 140 & 2 & $.47 * * *$ & {$[.47, .47]$} & 17 & $.47 * * *$ & {$[.47, .47]$} & 17 & 0.36 & 100.00 \\
\hline Importance of environment & 140 & 2 & $-.57 * * *$ & {$[-.57,-.57]$} & 21 & $-.57 * * *$ & {$[-.57,-.57]$} & 21 & 1.66 & 100.00 \\
\hline Importance of public health & 140 & 2 & $-.36 * * *$ & {$[-.36,-.36]$} & 12 & $-.36 * * *$ & {$[-.36,-.36]$} & 12 & 0.04 & 100.00 \\
\hline $\begin{array}{l}\text { Social dilemma variable } \\
\text { (Pro-)Social value orientation }\end{array}$ & 372 & 3 & $-.21 * * *$ & {$[-.21,-.21]$} & 9 & $-.21 * * *$ & {$[-.21,-.21]$} & 9 & 0.98 & 100.00 \\
\hline
\end{tabular}

NB: $* p<.05, * * p<.01, * * * p<.001 . \rho$ denotes effect corrected for measurement reliabilities. Where $r_{+}$is equal to $\rho$, there was no available measurement reliability data to allow correction.

${ }^{21}$ Values below 75 suggest heterogeneity, hence values of 75 or above signify homogeneity of effects. To aid interpretation, an asterisk (*) is assigned to heterogeneous values $(<75)$. 


\subsubsection{Travel concerns}

Two studies assessed effects of subjective importance assigned to travel time, travel flexibility, environmental preservation, and public health, on preferences for car versus public transport in simulated commuting scenarios (van Vugt et al., 1995; Joireman et al., 1997). Perhaps due to study design similarities, statistical homogeneity was observed for average correlations for each variable (travel time: $\chi^{2}=0.38, p=.54$; $100 \%$; flexibility: $\chi^{2}=0.36, p=.55 ; 100 \%$; environment: $\chi^{2}=1.66, p=.20 ; 100 \%$; public health: $\chi^{2}=0.04, p=.84 ; 100 \%$ ). The importance of environmental preservation $\left(r_{+}=-.57, \rho=-.57 ;\right.$ failsafe $\left.N_{r_{+}}=21, N_{\rho}=21\right)$ and flexibility concerns $\left(r_{+}=.47 ; \rho=.47\right.$; failsafe $N_{r+}=17, N_{\rho}=17$ ) displayed strongest effects on intentions. Public health concerns had a medium to large negative impact $\left(r_{+}=-.36, \rho=-.36\right.$; failsafe $N_{r+}=17$, $\left.N_{\rho}=17\right)$, and travel time a small to medium positive effect $\left(r_{+}=.24, \rho=.24\right.$; failsafe $\left.N_{r+}=8, N_{\rho}=8\right)$ on car use intentions.

\subsubsection{Social value orientation}

Van Vugt and colleagues (e.g. Joireman et al., 1997; van Vugt et al., 1995; van Vugt, van Lange \& Meertens, 1996) have characterised travel mode choice as a social dilemma involving a trade-off of personal and collective costs and benefits. Three study effects underpinned a small to medium homogeneous negative effect of social value orientation $\left(r_{+}=-.21, \rho=-.21 ; \chi^{2}=0.98, p=.61 ; 100 \%\right)$, with tendencies towards a 'pro-self' value orientation more closely associated with driving preferences, but evidence for the effect was relatively weak (failsafe $N_{r+}=9, N_{\rho}=9$ ).

\subsubsection{Correlates of willingness to reduce car use}

Only four publications modelling non-conditional willingness to voluntarily reduce car use, albeit each featuring large samples of around 1000-1500 participants, could be identified (Garvill, 1999; Nordlund \& Garvill, 2003; Polk, 2003, 2004). No evidence was presented to quantify the relationship between willingness and behaviour. Each variable was assessed in two studies unless otherwise stated; see table 4.6.

\subsubsection{Environmental variables}

The most frequently assessed correlate of willingness was the perception of cars as a source of environmental problems, which was explored in three studies. The medium sized effect was robust $\left(r_{+}=.32, \rho=.42\right.$; failsafe $\left.N_{r+}=16, N_{\rho}=22\right)$. 
Table 4.6. Correlates of willingness to reduce driving

\begin{tabular}{|c|c|c|c|c|c|c|c|c|c|c|}
\hline \multirow[b]{2}{*}{ Variable } & \multirow[b]{2}{*}{$N$} & \multirow[b]{2}{*}{$k$} & \multicolumn{3}{|c|}{ Unadjusted effect sizes } & \multicolumn{3}{|c|}{ Adjusted effect sizes } & \multirow{2}{*}{\multicolumn{2}{|c|}{ Heterogeneity indices }} \\
\hline & & & $\boldsymbol{r}_{+}$ & $95 \% C I(r+)$ & Failsafe $N_{r+}$ & $\rho$ & $\left.95 \% C I{ }_{\rho}\right)$ & Failsafe $N_{\rho}$ & & \\
\hline & & & & & & & & & $\chi^{2}$ & $\begin{array}{l}\text { \% variance } \\
\text { due to } \\
\text { sampling } \\
\text { error }^{22}\end{array}$ \\
\hline Environmental variables & & & & & & & & & & \\
\hline $\begin{array}{l}\text { Car as cause of environmental } \\
\text { problems }\end{array}$ & 3984 & 3 & $.32 * * *$ & {$[.27, .38]$} & 16 & $.42 * * *$ & {$[.36, .49]$} & 22 & $6.26 *$ & $47.92 *$ \\
\hline Perceived threat to humankind & 2934 & 2 & $.31 * * *$ & {$[.29, .32]$} & 10 & $.34 * * *$ & {$[.32, .36]$} & 12 & 2.23 & 89.71 \\
\hline Perceived threat to biosphere & 2934 & 2 & $.29 * * *$ & {$[.29, .29]$} & 10 & $.32 * * *$ & {$[.32, .32]$} & 11 & 1.40 & 100.00 \\
\hline $\begin{array}{l}\text { Perceived degree of seriousness } \\
\text { of problem }\end{array}$ & 2932 & 2 & $.39 * * *$ & {$[.39, .39]$} & 13 & $.42 * * *$ & {$[.43, .43]$} & 15 & 0.10 & 100.00 \\
\hline $\begin{array}{l}\text { Misc. other variables } \\
\text { Self-transcendent values }\end{array}$ & 2476 & 2 & $.20 * * *$ & {$[.13, .27]$} & 6 & $.26 * * *$ & {$[.17, .35]$} & 8 & $5.28 *$ & $37.89^{*}$ \\
\hline
\end{tabular}

NB: $* p<.05, * * p<.01, * * * p<.001 . \rho$ denotes effect corrected for measurement reliabilities. Where $r_{+}$is equal to $\rho$, there was no available measurement reliability data to allow correction.

${ }^{22}$ Values below 75 suggest heterogeneity, hence values of 75 or above signify homogeneity of effects. To aid interpretation, an asterisk (*) is assigned to heterogeneous values $(<75)$. 
Heterogeneity $\left(\chi^{2}=6.26, p=.04 ; 47.92 \%\right)$ was reduced by removing the largest effect (Polk, 2003: $r=.38$ ) where the remaining two studies reported effects around .30 (Garvill, 1999; Nordlund \& Garvill, 2003) $\left(r_{+}=.31, \rho=.32 ; \chi^{2}=0.80, p=.37 ; 100 \%\right)$.

The threat of car use and its associated environmental problems to humankind yielded a homogeneous effect, $r_{+}=.31\left(\rho=.34 ; \chi^{2}=2.23, p=.14 ; 89.71 \%\right.$; failsafe $N_{r+}$ $=10, N_{\rho}=12$ ). The average effect for the perceived threat of car use to the biosphere and willingness, $r_{+}=.29(\rho=.32)$, was also homogeneous $\left(\chi^{2}=1.40, p=.24 ; 100 \%\right.$;

failsafe $N_{r+}=10, N_{\rho}=11$ ). A stronger homogeneous effect was found on willingness for perceived seriousness of environmental problems arising from car use, $r_{+}=.39(\rho=.42$; $\chi^{2}=0.10, p=.75 ; 100 \%$; failsafe $\left.N_{r+}=13, N_{\rho}=15\right)$.

\subsubsection{Self-transcendent values}

Evidence of a relationship between willingness and self-transcendent values i.e. preferences for non-personally-beneficial outcomes - was weak (failsafe $N_{r+}=6, N_{\rho}$ $=8)$. An average correlation of $r_{+}=.20(\rho=.26)$ was an inadequate fit to the two study effects $\left(\chi^{2}=5.28, p=.02 ; 37.89 \%\right)$ : Nordlund and Garvill (2003) reported an effect of $r$ $=.16$, and Polk (2004) obtained an effect of $r=.25$.

\subsection{Discussion}

Meta-analyses were performed on 28 unique datasets which measured car use behaviour, intentions, and/or willingness to reduce car use. Intention, car use habit and perceived behavioural control (PBC) over non-car use displayed large effects on behaviour (Cohen, 1992). Uniformly stronger effects on both intention and behaviour were found for Theory of Planned Behaviour (TPB) cognitions regarding use of non-car transport or restricting driving than for matched cognitions pertaining to car use. The findings confirm TPB-predicted associations between attitudes, subjective norms, PBC and intention. Moreover, with the exception of subjective norm, these constructs also correlated with behaviour, suggesting that TPB-specified determinants are potentially useful targets for behaviour change interventions. However, we also found that habit was associated with intention and strongly associated with behaviour across studies, indicating that more than intention change may be necessary to initiate behaviour change. There was little evidence to evaluate relationships between pro-environment cognitions, intentions and behaviour and, more generally, surprisingly few studies of modifiable antecedents of driving were available. 
Our results showed large effects of intention, habit, and PBC - albeit over using non-car transports - on decisions to drive. Intention was most closely associated with non-car use PBC, whilst there were also strong effects for attitude to non-car use, PBC over car use, and concerns for the environment and flexibility when making a journey. Our findings thus largely endorse the efficacy of the TPB as a conceptual model of car use decisions, whilst also suggesting that the predictive utility of the model in this domain is likely to be enhanced where supplemented by measures of habit (Bamberg $\&$ Schmidt, 2003; Triandis, 1977).

No study was found to have quantified the relationship between willingness to reduce driving and car use intentions or behaviour, and so it remains unclear what role, if any, willingness plays in car use reduction. Further research is required to establish willingness to reduce car use as an outcome of behavioural significance and thus a legitimate target for car use reduction campaigns (but see Beale \& Bonsall, 2007).

We found stronger negative effects of cognitions about not driving on both intentions and behaviour than the positive effects observed for corresponding car use cognitions. Whilst our results generally support the explanatory framework of the TPB, cognitions measured in relation to driving may not adequately capture effects of attitudinal, normative and control perceptions of alternatives, and so future TPB applications might benefit from supplementing car use cognitions with measures relating to non-car travel. Moreover, these findings tentatively suggest that reluctance to adopt alternative transport modes may result more from perceived unattractiveness of alternative options than the appeal of the car, and so car use reduction campaigns might be more effective where they address negative attitudes towards public transport and enhance drivers' perceptions of control over using non-car transports, rather than attempting to change pro-car cognitions. Of course, car users may misperceive non-car alternatives: for example, drivers tend to overestimate public transport travel times (Fujii et al., 2001) and may form negative attitudes on the basis of isolated negative public transport experiences (see chapter 2). Further evidence of non-car cognition effects is required, and qualitative investigation might clarify the underpinnings of drivers' negative perceptions of non-car transport (Mann \& Abraham, 2006; chapter 2).

Our analysis highlights a general lack of evidence of effects of proenvironmental cognitions on behaviour or intentions. The observed small to medium effects of environmental variables on behaviour may have concealed indirect effects as mediated by intention (Heath \& Gifford, 2002), but there was insufficient evidence to 
assess this. More research is needed to clarify the role of pro-environment cognitions on driving, and demonstrate the relationships between environment-related cognitions, car use attitudes and intentions, because many driving reduction campaigns assume that emphasising environmental benefits will motivate drivers to use non-car transport (see e.g. "Commuter Challenge", 2007).

Evidence for effects of pro-environment variables may be limited because environmental concerns have been operationalised using various discernable cognitions (e.g. problem awareness, perceived seriousness, perceived threats of environmental damage to oneself; Baldassare \& Katz, 1992; Garvill, 1999; Loukopoulos \& Gärling, 2005). Considerably more work is needed to determine whether and how these cognitions are inter-related, and which of these variables represent the more proximal determinants of intentions and/or behaviour. Indeed, we presumed that perceived responsibility for causation and for reduction of problems would represent a unified cognitive construct (cf. Heath \& Gifford, 2002), but heterogeneity around the effect for the unified variable might suggest our operationalisation conflated conceptually independent constructs. Whilst perceived responsibility for causation yielded a very small effect on behaviour ( $r=-.06$; Steg $\&$ Sievers, 2000), perceived responsibility for reduction was moderately correlated with behaviour ( $r=-.43$; Tanner, 1999). Drivers may accept responsibility for causing environmental problems, yet attribute responsibility for reducing these problems to external parties. For example, believing that alternative transport choices are inadequate may allow drivers to attribute responsibility for reducing driving to government or local authorities. Yet these perceptions of alternatives may be erroneous (Fujii et al., 2001). Thus, if environmentrelated cognitions are to be targeted, driving reduction campaigns should seek to persuade drivers to assume personal responsibility for reducing car use, whilst also enhancing perceptions of control over use of non-car transport to meet personal journey demands.

Small to medium effects of social value orientation were found on driving preferences, but this may be a by-product of the social dilemma paradigm, which presupposes that drivers are aware of the individual and collective costs and benefits involved in travel mode choice (Joireman et al., 1997; van Lange et al., 1998; van Vugt et al., 1995; van Vugt, van Lange \& Meertens, 1996). If car users are unaware of the social dilemma arising from driving it seems unlikely that collective versus individual benefit preferences will influence travel mode choice, and there is little evidence to 
suggest that real-world travel scenarios are experienced as social dilemmas (see e.g. van Vugt et al., 1996). Furthermore, contrary to the assumption that car use provides personal benefit, growing evidence suggests that car use is not enjoyed but rather is seen as the 'least worst' available option (e.g. Mann \& Abraham, 2006; see too chapter 2). Further qualitative work might investigate the applicability of the social dilemma framework to drivers' everyday experiences as a precondition for further dilemma research.

Our results suggest improvements to research designs in this field. Smaller effects on behaviour were found for car use attitudes and habits when behaviour was measured over shorter time periods (Garvill et al., 2003; Verplanken et al., 1998). Potential unforeseen disturbances of attitude-behaviour relations - e.g., bad weather, or a broken-down car, on one or more days of the study period - can have more pronounced disruptive effects over shorter periods of time which may therefore underestimate the magnitude of the relationship between psychological constructs and 'true' transport use patterns (see e.g. Yang-Wallentin et al., 2004). Behavioural effects of non-car attitudes on behaviour were also more marked where no timeframe was specified than where a two-month behaviour measure was used (Verplanken et al., 1994). Thus, prospective studies with longer follow-ups are recommended.

Whilst our analysis proposes a number of variables as targets for car use reduction initiatives, how to modify these variables remains unclear, largely because our results do not establish whether car use is primarily habitual or whether careful deliberation precedes a decision to drive. Large effects of intentions and habit on behaviour support both the reasoned action view that driving is based on rational utilitarian deliberation (Bamberg et al., 2003), and the argument that the decision to drive is largely a non-conscious, automated process (e.g. Verplanken et al., 1994). These apparently contradictory findings might be due to stable decisional contexts, in which drivers repeatedly make deliberative decisions to drive and thus develop a habit (Aarts et al., 1998). In such situations, drivers are likely to have car use habits and strong intentions to drive, and so the 'true' proximal determinant of driving is obscured. Habit research would therefore be better undertaken in contexts in which intentions and habits conflict: such conditions can be experimentally induced (Gärling et al., 2001).

Perhaps the most significant finding of the current study is the lack of available evidence. Given the few publications in this area, it is all the more imperative that authors are open with their data (cf. Wicherts, Borsboom, Kats, \& Molenaar, 2006); our 
findings may have been significantly different had more data been readily available from authors. The lack of evidence devalues existing research by prohibiting formulation of reliable evidence-based driving reduction interventions. Considerable work is required to plug gaps in understandings of motivations for car use, particularly in clarifying the roles of habit and non-car and pro-environment cognitions on decisions to drive. In the absence of such evidence, it is perhaps unsurprising that car use reduction strategies, such as the travel feedback programme (Ampt, 1999; Brög, 1998), have been developed independently of research into potentially modifiable targets for behaviour change. Whilst there is potential for transport psychology to offer effective evidence-based driving reduction strategies more work is needed to realise these objectives. 


\section{Chapter 5. Study 4: Going green? Modelling the impact of environmental concerns and perceptions of transport alternatives on decisions to drive $\mathrm{e}^{* * *}$}

\subsection{Abstract}

Previous research into the determinants of car use has focused on utility-based beliefs as determinants of attitudes, and primarily modelled intentions to drive on cognitions relating to car use. This approach fails to model the impact of beliefs about alternative travel modes. Previous research has also tended to neglect the influence of environmental concerns on driving motivation. This study tested an integrative model based on the Theory of Planned Behaviour which incorporated cognitions relating to non-car transport use, personal and descriptive norms, and environment-related cognitions and beliefs. 190 residents of a small UK city with excellent infrastructure to support non-car travel completed cognition and behaviour measures relating to intracity car journeys. $62 \%$ of variance in behaviour was predicted by intention and participant age. $56 \%$ of intention variance was predicted by car use PBC and descriptive norms, and non-car use attitudes, subjective norms and personal norms. Environmental concern and perceived efficacy for reducing car-related environmental problems were best modelled as determinants of non-car use attitudes and personal norms. Results demonstrate the importance of modelling travel mode choice on cognitions relating not only to the focal transport mode, but also to alternative transports. Theoretical implications and policy recommendations are discussed.

\subsection{Literature review}

Traffic emissions contribute to climate change (Oskamp, 2000) and cardiovascular and respiratory diseases (Peters et al., 2004), and are predominantly attributable to car use (Berntsen, 2004; Department for Transport [DfT], 2006b). In the UK in 2004, private cars produced around 19.5 million tonnes of $\mathrm{CO}_{2}$, accounting for $13 \%$ of total $\mathrm{UK} \mathrm{CO}_{2}$ emissions (DfT, 2006b). Moreover, 25\% of UK car journeys cover less than 2 miles (Department of the Environment, Transport and the Regions, 2000) and so produce disproportionately more carbon emissions (Saleh, Nelson \& Bell, 1998), and in most cases could be undertaken using alternative transportation (Goodwin, 1997).

\footnotetext{
*** A version of this chapter has been accepted for publication as Gardner, B., \& Abraham, C. (in press) Going green? Modeling the impact of environmental concerns and perceptions of transport alternatives on decisions to drive. Journal of Applied Social Psychology.
} 
As argued in chapter 1 (pp.2-3), persuading people to switch transport modes by changing beliefs, attitudes and intentions is less expensive and more publicly acceptable than modifications to transport infrastructure (e.g. bus priority lanes) or the imposition of punitive measures such as congestion charging (Emmerink, Nijkamp \& Rietveld, 1995; Steg, 2003; Stern, 1992; Tisato \& Robinson, 1999). Effective persuasion interventions depend upon accurate modelling of modifiable psychological antecedents of car use (Bartholomew, Parcel, Kok \& Gottlieb, 2006).

\subsubsection{The theory of planned behaviour}

The most widely applied model of modifiable cognitive antecedents of travel mode choice is Ajzen's (1991) Theory of Planned Behaviour (TPB; Bamberg, Ajzen \& Schmidt, 2003; Bamberg \& Schmidt, 1999, 2003; Forward, 2004; Harland, Staats \& Wilke, 1999; Heath \& Gifford, 2002; Kaiser \& Gutscher, 2003; Verplanken, Aarts, van Knippenberg \& Moonen, 1998). As summarised earlier (e.g. chapter 3, pp.39-40), the theory posits that behaviour is most closely determined by intention and perceived control over action (perceived behavioural control; $\mathrm{PBC}$ ). $\mathrm{PBC}$ also predicts intention because we do not usually intend to do things we think we cannot. Intention is also determined by attitudes, which measure evaluations of the perceived outcomes of the behaviour in question (e.g., car use), and subjective norms, which refer to perceived social approval of significant others for the behaviour (Ajzen, 1991). The theory has been well supported as a model of cognitive antecedents of car use, typically explaining $50-60 \%$ of variance in driving intentions and $40-60 \%$ variance in car use (Bamberg, Ajzen \& Schmidt, 2003; Bamberg \& Schmidt, 2003; Forward, 2004); for example, Bamberg and Schmidt (1999) reported that TPB cognitions accounted for $68 \%$ and $70 \%$ of variance in intentions to commute by car and car commuting respectively. However, the theory is not exhaustive and Ajzen (1991) has invited augmentation cognitions where predictive utility can be enhanced.

\subsubsection{Environmental considerations and personal moral norms}

In exploring beliefs which may underpin attitudes and intention, transport researchers have tended to focus on personally beneficial outcomes relating to perceived monetary costs, journey times, and flexibility (e.g. Bamberg \& Schmidt, 1999), but transport users may also be motivated by concerns for environmental conservation (e.g. van Vugt, Meertens \& van Lange, 1995). Indeed a number of studies suggest that environmental beliefs may influence travel mode decisions (e.g. Loukopoulos \& Gärling, 2005; Nilsson \& Küller, 2000; Steg \& Sievers, 2000; Tanner, 
1999), and several types of environmental cognition have been measured:

environmental problem awareness (Nilsson \& Küller, 2000; Steg \& Vlek, 1997); consideration of environmental problems (cf. Collins \& Chambers, 2005); concern for the environment (Polk, 2003); perceived severity of the environmental problem (Tanner, 1999); perceived threats of environmental damage to the individual, society, and/or the biosphere (Baldassare \& Katz, 1992; Collins \& Chambers, 2005; Tanner, 1999); perceived utility of car use reduction for lessening the environmental problem (Steg \& Sievers, 2000); and belief in one's ability to exert influence over the problem through transport decisions (Tanner, 1999).

Klöckner and Matthies (2004) suggest that environmental beliefs arouse a perceived moral obligation to perform pro-environment actions (Schwartz, 1977), and, consequently, impact on intentions through personal moral norms (cf. Bamberg \& Schmidt, 2003; Hunecke, Blöbaum, Matthies \& Höger, 2001), which have been shown to contribute variance in travel mode choice over and above TPB cognitions (Harland et al., 1999). However, the TPB predicts that concerns about the environment should contribute to general attitudes towards driving which represent evaluations of overall outcomes. Relationships between environmental concerns, personal moral norms and attitudes have not been adequately researched in relation to driving ${ }^{23}$ and further work needs to clarify how these additional constructs should be used in combination with the TPB.

\subsubsection{Descriptive norms}

In a revised version of the TPB, Ajzen and Fishbein (2005) have included descriptive norms (Cialdini, Kallgren \& Reno, 1991), i.e. the perception that others are engaging in the behaviour (e.g., car use). Descriptive norms are potentially important determinants of driving (e.g. Garvill, 1999). For example, Steg $(2004,2005)$ reported that a measure of descriptive norms relating to perceptions of driving among friends, family and colleagues correlated .40 with self-reported car commuting. Similarly, Kaiser and Gutscher (2003) observed that a measure of descriptive norms relating to refraining from driving in the local city centre correlated .42 with intentions to refrain from driving in the centre, and -.36 with reported city centre car use (F.G. Kaiser,

\footnotetext{
${ }^{23}$ The systematic search for studies modelling car use intentions and/or behaviour described in chapter 4 (p.69) identified only one study (Bamberg \& Schmidt, 2003) which measured TPB variables, personal norms and environmental concerns in relation to car use. However, the parameters in Bamberg and Schmidt's predictive model appear to have been fixed such that attitudes were perfectly correlated with beliefs relating to speed, comfort, stress and flexibility, and so it was statistically impossible for environmental concerns to contribute unique variance to the explanation of attitudes within their model.
} 
personal communication, $17^{\text {th }}$ November 2006). Again however, no published study to date has incorporated descriptive norms into a TPB model of car use (but see Heath \& Gifford, 2002, for an application to bus use).

\subsubsection{Cognitions towards non-car use}

As argued in chapter 1 (pp.11-12), behavioural decisions often entail selection amongst several competing alternative goal-directed options (Sheppard, Hartwick \& Warshaw, 1988). Travel decisions are usually motivated by journey needs (see chapter 2; but see too Ory \& Mokhtarian, 2005), and hence non-car transport options represent behavioural alternatives. Real-world transport decisions are likely to be informed by choice between available options (Abraham \& Sheeran, 2003), but conventional TPB operationalisations focus only on the attractiveness of one particular behavioural option and so may fail to capture the process of selection between alternatives (Ajzen, 2006; Conner \& Sparks, 1996; Fishbein \& Ajzen, 1975). Taking account of beliefs about alternatives may therefore enhance the predictive utility of the TPB. For example, Mann (2004) found that a TPB model of public transport use intentions was significantly enhanced by a measure of PBC over car use. Furthermore, attitudes, subjective norms, and $\mathrm{PBC}$ relating to not driving tend to yield stronger correlations with driving intentions and behaviour than do cognitions focused on car use (Forward, 2004; Gärling, Fujii \& Boe, 2001; Garvill, Marell \& Nordlund, 2003; Harland et al., 1999; Kaiser \& Gutscher, 2003; Matthies, Klöckner \& Preißner, 2006; Nilsson \& Küller, 2000; Staats, Harland \& Wilke, 2004; Verplanken et al., 1998). However, no published evidence is available to assess the relative contributions of TPB cognitions relating to car use and to non-car transport.

\subsubsection{The present study}

Building on the evidence that the TPB provides a useful model of car use, this study sought to explore whether three groups of additional measures could enhance the capacity of the model to predict driving. These were measures of (i) environmental concern and control, (ii) descriptive and personal norms concerning transport mode choice and (ii) attitudes, norms and PBC focusing on non-car transport modes. Hence we tested four hypotheses. Note that we use the word "predict" below in a statistical sense to indicate relationships between dependent and independent variables. 
Hypothesis 1: Following from TPB predictions, we anticipate that (a) intention and car use PBC will predict car use and (b) car use PBC, attitudes and subjective norm will predict intentions to drive.

Hypothesis 2: Attitudes, subjective norms, and PBC towards not using a car to travel will predict intentions to drive over and above car use TPB cognitions.

Hypothesis 3: Personal moral norms and descriptive norms will predict intention over and above attitudes, subjective norms, and PBC.

Hypothesis 4: Environmental considerations (problem awareness, environmental concern, efficacy for reduction of the environmental problem) will predict car and noncar use attitudes, and personal norms.

\subsection{Method}

A cross sectional survey was employed to explore these relationships because car use behaviour has been shown to be stable over time. For example, Bamberg, Ajzen and Schmidt (2003) found that self-reported car use measures taken one year apart correlated at .72, and Mann (2004) observed that proportions of car use over one week correlated .87 with the same measure taken one week later. Thus, in the absence of intervention, we would expect cross-sectional and prospective "prediction" of driving to yield near-identical results.

\subsubsection{Procedure and participants}

Car drivers living in a small UK city were recruited. The city has an excellent public transport infrastructure: bus services are frequent, with some routes operating 24 hours; eight train stations offer good suburban links; and extensive cycle lanes provide safe routes throughout much of the city. Thus non-car transport represented a feasible alternative for participants' intra-city journeys. Questionnaires were sent with a prepaid addressed envelope by post to car drivers invited to participate in a travel feedback intervention programme. This yielded 85 responses. The same questionnaire was also posted on a website and a hyperlink emailed to staff and students at a local university. This yielded 105 participants who were current drivers. All participants were entered into a $£ 50$ prize draw. 
Overall, 190 participants (115 females, 73 males, 2 of unspecified gender) were entered into the analysis. Participants' age ranged from 18 to 86 years $(M=36.89$ years, $S D=18.21$ ). A power analysis with a significance criterion of .05 , presupposing medium effect sizes for a maximum of 11 potential predictors indicated that a sample of 123 participants would yield an 80\% chance of detecting real effects (Cohen, 1992; Faul \& Erdfelder, 1992).

\subsubsection{Measures}

Car use was measured using the mean of 2 items ('In the last week, how many of your journeys within Brighton and Hove were made using: a) a car [including taxis]; b) other transport modes [e.g. bus, train, bike, walking]?' [All journeys; Most journeys; Some journeys; Few journeys; No journeys]; $r=-.80, p<.001$ ), with the second item recoded, so that values on this variable reflected the proportion of car to non-car use. Values of $>0.5$ indicate greater proportions of car use while values of $<0.5$ indicate greater non-car transport mode use.

Unless otherwise stated, cognition measures employed seven-point response options on which participants marked their agreement with provided statements ('strongly agree' to 'strongly disagree') and were coded so that high scores indicated stronger reporting of the measured cognition. Items were designed in accordance with TPB questionnaire conventions (e.g. Ajzen, 2006; Conner \& Sparks, 1996, 2005), or derived from reliable operationalisations in past travel mode research (e.g., Bamberg, Ajzen \& Schmidt, 2003; Bamberg, Rölle \& Weber, 2003; Collins \& Chambers, 2005; Nilsson \& Küller, 2000; Verplanken et al., 1998).

Intention to use a car was measured using four items ('Next week, I intend to use a car for most of my journeys within Brighton and Hove'; 'I plan to use a car to make most of my journeys within Brighton and Hove next week', 'Next week, I intend to make most of my journeys within Brighton and Hove without using my car' [reverse-coded]; 'I plan to make most of my journeys within Brighton and Hove next week without using my car' [reverse-coded]; Cronbach's alpha $[\alpha]=.91$ ).

Attitude towards using a car and attitude towards using non-car modes were both measured using 2 items following the stem: 'Making most of my journeys within Brighton and Hove next week [by car/without using my car] would be': (very bad-very good; very unattractive-very attractive; $\alpha[$ car $]=.74 ; r=.58, p<.001 ; \alpha$ [non-car $]=.77$; $r=62, p<.001)$. 
Perceived behavioural control (PBC) over car use and non-car use were each measured using 2 items (e.g., 'I am able to control whether I use a car for most of my journeys in Brighton and Hove next week', 'I have no control over whether I use a car for most of my journeys in Brighton and Hove next week' $[\alpha=.64 ; r=.47, p<.001]$; 'I am able to control whether I make most of my journeys in Brighton and Hove next week without using a car'; $[\alpha=.75 ; r=.61, p<.001])$.

Subjective norms relating to car use and subjective norms relating to non-car use were measured using matched single items (i.e., 'If I use a car for most of my journeys within Brighton and Hove in the next week, most people who are important to me would approve'; 'If I make most of my journeys within Brighton and Hove in the next week without using a car, most people who are important to me would approve').

Descriptive norm for car use was measured using 2 items ('Most people who are important to me use a car for most of their journeys within the city'; 'How do the people that are important to you make most of their journeys within the city? [Others never use a car-others always use a car]'; $\alpha=.83 ; r=.70, p<.001)$. Descriptive norm for non-car use was not measured because it was assumed that the perception that others mostly use cars was equivalent to the belief that others mostly do not use non-car transports.

Personal norm for non-car use was measured using 3 items (e.g. 'No matter what other people do, I feel it is right to use my car as little as possible'; $\alpha=.76$ ). Personal norms for car use were not measured because personal norms are morally guided (Schwartz, 1977) and, unlike non-car travel, car use is unlikely to be undertaken for moral purposes.

Environmental problem awareness was measured using 2 items ('Car use causes environmental problems'; 'Cars are bad for the environment'; $\alpha=.71 ; r=.54$, $p<.001)$.

Environmental concern was measured using 2 items ('I am concerned about problems such as air pollution, noise and energy use'; 'I am worried about environmental problems such as air pollution, noise and energy use'; $\alpha=.79 ; r=.65$, $p<.001)$.

Perceived control over (car-related) environmental problem reduction (PCE) was measured using 2 items ('Through my transport decisions, I can make a difference to the environment'; 'How I choose to travel does not affect the environment'; $\alpha=.71$; $r=.55, p<.001)$. 


\subsection{Results}

\subsubsection{Sample homogeneity}

Participants in the postal group reported more car use $(M=3.57, S D=1.18)$ than did the internet-based group $(M=3.10, S D=1.26 ; t[186]=2.62, p=.01)$, and group differences were observed on five other study variables (intention, car PBC, noncar PBC, car subjective norm, descriptive norm). These group differences were largely attributable to age differences: participants recruited by post were significantly older (range 22-86 years, $M=52.48$ years, $S D=15.10$ ) than participants recruited online (range 18-70 years, $M=24.42$ years, $S D=8.03 ; t[119.94]=16.37, p<.001$ ). Dividing the combined dataset at the median age (30 years) achieved homogeneity within each age subset, leaving few differences between recruitment groups. Within the belowmedian age group, participants recruited by post perceived marginally greater pro-car subjective norms $(t[90]=2.01, p=.048)$ and somewhat lower descriptive norms $(t[92]$ $=-2.16, p=.033$ ) than did participants recruited by email. Overall, however, the two groups were homogenous across measures, controlling for age.

\subsubsection{Descriptive statistics and correlations}

Table 5.1 shows that mean scores fell around the midpoint for most variables. Participants used cars more than non-car modes for their journeys $(M=0.58)$, but also held strong pro-environmental views (all $M \mathrm{~s}>5.45$ ). With the exception of PBC (car use PBC: $M=4.84$; non-car use PBC: $M=4.80$ ), mean TPB cognition scores were more favourable towards non-car use (attitude: $M=4.50$; subjective norm: $M=4.59$ ) than car use (attitude: $M=3.94$; subjective norm: $M=4.06$ ).

Table 5.1 also shows that most variables significantly correlated with car use intentions in the expected direction. Intention to drive was the strongest correlate of car use $(r=.76, p<.001)$. Car use PBC was unexpectedly negatively correlated with car use $(r=-.33, p<.001)$ and intention $(r=-.37, p<.001)$. Car use and non-car use PBC were highly positively correlated $(r=.76, p<.001)$. A principal component analysis extracted a single factor that explained $68.13 \%$ of variance in the four PBC questionnaire items, and onto which each item loaded highly (minimum item loading $=.72$ ). Both car and non-car use PBC measures were therefore likely to have been underpinned by a single latent variable relating to perceived transport choice. Descriptive norms for car use were also unexpectedly negatively associated with behaviour $(r=-.24, p=.001)$ and intention $(r=-.28, p<.001)$. 
Table 5.1. Intercorrelations and descriptive statistics.

\begin{tabular}{|c|c|c|c|c|c|c|c|c|c|c|c|c|c|c|c|c|}
\hline & 1. & 2. & 4. & 5. & 6. & 7. & 8. & 9. & 10. & 11. & 12. & 13. & 14. & $N$ & Mean & $S D$ \\
\hline 1. Car use & & $.76 * * *$ & $-.33 * * *-.30 * * *$ & *.32*** & $-.46 * * *$ & $* .12$ & $-.22 * *$ & $-.24 * *$ & $-.41 * * *$ & $*-.19 * *$ & $-.24 * *$ & $-.15^{*}$ & $.24 * *$ & 188 & 0.58 & 0.29 \\
\hline 2. Intention to drive & & & $-.37 * * *-.35 * * *$ & *.43*** & $-.56 * * *$ & $* .21^{* *}$ & $-.41 * * *$ & $*-.28 * * *$ & $*-.49 * * *$ & $*-.21 * *$ & $-.29 * *$ & $-.21 * *$ & .12 & 190 & 4.04 & 1.91 \\
\hline 3. Car use PBC & & & $.76^{* * * *}$ & $-.15^{*}$ & $.16^{*}$ & $-.17 *$ & $.15^{*}$ & .06 & .07 & .12 & .09 & .12 & -.14 & 190 & 4.84 & 1.75 \\
\hline 4. Non-car use PBC & & & & $-.19 *$ & $.16^{*}$ & -.01 & $.17^{*}$ & .10 & .01 & .07 & .10 & .09 & -.11 & 190 & 4.80 & 1.81 \\
\hline 5. Car use attitude & & & & & $-.46 * * *$ & $* .22 * *$ & $-.29 * * *$ & $*-.16 *$ & $-.38 * * *$ & $*-.21 * *$ & $-.17 *$ & $-.22 * *$ & .07 & 187 & 3.94 & 1.56 \\
\hline 6. Non-car use attitude & & & & & & -.12 & $.43 * * *$ & $.21 * *$ & $.55^{* * * *}$ & $.30 * * *$ & $.30 * * *$ & $.35^{* * *}$ & -.02 & 188 & 4.50 & 1.66 \\
\hline 7. Car use subjective norm & & & & & & & -.03 & -.12 & -.14 & -.11 & -.12 & $-.17 *$ & $.15^{*}$ & 188 & 4.06 & 1.65 \\
\hline 8. Non-car use subjective norm & & & & & & & & $.16^{*}$ & $.32 * * *$ & $.28 * * *$ & $.27 * * *$ & $.28 * * *$ & .00 & 189 & 4.59 & 1.81 \\
\hline $\begin{array}{l}\text { 9. Descriptive norm } \\
\text { for car use }\end{array}$ & & & & & & & & & $.21 * *$ & .07 & .11 & .10 & $-.23 * *$ & 190 & 3.97 & 1.81 \\
\hline $\begin{array}{l}\text { 10. Personal norm } \\
\text { for non-car use }\end{array}$ & & & & & & & & & & $.45 * * *$ & $.42 * * *$ & $.47 * * *$ & .02 & 189 & 4.66 & 1.50 \\
\hline 11. Environmental concern & & & & & & & & & & & $.51 * * *$ & $.49 * * *$ & .09 & 189 & 5.94 & 1.16 \\
\hline 12. Problem awareness & & & & & & & & & & & & $.60 * * *$ & $-.17 *$ & 189 & 5.98 & 1.19 \\
\hline 13. PCE & & & & & & & & & & & & & -.02 & 190 & 5.48 & 1.32 \\
\hline 14. Age & & & & & & & & & & & & & & 189 & 36.89 & 18.21 \\
\hline
\end{tabular}

$*=p<.05, * *=p<.01, * * *=p<.001$

$\mathrm{PBC}=$ Perceived behavioural control. $\mathrm{PCE}=$ Perceived control over environmental problem reduction 


\subsubsection{Modelling car use: A path analysis}

A series of hierarchical multiple regressions were conducted, entering only significant correlates to explore associations between variables. Structural equation modelling was not employed due to power problems associated with the relatively small sample size. Non-car PBC was excluded from all analyses due to collinearity with car use PBC.

In the first regression analysis, car use was the dependent variable with age entered first, as a covariate, followed by intention and car use PBC in a second step. Controlling for age and intention, car use PBC was not a significant predictor of car use $(\beta=-.05, p=.30)$. Age $(\beta=.15, p=.002)$ and intention $(\beta=.75, p<.001)$ explained $61 \%$ of variance in behaviour (Model $F[2,184]=147.90, p<.001$ ), with intention explaining $56 \%(\Delta F[1,184]=268.46, p<.001)$, providing mixed support for hypothesis 1a.

Potential moderators of the age-car use and intention-car use relationships were explored by calculating multiplicative interaction terms from means-centred scores on each predictor variable and each of the ten remaining cognition measures. For each potential moderator, a two-step regression was run entering firstly the predictor and potential moderator, and secondly the corresponding interaction term. Interaction terms found to contribute significant unique variance in behaviour were then entered into a separate regression of behaviour with age and intention entered at the first step and the interaction variable at the second step, but no interaction term was found to explain additional variance over and above effects of age and intention. Hence, no moderators of the age-car use and intention-car use relationships were identified.

In a second regression, intention was regressed firstly on car use PBC, attitudes and subjective norm, followed by matched variables relating to non-car use in a second step. Personal and descriptive norms were added in the third step, and environmental variables (environmental concern, problem awareness, and PCE) in a fourth step. Age was not co-varied because it did not correlate with intention. Each step resulted in a significant increment in explained variance. The procedure was rerun excluding variables that failed to account for independent significant proportions of variance (i.e., car use subjective norm, problem awareness, environmental concern). Results are shown in table 5.2. Lower car use PBC and positive car use attitudes predicted $28 \%$ of the variance in intentions to drive but car 
Table 5.2. Trimmed regression of intention including interaction terms $(N=187)$

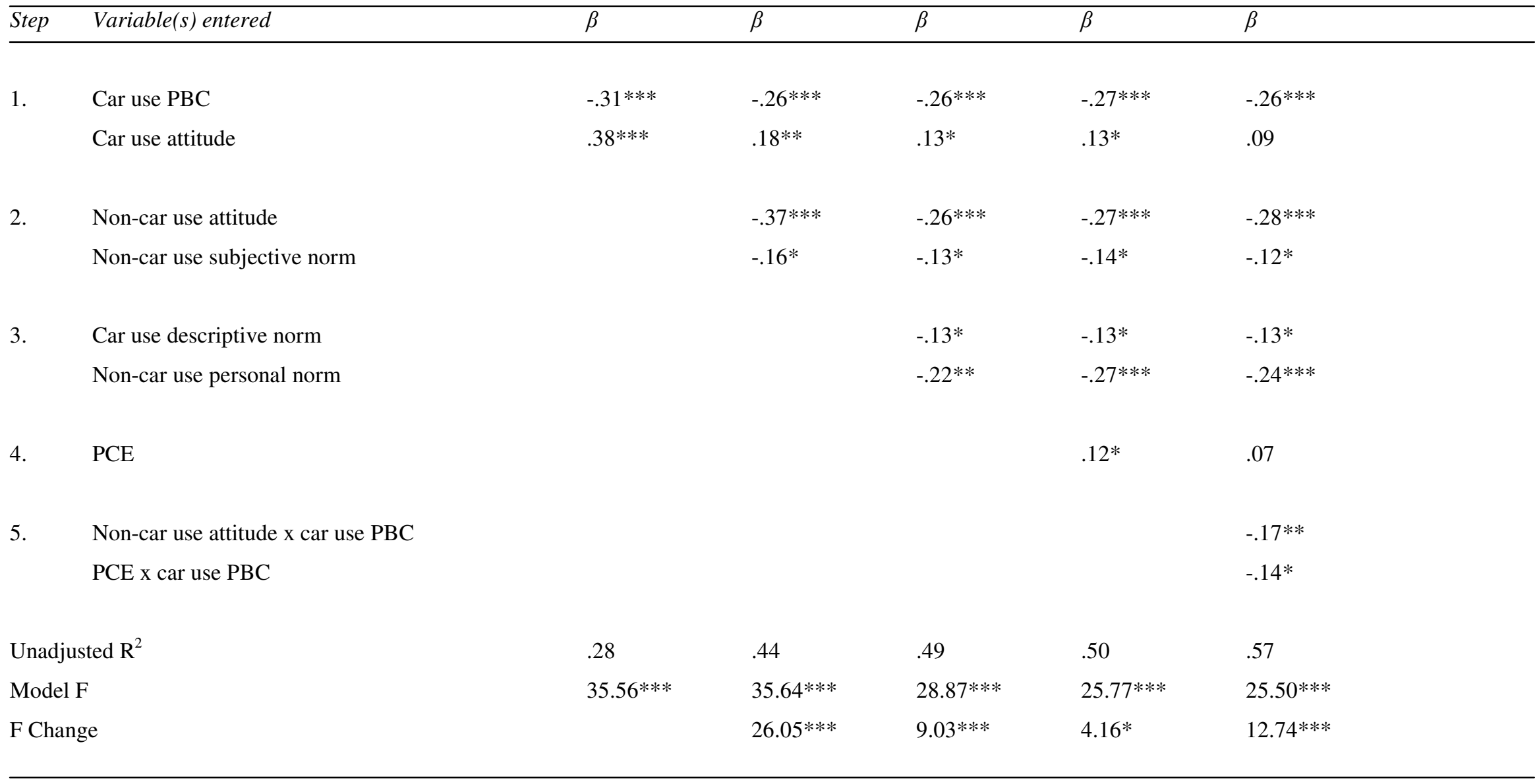

$* p<.05, * * p<.01, * * * p<.001 . \mathrm{PBC}=$ Perceived behavioural control; PCE = Perceived control over environmental problem reduction 
use subjective norm did not add to explained variance. These findings partially support hypothesis $1 b$.

The addition of non-car use cognitions at the second step resulted in a $16 \%$ increment in explained variance $\left(\Delta R^{2}=.16, \Delta F=26.05, p<.001\right)$ with non-car use attitude and subjective norm measures significantly adding to the variance explained (with lower scores predicting greater intentions to travel by car), thereby supporting hypothesis 2 . It is worth noting that when this analysis was re-run using an intention measure comprising only items related to car use, the addition of non-car cognitions continued to contribute significantly to the predictive utility of the model over and above car use cognitions $\left(\Delta R^{2}=.11, \Delta F=15.41, p<.001\right)$.

Personal and descriptive norm measures explained a further $5 \%$ of the variance in intention $\left(\Delta R^{2}=.05, \Delta F=9.03, p<.001\right)$. Hypothesis 3 was therefore supported, but the direction of the descriptive norm effect was unexpectedly negative: participants were less motivated to travel by car where others were also expected to drive, perhaps due to expected congestion problems (see van Vugt et al., 1995).

By way of exploratory post hoc analyses environmental problem awareness, environmental concern and PCE were added in a fourth step. Only PCE added significantly to the variance explained, contributing a further $1 \%\left(\Delta R^{2}=.01, \Delta F=\right.$ 4.16, $p=.04)$.

Potential moderators of relationships between intention and each of its determinants were explored. For each such relationship, interactions between the predictor variable and each of the remaining ten pre-intention cognitions were calculated. A series of two-step regressions were run entering the predictor and potential moderator variable at the first step and the interaction term at the second step. Eleven unique moderators were found in total, but only two of these significantly increased the model of intentions achieved at step 4 in table 5.2. These two interaction terms increased the variance explained in intention by $6 \%$ as is shown in table $5.2\left(\Delta R^{2}=.06, \Delta F=12.74, p<.001\right)$, but the direct effect of PCE was reduced to non-significance $(\beta=.08, p=.19)$. Overall then, the model explained $57 \%$ of variance in intention (Model $F[9,177]=25.50, p<.001)$. Non-car attitude $(\beta=-.28$, $p<.001)$, car use $\operatorname{PBC}(\beta=-.26, p<.001)$, and personal norm $(\beta=-.24, p<.001)$ were the strongest predictors with additional effects of car use descriptive norm $(\beta=-.13$, $p=.01)$ and interactions between non-car attitude and car use $\operatorname{PBC}(\beta=-.17, p=.002)$, and PCE and car use PBC ( $\beta=-.14, p=.01)$. 
The two interaction terms which improved the model of car use intention were decomposed using simple slopes analyses (Aiken \& West, 1991; Cohen, Cohen, West, \& Aiken, 2003). As figure 5.1 shows, for participants whose attitudes towards non-car use were negative (i.e., low scores), perceived control over car use had no effect on intentions to travel by $\operatorname{car}(\beta=-.02, p=.76)$, i.e., they intended to travel by car regardless of their perceptions of control over driving. Conversely, for those holding more positive attitudes towards non-car use (medium and high scores), car PBC was related to intentions to travel by car (medium score $\beta=-.31, p<.001$; high score $\beta=-.59, p<.001)$. Participants who held positive attitudes towards non-car transport modes intended to travel by car if they felt they had no control over their transport choice, but where they felt they had control over this choice their intentions to travel by car were much lower. Similarly, figure 5.2 shows that those participants who felt unable to reduce car-related environmental problems intended to drive irrespective of their perceptions of control over driving $(\beta=-.06, p=.55)$. However, participants who felt more able to make a personal impact on detrimental environmental effects of car use were less likely to intend to drive if they felt they had control over choosing to travel by $\operatorname{car}(\beta=-.56, p<.001)$.

Figure 5.1. Non-car use attitude as moderator of car use PBC-intention relation

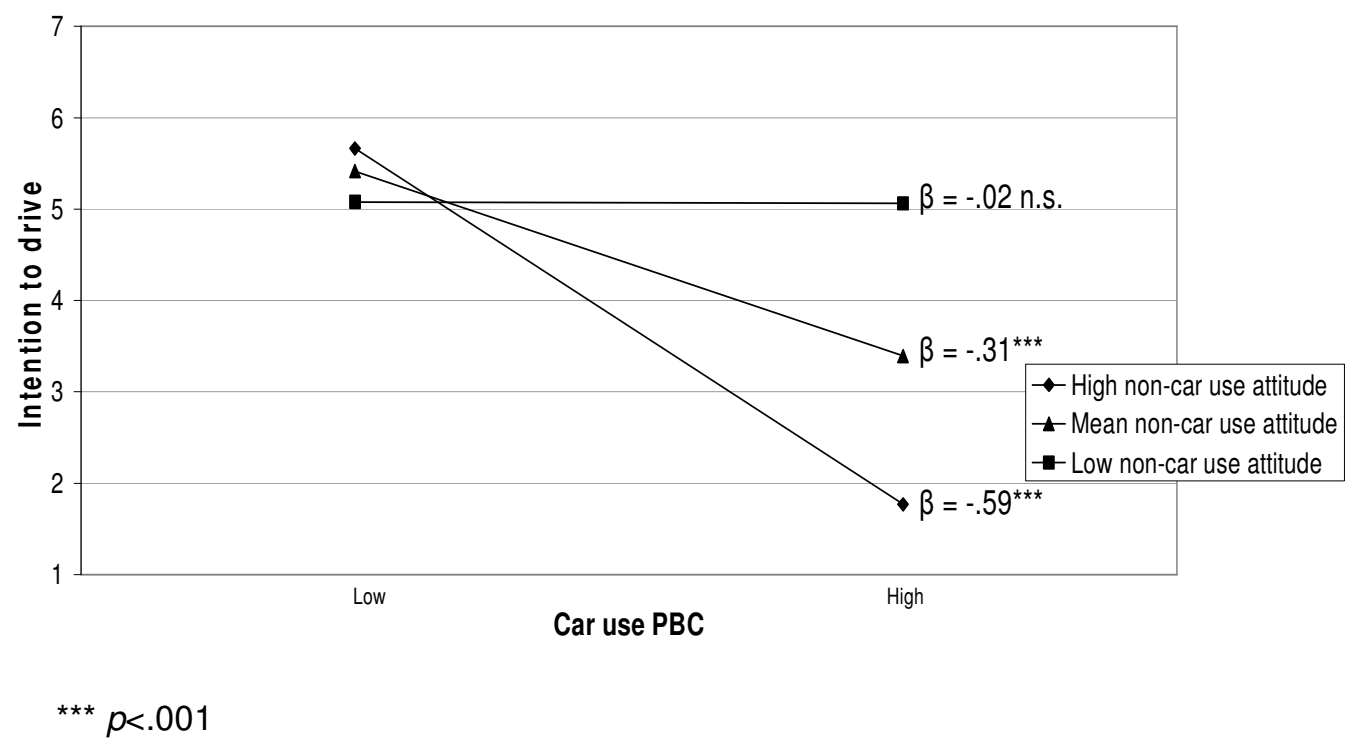


Figure 5.2. PCE as moderator of car use PBC-intention relation

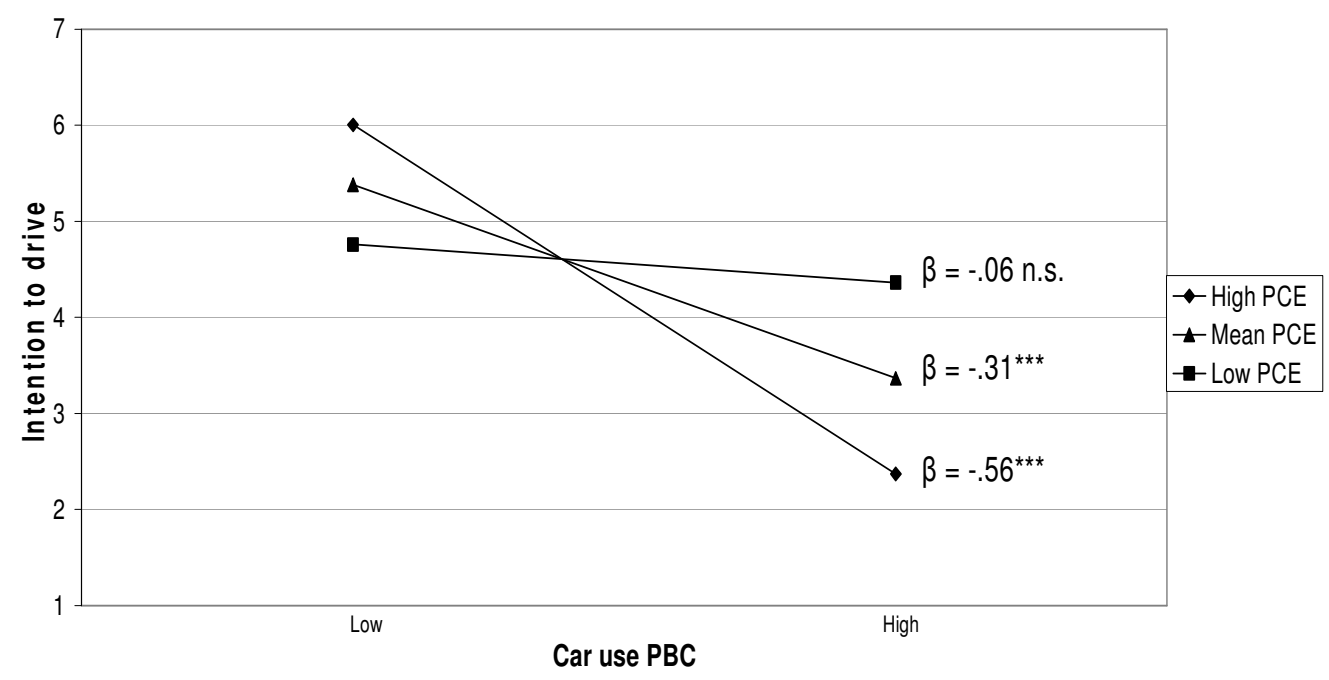

${ }^{* * *} p<.001$

In a third regression analysis car use attitude was regressed onto the three environmental cognitions (problem awareness, environmental concern and PCE). None of these explained significant variance in car use attitudes. By contrast, when non-car use attitude was regressed onto the same three variables, $\operatorname{PCE}(\beta=.22$, $p=.01$ ) was significantly predictive, and there was a marginal effect of environmental concern $(\beta=.14, p=.09)$. A trimmed regression showed that these two measures explained $14.2 \%$ of the variance in non-car use (Model $F[2,185]=15.35, p<.001)$, with both environmental concern $(\beta=.27, p=.001)$ and $\operatorname{PCE}(\beta=.17, p=.03)$ significantly contributing to the final equation.

In a fourth regression analysis personal norm was also regressed onto the three pro-environment cognitions. Environmental concern and PCE were significant predictors, but problem awareness was not $\left(R^{2}=.28\right.$, Model $F[2,186]=36.71$, $p<.001)$. Within this two-variable model, $\operatorname{PCE}(\beta=.34, p<.001)$ was a stronger predictor than environmental concern $(\beta=.28, p<.001)$. Thus environmental cognitions influenced intentions via personal norm and non-car use attitudes, but had little effect on attitudes to car use. Thus hypothesis 4 was partly supported. Figure 5.3 shows the path model constructed on the basis of the four trimmed hierarchical regression analyses. Participants were, unsurprisingly, more likely to 
have travelled by car over the past week if they intended to do so and were older. Participants were more likely to intend to travel by car if they: perceived less control over car use; held negative attitudes towards non-car use; experienced less social pressure not to drive; perceived non-car use to be a normative behaviour among significant others; and held a personal norm for non-car use. The car use PBCintention relationship was moderated by non-car use attitudes and perceived efficacy for reducing car-related environmental problems. Non-car use attitudes and personal norm were each informed by perceived control over environmental problem reduction and environmental concern.

\subsection{Discussion}

The present study offered the first TPB-based model of car use to include both cognitions relating to driving and those relating to alternative transport, as well as environment-related beliefs. The study focused on local car journeys among residents living in a city with excellent non-car transport facilities, and thus produced a model of motivations to drive where high-quality alternative transport is available. Unsurprisingly, intention to drive was the strongest proximal determinant of car use. Intention was in turn predicted by PBC and descriptive norms for car use, and attitudes, subjective norms and personal norms for non-car use. Findings support both the predictive utility of the TPB in this domain (Bamberg \& Schmidt, 1999, 2003) and the value of the TPB as a conceptual foundation for behaviour-specific predictive models.

In addition our study provided a rare illustration of motivational influences on driving based on perceptions both of driving and of non-car travel. Cognitions towards non-car transport contributed to the explanation of car use intentions and behaviour after controlling for cognitions surrounding car use, demonstrating that measures of beliefs towards driving may not sufficiently encompass perceptions of transport alternatives (Abraham \& Sheeran, 2003; Fishbein \& Ajzen, 1975). Non-car use cognitions tended to play the greater role in predicting driving: intentions to drive were most strongly predicted by attitudes towards non-car use, and while non-car use subjective norm had effects on intention, car use attitudes and subjective norms did not. Rather than seeking to decrease the appeal of driving, driving reduction campaigns might therefore address the perceived unattractiveness of alternative transport. The role of non-car use attitudes may offer considerable potential in this 
Figure 5.3: Path model with standardised regression coefficients and explained variances

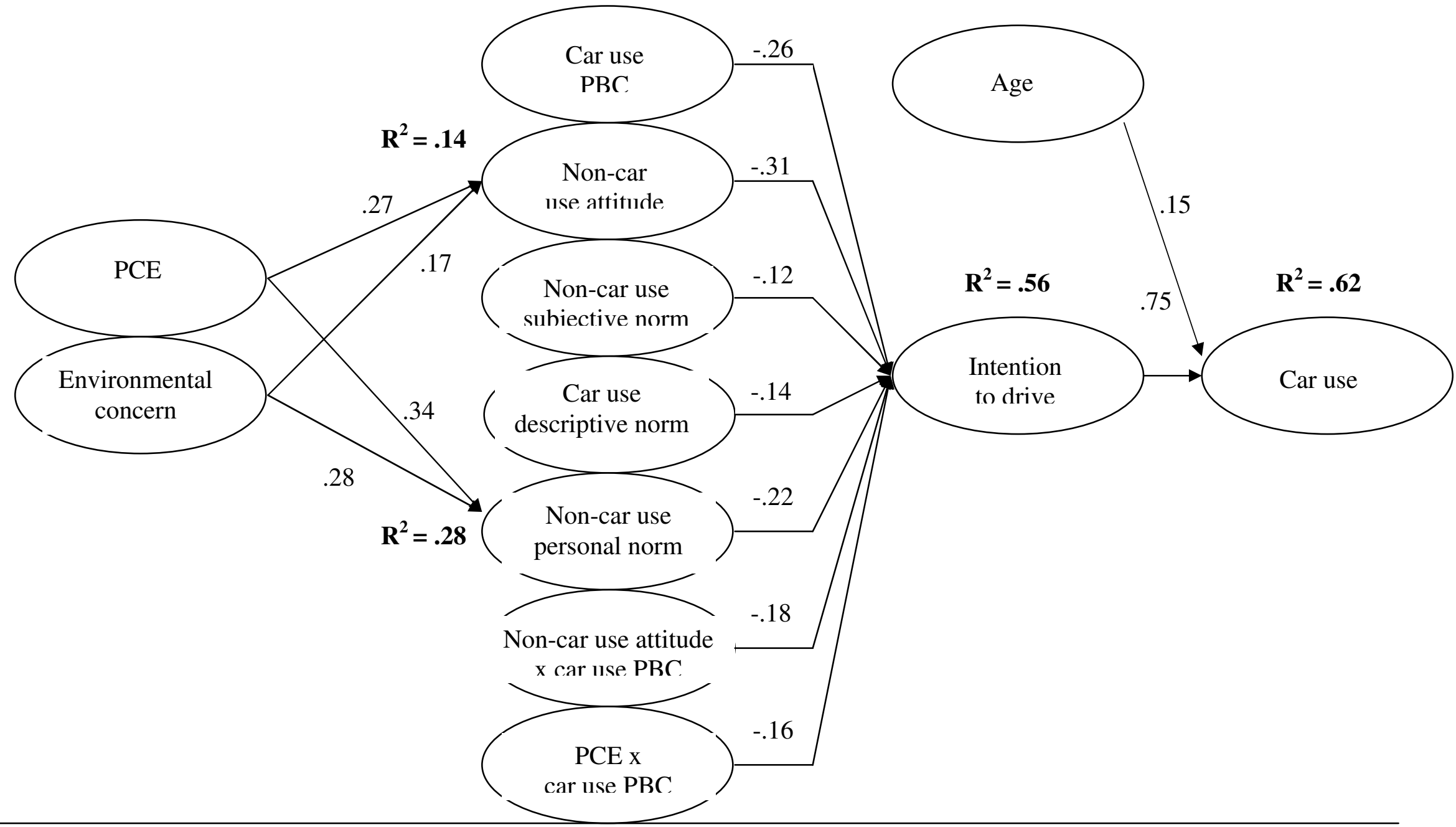

All paths significant at $p<.05 . \mathrm{PBC}=$ Perceived behavioural control; $\mathrm{PCE}=$ Perceived control over environmental problem reduction. 
regard, because drivers often hold misconceptions regarding non-car travel (see chapter 2), tending for example to overestimate public transport times (Fujii \& Kitamura, 2003).

The strong effect of personal moral norms on intention concurs with previous suggestions that car use has a moral dimension not captured by utility-based cognitions (Harland et al., 1999; Klöckner \& Matthies, 2004; Matthies et al., 2006; but see also Bamberg \& Schmidt, 2003). Our results also echo previous findings that driving is seen as morally relevant where individuals are concerned about its ecological consequences (Klöckner \& Matthies, 2004; Matthies et al., 2006; Taniguchi, Hara, Takano, Kagaya, $\&$ Fujii, 2003). We found no effects of problem awareness on personal norm, but this may be due to conceptual overlap between environmental cognition measures: problem awareness was strongly correlated with PCE, and indeed post-hoc analyses revealed that substituting problem awareness for PCE in regressions of non-car attitude and personal norm resulted in significant effects for problem awareness, although in both instances, explained variance was reduced. Thus, emphasising the environmental impact of car use and persuading drivers to acknowledge their control over remedial action may best enhance perceived moral obligations to use less polluting transport.

Concern for the environment and PCE also influenced non-car use attitudes, but only $14 \%$ of variance in non-car attitude scores was explained, and so these beliefs are likely to compete with other perceptions in the formation of attitudes towards non-car transports. Previous research suggests transport mode attitudes are typically informed by utility-based beliefs regarding the effectiveness of available modes for meeting personal journey needs (e.g. Bamberg \& Schmidt, 2003; Heath \& Gifford, 2002; van Vugt, van Lange, Meertens, \& Joireman, 1996; see too van Vugt et al., 1995). Changing attitudes towards non-car travel may therefore hinge not only upon promoting ecological benefits, but also the self-oriented consequences of proenvironment transport mode use, such as reduced cognitive effort (Wardman, Hine \& Stradling, 2001) and greater opportunities for relaxation when using public transport (Hiscock, Macintyre, Kearns, \& Ellaway, 2002).

Our results support an extension of the normative component of the TPB, but the effect of car use descriptive norms on intention was surprisingly negative: participants were more likely to intend to drive where they expected others not to drive. This counters research that shows that transport users are more likely to choose travel modes that they believe to be used frequently by others (Heath \& Gifford, 2002). 
However, van Vugt et al. (1995) found that where the majority of other transport users were expected to use public transport, individuals with preferences for positive selforiented outcomes over socially-beneficial consequences were more likely to prefer to drive, so as to benefit from lessened road congestion. Conversely, and more in line with TPB predictions (Ajzen \& Fishbein, 2005), participants with prosocial value orientations tended to choose public transport, due to strengthened perceived moral duty to use public transport where others also chose to do so (van Vugt et al., 1995). Thus, social value orientations might moderate effects of descriptive norms on intentions (van Vugt et al., 1995). Further research is needed to clarify the motivational role of descriptive norms in real-world settings, both in isolation and in light of potential interaction with social value priorities (van Vugt et al., 1996).

Contrary to TPB predictions, car use PBC correlated negatively with intentions and behaviour: participants who felt less able to exert control over their car use choices were more likely to drive. PBC has previously been analysed into self-efficacy (Bandura, 1997) - i.e. confidence in one's ability to initiate behaviour - and perceived controllability (Ajzen, 2002b), which relates to perceived external constraints (Trafimow, Sheeran, Conner \& Finlay, 2002). A single latent variable underpinned car and non-car PBC measures, suggesting that PBC tapped perceptions of the choice and availability of non-car alternatives, addressing controllability rather than self-efficacy for performing the actions required to initiate car use. We were unable to adequately model car use PBC on any other variables, and so the beliefs underpinning participants' control perceptions were unknown. The lack of a direct effect of PBC on behaviour might signify that participants held distorted views of their actual control over travel mode choice, because control perceptions are likely to influence behaviour where they accurately reflects actual control (Ajzen, 1991; Bandura, 1997).

Interpretation of the observed interaction between perceived efficacy for reducing environmental problems and car use $\mathrm{PBC}$ is complicated by the negative correlation found between car use PBC and behaviour. If car use PBC measures tapped perceived choice over travel mode use, the interaction suggests greater perceived choice and enhanced self-efficacy for stemming environmental problems reduced intentions to drive. This might suggest that some car users continue to drive because they feel able to reverse the environmental damage caused by driving at some point in the future. It is not immediately clear however why, when perceived choice was low, 
higher efficacy for tackling environmental detriments should have increased intentions to drive. Further work is needed to probe the robustness of these effects.

Limitations of the present study should be acknowledged. Our cognition measures related to future behaviour and so did not correspond with the behaviour measure, which related to past behaviour (e.g. Ajzen, 2006). However, previous research suggests that travel mode choice is a stable behaviour (Bamberg, Ajzen \& Schmidt, 2003; Mann, 2004), and so although a prospective design would have allowed for observance of the temporal sequence of the TPB, longitudinal data is unlikely to have produced significantly different results.

Our model assumes that motivation is sufficient to guide action (Ajzen, 1991), but intentions may only translate into behaviour 50\% of the time (Sheeran, 2002), because there may be various unanticipated barriers to the transition of travel mode motivations into behaviour (see Fishbein et al., 2001), such as cost and access restraints (Collins \& Chambers, 2005), or habits (Verplanken et al., 1998). However, while best policy practice might require adoption of infrastructural and/or legislative strategies in tandem with persuasive psychological strategies (Fujii, Gärling \& Kitamura, 2001), our data suggest that enhancing motivations to decrease car use in isolation is likely to have a major behavioural impact. In particular our findings highlight the importance of cognitions relating to non-car use alternatives and of pro-environmental cognitions in shifting driving motivations. 


\section{Chapter 6. Studies 5-7: Is travel mode choice an automatic decision? ${ }^{* * * * *}$}

\subsection{Abstract}

Reasoned action approaches to travel mode choice neglect the often habitual nature of transport decisions. A growing literature suggests that travel mode choice is habitual, but research into travel habits has been constrained by the lack of appropriate habit measures. Verplanken and Orbell's (2003) self-report habit index (SRHI) represents the best available measure, but potentially conflates cognitive automaticity with behavioural repetition. This chapter reports three studies. In the first study, a new, reliable selfreport automaticity measure (AM) was developed using data from $56 \mathrm{UK}$ drivers. In two subsequent studies, the AM was tested in relation to car commuting among $107 \mathrm{UK}$ drivers, and bicycle commuting among 102 Dutch participants respectively. In the latter two studies, the AM showed convergent validity with existing habit measures, but failed to moderate the intention-behaviour relationship and so failed to meet theoretical criteria specified for a new measure of habit. Results testified to the superiority of the SRHI as a habit measure, which successfully moderated effects of intention on behaviour even where a modified SRHI was used which omitted behavioural frequency items. Findings demonstrated the strong habitual nature of commuters' mode choices. Theoretical, methodological and practical implications are discussed.

\subsection{Literature review}

Traffic emissions contribute to climate change, fossil fuel consumption (Oskamp, 2000), and cardiovascular and respiratory diseases (Peters et al., 2004), and are primarily attributable to car use (Berntsen, 2004; Department for Transport [DfT], 2006b). Private car use accounts for around $13 \%$ of total $\mathrm{UK} \mathrm{CO}_{2}$ emissions (DfT, $2006 \mathrm{~b}$ ), but $25 \%$ of UK car journeys cover distances of less than 2 miles (Department of the Environment, Transport and the Regions [DETR], 2000), and so in most instances could feasibly be undertaken using alternative transport (Goodwin, 1997).

As previously argued (e.g. chapter 1, pp.2-3), voluntary behaviour change programmes which seek to change drivers' beliefs and attitudes, are less expensive and more publicly acceptable than infrastructural modifications or punitive strategies such as congestion charging (Emmerink, Nijkamp \& Rietveld, 1995; Steg, 2003; Stern, 1992;

\footnotetext{
**** Data from Studies 6 and 7 have been re-analysed and accepted for publication as Gardner, B. (in press) Modelling habit and motivation in stable contexts. Transportation Research Part F.
} 
Tisato \& Robinson, 1999), but developing effective persuasive interventions depends on identifying the modifiable psychological antecedents of car use (Bartholomew, Parcel, Kok \& Gottlieb, 2006; Michie \& Abraham, 2004).

The most widely applied model of modifiable cognitive antecedents of car use is the Theory of Planned Behaviour (TPB; Ajzen, 1991; Bamberg, Ajzen \& Schmidt, 2003; Bamberg \& Schmidt, 1999, 2003; Forward, 2004; Harland, Staats \& Wilke, 1999; Heath \& Gifford, 2002; Kaiser \& Gutscher, 2003; Verplanken, Aarts, van Knippenberg \& Moonen, 1998). As previously outlined (e.g. chapter 1, pp.7-8), the TPB suggests that behaviour is most closely determined by an intention to act. Intention in turn captures attitudes (i.e. evaluation of expected outcomes of the behaviour), subjective norm (perceived social approval of significant others for the action), and perceived behavioural control (PBC; the perceived ease or difficulty of performing the behaviour). Where PBC reflects actual behavioural control, PBC will also have influence behaviour directly, because individuals tend not to perform actions over which they believe they have little control.

The TPB offers a primarily motivational account of behaviour, assuming that intentions and $\mathrm{PBC}$ are sufficient to prompt behaviour, and that car use arises from deliberation over the advantages and disadvantages of choosing to drive versus using alternative transport modes, and an appreciation of the choice situation (e.g. Ajzen, 1991). However, Verplanken and colleagues (e.g. Verplanken, Aarts, van Knippenberg \& van Knippenberg, 1994) point out that this approach ignores the often repetitive nature of travel mode decisions (Aarts, Verplanken \& van Knippenberg, 1998), because frequently repeated decisions lead to behaviour acquiring an automated, habitual component (e.g. Verplanken, 2006), which is not adequately captured by the TPB (Verplanken et al., 1998; but see Bamberg \& Schmidt, 2003).

\subsubsection{Habits in travel mode choice}

Habits may be defined as goal-directed behaviours which have become sufficiently associated with specific cues as to be initiated automatically (Aarts, Verplanken \& van Knippenberg, 1997; Verplanken \& Aarts, 1999; Verplanken, Aarts \& van Knippenberg, 1997). Initially deliberated behavioural choices satisfactorily experienced in attaining a goal create an association between goal and action (or sequence of actions), and repeated decisions, actions and subsequent goal achievement in unchanging decisional contexts strengthen this association (Gärling, Fujii \& Boe, 
2001). Habits are mentally represented as behavioural scripts (Gärling et al., 2001), which, upon activation of an appropriate goal, guide behaviour automatically (Aarts \& Dijksterhuis, 2000b). Automated decisions are cognitively economical, being characterised by an absence of conscious deliberation (Bargh, 1994, 1996). Thus, Triandis (1977) suggested that the relationship between habit and conscious motivations in predicting behaviour is inversely proportional: while intentions inform behaviour where habit is weak, stronger habits disrupt the transition of intention into action (Verplanken et al., 1994; Verplanken et al., 1998). Triandis's hypothesis suggests that, where habitual and intentional tendencies conflict, habit will have the greater influence on subsequent behavioural outcomes.

A growing literature suggests that travel decisions are often habitual (e.g. Klöckner, Matthies \& Hunecke, 2003; Verplanken et al., 1994), and commuting mode choice in particular has been highlighted as an archetypal habitual behaviour (e.g. Aarts et al., 1998; Mann, 2004). For example, in line with Triandis's (1977) predictions, Verplanken et al. (1998) found that, among villagers, intentions not to drive to a nearby city were more strongly predictive of travel mode choice where driving habits were weak. Conversely, where participants scored highly on a habit measure, intention had no effect on behaviour (see too Klöckner et al., 2003; Møller \& Thøgersen, 2003; Verplanken et al., 1994).

Research into the cognitive processes underpinning habitual decision-making has highlighted the economical nature of transport decisions where habit is strong (e.g. Aarts \& Dijksterhuis, 2000a; Aarts et al., 1997, 1998; Verplanken et al., 1997). In a laboratory study, Verplanken et al. (1997, study 2) measured participants' bicycle habits, and then presented participants with a hypothetical travel situation in which they were required to journey to a city centre. Participants accessed information relating to various attributes of each available transport option (e.g. travel time, physical effort requirement) before choosing which mode to use. Participants with stronger bicycle habits chose the bicycle more often, but more importantly accessed significantly less information prior to making their decisions than did participants with weak habits, despite the unfamiliarity of the situation. Aarts et al. (1997) and Verplanken et al. (1997, study 3) have also shown that habitual drivers make less reference to demands of the choice situation - e.g. weather conditions, weight of luggage - before making transport mode decisions (see too Gärling et al., 2001). 
Habitual travel decisions involve reduced predecisional information searching and processing (Verplanken et al., 1997), and so pose a considerable challenge to driving reduction campaigns. Drivers with stronger car use habits - who drive more frequently (Ouellette \& Wood, 1998) - are less likely to attend to information-based persuasive campaigns (Aarts et al., 1997; Verplanken et al., 1997). Furthermore, even if habitual drivers can be encouraged to deliberate (see e.g. Aarts et al., 1997; Verplanken et al., 1997) and form car use reduction intentions, habitual tendencies for driving are more likely to influence subsequent behaviour (Møller \& Thøgersen, 2003; Triandis, 1977; Verplanken et al., 1994).

\subsubsection{Habit measurement}

Previous research into travel mode habits has been limited by the lack of an appropriate habit measurement instrument (Ajzen, 2002a). Habit is a form of automaticity (Aarts \& Dijksterhuis, 2000b; Verplanken \& Aarts, 1999), and so may be characterised by mental efficiency, lack of controllability and awareness, and behavioural repetition (Bargh, 1996; Verplanken \& Orbell, 2003). Habit thereby comprises a cognitive (automaticity) and a behavioural component (repeated performance), which are nonetheless interlinked: behavioural repetition informs the development of automaticity, which in turn informs further behavioural repetition (e.g. Gärling et al., 2001).

6.2.2.1. Past behaviour. The suggestion that habits occur outside of awareness led some commentators to reason that habits are inaccessible to conscious thought, and thus that it is difficult to tap habit using direct self-report measures (e.g. Eagly \& Chaiken, 1993). Past behavioural frequency has therefore traditionally been treated as a proxy for habit (Ouellette \& Wood, 1998; Triandis, 1977; Wood, Quinn \& Kashy, 2002).

Expectancy-value models such as the TPB argue that past behaviour has an effect on future behaviour mediated by reasoned cognitions: previous experiences of action enhance attitudes towards and perceptions of control over the behaviour, while also providing information on relevant social norms, and thus make future performance of the behaviour more likely (e.g. Ajzen, 1991, 2002). However, past behaviour often exhibits effects on future behaviour over and above reasoned cognitions (Ouellette \& Wood, 1998), which may indicate the presence of habit (Sutton, 1994). 
Numerous problems surround past behaviour as an indicator of habit. Ajzen (2002a) points out that, in stable decisional contexts, an individual who repeatedly deliberates would display the same behavioural pattern as would an individual who acts habitually. In such instances, even where habits have developed, variables that influence future behaviour (e.g. TPB-specified cognitions) would also have determined past behaviour. Thus, past behaviour represents the unmeasured influence of an unknown number of variables on behaviour, and has no explanatory value, reflecting only behaviour stability (Ajzen, 2002a). Thus, behavioural frequency is a necessary but not a sufficient indicator of habit (Mittal, 1988; Verplanken, 2006; see Verplanken, Myrbakk $\&$ Rudi, 2005). Hence, habit measures must distinguish cognitive aspects of habit - i.e. automaticity - from behavioural frequency (Ronis, Yates \& Kirscht, 1989; Verplanken, 2006).

\subsubsection{Response-frequency measure. Verplanken et al. (1994) devised an indirect} measure of habit, whereby participants are presented with a series of hypothetical travel scenarios where only the destination and purpose of the trip is given. Participants indicate as quickly as possible which mode of transport they would choose to use for each scenario. This measure assumes that habitual responses are more cognitively accessible. Minimal information regarding the demands of each trip diminishes opportunities for deliberation, and the imposition of time pressure seeks to increase the likelihood of eliciting the first (i.e. habitual) response that comes to mind. Habit is indexed by invariance across responses, i.e. the frequency with which a particular transport mode is chosen.

Numerous studies have shown that the response-frequency measure (RFM) meets theoretical criteria for habit by moderating motivation-behaviour relationships (Triandis, 1977; Verplanken et al., 1994; Verplanken et al., 1998), but debate surrounds the validity of the measure. As Ajzen (2002a) notes, RFM scores may represent generalised intentions or preferences as aggregated across specific situations (Fujii \& Gärling, 2003a). Some vignettes (e.g. 'visiting a bar in the evening'; Bamberg, Ajzen \& Schmidt, 2003) may contain sufficient information to prompt deliberative responses (e.g. not driving to allow alcohol consumption), or to prompt participants to respond in line with past behavioural decisions (Ajzen, 2002a). Habits only guide responses in the presence of relevant goals (Aarts \& Dijksterhuis, 2000a), and thus pilot work should ideally be undertaken to select RFM items relevant to the study sample (Verplanken $e t$ 
al., 2005). In addition, the timed nature of the measure makes it ill-suited to selfadministered questionnaire designs (Verplanken et al., 2005; see Bamberg et al., 2003). The RFM can therefore be difficult to administer to large samples.

6.2.2.3. Self-report habit index. Verplanken and Orbell (2003) proposed a 12-item selfreport habit index (SRHI). Items follow a stem ('Behaviour X is something...') and require participants to reflect upon the automatic initiation ('...I do automatically'), lack of awareness ('...I do without thinking'), lack of control ('...that would require effort not to do'), mental efficiency ( '...I have no need to think about doing'), and repetitiveness ('...I do frequently') with which a particular behaviour is performed (Bargh, 1994, 1996). The scale also incorporates self-identity as an aspect of habit ('Behaviour $\mathrm{X}$ is something that's typically “me”). While being a self-report measure, the SRHI can be said to measure habit indirectly in that it focuses on theoreticallystipulated components of habit (Bargh, 1994, 1996) and so does not require participants to report directly on the habitual nature of specified behaviours. Tests of the SRHI have demonstrated its convergent validity with existing habit measures (Verplanken et al., 2005), but to date the scale has not been applied to the prediction of travel mode choice.

The SRHI is an advance within habit theory because it demonstrates that, while people may not be aware of initiation of habitual behaviours, participants' self-reports demonstrate awareness of the automaticity of past actions. Thus, the measurement problem of non-awareness of habitual behaviours may be solved: participants are sufficiently aware when reflecting on their behaviour that they were not aware when they performed the behaviour (cf. Ajzen, 2002a).

While the SRHI demonstrates potential for measuring automaticity via selfreport, the measure also includes items relating to behavioural frequency ('Behaviour X is something...' '...I do frequently'; '...I have been doing for a long time’). Verplanken (Verplanken \& Orbell, 2003; Verplanken et al., 2005; Verplanken, 2006) acknowledges this, but points to the strong reliability of the scale, which regularly achieves strong alpha coefficients (>.90; see Verplanken et al., 2005). However, alphas are partially a function of the number of scale items (Cronbach, 1951), and the unifactorial structure of the scale would be better assessed by principal component analyses. Evidence regarding the factor structure of the scale is equivocal: in a test of the convergent validity of the SRHI in relation to travel mode decisions, Verplanken et al. (2005) found a primarily unidimensional structure underlying car use SRHI items, but a two-factor structure 
emerged for bus use SRHI, with item loadings demonstrating that the factors related to lack of awareness and behavioural repetition respectively. These data raise the possibility that the SRHI incorporates separate measures of automaticity and behavioural repetition (Ajzen, 2002a).

\subsubsection{Developing a new measure of automaticity}

The aim of the present study was to develop and test a brief multi-item selfreport measure of automaticity in commuting mode decisions. Such an instrument would be of practical benefit, being easier to administer than the 12-item SRHI, whilst clearly distinguishing cognitive automaticity from behavioural repetition. First, we report results from an exploratory study which sought to extract a brief, reliable multiitem scale from a set of newly designed questionnaire items using principal component analyses. Secondly, we describe two studies designed to test the convergent, discriminant, and theoretical validity of the new automaticity measure when applied to car and bicycle commuting respectively.

\subsection{Study 5: Developing an automaticity measure}

Research that has utilised Verplanken and Orbell's (2003) SRHI has demonstrated that individuals can reflect reliably on automated actions, but the scale potentially conflates automaticity and behavioural repetition (Verplanken et al., 2005). We aimed to develop a brief multi-item self-report automaticity measure (AM) by devising a series of questionnaire items and identifying highly correlated items.

\subsubsection{Method}

18 self-report questionnaire items designed to tap car use automaticity were administered to university-based staff and student drivers (see tables $6.1 \& 6.2$ ). 56 participants ( 52 females, 4 males; mean age $=23.16$ years) who drove to the university campus were recruited. Participants received a hyperlink to an electronic questionnaire, and course credits or an entry into a (£25) cash prize draw upon completion.

\subsubsection{Results}

As table 6.1 shows, all automaticity items were significantly correlated in the expected direction, with the exception of one item ('I could easily make more of my 
journeys by public transport, instead of driving'), which correlated negatively with all other items ${ }^{24}$. The remaining 17 items typically correlated between .35 and .75 , and were entered into a principal component analysis to determine the underlying factor structure (see table 6.2). Direct oblimin rotation was performed to allow for potential correlation between factors (see Field, 2005, p.637).

Sampling $(K M O=.90)$ and sphericity $\left(\chi^{2}[136]=823.82, p<.001\right)$ were acceptable (Field, 2005). Two factors with eigenvalues greater than 1 were extracted. The first factor (eigenvalue $=10.68$ ) explained $62.82 \%$ of variance, whilst the second factor (eigenvalue $=1.25$ ) accounted for $7.37 \%$ of variance.

Both pattern and structure matrices, which respectively show regression coefficients for each item on the underlying factor(s) and correlation coefficients between each item and the underlying factor(s), were consulted in accordance with Graham, Guthrie and Thompson's (2003) recommendations. Both matrices demonstrated that 16 items loaded significantly on the first factor, but output from the structure matrix suggested that 9 items also loaded significantly $(>.40)$ on the second factor. Table 6.2 shows factor loadings derived from the structure matrix.

Of the 7 items loading exclusively on the first factor, the 5 items that loaded most highly in both pattern and structure matrices (>.80) were selected as a multi-item automaticity measure. The reliability of the resultant scale was good $(\alpha=.93)$, and could not be improved by omission of any of the items. Inter-correlations between the 5 items ranged from .68 to .83 .

\subsubsection{Discussion}

A new brief self-report measure of automaticity (AM) was developed using correlation and principal component analyses of responses from 56 university-based car commuters to eighteen questionnaire items. Five items were selected to represent automaticity because they demonstrated high intercorrelations and a unifactorial structure.

\footnotetext{
${ }^{24}$ On reflection, this item may have tapped public transport use efficacy or behavioural control (cf. Ajzen, 1991). Correlations between this item and automaticity items were negative, albeit small in magnitude (around -.25), suggesting that greater car choice automaticity was associated with stronger public transport control beliefs. This may corroborate findings from study 4 (chapter 5, p.97) suggesting that both public transport and car use control beliefs can reflect a sense of control over transport mode use more generally.
} 
Table 6.1. Study 5: Intercorrelations between piloted automaticity items

\begin{tabular}{|c|c|c|c|c|c|c|c|c|c|}
\hline & 1. & 2. & 3. & 4. & 5. & 6. & 7. & 8. & 9. \\
\hline $\begin{array}{l}\text { 1. 'When I need to travel, I often think whether } \\
\text { it is best to drive or use public transport' }\end{array}$ & & .34 & .53 & .62 & .59 & .64 & .65 & .31 & .71 \\
\hline $\begin{array}{l}\text { 2. 'I carefully consider all available transport } \\
\text { options before choosing which type of transport } \\
\text { to use' }\end{array}$ & & & .61 & .38 & .43 & .27 & .29 & .24 & .33 \\
\hline $\begin{array}{l}\text { 3. 'I hardly ever think about using public transport } \\
\text { when I need to go somewhere' }\end{array}$ & & & & .57 & .58 & .54 & .56 & .38 & .54 \\
\hline $\begin{array}{l}\text { 4. 'When I need to travel, choosing to drive is } \\
\text { something I do automatically, without really } \\
\text { thinking' }\end{array}$ & & & & & .61 & .72 & .62 & .45 & .62 \\
\hline $\begin{array}{l}\text { 5. 'It takes something unusual for me to consider } \\
\text { public transport when I want to get somewhere' }\end{array}$ & & & & & & .58 & .62 & .37 & .69 \\
\hline $\begin{array}{l}\text { 6. 'When you need to make a journey, is choosing } \\
\text { to drive something you do automatically, without } \\
\text { thinking?' }\end{array}$ & & & & & & & .83 & .57 & .65 \\
\hline $\begin{array}{l}\text { 7. 'When I have to make a journey, I tend NOT to } \\
\text { think about the modes of transport available to me' }\end{array}$ & & & & & & & & .69 & .72 \\
\hline $\begin{array}{l}\text { 8. 'When planning a journey, I am not usually aware } \\
\text { of making a decision about what mode of transport } \\
\text { (e.g. car, bus, train, etc) I should use' }\end{array}$ & & & & & & & & & .40 \\
\hline $\begin{array}{l}\text { 9. 'When you need to make a journey, do you consider } \\
\text { all the available transport options before deciding } \\
\text { which transport mode you will use?' }\end{array}$ & & & & & & & & & \\
\hline
\end{tabular}




10. $11 . \quad 12 . \quad 13 . \quad 14 . \quad 15 . \quad 16 . \quad 17 . \quad 18$.

1. 'When I need to travel, I often think whether

it is best to drive or use public transport'

2. 'I carefully consider all available transport

options before choosing which type of transport

to use'

3. 'I hardly ever think about using public transport

when I need to go somewhere'

$\begin{array}{llllllllll}.74 & .69 & .52 & .74 & -.22+ & .57 & .62 & .72 & .61 \\ .42 & .30 & .33 & .42 & -.33 & .32 & .16+ & .26 & .40 \\ .53 & .47 & .49 & .63 & -.15+ & .55 & .36 & .53 & .61 \\ .80 & .62 & .54 & .64 & -.11+.73 & .59 & .77 & .64\end{array}$

4. 'When I need to travel, choosing to drive is

something I do automatically, without really

thinking'

5. 'It takes something unusual for me to consider

public transport when I want to get somewhere'

6. 'When you need to make a journey, is choosing

to drive something you do automatically, without

thinking?'

7. 'When I have to make a journey, I tend NOT to

think about the modes of transport available to me'

8. 'When planning a journey, I am not usually aware

of making a decision about what mode of transport

(e.g. car, bus, train, etc) I should use'

$\begin{array}{lllllllll}.69 & .64 & .63 & .74 & -.26 & .58 & .48 & .74 & .58 \\ .76 & .62 & .53 & .64 & -.30 & .80 & .78 & .71 & .63 \\ .67 & .57 & .58 & .70 & -.27 & .78 & .68 & .67 & .63 \\ .50 & .41 & .47 & .44 & -.19 & .52 & .53 & .49 & .40\end{array}$

9. 'When you need to make a journey, do you consider

all the available transport options before deciding

which transport mode you will use?'

$\begin{array}{lllllllll}.74 & .79 & .53 & .77 & -.37 & .67 & .60 & .75 & .68\end{array}$




10. 11. 12. 13. 14. 15. 16. 17. 18.

10. 'When I need to go somewhere I automatically think about driving there'

11. 'When I need to make a journey, I DO NOT consider all available transport options before I choose to drive'

12. 'When I need to get somewhere, I would find it difficult to stop myself from driving there'

13. 'When I have to go somewhere, I tend to think about the different modes of transport (e.g. car, bus, train, etc) available to me'

14. 'I could easily make more of my journeys by public transport, instead of driving'

15. 'When I have to make a journey, I often drive without really thinking about the possibility of using other transport modes'

16. 'When I have to make a journey, deciding to drive is something I do automatically'

\section{7. 'I automatically choose to drive when I have}

to make a journey'

18. 'I consider all transport options when I have

to make a journey' 
Table 6.2. Study 5: Automaticity scale items and factor loadings

\begin{tabular}{|c|c|c|c|}
\hline \multirow[t]{2}{*}{ Item } & \multirow[t]{2}{*}{ Response range } & \multicolumn{2}{|c|}{ Factor loadings* } \\
\hline & & Factor 1 & Factor 2 \\
\hline $\begin{array}{l}\text { When I need to travel, I often think about whether } \\
\text { it is best to drive or use public transport }\end{array}$ & $\begin{array}{l}\text { Strongly disagree - } \\
\text { strongly agree*** }\end{array}$ & .78 & .44 \\
\hline $\begin{array}{l}\text { I carefully consider all available transport options } \\
\text { before choosing which type of transport to use }\end{array}$ & $\begin{array}{l}\text { Strongly agree - } \\
\text { strongly disagree }\end{array}$ & & .84 \\
\hline $\begin{array}{l}\text { I hardly ever think about using public transport } \\
\text { when I need to go somewhere }\end{array}$ & $\begin{array}{l}\text { Strongly agree - } \\
\text { strongly disagree** }\end{array}$ & .61 & .75 \\
\hline $\begin{array}{l}\text { When I need to travel, choosing to drive is } \\
\text { something I do automatically, without really thinking }\end{array}$ & $\begin{array}{l}\text { Strongly disagree - } \\
\text { strongly agree }\end{array}$ & .80 & .41 \\
\hline $\begin{array}{l}\text { It takes something unusual for me to consider } \\
\text { public transport when I want to get somewhere }\end{array}$ & $\begin{array}{l}\text { Strongly disagree - } \\
\text { strongly agree }\end{array}$ & .74 & .59 \\
\hline $\begin{array}{l}\text { When you need to make a journey, is choosing } \\
\text { to drive something you do automatically, } \\
\text { without thinking? }\end{array}$ & $\begin{array}{l}\text { Definitely yes - } \\
\text { definitely no }\end{array}$ & .88 & \\
\hline $\begin{array}{l}\text { When I have to make a journey, I tend NOT to } \\
\text { think about the modes of transport available to me }\end{array}$ & $\begin{array}{l}\text { Strongly disagree - } \\
\text { strongly agree }\end{array}$ & .87 & \\
\hline $\begin{array}{l}\text { When planning a journey, I am not usually aware } \\
\text { of making a decision about what mode of } \\
\text { transport (e.g. car, bus, train, etc) I should use }\end{array}$ & $\begin{array}{l}\text { Strongly agree - } \\
\text { strongly disagree** }\end{array}$ & .64 & \\
\hline $\begin{array}{l}\text { When you need to make a journey, do you consider } \\
\text { all the available transport options before } \\
\text { deciding which transport mode you will use? }\end{array}$ & $\begin{array}{l}\text { Definitely do not - } \\
\text { definitely do** }\end{array}$ & .83 & .44 \\
\hline $\begin{array}{l}\text { When I need to go somewhere I automatically } \\
\text { think about driving there }\end{array}$ & $\begin{array}{l}\text { Strongly disagree - } \\
\text { strongly agree }\end{array}$ & .90 & .40 \\
\hline $\begin{array}{l}\text { When I need to make a journey, I DO NOT consider } \\
\text { all available transport options before I choose to drive }\end{array}$ & $\begin{array}{l}\text { Strongly disagree - } \\
\text { strongly agree }\end{array}$ & .80 & \\
\hline $\begin{array}{l}\text { When I need to get somewhere, I would find it } \\
\text { difficult to stop myself from driving there }\end{array}$ & $\begin{array}{l}\text { Strongly agree - } \\
\text { strongly disagree** }\end{array}$ & .72 & .43 \\
\hline $\begin{array}{l}\text { When I have to go somewhere, I tend to think } \\
\text { about the different modes of transport (e.g. car, } \\
\text { bus, train, etc) available to me }\end{array}$ & $\begin{array}{l}\text { Definitely do - } \\
\text { definitely do not }\end{array}$ & .85 & .58 \\
\hline $\begin{array}{l}\text { I could easily make more of my journeys } \\
\text { by public transport, instead of driving }\end{array}$ & $\begin{array}{l}\text { Strongly disagree - } \\
\text { strongly agree*** }\end{array}$ & (Not ent & ed) \\
\hline $\begin{array}{l}\text { When I have to make a journey, I often } \\
\text { drive without really thinking about the } \\
\text { possibility of using other transport modes }\end{array}$ & $\begin{array}{l}\text { Definitely do - } \\
\text { definitely do not }\end{array}$ & .85 & \\
\hline $\begin{array}{l}\text { When I have to make a journey, deciding to } \\
\text { drive is something I do automatically }\end{array}$ & $\begin{array}{l}\text { Strongly disagree - } \\
\text { strongly agree }\end{array}$ & .84 & \\
\hline $\begin{array}{l}\text { I automatically choose to drive when I } \\
\text { have to make a journey }\end{array}$ & $\begin{array}{l}\text { Strongly disagree - } \\
\text { strongly agree }\end{array}$ & .89 & \\
\hline $\begin{array}{l}\text { I consider all transport options when I have } \\
\text { to make a journey }\end{array}$ & $\begin{array}{l}\text { Strongly agree - } \\
\text { strongly disagree }\end{array}$ & .80 & .54 \\
\hline
\end{tabular}

NB: All items measured on 7-point scales.

* Factor loadings derived from structure matrix for direct oblimin rotation; see Field (2005).

** Item reverse-coded for analysis.

Items in bold selected for inclusion in the 5-item automaticity measure. 
The five selected AM items explicitly address automaticity and the concomitant lack of thought directed at potential alternative behavioural courses (Aarts et al., 1997; Bargh, 1994, 1996), offering further evidence that people are able to reflect upon automatically initiated behaviours (Verplanken \& Orbell, 2003). Moreover, the scale offers a potential instrument for capturing cognitive dimensions of habitual decision making whilst maintaining conceptual separation from behavioural frequency. Inspection revealed near-normal distributions for each of the five constituent items and the composite scale, suggesting the AM should remain reliable where applied to other samples of car drivers.

\subsection{Study 6: Car use as a habitual behaviour}

In this study, the convergent validity of the 5-item automaticity measure (AM) developed in study 5 was tested in relation to existing habit measures (RFM and SRHI). We predicted that ${ }^{25}$ :

Hypothesis 1: The new self-report automaticity measure (AM) will show convergent validity with the RFM and SRHI.

Hypothesis 2: AM will be significantly correlated with behaviour, but the strength of this correlation will be lower than that observed between SRHI and behaviour because of the absence of behavioural repetition items.

The study also provided an opportunity to test and compare each of the three habit indices as moderators of prospective intention-behaviour relationships, and so we expected that:

Hypothesis 3: Habit - as indexed by the RFM, SRHI and AM scales - will moderate the relationship between intentions and behaviour, such that where habit is strong, intentions will have a weaker effect on behaviour, and vice versa.

\footnotetext{
${ }^{25}$ Automaticity should also mediate effects of past behaviour on later behaviour where behaviours are relatively novel (e.g. Gärling et al., 2001), but data collection took place in the middle of the academic year, by which time travel mode habits should have been well established (cf. Ronis et al., 1989), and so we did not hypothesise for this effect.
} 
Since the SRHI incorporates both behavioural frequency and automaticity, we hypothesised that:

Hypothesis 4: A measure of the SRHI omitting items relating to behavioural frequency (the 'modified SRHI') will be less strongly correlated with behaviour, and will exhibit a weaker moderation effect of the intention-behaviour relationship.

\subsubsection{Method}

\subsubsection{Participants and procedure}

108 staff and student university-based car commuters with access to a car over the preceding week were recruited. The university campus is situated 3 miles from the city centre and served by frequent bus services, a train station with intra- and inter-city links, and cycle paths, making non-car transport a feasible option.

The study used a prospective design. At the first timepoint (time 1; T1), participants attended a lab and completed a brief paper-based questionnaire measuring past behaviour, before completing a two-part electronic questionnaire. The main portion of the electronic questionnaire presented TPB, SRHI and the five AM items, and a separate section presented participants with RFM items; the order of presentation was randomised using a random number generator (see www.random.org) to control for potential order effects. One week later (time 2; T2), participants were asked to provide behaviour measures via email. Participants who responded at both timepoints received $£ 5$.

One participant did not provide follow-up behaviour data and so was removed from analysis, leaving a final sample of 107 drivers (33 males, 74 females). Participants' age ranged from 18 to 55 years $(M=27.53$ years, $S D=9.69)$. A power analysis with significance set at .05 and presupposing medium effect sizes for a maximum of four predictors of behaviour (intention, PBC, habit, past behaviour) indicated a sample of 85 participants was sufficient to achieve power at 80 (Cohen, 1992; Faul \& Erdfelder, 1992).

\subsubsection{Measures}

Behaviour. Participants were asked to indicate how many journeys over the last week they had made to the university campus: a) in total; b) by car; c) by public transport; and 
d) by any other form of transport ${ }^{26}$. Behaviour was measured as the proportion of journeys to the university campus made by car, ranging from $0-100 \%$. T2 behaviour was the dependent variable for our analyses, and T1 behaviour scores were used as an index of past behaviour.

At time 2, participants also completed an item concerning the number of journeys over the past week for which a car was unavailable; these journeys were excluded from the behaviour calculation. Responses indicated that no journeys were made using multiple modes (i.e. car and public transport).

Unless otherwise specified, all cognition measures took the form of statements with which participants marked their agreement on seven-point response scales ranging from 'strongly disagree' to 'strongly agree'.

TPB items were worded in relation to making 'most of my journeys to the university campus over the next week' (e.g. 'I intend to use a car for most of my journeys to the university campus over the next week', 'Most people who are important to me think that I should use a car for most of my journeys to the university campus next week').

Intention was measured using four items ('I intend to drive for...', 'I will try to drive for...'; 'I plan to drive for...'; 'I aim to drive for...'; $\alpha=.96$ ).

Five items measuring attitude followed a stem ('Using a car for most of my journeys to the university campus over the next week would be'), with responses ranging from harmful-beneficial, pleasant-unpleasant, good-bad, enjoyableunenjoyable, foolish-wise, the former four of which were recoded $(\alpha=.80)$.

Subjective norm was measured using three items ('Most people who are important to me think that I should use a car for...'; 'People who are important to me expect me to use a car for...'; 'If I use a car for most of my journeys to the university campus over the next week, people who are important to me would approve'; $\alpha=.85$ ).

Perceived behavioural control was measured using four items ('If I wanted to, I could use a car for...', 'It is mostly up to me whether or not I use a car for...', 'I am able to control whether I use a car for...', 'How much control do you have over using a car for most of your journeys to the university campus over the next week?' [no controlcomplete control]; $\alpha=.74)$.

\footnotetext{
${ }^{26}$ The distinction between non-car transports was unimportant for our analyses, but was made to minimise participants' awareness of the purpose of the study, which could potentially have affected selfreported behaviour measures for self-presentational reasons (see Steg, Vlek \& Slotegraaf, 2001).
} 
Response-frequency habit measure (RFM) items were preceded by the following instructions: 'The following section of the questionnaire presents leisure activities that you may or may not engage in. Assume that you want to spontaneously engage in this activity. Which mode of transport would you be most likely to use? Your responses are being timed. Please respond as quickly as possible without much deliberation.' Each item was programmed to appear for a maximum of 10 seconds, but no participant required longer than 10 seconds to respond. When a response was given, the next item was presented immediately. Participants received 5 practice trials to control for potential practice effects.

Ten response-frequency items ${ }^{27}$, taken from previous studies, were presented in a random order: 'visiting a friend', 'going to a concert', 'playing sports', 'taking a trip on a nice day', 'routine grocery shopping', 'going to the movies', 'going on a date', 'going out for dinner', 'shopping after work', 'going shopping for clothes' (Aarts et al., 1997; Bamberg et al., 2003; Fujii \& Kitamura, 2003; Matthies, Kuhn \& Klöckner, 2002; Verplanken et al., 1997). For each journey, participants were required to indicate whether they would use a car, bus, train, or any other mode of transport ${ }^{28}$. RFM scores were calculated by summing the frequency with which the car was chosen, and so reliability coefficients are not applicable. Scores could not be calculated for two participants who failed to give valid responses to any of the items.

The self-report habit index (SRHI) was measured using Verplanken and Orbell's (2003) twelve items (e.g. 'Using a car to commute to campus is something I do automatically', 'Using a car to commute to campus is something I do without having to consciously remember'; see p.1329). The reliability alpha was good $(\alpha=.95)$. The factor structure was examined using principal component analysis (PCA), which extracted a single factor (eigenvalue $=7.78$ ) which explained $64.82 \%$ of variance. A modified SRHI, omitting behavioural frequency items ('Using a car to commute to campus is something: 'I do frequently', 'I have been doing for a long time') also showed good reliability $(\alpha=.94)$, and PCA highlighted one factor $($ eigenvalue $=6.53)$ which explained $65.26 \%$ variance.

\footnotetext{
${ }^{27}$ These items were selected because they were likely to represent short journeys possible by car or bicycle, and hence would be equally valid in measuring car and bicycle habits, permitting matched RFM measures across Studies 6 and 7.

${ }^{28}$ See footnote 3.
} 
The newly-developed automaticity measure (AM) included five items (e.g. 'When I have to make a journey, deciding to drive is something I do automatically', 'I automatically choose to drive when I have to make a journey'; $\alpha=.91$ ).

\subsubsection{Results}

\subsubsection{Skewness}

$\mathrm{T} 2$ behaviour values were negatively skewed $\left(\mathrm{z}_{\text {skewness }}=-5.55\right)$, but squaring values on this variable did not reduce skew sufficiently $\left(\mathrm{z}_{\text {skewness }}=-4.33\right)$, and hence we used untransformed $\mathrm{T} 2$ behaviour values in our analyses.

\subsubsection{Descriptives and correlations}

As table 6.3 shows, participants made the majority of commuting journeys at both timepoints by car (behaviour: $M=77.94, S D=35.76$; past behaviour: $M=77.13$, $S D=38.43)$, and behaviour was stable over the two timepoints $(r=.86)$. Participants generally intended to drive $(M=5.08, S D=2.32)$, and pre-intention TPB cognition means favoured car use. TPB cognitions, behaviour and past behaviour were significantly correlated $(p s<.001)$, with the exception of PBC, which did not correlate with any other variable (maximum $r=-.15, p=.12$ ), thereby suggesting that driving could be modelled as a planned behaviour ${ }^{29}$.

Mean RFM $(M=5.44, S D=2.76)$ and SRHI scores $(M=4.62, S D=1.81)$ indicated tendencies towards habitual car choices, but mean AM scores were marginally below the midpoint $(M=3.95, S D=1.80)$.

The RFM, SRHI and AM scales were all strongly correlated ( $r \mathrm{~s}=.52-.66)$, supporting hypothesis 1 . The RFM showed only moderate to strong correlations with behaviour $(r=.45)$ and past behaviour $(r=.41)$. The SRHI scale was very highly correlated with behaviour $(r=.82)$ and past behaviour $(r=.82)$, and AM was significantly less strongly correlated with both behaviour $(r=.40 ; Z=6.82, p<.001$; see Meng, Rosenthal \& Rubin, 1992) and past behaviour ( $r=.39 ; Z=7.34, p<.001)$. Hypothesis 2 was supported: the distinct measure of automaticity was more weakly correlated with behaviour than the SRHI, which potentially fuses automaticity and behavioural repetition.

\footnotetext{
${ }^{29}$ A regression of intention on attitude and subjective norm confirmed this, with $60 \%$ variance explained, and both variables achieving moderate to strong Beta weights $(\beta>.40)$.
} 
Table 6.3. Study 6: Descriptive statistics and correlations

\begin{tabular}{|c|c|c|c|c|c|c|c|c|c|c|c|c|c|}
\hline & 1. & 2. & 3. & 4. & 5. & 6. & 7. & 8. & 9. & 10 & Mean & $S D$ & $N$ \\
\hline 1. Behaviour $(\mathrm{T} 2)^{\dagger}$ & & $.86^{* * *}$ & $.41 * * *$ & $.45 * * *$ & $.81 * * *$ & $.79 * * *$ & $.83 * * *$ & -.15 & $.60 * * *$ & $.54 * * *$ & 77.94 & 35.76 & 107 \\
\hline 2. Past behaviour & & & $.39 * * *$ & $.41 * * *$ & $.82 * * *$ & $.80 * * *$ & $.86^{* * * *}$ & -.05 & $.57 * * *$ & $.52 * * *$ & 77.13 & 38.43 & 107 \\
\hline 3. AM & & & & $.60 * * *$ & $.64 * * *$ & $.66 * * *$ & $.53 * * *$ & .00 & $.52 * * *$ & $.41 * * *$ & 3.95 & 1.80 & 107 \\
\hline 4. RFM & & & & & $.52 * * *$ & $.53 * * *$ & $.48 * * *$ & -.06 & $.39 * * *$ & $.43 * * *$ & 5.44 & 2.76 & 105 \\
\hline 5. SRHI & & & & & & $.99 * * *$ & $.90 * * *$ & -.07 & $.65 * * *$ & $.65 * * *$ & 4.62 & 1.81 & 107 \\
\hline 6. Modified SRHI & & & & & & & $.87 * * *$ & -.08 & $.65 * * *$ & $.65 * * *$ & 4.52 & 1.80 & 107 \\
\hline 7. Intention & & & & & & & & -.03 & $.70 * * *$ & $.67 * * *$ & 5.08 & 2.32 & 107 \\
\hline 8. $\mathrm{PBC}$ & & & & & & & & & -.07 & -.01 & 6.01 & 1.14 & 107 \\
\hline 9. Attitude & & & & & & & & & & $.57 * * *$ & 4.54 & 1.34 & 107 \\
\hline 10. Subjective norm & & & & & & & & & & & 4.46 & 1.63 & 107 \\
\hline
\end{tabular}

$* * * p<.001$.

${ }^{\dagger}$ All scales range from 1-7, except behaviour (range 0-100) and RFM (range 1-10). 
Interestingly, the modified SRHI, which omitted two behavioural frequency items, was essentially interchangeable with the original SRHI $(r=.99)$, and thus retained very high correlations with past and future behaviour $(r \mathrm{~s}=.79$ and .80 , respectively).

Given the strong intercorrelations, all future and past behaviour, intention, SRHI and AM items were entered into a PCA. Using direct oblimin rotation, two factors were extracted which accounted for $60.84 \%$ and $11.82 \%$ of variance respectively (eigenvalues $=13.99 \& 2.72$ ). Inspection of the structure matrix revealed that all items loaded on both factors at at least .30. However, as table 6.4 shows, behaviour, past behaviour, intention, and ten SRHI items loaded more highly on the first factor, while two SRHI items and all five AM items loaded more highly on to the second factor. Thus, the SRHI and measures of intention and behaviour appeared to tap a single dimension, whereas the AM items form a distinct factor. Conceptual labelling of the two factors was however problematic, because items loading most heavily on the first factor represented both behavioural frequency and the SRHI items relating to automaticity. Furthermore, SRHI items tended to load significantly (>.40) on both factors, which were strongly correlated $(r=.53)$, indicating conceptual overlap between the two dimensions.

\subsubsection{Habit as a moderator of the intention-behaviour relation}

To test hypothesis 3, a series of two-step regressions of behaviour was run, entering firstly intention and the habit measure (RFM, SRHI, modified SRHI, or AM), and a mean-centred interaction term (e.g. intention x RFM, intention x SRHI, etc.) at the second step.

As table 6.5 shows, the $\operatorname{RFM}(\beta=.07, p=.29)$ did not have a direct effect on behaviour over and above intention, but the interaction term entered at the second step was a significant moderator of the intention-behaviour relation $(\beta=-.15, p=.01)$. This effect was decomposed using simple slope analyses (e.g. Aiken \& West, 1991).

As figure 6.1 demonstrates, where intention was low, participants were likely to report greater car use where RFM scores were high $(\beta=.59, p<.001)$, and less car use where RFM scores were low $(\beta=.74, p<.001)$, compared to participants with mean average $\mathrm{RFM}$ scores $(\beta=.89, p<.001)$. 
Table 6.4. Study 6: Principal component analyses for behaviour, intention, SRHI and automaticity items

\begin{tabular}{|c|c|c|c|}
\hline \multirow[t]{2}{*}{ Variable } & \multirow[t]{2}{*}{ Item } & \multicolumn{2}{|c|}{ Factor loadings* } \\
\hline & & Factor 1 & Factor 2 \\
\hline Behaviour & & .89 & .42 \\
\hline $\begin{array}{l}\text { Past } \\
\text { behaviour }\end{array}$ & & .91 & .41 \\
\hline \multirow[t]{4}{*}{ Intention } & $\begin{array}{l}\text { I intend to drive for most of my journeys to the } \\
\text { university campus over the next week }\end{array}$ & .94 & .53 \\
\hline & $\begin{array}{l}\text { I will try to drive for most of my journeys to the } \\
\text { university campus over the next week }\end{array}$ & .84 & .56 \\
\hline & $\begin{array}{l}\text { I plan to drive for most of my journeys to the } \\
\text { university campus over the next week }\end{array}$ & .93 & .45 \\
\hline & $\begin{array}{l}\text { I aim to drive for most of my journeys to the } \\
\text { university campus over the next week }\end{array}$ & .92 & .50 \\
\hline \multirow[t]{11}{*}{ SRHI } & Using a car to commute to campus is something... & & \\
\hline & I do frequently & .88 & .39 \\
\hline & I have been doing for a long time & .81 & .45 \\
\hline & that belongs to my daily routine & .90 & .50 \\
\hline & that's typically "me" & .75 & .65 \\
\hline & $\begin{array}{l}\text { I do automatically } \\
\text { I do without having to consciously remember }\end{array}$ & .83 & .71 \\
\hline & that makes me feel weird if I do not do it & .63 & .59 \\
\hline & I do without thinking & .77 & .75 \\
\hline & that would require effort not to do & .80 & .33 \\
\hline & $\begin{array}{l}\text { I start doing before I realise I'm doing it } \\
\text { I would find hard not to do }\end{array}$ & .66 & .75 \\
\hline & I have no need to think about doing & .46 & .50 \\
\hline \multirow[t]{5}{*}{$A M$} & $\begin{array}{l}\text { When you need to make a journey, is choosing to } \\
\text { drive something you do automatically, without } \\
\text { really thinking? }\end{array}$ & .50 & .92 \\
\hline & $\begin{array}{l}\text { When I have to make a journey, I tend NOT to think } \\
\text { about the modes of transport a vailable to me }\end{array}$ & .37 & .80 \\
\hline & $\begin{array}{l}\text { When I have to make a journey, I often drive } \\
\text { without really thinking about the possibility } \\
\text { of using other transport modes }\end{array}$ & .42 & .79 \\
\hline & $\begin{array}{l}\text { When I have to make a journey, deciding to } \\
\text { drive is something I do automatically }\end{array}$ & .49 & .89 \\
\hline & $\begin{array}{l}\text { I automatically choose to drive when I have } \\
\text { to make a journey }\end{array}$ & .38 & .88 \\
\hline
\end{tabular}

* Factor loadings derived from structure matrix for direct oblimin rotation; see Field (2005).

Values in bold signify higher loadings. 
Table 6.5. Study 6: RFM as moderator of intention-behaviour relationship $(N=105)$

\begin{tabular}{llll}
\hline Step & Variable $(s)$ entered & $\beta$ & $\beta$ \\
\hline $\begin{array}{l}\text { 1. } \quad \text { Intention } \\
\quad \text { RFM }\end{array}$ & $.80^{* * * *}$ & $.74^{* * *}$ \\
$\quad$ Intention x RFM & .07 & .07 \\
2. & & $-.15^{*}$ \\
Unadjusted $R^{2}$ & .69 & .71 \\
Model $F$ & $115.62^{* * *}$ & $83.79^{* * *}$ \\
$F$ change & & $6.85^{*}$ \\
\hline
\end{tabular}

$* p<.05, * * p<.01, * * * p<.001$

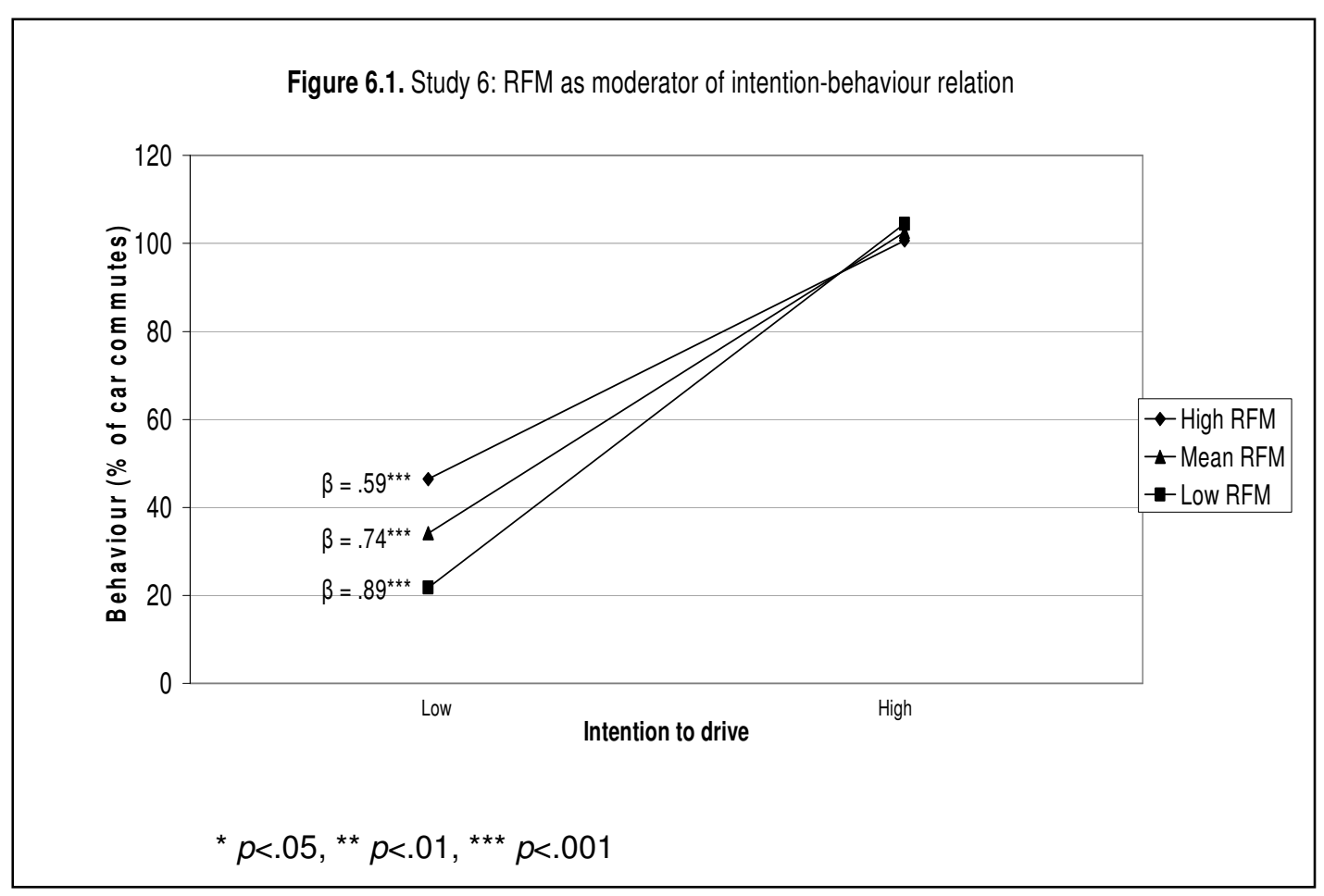

The second step of the model in table 6.6 shows that the SRHI operated both as a direct predictor of behaviour $(\beta=.38, p=.001)$ over and above intention $(\beta=.27$, $p=.04)$, and also moderated the transition of intention into behaviour $(\beta=-.28$, $p=.001$ ). Simple slopes analysis (see figure 6.2) highlighted a powerful moderation effect for SRHI: at low levels of habit, intention had a strong effect on behaviour $(\beta=$ 
$.55, p<.001)$, but where habit was strong, the relationship between intention and behaviour was nullified $(\beta=-.02, p=.94)$.

Table 6.6. Study 6: SRHI as moderator of intention-behaviour relationship $(N=107)$

\begin{tabular}{llll}
\hline Step & Variable $($ s) entered & $\beta$ & $\beta$ \\
\hline 1. & Intention & $.51^{* * *}$ & $.27^{*}$ \\
& SRHI & $.36^{* *}$ & $.38^{* *}$
\end{tabular}

2. Intention x SRHI - $-28 * *$

Unadjusted $R^{2}$

Model $F$

$F$ change
.71

$125.72 * * *$
.74

$97.68 * * *$

$* p<.05, * * p<.01, * * * p<.001$

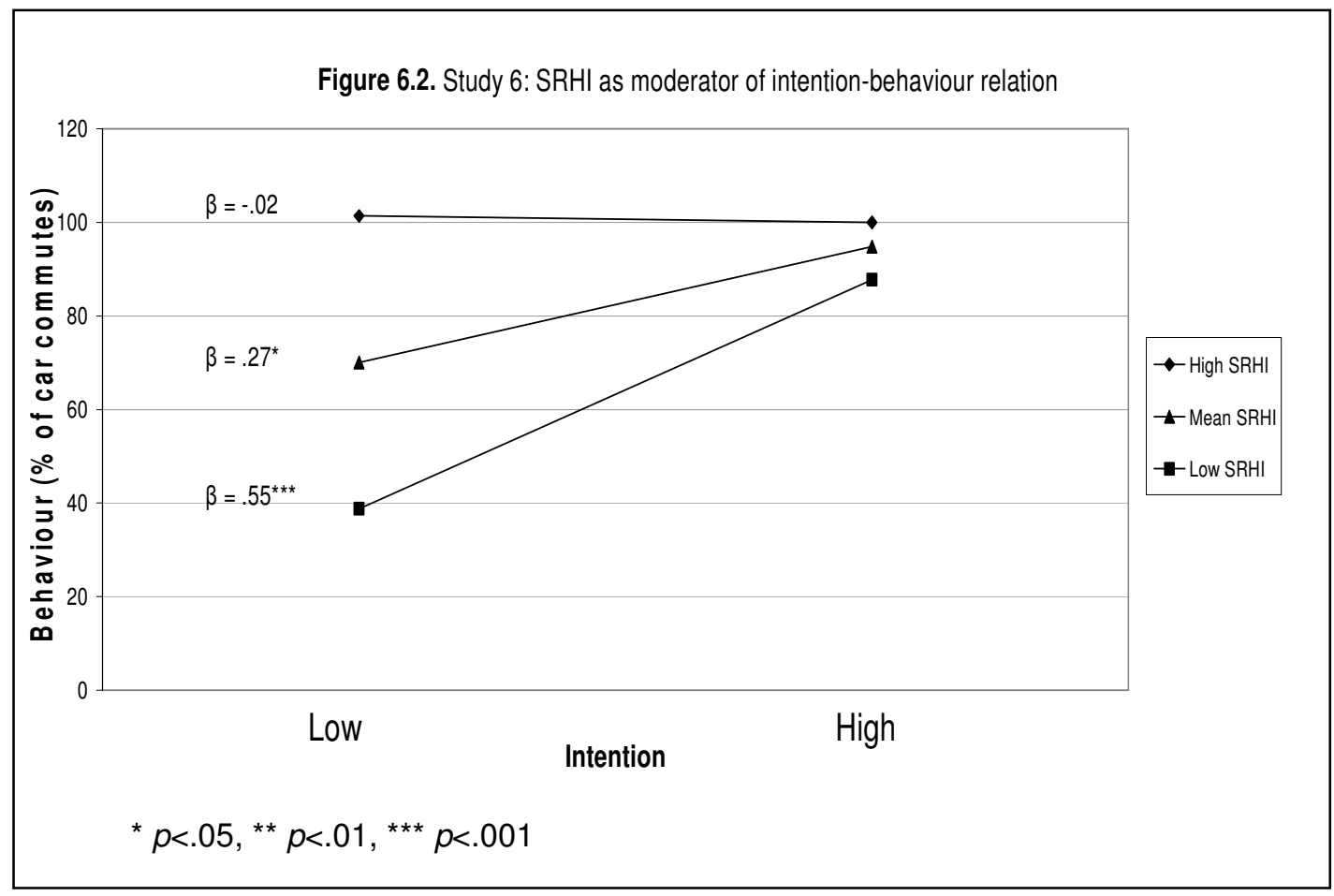


As table 6.7 and figure 6.3 indicate, the modified SRHI achieved very similar results to those obtained for the unmodified SRHI. Hypothesis 4 was therefore rejected.

Table 6.7. Study 6: Modified SRHI as moderator of intention-behaviour relationship $(N=107)$

\begin{tabular}{llll} 
Step & Variable $(s)$ entered & $\beta$ & $\beta$ \\
\hline 1. & Intention & $.58^{* * *}$ & $.32^{*}$ \\
& Modified SRHI & $.29 *$ & $.34 * *$
\end{tabular}

2. Intention x Modified SRHI

Unadjusted $R^{2}$

Model $F$

$F$ change
.70

$122.41 * * *$
.73

$94.69 * * *$

$12.40 * *$

$* p<.05, * * p<.01, * * * p<.001$

Figure 6.3. Study 6: Modified-SRHI as moderator of intention-behaviour relation

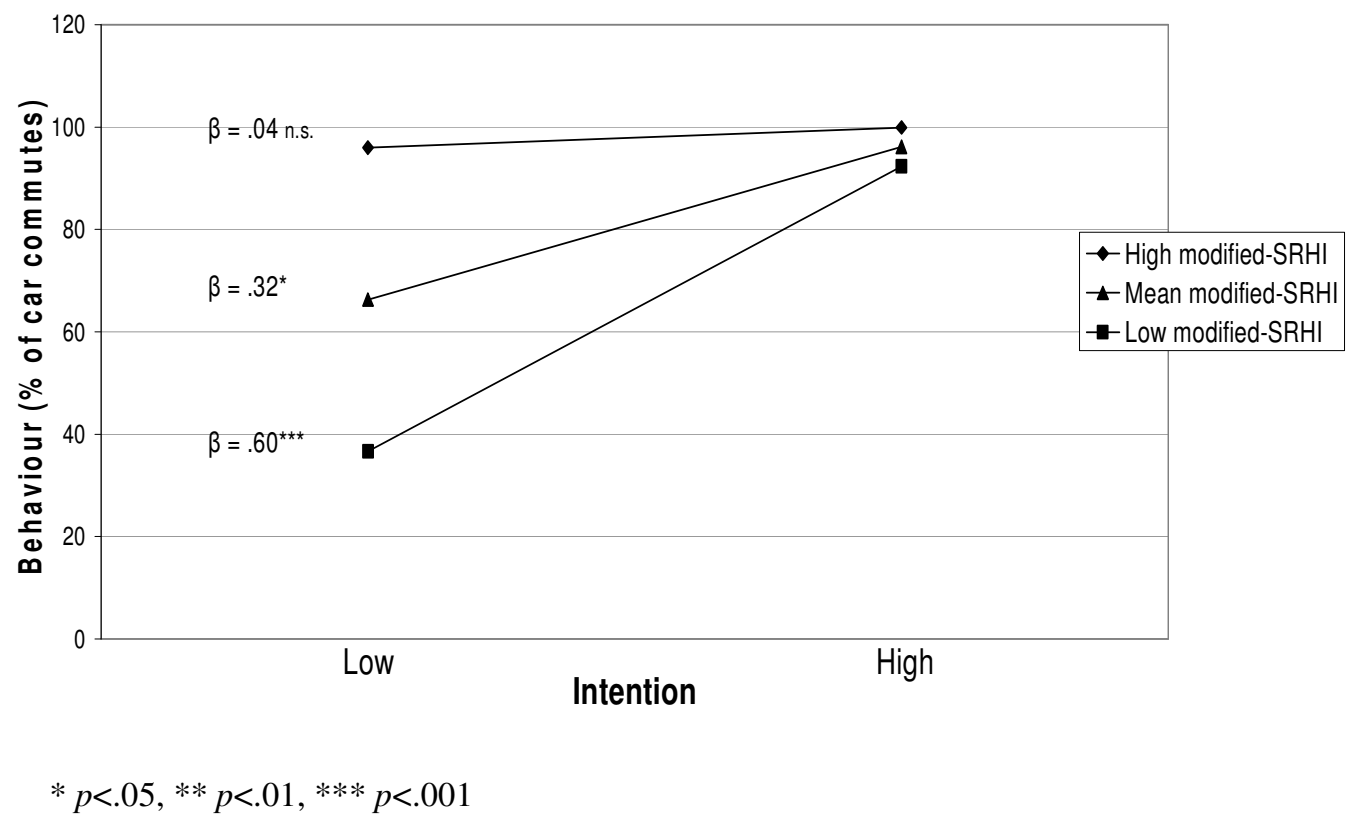


AM did not predict behaviour over and above intention (step one: $\beta=-.04, p=.54$ ), nor did it moderate the intention-behaviour association (step two: $\beta=-.03, p=.60$; see table 6.8).

Table 6.8. Study 6: AM as moderator of intention-behaviour relationship $(N=107)$

\begin{tabular}{llll} 
Step & Variable $(s)$ entered & $\beta$ & $\beta$ \\
\hline 1. & Intention & $.85^{* * *}$ & $.83^{* * *}$ \\
& $\mathrm{AM}$ & -.04 & -.03
\end{tabular}

Unadjusted $R^{2}$

Model $F$

$F$ change
.68

$112.40 * * *$
.69

$74.51 * * *$

0.28

$* p<.05, * * p<.01, * * * p<.001$

Thus, there was mixed support for hypothesis 3: the RFM and SRHI operated as moderators of the translation of intention into behaviour, but AM did not.

\subsubsection{Discussion}

A study of car commuters' driving behaviour showed that a new brief selfreport measure of automaticity in driving choice had convergent validity with existing habit measures, whilst also correlating with past and future behaviour. Initial analyses suggested that, while an existing habit measure which comprises automaticity and behavioural frequency (the SRHI) was sufficiently associated with intention and behaviour to be treated as a measure of a single latent construct, AM tapped a discreet underlying dimension. However, tests of the hypothesised moderation effect showed that the SRHI was the optimal habit measure, showing strong moderation effects in line with theoretical criteria (Triandis, 1977): i.e., where self-reported habit was strong, behaviour was determined solely by habit, and not by deliberative intentions. 
By contrast, AM failed to moderate the intention-behaviour relationship. Identical results were obtained for all habit indices in post-hoc models of past rather than future behaviour.

Our analysis also demonstrated that the SRHI was sufficiently distinct from behaviour, and furthermore a modified version of the SRHI which omitted two items relating to behavioural repetition produced results practically identical to those obtained using the original SRHI.

Given the apparent unifactorial structure underlying SRHI, behaviour and intention measures, the direct and indirect effects of the SRHI on behaviour were noteable, suggesting that the SRHI is able to predict behaviour over and above intention even when intention is very highly correlated with behaviour. Indeed, the unusually strong correlation observed between intention and behaviour $(r \approx .85$; see chapter 4, p.78) might have suppressed potential effects of automaticity, because little residual behaviour variance remained after intention was entered into the regression model.

\subsection{Study 7: Bicycle use as a habitual behaviour}

To establish the robustness of the findings of the previous study, we conducted a replication of study 6 but focused on bicycle use among a sample of commuters in the Netherlands, where cycling is the dominant mode of transport for short trips (e.g. Ministerie van Verkeer en Waterstaat, 2004) and is hence likely to be habitual (e.g. Aarts \& Dijksterhuis, 1999, 2000a, 2000b).

As in study 6, we sought to test the convergent validity of the AM in relation to existing habit measures (RFM and SRHI) and examine whether AM moderated the intention-behaviour relationship, as well as explore how a modified version of the SRHI which excluded behavioural repetition items would perform in relation to the original SRHI. Hence, the same hypotheses used in study 6 were tested (as reproduced below):

Hypothesis 1: The new self-report automaticity measure (AM) will show convergent validity with the RFM and SRHI. 
Hypothesis 2: AM will be significantly correlated with behaviour, but the strength of this correlation will be lower than that observed between SRHI and behaviour because of the absence of behavioural repetition items.

Hypothesis 3: Habit - as indexed by the RFM, SRHI and AM scales - will moderate the relationship between intentions and behaviour, such that where habit is strong, intentions will have a weaker effect on behaviour, and vice versa.

Hypothesis 4: A measure of the SRHI omitting items relating to behavioural frequency (the 'modified SRHI') will be less strongly correlated with behaviour, and will exhibit a weaker moderation effect of the intention-behaviour relationship.

\subsubsection{Method}

\subsubsection{Participants and procedure}

107 English-speaking staff and students at a Dutch university with access to a bicycle over the preceding week were recruited. The university site used by all participants is situated 2 miles from the city centre and served by frequent bus services, a train station with intra- and inter-city links, and cycle paths.

A prospective design was employed. The procedure was identical to that of study 6. Participants who completed all measures received $€ 5(\approx £ 3.50)$.

Three participants who did not provide follow-up behaviour data were removed from analysis. To facilitate comparison with the previous study, data from two participants who made mixed-mode journeys (using bicycle and train) were also excluded.

Of the remaining 102 participants, 25 were male and 77 female. Participants were aged between 18 and 37 years $($ mean $=21.58$ years, S.D. $=3.47) .2$ participants did not indicate their age.

\subsubsection{Measures}

Behaviour was measured by asking participants to indicate how many journeys over the preceding week they had made to the university site: a) in total; b) by bicycle; c) by car; and d) by any other form of transport. Behaviour was measured as the proportion of journeys to the university campus made by bicycle, and ranged 
from $0-100 \%$. T2 behaviour was the dependent variable for our analyses. T1 behaviour scores were used as an index of past behaviour.

At one-week follow-up, participants also completed an item concerning the number of journeys over the past week for which a bicycle was unavailable, and these journeys were excluded from the behaviour calculation.

Cognitions were measured using the same items used in study 6 , but the focal behaviour was changed from 'driving' or 'using a car' to 'using a bicycle' (e.g. 'I intend to use a bicycle for most of my journeys to the university campus next week'). All items were presented in English, and formed reliable measures (intention: $\alpha=.96$; PBC: $\alpha=.76$; attitude: $\alpha=.84$; subjective norm: $\alpha=.77$ ).

Habit measures were also identical to study 6 , but possible responses to RFM items were changed to bicycle, car, public transport, and any other form of transport. RFM scores could not be computed for three participants who failed to respond to all ten items ${ }^{30}$. All habit measures were reliable (AM: $\alpha=.91$; SRHI: $\alpha=.95$; modified SRHI: $\alpha=.94$ ), and a PCA run to examine the factorial structure of the SRHI extracted a single factor (eigenvalue $=8.08$ ), which explained $67.31 \%$ of variance. One factor was also extracted from the modified SRHI (eigenvalue $=6.57 ; 65.66 \%$ variance).

\subsubsection{Results}

\subsubsection{Skewness}

Behaviour values were negatively skewed $\left(\mathrm{z}_{\text {skewness }}=-6.03\right)$, and squaring these values did not sufficiently reduce skew $\left(\mathrm{z}_{\text {skewness }}=-4.60\right)$, so, as in study 6 , we used untransformed behaviour values in our analyses.

\subsubsection{Descriptives and correlations}

Cycling was the dominant mode of commuting, with mean behaviour scores mirroring those in the preceding driving study (behaviour: $M=78.17, S D=36.56$; past behaviour: $M=78.84, S D=35.51$ ). Behaviour over the two timepoints was highly stable $(r=.92)$.

Participants intended to cycle to university $(M=5.93, S D=1.81)$. Preintention cognition scores, and mean habit scores (RFM: $M=6.11, S D=2.49$; SRHI:

\footnotetext{
${ }^{30}$ Although Klöckner et al. (2003) have shown that the RFM habit measure may alternatively be operationalised as the percentage rather than frequency of choices, we chose to use the frequency measure to facilitate comparison with the preceding car study.
} 
$M=5.18, S D=1.67$; AM: $M=4.77, S D=1.66$ ) were all above the midpoint, signifying pro-bicycle use cognitions and habitual tendencies.

All variables were significantly correlated, with the exception of PBC and AM ( $r=.11, p=.26$ ), and correlations between TPB cognitions suggested that cycling could be modelled as a reasoned action ${ }^{31}$. Moreover, the RFM, SRHI and AM were all strongly correlated ( $r \mathrm{~s}=.59-.76$ ), further supporting hypothesis 1 .

All three habit indices were strong correlates of behaviour and past behaviour, but correlations between AM and both past behaviour $(r=.66)$ and future behaviour ( $r=.61)$ were significantly less strong than behaviour correlations observed for the SRHI (behaviour: $r=.86, Z=5.97, p<.001$; past behaviour: $r=.91, Z=7.02$, $p<.001)$. This provided additional support for hypothesis 2 .

The modified SRHI scale was very highly correlated with the unmodified SRHI $(r=1)$, contrary to hypothesis 4 .

The SRHI, intention, and past and future behaviour were observed to correlate at $>.80$, but AM correlated less strongly with intention $(r=.57)$ and behaviour (past behaviour $r=.66$; future behaviour $r=.61$ ). A PCA run to explore the factor structure underlying the SRHI, AM, intention and behaviour items again extracted two factors, the first of which explained $64.93 \%$ variance (eigenvalue $=14.93$ ), and the second accounted for $8.17 \%$ unique variance (eigenvalue $=1.88$ ).

As table 6.10 shows, higher loadings on the first factor were observed for behaviour, intention, and ten SRHI items, whereas automaticity items and the remaining two SRHI items loaded more highly on to the second dimension. The SRHI, intention and behaviour thus appeared to form a single dimension, whereas AM items tapped a distinct dimension, but SRHI items loading most heavily on the first factor represented both behavioural frequency and automaticity. All items loaded on both factors (>.40), and the strong observed correlation between the factors $(r=$ .63) suggests conceptual overlap.

\subsubsection{Habit as a moderator of the intention-behaviour relation}

Regression analyses to test for moderation effects of habit were run according to the procedure outlined in study 6 (see p.127), and as table 6.11 indicates, the RFM

\footnotetext{
${ }^{31}$ Regression analysis showed that a combination of attitudes, subjective norms and PBC explained $47 \%$ variance in intention, though within this model only attitudes were significantly predictive.
} 
Table 6.9. Study 7: Descriptive statistics and correlations

\begin{tabular}{|c|c|c|c|c|c|c|c|c|c|c|c|c|c|}
\hline & 1. & 2. & 3. & 4. & 5. & 6. & 7. & 8. & 9. & 10. & Mean & $S D$ & $N$ \\
\hline 1. Behaviour $(\mathrm{T} 2)^{\dagger}$ & & $.92 * * *$ & $.61 * * *$ & $.62 * * *$ & $.86^{* * *}$ & $.85^{* * * *}$ & $.80 * * *$ & $.25^{*}$ & $.48^{* * *}$ & $.34 * *$ & 78.17 & 36.56 & 102 \\
\hline 2. Past behaviour & & & $.66^{* * *}$ & $.65 * * *$ & $.91 * * *$ & $.89 * * *$ & $.87 * * *$ & $.28 * *$ & $.53 * * *$ & $.39 * * *$ & 78.84 & 35.51 & 102 \\
\hline 3. Automaticity & & & & $.59 * * *$ & $.75 * * *$ & $.76^{* * * *}$ & $.57 * * *$ & .11 & $.43^{* * *}$ & $.27 * *$ & 4.79 & 1.66 & 102 \\
\hline 4. RFM & & & & & $.67 * * *$ & $.65 * * *$ & $.65 * * *$ & $.25^{*}$ & $.48 * * *$ & $.33 * *$ & 6.11 & 2.49 & 99 \\
\hline 5. SRHI & & & & & & $.99 * * *$ & $.86^{* * * *}$ & $.27 * *$ & $.63 * * *$ & $.45^{* * *}$ & 5.18 & 1.67 & 102 \\
\hline 6. Modified SRHI & & & & & & & $.84^{* * *}$ & $.25^{*}$ & $.63 * * *$ & $.45^{* * *}$ & 5.05 & 1.65 & 102 \\
\hline 7. Intention & & & & & & & & $.37 * * *$ & $.67 * * *$ & $.48 * * *$ & 5.93 & 1.81 & 102 \\
\hline 8. $\mathrm{PBC}$ & & & & & & & & & $.38 * * *$ & $.32 * *$ & 6.17 & 1.10 & 102 \\
\hline 9. Attitude & & & & & & & & & & $.57 * * *$ & 5.51 & 1.22 & 102 \\
\hline 10. Subjective norm & & & & & & & & & & & 4.72 & 1.56 & 102 \\
\hline
\end{tabular}


Table 6.10. Study 7: Principal component analyses for behaviour, intention, SRHI and automaticity items

\begin{tabular}{|c|c|c|c|}
\hline \multirow[t]{2}{*}{ Variable } & \multirow[t]{2}{*}{ Item } & \multicolumn{2}{|c|}{ Factor loadings* } \\
\hline & & Factor 1 & Factor 2 \\
\hline $\begin{array}{l}\text { Past } \\
\text { behaviour }\end{array}$ & & $\begin{array}{l}.91 \\
.95\end{array}$ & .62 \\
\hline Intention & $\begin{array}{l}\text { I intend to use a bicycle for most of my journeys to the } \\
\text { university campus over the next week } \\
\text { I will try to use a bicycle for most of my journeys to the } \\
\text { university campus over the next week } \\
\text { I plan to use a bicycle for most of my journeys to the } \\
\text { university campus over the next week } \\
\text { I aim to use a bicycle for most of my journeys to the } \\
\text { university campus over the next week }\end{array}$ & $\begin{array}{l}.93 \\
.89 \\
.90 \\
.88\end{array}$ & $\begin{array}{l}.49 \\
.49\end{array}$ \\
\hline SRHI & $\begin{array}{l}\text { Using a bicycle to commute to campus is something... } \\
\text { I do frequently } \\
\text { I have been doing for a long time } \\
\text { that belongs to my daily routine } \\
\text { that's typically "me" } \\
\text { I do automatically } \\
\text { I do without having to consciously remember } \\
\text { that makes me feel weird if I do not do it } \\
\text { I do without thinking } \\
\text { that would require effort not to do } \\
\text { I start doing before I realise I'm doing it } \\
\text { I would find hard not to do } \\
\text { I have no need to think about doing }\end{array}$ & $\begin{array}{l}.96 \\
.84 \\
.97 \\
.80 \\
.91 \\
.84 \\
.66 \\
.88 \\
.58 \\
.82 \\
.66 \\
.48\end{array}$ & $\begin{array}{l}.58 \\
.62 \\
.65 \\
.61 \\
.74 \\
.60 \\
.66 \\
.70 \\
.69 \\
.64 \\
.51 \\
.50\end{array}$ \\
\hline$A M$ & $\begin{array}{l}\text { When you need to make a journey, is choosing to } \\
\text { use a bicycle something you do automatically, without } \\
\text { really thinking? } \\
\text { When I have to make a journey, I tend NOT to think } \\
\text { about the modes of transport available to me } \\
\text { When I have to make a journey, I often use a } \\
\text { bicycle without really thinking about the possibility } \\
\text { of using other transport modes } \\
\text { When I have to make a journey, deciding to use a } \\
\text { bicycle is something I do automatically } \\
\text { I automatically choose to use a bicycle when I have } \\
\text { to make a journey }\end{array}$ & $\begin{array}{l}.64 \\
.35 \\
.65 \\
.57 \\
.61\end{array}$ & $\begin{array}{l}.89 \\
.90\end{array}$ \\
\hline
\end{tabular}

* Factor loadings derived from structure matrix for direct oblimin rotation; see Field (2005). 
Table 6.11. Study 7: RFM as moderator of intention-behaviour relationship $(N=99)$

\begin{tabular}{|c|c|c|c|}
\hline Step & Variable(s) entered & $\beta$ & $\beta$ \\
\hline \multirow[t]{2}{*}{1.} & Intention & $.68 * * *$ & $.67 * * *$ \\
\hline & RFM & $.18^{*}$ & $.18^{*}$ \\
\hline 2. & Intention $\mathrm{x}$ RFM & & -.01 \\
\hline \multicolumn{2}{|c|}{ Unadjusted $R^{2}$} & .65 & .65 \\
\hline \multicolumn{2}{|c|}{ Model $F$} & $88.66 * * *$ & $58.50 * * *$ \\
\hline \multicolumn{2}{|c|}{$F$ change } & & 0.01 \\
\hline
\end{tabular}

$* p<.05, * * p<.01, * * * p<.001$

Table 6.12. Study 7: SRHI as moderator of intention-behaviour relationship $(N=102)$

\begin{tabular}{|c|c|c|c|}
\hline Step & Variable $(s)$ entered & $\beta$ & $\beta$ \\
\hline \multirow[t]{2}{*}{1.} & Intention & $.20^{*}$ & .02 \\
\hline & SRHI & $.69 * * *$ & $.66 * * *$ \\
\hline 2. & Intention x SRHI & & $-.23 *$ \\
\hline \multicolumn{2}{|c|}{ Unadjusted $R^{2}$} & .76 & .77 \\
\hline \multicolumn{2}{|c|}{ Model $F$} & $153.41 * * *$ & $107.35 * * *$ \\
\hline \multicolumn{2}{|c|}{$F$ change } & & $4.47 *$ \\
\hline
\end{tabular}

$* p<.05, * * p<.01, * * * p<.001$ 
had a direct effect on behaviour over and above intention $(\beta=.18, p=.03)$, but did not moderate the transition of intention into behaviour $(\beta=-.01, p=.91)$.

The first step of the model in table 6.12 demonstrates that the SRHI had a direct effect on behaviour $(\beta=.69, p<.001)$ independent of intention $(\beta=.20, p=.04)$. The addition of the SRHI $x$ intention interaction term to the model significantly enhanced the model $(\Delta F=4.47, p=.04)$. Not only was the interaction term significantly predictive ( $\beta=-.23, p=.04)$, but the addition of the interaction term reduced the effect of intention to non-significance $(\beta=.02, p=.86)$. As simple slope analyses showed (see figure 6.4 ), cycling was almost solely a function of self-reported habit, such that, at all levels of the SRHI, intentions had no significant influence over behaviour, but a tendency for intentions to better inform cycling where SRHI was low approached statistical significance $(\beta=1.61, p=.11)$.

This effect was revealed more clearly using the modified SRHI: decomposition of the significant interaction between the modified self-report habit scale and intention (see table 6.13) showed that the relationship between intention and behaviour was only statistically significant at low levels of SRHI $(\beta=.22, p=.02$; see figure 6.5$)$. There was no effect of intention over and above SRHI where SRHI scores were at the mean, or one standard deviation above the mean.

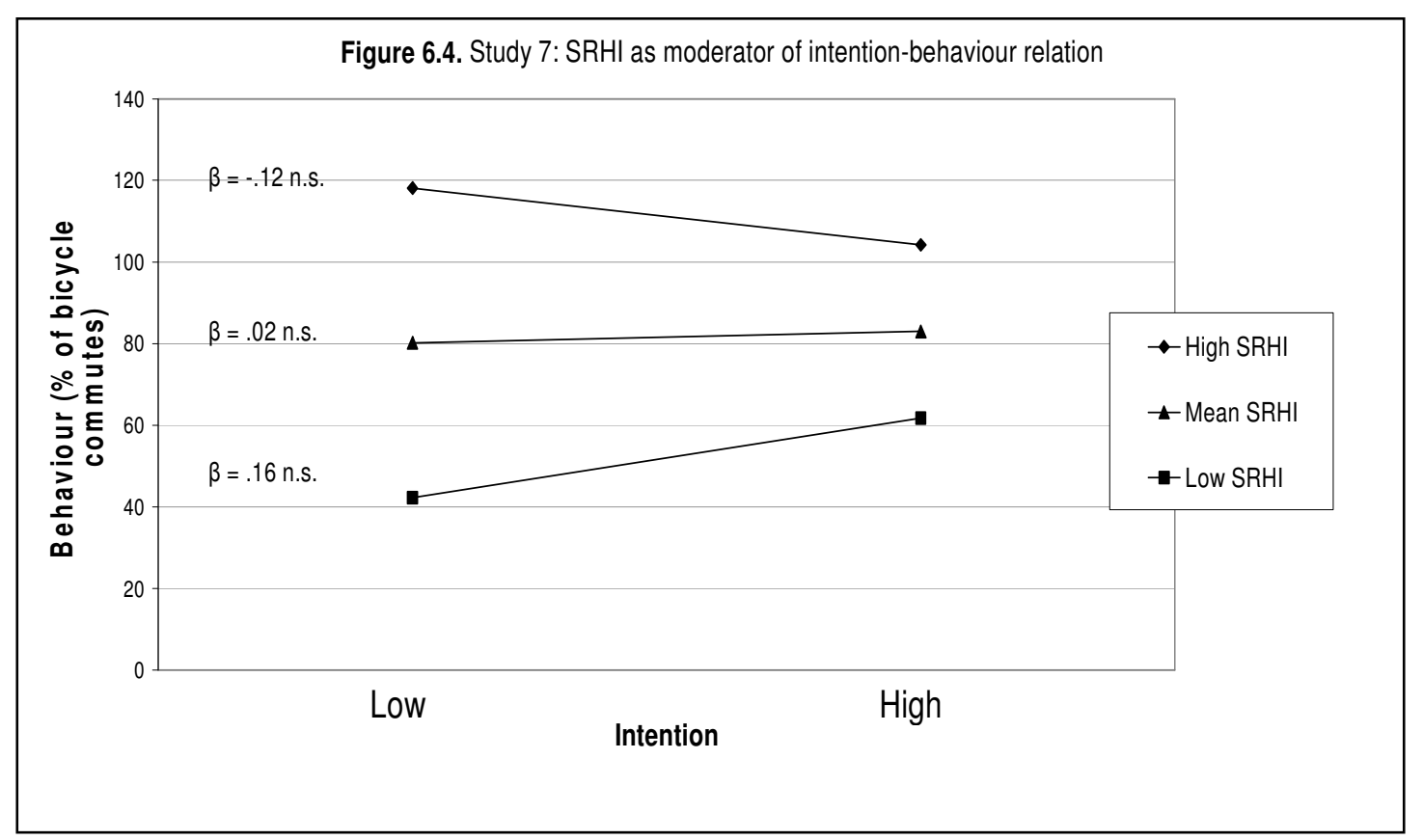


Table 6.13. Study 7: Modified-SRHI as moderator of intention-behaviour relationship $(N=102)$

\begin{tabular}{|c|c|c|c|}
\hline Step & Variable $(s)$ entered & $\beta$ & $\beta$ \\
\hline \multirow[t]{2}{*}{1.} & Intention & $.28 * *$ & .05 \\
\hline & Modified-SRHI & $.61 * * *$ & $.60 * * *$ \\
\hline 2. & Intention x Modified-SRHI & & $-.28 *$ \\
\hline \multicolumn{2}{|c|}{ Unadjusted $R^{2}$} & .75 & .76 \\
\hline \multicolumn{2}{|c|}{ Model $F$} & $144.75 * * *$ & $104.35^{* * *}$ \\
\hline \multicolumn{2}{|c|}{$F$ change } & & $6.75^{*}$ \\
\hline
\end{tabular}

$* p<.05, * * p<.01, * * * p<.001$

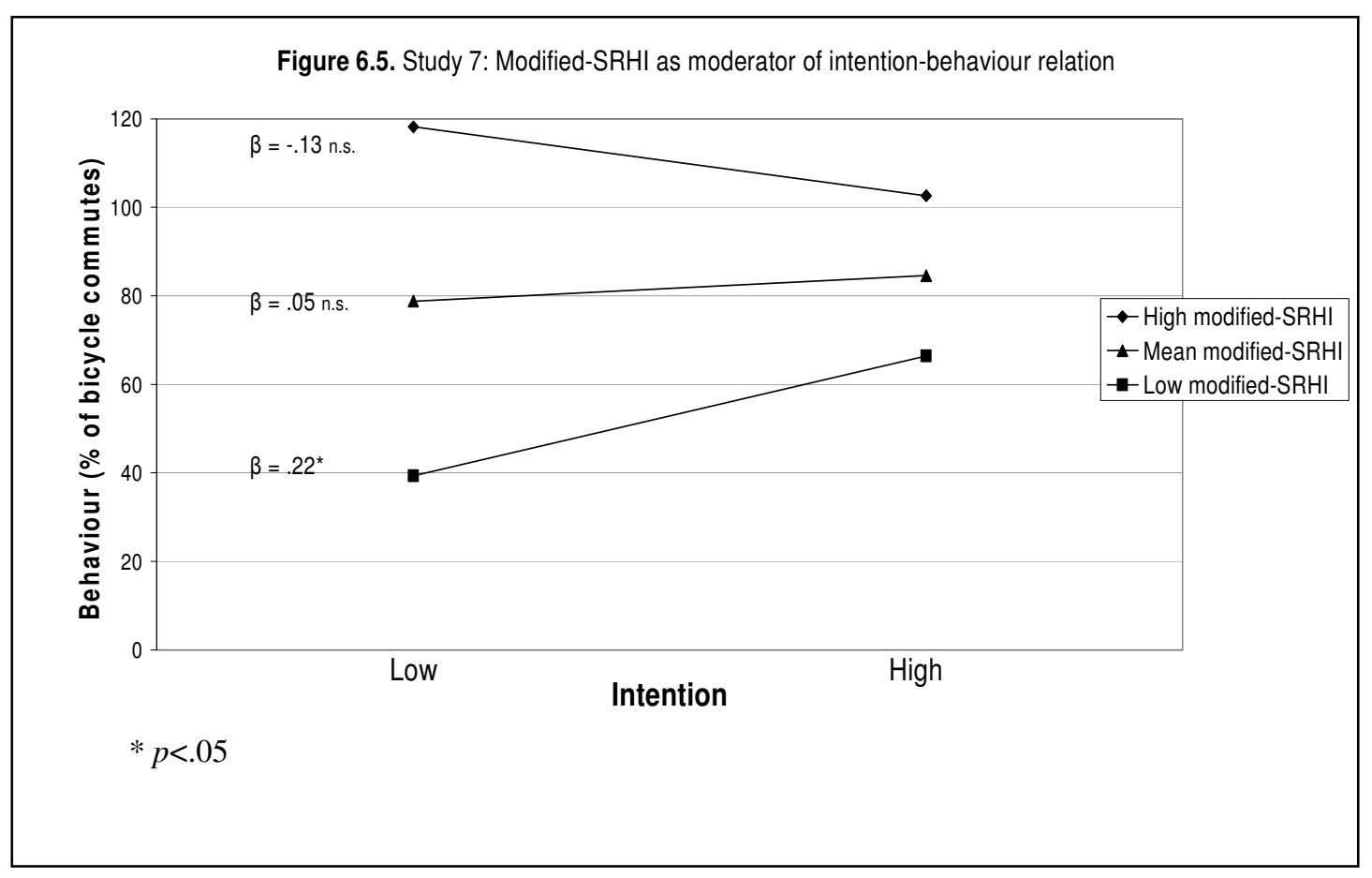

$\mathrm{AM}$ was found to have a direct effect on behaviour over and above intention $(\beta=.23$, $p=.001$ ), but no moderation effect was found; see table 6.14 . 
Table 6.14. Study 7: AM as moderator of intention-behaviour relationship $(N=102)$

\begin{tabular}{|c|c|c|c|}
\hline Step & Variable $(s)$ entered & $\beta$ & $\beta$ \\
\hline \multirow[t]{2}{*}{1.} & Intention & $.66 * * *$ & $.62 * * *$ \\
\hline & Automaticity & $.23 * *$ & $.24 * *$ \\
\hline 2. & Intention x Automaticity & & -.06 \\
\hline \multicolumn{2}{|c|}{ Unadjusted $R^{2}$} & .67 & .67 \\
\hline \multicolumn{2}{|c|}{ Model $F$} & $100.62 * * *$ & $66.83^{* * *}$ \\
\hline \multicolumn{2}{|c|}{$F$ change } & & 0.42 \\
\hline
\end{tabular}

$* p<.05, * * p<.01, * * * p<.001$

Mixed support was again found for hypothesis 3: the SRHI moderated the intentionbehaviour relationship in accordance with theoretical criteria, but the RFM and AM scales did not.

\subsubsection{Discussion}

Results from a study of bicycle commuting habits largely echoed those previously obtained among car commuters. AM displayed convergent validity with existing habit measures, and was less strongly correlated with behaviour than was the SRHI. Principal component analyses again highlighted a two-factor structure underpinning intention, behaviour, SRHI and AM items. The former three constructs loaded most highly on to the first factor, which explained most variance, whereas AM appeared to primarily tap a distinct dimension.

Findings pointed to the strong habitual nature of bicycle commuting. The SRHI offered the best measure of habit according to theoretical criteria, producing a strong direct effect on behaviour, and also moderating the intention-behaviour link. Similar results were obtained for a modified SRHI scale which omitted two behavioural frequency items. The RFM was found to have a direct effect on behaviour over and above intention, but had no effect on the intention-behaviour association. 
AM showed some potential as a habit measure, directly predicting behaviour over and above intention, but did not moderate the intention-behaviour relationship.

\subsection{General Discussion of Studies 5, 6 and 7}

The studies reported in this chapter aimed to construct and validate a self-report automaticity measure (AM) in commuting mode choice in relation to existing habit measures and theoretical criteria regarding the relationship between habit, intention, and behaviour (Triandis, 1977). We also sought to highlight the limitations of the dominant existing self-report habit index (SRHI; Verplanken \& Orbell, 2003), which combines items relating to both behavioural frequency and cognitive automaticity, in predicting travel mode choice.

Study 5 demonstrated the potential for automaticity to be tapped directly using self-report measures, and showed AM to have a unifactorial structure. Studies of car commuting among a UK-based sample (study 6), and bicycle commuting in the Netherlands (study 7) confirmed the convergent validity of the AM, which correlated strongly with two existing habit measures. Findings also pointed to the discriminant validity of AM in relation to behavioural frequency, which correlated strongly but less so than did behaviour and the SRHI. Both studies demonstrated the superiority of the SRHI, which was found to predict behaviour over and above intention and successfully moderate the intention-behaviour relationship. By contrast, AM only had a direct effect on behaviour for bicycle commuting, but did not have an effect on the intention-bicycle use relationship.

Habitual behaviours are characterised in part by behavioural repetition (Bargh, 1994, 1996), and dominate decision-making so that, where habit is strong, reasoned intentions have little influence on behaviour (Triandis, 1977; Verplanken et al., 1994; Verplanken et al., 1998). An appropriate habit measure must therefore correlate with behavioural frequency, and also moderate the intention-behaviour relationship. The SRHI, Verplanken et al's (1994) response frequency habit measure (RFM), and the AM all satisfied the former criterion. However, results from both studies demonstrated the superiority of the SRHI as a moderator of the intention-behaviour association. The RFM moderated the relationship between intentions and behaviour for driving, but not cycling. 


\subsubsection{Habit measurement}

The lack of a moderation effect for AM on the intention-behaviour relationship was unexpected. AM was highly positively correlated with the SRHI, and post-hoc examination of inter-item correlations showed that, in both studies 6 and 7, the SRHI item relating to automaticity ('Behaviour X is something I do automatically') strongly correlated with each AM item. It is possible that effects for AM might have been constrained by the strong statistical association between intention and behaviour in both datasets (rs>.80), and that applications of the AM to domains where intentions and behaviour are less strongly related may yield effects for AM more in line with our expectations. Conversely however, both the RFM and SRHI performed as hypothesised despite the strong intention-behaviour relation, and hence a new automaticity measure may not be needed.

The lack of effects for AM may have arisen from biased self-reports. AM items primarily framed automated decision-making as an absence of forethought and lack of deliberation over alternative options (e.g. '...I often drive without really thinking about the possibility of using other transport modes', '...I tend not to think about the modes of transport available to me'). This may have suggested thoughtlessness and a lack of rationality and decision-making competence to some participants. Participants may therefore have been unwilling to report habitual decision-making in response to AM items, instead responding according to self-presentational concerns for appearing rational. By contrast, the SRHI tends to frame habitual decision-making as a form of cognitive efficiency (e.g. 'Behaviour $\mathrm{X}$ is something: 'I do without having to consciously remember', 'I have no need to think about doing'), which may pose little threat to perceived decisional competence. The SRHI items may therefore avoid potential impression management problems and so elicit more accurate self-reports of habit. This interpretation might explain the two-factor structure that emerged from principal component analyses (PCA) in both studies 6 and 7. SRHI items, intention and behaviour loaded most heavily on one factor, which explained the majority of variance in item responses, while AM items loaded more strongly on a second factor. The first factor might have captured honest reflections on habit and behavioural frequency, while the second factor represented biased responses to the presentation of habit as thoughtlessness rather than cognitive economy. Indeed, the two SRHI items that addressed an absence of forethought ('Behaviour X is something: 'I do automatically', 'I do without thinking') while loading primarily on the former factor, also loaded very 
highly on the latter factor, suggesting that these two items might also invite responses distorted by self-presentation concerns. Further, experimental work might explore whether presenting habit as absence of thought versus efficiency of thought influences willingness to report habits.

The SRHI incorporates items relating to behavioural repetition and cognitive components of habit (i.e. automaticity, and concomitant lack of awareness and mental efficiency; Bargh, 1994, 1996). We criticised the scale for failing to distinguish between past behavioural frequency - which might reflect the influence of a host of unmeasured variables, aside from habit (Ajzen, 2002a) - and habit as a cognitive construct (Verplanken, 2006), but our results showed that the SRHI had a unifactorial structure and was the superior habit index in accordance with theoretical predictions (cf. Verplanken \& Orbell, 2003). We also found that a modified SRHI which omitted two behavioural items was essentially identical to the unmodified scale (see Verplanken, 2006). We also ran post-hoc tests on a further SRHI modification, which removed two more items which may relate more to behavioural frequency than habit as cognition ('Behaviour $\mathrm{X}$ is something: 'that belongs to my daily routine'; 'that's typically "me"'; the latter of which might be attributed to post-behavioural self-perceptions; Bem, 1967). For both car and bicycle commuting, the resultant 8-item SRHI produced very similar effects to those observed for the 12- and 10-item scales. Removing four behavioural items from the SRHI thus conserved the reliability, validity and predictive utility of the scale. We believe that the abbreviated scales offer preferable habit indices, overcoming conceptual problems arising from conflating behavioural and cognitive components of habit (see Verplanken et al., 2005), while being easier to administer and more participant-friendly.

We obtained mixed results for the RFM, which interacted with intention for drivers, and had a direct effect on behaviour for bicycle users. The RFM is designed to operate on the basis that habitual transport choices are activated automatically in response to travel goals, and are therefore more cognitively accessible and likely to be elicited under time pressure (e.g. Verplanken et al., 1994; Verplanken \& Aarts, 1999). We imposed a ten-second time limit on RFM item responses, and so participants may have deliberated over their responses within this time limit. We conducted post-hoc analyses to explore whether response times interacted with RFM scores in predicting behaviour. For both study 6 and 7 datasets, we computed summed response times across the ten items, and regressed behaviour firstly onto this variable and RFM scores, adding 
the response time $\mathrm{x}$ RFM interaction term at the second step. There was no significant direct or interaction effect for response time in either dataset, and so response time did not appear to influence the predictive utility of the RFM (cf. Klöckner et al., 2003).

Alternatively, contrasting results for the RFM across the studies may have arisen because, although items used to measure the RFM in both datasets were matched, the extent to which summed responses to these items accurately reflected travel habits may not have been matched. Aarts and Dijksterhuis (2000a) have shown that RFM items which relate to longer-distance journeys are less able to tap bicycle habits, because the bicycle is less frequently used for longer journeys. Short journeys however may feasibly be undertaken frequently by car (DETR, 2000; Mackett, 2003), and so RFM items may not have been able to elicit habitual travel goals equally across transport modes. We selected RFM items that we thought likely to represent habitual journeys (cf. Klöckner \& Matthies, 2004), but it may be necessary to pilot items to ensure that they tap journeys performed habitually within particular samples (Verplanken et al., 2005). A standard set of RFM items is unlikely to be uniformly applicable to all samples and contexts. Conversely, using RFM measures matched to the travel characteristics of the sample limits comparability across samples. Given also practical difficulties of administering the RFM in non-controlled contexts (see Bamberg et al., 2003), our results suggest the SRHI is the better habit measure.

\subsubsection{Is travel mode choice habitual?}

Our results suggest that commuting mode choice is often habitual (e.g. Klöckner \& Matthies, 2004; Verplanken et al., 1994; Verplanken et al., 1998), but we also acknowledge the role of cognitive deliberation: where habits were weak, travel mode choice was best modelled as a reasoned action (cf. Triandis, 1977). For both car and bicycle use, pre-intention cognitions, intentions and habits all concurred, and so had habit not been controlled for, our results would point to transport choice being a planned behaviour (Ajzen, 1991): intention alone predicted around $65 \%$ of variance in behaviour, which exceeds the typical travel mode intention-behaviour association (e.g. Bamberg \& Schmidt, 2003; see chapter 4, pp.77-78). When a particular transport mode has been repeatedly paired with a travel goal, behaviour acquires a habitual nature, so that future behaviour is automatically initiated when the goal is activated (Verplanken et al., 1997): our results show that where habits were strong, behaviour was dominated by habitual tendencies, rather than intended actions (cf. Verplanken et al., 1994; 
Verplanken et al., 1998). Previous reasoned action research might have overemphasised the deliberative nature of travel mode choice (Bamberg et al., 2003), which is likely to apply only to novel travel situations (Aarts et al., 1998; Fujii \& Kitamura, 2003; Verplanken et al., 1998).

Our findings point to the limited predictive utility of salient reasoned cognitions where habit is strong (Verplanken et al., 1997). Previous research has shown that where travel mode choice is habitual, transport users make less use of information relating to aspects of choice options and of the choice scenario, to the extent that subsequent decisions can be argued to have lost much of their reasoned nature (Aarts et al., 1997, 1998; Verplanken et al., 1997; Verplanken et al., 1998). In such instances, informationbased driving reduction initiatives which target attitude and belief change may have only limited behavioural impact, and strategies must be devised which acknowledge the limited cognitive constraints that characterise habitual decision-making (Aarts et al., 1997; Bargh, 1994, 1996; Verplanken et al., 1997).

\subsubsection{How can habits be broken?}

Aside from infrastructural modifications, which can prevent the enactment of driving habits (e.g. Fujii, Gärling \& Kitamura, 2001), the extant literature suggests a number of strategies for reducing effects of driving habits.

Garvill, Marell and Nordlund (2003) conducted a field experiment whereby drivers kept diaries detailing departure times, travel modes and distances for journeys over a 3-week period. Habitual drivers who were also asked to deliberate and record journey requirements (e.g. time restrictions, weather and road conditions) and consider alternative transport modes prior to each journey subsequently drove less than did weak-habit drivers, or drivers who did not record journey requirements. Verplanken et al. (1998) found that instructing participants to deliberate prior to making transport choices reduced effects of habit and enhanced the influence of intention on transport choice. Thus, employers might provide incentives and/or ask employees to keep diaries recording reasons for driving to promote deliberation over transport decisions.

If habitual car users can be persuaded to form intentions to reduce their car use, habitual driving tendencies are likely to interfere with such intentions and exert greater influence over subsequent travel behaviour (Triandis, 1977). In such situations, encouraging individuals to make detailed plans regarding where, when and how they will enact their intentions (i.e. implementation intentions; Gollwitzer, 1999) are likely to 
facilitate enactment of intentions (e.g. Bamberg, 2000; Verplanken \& Faes, 1999). For example, Verplanken and Faes (1999) showed that forming implementation intentions to eat healthily diminished the effect of unhealthy eating habits on subsequent eating patterns, and Bamberg (2000) showed that students who did not usually use public transport were more likely to try public transport on one occasion where they had formed implementation intentions.

These strategies require sustained engagement with drivers and so may be difficult to administer to large samples. Moreover, where drivers are unwilling to reduce their car use, such interventions might prompt psychological reactance, causing drivers to increase their car use as a means of asserting their freedom (Beale \& Bonsall, 2007; Brehm, 1966; Tertoolen, van Kreveld, \& Verstraten, 1998). Alternatively, undesirable habits might be disrupted - and pro-environment habits formed - via modifications to

the structure of the decisional environment (e.g. Fujii \& Gärling, 2005; but see Aarts et al., 1997). Fujii and Kitamura (2003) showed that giving regular drivers a free onemonth pass for local bus services - thereby diminishing the perceived financial benefits of car use (see chapter 2) - significantly reduced driving behaviour and habits, while also increasing bus use habits, and these gains remained one month later (see too Fujii \& Gärling, 2005). Hence, if financial incentives can be provided for a sufficient duration so as to not only disrupt existing driving habits, but also allow formation of pro-environment transport habits (cf. Ronis et al., 1989), behavioural change may be sustained (Fujii \& Kitamura, 2003). However, further research is necessary to determine the specific conditions under which drivers are likely to attend to changes in the decisional environment (see Aarts et al., 1997).

\subsubsection{Limitations}

Limitations of the current studies should be acknowledged. Firstly, AM was developed on the basis of a sample of 56 drivers, and we might have produced a more valid measure if we had employed a larger sample when devising the AM. We might also have employed a sample of bicycle users for this purpose. Furthermore, the samples of car and bicycle commuters recruited to both studies were somewhat small in size, and we might have obtained different results had we been able to study a larger group of transport users. However, both car and bicycle user samples met statistical power requirements (e.g. Cohen, 1992), and the AM exhibited high reliability alphas and unifactorial structures. 
Results for the AM are likely to have been influenced by our use of items which may have elicited unforeseen self-presentational biases. Development of reliable selfreport indices may therefore depend on framing habit in a way that bypasses impression management concerns.

\subsubsection{Conclusion}

While we did not obtain expected effects for AM, our results generally testify to the validity and robustness of an existing habit measure - the SRHI - as a tool for measuring transport habits. Our study is the first of which we are aware to test direct and interaction effects of the SRHI on commuting mode choice (see Verplanken et al., 2005). Research in novel and stable travel situations is needed to explore whether initial behavioural repetition causes increments in SRHI, and thus that the SRHI mediates between past behaviour and future behaviour. However, our results showed that, across two samples and two frequently used modes of transport, commuting mode choice is often best characterised as the product of habitual rather than reasoned decision making. Policy strategists must therefore acknowledge and account for potential habit-related complications when designing car use reduction campaigns. 


\section{Chapter 7. Discussion}

\subsection{Overview}

We have seen that car transport emissions contribute significantly to climate change (Oskamp, 2000), air pollution (UK National Air Quality Information Archive [UKNAQIA], undated) and cardiovascular and respiratory diseases (Peters et al., 2004), yet the number of car journeys continues to rise in the UK (Department of the Environment, Transport and the Regions [DETR], 2000). Infrastructural and legislative modifications or punitive measures (such as congestion charging) aim to coerce drivers into changing their transport behaviour (Gärling \& Schuitema, 2007), but are often costly and politically problematic due to lack of public acceptance (Emmerink, Nijkamp \& Rietveld, 1995). Persuading drivers to switch transport modes voluntarily by changing beliefs, attitudes and intentions is, therefore, likely to play an important role in reducing car use. However, developing effective evidence-based interventions will depend upon identification of modifiable psychological antecedents of driving (Bartholomew, Parcel, Kok \& Gottlieb, 2006).

Research into the psychological underpinnings of car use has been primarily quantitative and deductively driven, using measures taken from nomothetic social cognitive theories and frameworks which specify potentially modifiable antecedents of behaviour. The most widely applied and well-supported model of the cognitive antecedents of travel mode choice is Ajzen's (1991) Theory of Planned Behaviour (TPB; Bamberg \& Schmidt, 2003). However, inductively guided qualitative analysis can reveal beliefs that underpin attitudes and intentions, and so may offer targets for intervention (Guiver, 2007; Hiscock, Macintyre, Ellaway \& Kearns, 2002; Mann \& Abraham, 2006).

The present thesis reported seven studies which used inductive and deductive approaches and qualitative and quantitative methods to identify antecedents of driving. This summary chapter presents an overview of the studies and key findings, and then explores theoretical and applied implications. Avenues for future research are also outlined.

\subsection{The present findings}

Study 1 employed a qualitative analysis of semi-structured interviews to identify motives for car use as cited by a sample of 19 regular car commuters. Using 'grounded 
theory' coding and analysis techniques (Strauss \& Corbin, 1990, 1998), we identified five key reasons for continued car commuting: concerns for minimising journey times and enhancing affective experiences of the in-journey experience; physical and cognitive effort minimisation; personal space enjoyment; and financial cost minimisation. These were rooted in a desire for control over the transport experience. These motives echoed previous research: time and cost concerns continue to be emphasised in economic transport models (e.g. Vredin Johansson, Heldt \& Johansson, 2006), and perceived effort required to use non-car alternatives has been shown to correlate positively with decisions to drive (Loukopoulos \& Gärling, 2005; cf. Wardman, Hine \& Stradling, 2001). More recent research has also focused on affectbased motives for driving (Mann \& Abraham, 2006; Steg, 2004, 2005; Steg, Vlek \& Slotegraaf, 2001), and demonstrated drivers' desire to avoid negative affective consequences of personal space intrusions (Hiscock et al., 2002). Moreover, we showed how these concerns were underpinned by misconceptions and biases: car costs were equated with petrol costs, which led to systematic underestimations of true costs and biased comparisons with public transport (PT) costs. Car travel was idealised and PT problematised, with drivers expecting traffic-free roads when driving, but service delays and congestion when using buses.

Study 2 sought to explore the predictive utility of the inductively-derived measures of motives identified in study 1 . Reliable quantified measures relating to PT and car commuting were used alongside TPB-specified constructs to predict PT commuting (i.e. decisions not to drive) using longitudinal data from a sample of more than 200 regular car commuters. The TPB was found to predict significant variance in PT use intentions and behaviour, but inductively-derived measures did not predict behaviour. Journey time, affect, effort and personal space beliefs were modelled as predictors of attitudes towards or perceived behavioural control (PBC) over PT use. Inductive belief measures explained $18 \%$ of the variance in attitude and $7 \%$ of the variance in $\mathrm{PBC}$ (see chapter 3, p.57) which contrasts markedly with previous research which has shown similar beliefs to predict over $85 \%$ of variance in attitudes and PBC (Bamberg \& Schmidt, 1999, 2003). The poor performance of our inductive measures cautions against developing theory on the basis of idiographic data from small samples - and by extension, questions the generalisability of findings from small qualitative analyses such as that reported in study 1 . These data suggest that more reliable models 
of transport mode choice can be developed through deductive derivation of cognition measures.

Study 3 revisited the extant literature and a meta-analysis was performed to synthesise effects of potentially modifiable cognitions which have been associated with willingness to reduce car use, intentions to drive and car use. Intention and habit were found to have strong effects on behaviour, but no evidence was available to assess the relationship between willingness and behaviour. TPB cognitions relating to non-car use had uniformly larger (negative) effects on behaviour and intentions than the positive effects observed for cognitions towards driving. We also found effects of descriptive and personal moral norms, and environmental beliefs on behaviour.

In study 4, we explored the relative contribution of car- and non-car use TPB cognitions - supplemented by non-car use personal moral norms, car use descriptive norms and pro-environment beliefs - to the prediction of intra-city car journeys and intentions among 190 residents of a city with high-quality infrastructure to support noncar use. Intention and participant age were direct predictors of car use, and intention in turn was best modelled as the outcome of a combination of car- and non-car TPB cognitions, and descriptive and personal norms. These findings demonstrated not only that TPB cognitions may fail to capture the process of selection among alternative goaldirected options (cf. Abraham \& Sheeran, 2003), but also that the motivation to drive may be influenced more by the unattractiveness of non-car alternatives than the appeal of car use per se. Environmental concern and perceived efficacy for reducing environmental problems associated with car use had effects on intention that were mediated by non-car attitudes and personal norms.

Studies 5, 6 and 7 explored whether habits might moderate the translation of motivation into action. We argued that, although there is growing evidence that decisions to drive are habitual, research in this area is constrained by the lack of an appropriate habit measure. The best-supported existing measure, Verplanken and Orbell's (2003) self-report habit index (SRHI), may be limited by conflating behavioural aspects of habit (i.e. repetition) and the main cognitive component of habit (automaticity). This is potentially problematic because although habitual behaviours are more frequently performed (Ouellette \& Wood, 1998), behavioural frequency may reflect the continued influence of unmeasured variables which may or may not include habit (Ajzen, 2002a). In study 5, we developed a new five-item unifactorial self-report automaticity measure (AM). In study 6 , the convergent and theoretical validity of the 
AM was compared to the SRHI, and the response-frequency measure of travel habit (RFM; Verplanken, Aarts, van Knippenberg \& van Knippenberg, 1994), in relation to car commuting. The AM showed convergent validity with existing habit measures, but while the RFM and SRHI met defined theoretical criteria by moderating the intentionbehaviour relationship - such that higher habit scores weakened the intention-behaviour association (Triandis, 1977) - the AM did not. Also, a version of the SRHI modified to omit behavioural frequency items performed identically to the unmodified SRHI. Study 7 essentially replicated these findings among a sample of bicycle commuters in the Netherlands, although no moderation effect was found for the RFM. These results testified to the superiority of the SRHI, but showed that a conceptually clarified SRHI which removed behavioural frequency items was able to perform identically to the unmodified SRHI. The AM did not perform well as a habit measure, perhaps due to portraying habit as undesirable, i.e. as absence of thought, where the SRHI primarily presents habit as efficiency of thought. Further work on how participants view selfreport habit items could clarify these issues. The results confirmed the strong habitual nature of commuting mode choice (cf. Klöckner, Matthies \& Hunecke, 2003; Verplanken, Aarts, van Knippenberg \& Moonen, 1998).

\subsection{Theoretical implications: Towards an integrative model of car use}

In studies 1 and 2, we sought to explore whether concepts inductively derived from car commuters' discourses surrounding driving could provide a coherent predictive model of decisions to use PT among a larger sample of car commuters. However, study 2 showed that the inductive beliefs did not predict behaviour directly, and that the nomothetic concepts offered by the TPB offered superior prediction. Study 4 also supported the predictive utility of the TPB, and indeed the meta-analysis reported in study 3 showed that the TPB is well-supported in the extant literature. The TPB offers a cross-behaviour framework for integrating research findings (Taylor \& Todd, 1997) and, taken together, the studies reported in this thesis point towards augmentation of the basic TPB model to produce a more sophisticated account of decisions to drive, through specification of additional constructs within a TPB framework. Study 1 elicited

utility- and affect-based concerns relating to both PT and car use relating to decisions to drive to work among regular car commuters, and study 2 showed that these could be modelled as determinants of attitudinal and control perceptions surrounding PT use (i.e. non-car travel). Study 4 suggested that environmental concerns might compete with 
utilitarian and affective considerations in promoting positive attitudes towards non-car travel. Study 4 also demonstrated that prediction of driving intentions might be boosted by augmenting cognitions towards using one form of transport with matched measures relating to other modes of transport, while also pointing to roles for descriptive norms and personal norms as antecedents of intention. Studies 6 and 7 however showed that the influence of intentions on behaviour will be diminished where commuters have formed habits for using a transport mode (Triandis, 1977). Habit thus imposes a boundary condition on the reasoned model of action proposed by the TPB (Verplanken et al, 1994). Here we discuss the implications of our findings for the development of a comprehensive TPB-based predictive model of car use.

\subsubsection{Determinants of intentions to drive. Studies 2, 4, 6 and 7 demonstrated that the} TPB can sufficiently predict travel mode decisions. In study 2 proportions of explained variance in intention and behaviour were relatively small (14\% and $21 \%$ respectively; see chapter 3, p.57) while in study 4 an unmodified TPB explained $28 \%$ of intention variance and 56\% in behaviour (chapter 5, p.105). In studies 6 and 7, intention accounted for around 65-70\% of behaviour variance (chapter 6, pp.129-132 \& pp.139142). These figures generally concur with previous findings (e.g. Bamberg \& Schmidt, 1999, 2003; Harland et al., 1999; see too chapter 4, p.78), and support the efficacy of the TPB for predicting travel mode decisions. The meta-analysis (study 3 ) showed that, in the extant literature, perceptions of control and attitudes had stronger effects on intentions than did subjective norms, although there was considerable variation across studies. This was supported by study 2 , where subjective norms for PT use had no effect on intentions, and study 4, where there was only a small effect of subjective norms for non-car travel but stronger effects of car PBC and non-car attitudes. Explicit perceived social pressure may therefore have little influence on decisions to drive; however, as study 4 revealed, subjective norms for reducing driving or using non-car alternatives may have more potent motivational effects than approval for driving. Addressing attitudinal and perceived control barriers to non-car travel may thus offer more effective routes to changing drivers' motivations.

Study 4 showed that, at least for prediction of intention, the TPB could be enhanced by additional cognition measures: $16 \%$ of additional variance in intentions was explained by the addition of TPB cognitions relating to non-car travel (chapter 5, p.100). Ajzen (1991) suggests that cognitions concerning a specific behaviour 
sufficiently incorporate beliefs surrounding competing goal-directed alternatives, but our analysis suggested that measures of these cognitions may fail to capture the influence of alternative options (Abraham \& Sheeran, 2003; Sheppard, Hartwick \& Warshaw, 1988). This might explain the failure of the constructs identified in study 1 to predict cognitions in study 2: concepts derived from study 1 represented potential reasons for driving rather than for not using PT, and so we may have found that the inductively derived constructs predicted cognitions in study 2 if we had modelled cognitions towards car use, rather than PT. Predictive models of driving might be enhanced through the use of measures relating both to car and non-car transport alternatives. This is supported by previous meta-analytic work (Sheppard et al., 1988) showing that intentions are better predictors of behaviour specified as choice between actions rather than a simple behaviour (average $r$ s $=.72$ and.42, respectively).

A recent revision of the TPB (Ajzen \& Fishbein, 2005) which incorporates descriptive norms as an additional determinant of intention suggests that believing others are performing a behaviour enhances the likelihood of personal action. In study 4 descriptive norms for driving were found to contribute unique variance but had an unexpectedly negative effect on car use. This may imply that when others were expected not to drive, participants sought to capitalise on anticipated congestion-free roads (van Vugt, Meertens \& van Lange, 1995). Moreover, in study 2 we found no effect for descriptive norms on intention. The potential role of descriptive norms in driving requires further exploration, especially given the lack of available evidence, as revealed in study 3 .

Study 4 showed that effects of personal moral norms on intentions were not captured by existing TPB constructs. Moreover, models of transport behaviour which position moral norms as direct determinants of mode choice (Hunecke, Blöbaum, Matthies \& Hoger, 2001; Klöckner \& Matthies, 2004; Matthies, Klöckner \& Preißner, 2006) may overemphasise the moral underpinnings of transport behaviour because variance in behaviour explained by personal norm is typically low (see study 3 , chapter 4, p.78; cf. Hunecke et al., 2001). Study 4 demonstrated that personal norms are best modelled as distal determinants of behaviour, competing with attitudes, social influences and perceptions of control in shaping drivers' intentions and preferences (cf. Mann, 2004; Fujii \& Gärling, 2003a). Attempts to engineer behaviour change by emphasising the moral imperative to make pro-environment travel mode choices may therefore fail where competing cognitions favouring car use remain unchanged. 
7.3.2. Beliefs underlying pre-intention cognitions. Designing effective persuasive interventions to change drivers' intentions requires understanding of the behavioural beliefs that inform determinants of intention (Ajzen \& Fishbein, 1980). The TPB portrays the actor as rational and utility-oriented (Ajzen, 1991), and previous research into the beliefs underlying attitude and control perceptions has tended to focus on utility-based concerns regarding costs, journey time, flexibility, and physical effort required to use non-car transport (e.g. Bamberg \& Schmidt, 1999, 2003; see too Loukopoulos \& Gärling, 2005). Study 1 however showed that drivers have concerns not only for maximising utility, but also for achieving positive affect (and avoiding negative affect typically associated with PT). The TPB treats affect as an undifferentiated component of attitude, and study 2 showed that affect could be at least partially encompassed by TPB cognitions, because anticipated affective experiences of PT were a significant determinant of attitudes towards PT (cf. Fishbein \& Ajzen, 1975). However, the size of the relationship was small, and, although post-hoc analyses in study 2 revealed that affect could be regressed on to many of the quantified measures of the inductive beliefs, affect had only a very minor and distal effect on intentions and behaviour. Future research should focus on estimating how important anticipated affect is to the prediction of travel mode decisions.

Attempts to model attitudes and PBC on inductive beliefs in study 2 produced disappointing results. Car and PT journey times predicted attitudes towards PT use alongside PT affect, and effort and perceived car personal space opportunities influenced PT control perceptions, but little variance in attitudes and PBC was explained. Study 4 showed that attitudes towards non-car travel may be at least partially determined by environmental cognitions, and in particular environmental concern and perceived efficacy for reducing car-related environmental problems, but again explained variance was low. Although the TPB was shown to offer a useful model of behaviour, further research is needed to establish the beliefs that inform drivers' global attitude and control perceptions. Nevertheless, enhancing concern for the environment and drivers' sense of control over reducing the problem are likely to be important targets for driving reduction campaigns, because aside from effects on attitudes, we also found strong associations between these beliefs and personal moral norms. 
7.3.3. Barriers to the transition of intention into action. The TPB proposes that intention is the most proximal determinant of action (Ajzen, 1991) but a recent extension of the model (Fishbein et al., 2001) suggests that the effect of intention on behaviour may be moderated by situational constraints (cf. Triandis, 1977). Collins and Chambers (2005) have suggested that objective non-psychological factors such as costs, access and time constraints may represent barriers experienced at the volitional stages of action which obstruct the translation of motivation into behaviour (e.g. Heckhausen, 1991). However, study 1 pointed to the importance of transport users' interpretations of these situational barriers in determining behaviour (e.g. Koppelman, 1980): for example, increases in car running costs may have little effect in reducing car use because such costs were not salient to participants. Effects of situational barriers may thus be mediated by transport users' cognitive appraisals, and so there may be scope for modifying drivers' appraisals of situational constraints to better facilitate intention enactment.

Studies 6 and 7 provided strong evidence that travel mode choice - at least among car and bicycle commuters - is often more strongly influenced by habit than by motivation (e.g. Verplanken et al., 1994). Where habits for using the focal mode were strong, intentions had less influence on subsequent behaviour (Triandis, 1977; cf. Verplanken et al., 1998). Habits are likely to arise from initially reasoned decisionmaking, but when a travel goal arises frequently in an unchanging decisional context, repeated behavioural decisions are likely to create a goal-behaviour association such that goal activation is sufficient to prompt action in the absence of deliberation (Verplanken, Aarts \& van Knippenberg, 1997). In unchanging contexts, intentions and habits are therefore likely to concur. Hence, in studies 6 and 7, intention in isolation remained sufficiently predictive of behaviour to support a reasoned action analysis. Thus, as noted in chapter 6 , the role of intentions in guiding everyday travel mode choices may have been overstated in previous research (e.g. Bamberg \& Schmidt, 1999, 2003): intentions may be most important to novel travel decisions (Aarts, Verplanken \& van Knippenberg, 1998; Fujii \& Kitamura, 2003; Verplanken et al., 1998). Further empirical work is needed to assess whether travel habits for one journey type (e.g. commuting) generalise to other journey types (e.g. leisure trips). This would be important in establishing empirically whether commuting represents a particularly strongly habitual travel behaviour and thus requires different intervention strategies to non-commuting journeys. 


\subsection{Transport policy implications}

The programme of research reported in this thesis generally supports the view that for some drivers, evidence-based persuasive strategies may be sufficient to prompt changes in beliefs, attitudes and intentions, and thus engineer voluntary behaviour change in the absence of costly infrastructural modifications or legislative change (Gärling \& Schuitema, 2007). The seven studies reported in this thesis highlight potential targets for evidence-based persuasive car use reduction interventions.

Transport policy has traditionally been informed by economic analyses of traveller behaviour, which assume that objective changes to attributes of available options will prompt behaviour change because transport users are rational. Our findings challenge this assumption. Aside from drivers' potential concerns for maximising affective outcomes during the transport experience, study 1 suggested that even where drivers are utility-oriented, they are unlikely to make rational assessments of the utility of available transport, due to misconceptions regarding costs, journey times, and effort. Attention should be paid to correcting these beliefs. Furthermore, policymakers should recognise that persuading drivers of the benefits of alternatives to car use might not necessarily influence perceptions of the attractiveness of driving.

There may also be some scope for promoting travel mode choice as a moral decision, by raising awareness of the associated problems and how individual action can be effective in addressing these problems. Importantly however, the studies reported in this thesis suggest that a number of beliefs and cognitions compete in determining travel mode choice, and so while emphasis of the moral dimension to and environmental impact of car use may have an impact on intentions, campaigns should seek to modify a range of beliefs to engineer behaviour change (Mann, 2004).

As studies 6 and 7 demonstrated however, there may be limits to the effectiveness of persuasive campaigns where driving is habitual (Aarts, Verplanken \& van Knippenberg, 1997; Verplanken et al., 1997): drivers might fail to attend to motivational messages, and even if such messages do change motivations, these are unlikely to influence behaviour where strong habits remain (Triandis, 1977). In these situations, persuading drivers to deliberate when making transport decisions may be important, as might the provision of temporary financial incentives to use non-car travel as a means for disrupting driving habits and creating non-car travel habits (Fujii \& Kitamura, 2003). Structural modifications, which may frustrate drivers in the enactment of their habitual behaviour, are also likely to play a role in disrupting habits (Fujii \& 
Gärling, 2005; Fujii \& Kitamura, 2003), but their political success and public acceptance may also require persuasive campaigns to target drivers' underlying motivations.

Results from study 1 suggest that marketing transport interventions to drivers might require careful consideration of drivers' multiple social identities, and may depend on successfully appealing to drivers in their roles as 'pedestrians' or 'local residents', which might bypass concerns from drivers identifying as 'motorists'.

\subsection{Directions for future research}

Our data highlighted a number of cognitions that influence decisions to drive. Successful modification of these cognitions as a route to behaviour change depends however on changing the beliefs that underpin these cognitions (Ajzen \& Fishbein, 1980; Bartholomew et al., 2006). Unfortunately, our research offered limited insight into the specific beliefs that informed participants' self-reported cognitions. We sought to establish the underpinnings of attitudes and control perceptions using an idiographic approach in study 1 , but as study 2 showed, the emergent concepts from study 1 generally explained little variance in attitudes and PBC. This could be explored further by research testing the predictive validity of quantified measures of concepts derived from qualitative analyses. Alternatively, the non-compatibility of the qualitative concepts in study 1 and the quantifiable measures of these developed in study 2 may point to problems in quantifying qualitatively-generated concepts, and so future research might establish how best to use qualitative and quantitative methods in concert. Although the present studies support more strongly the utility of quantitative, deductive concepts for predicting transport mode choice, our successful identification in study 1 of many of the biases, misperceptions and non-rational concerns which drivers often wish to conceal for self-presentational reasons (e.g. Steg, Vlek \& Slotegraaf, 2001) suggests that inductively-driven qualitative methodologies will play an important role in revealing and exploring car users' beliefs (Guiver, 2007; Mann \& Abraham, 2006).

The poor predictive utility of the concepts from study 1 may alternatively have arisen because in study 1 we asked commuters to reflect on what studies 6 and 7 showed is a stable behaviour, and so participants in study 1 may have offered reflective justification of their car use choices, rather than insight into the factors that prompt their car use. If repetitive car use decisions form habits, future research might therefore seek to reveal beliefs and reasons for car use in novel situations (e.g. Fujii \& Gärling, 2005), 
and/or among samples of new drivers, where behaviour is more likely to be regulated by deliberative cognitive processing, to inform intervention at the early stages of habit formation.

Studying drivers in novel behavioural contexts might also help to address some of the shortcomings of the present literature surrounding driving habits. Study 6 showed that commuting by car represents a strongly habitual behaviour, but considerable additional research is necessary to illuminate the processes by which habits are formed and influence behaviour. In particular, little is known about the number of goalbehaviour associations necessary to develop a habit (see e.g. Ronis, Yates \& Kirscht, 1989). Additionally, there is little empirical evidence to assess whether travel habits can generalise across journey types (Fujii \& Gärling, 2003b; Fujii \& Kitamura, 2003). For example, is a habitual car commuter also likely to make novel leisure journeys by car, or would this commuter make more deliberative decisions concerning non-work journeys? Future research might therefore seek to observe the formation and generalisation of habits among transport users in new settings and across journey types (cf. Fujii \& Gärling, 2003b).

Study 3 demonstrated that the existing evidence base concerning the determinants of car use is weak. Surprisingly little data is available regarding the role of environment-related cognitions on intentions and behaviour. There are a number of different dimensions of environmental beliefs that could be explored (e.g. environmental awareness, concern, consideration, perceived severity, perceived responsibility; see chapter 5). However, study 4 showed that three environmental beliefs (awareness, concern, and perceived efficacy for reducing car-related environmental problems) were very strongly correlated (chapter 5, p.98), so it may be that these theoretical distinctions do not hold in drivers' everyday experiences. Future research could establish a standardised set of measures which encompass environment-related beliefs.

The research reported in this thesis - and, as the systematic search in study 3 showed, car use research in general - is highly dependent on self-report data, but these may potentially be distorted by biased responses arising from self-presentation concerns (e.g. Lajunen \& Summala, 2003) or tendencies to justify behaviour post-hoc (Kurz et al., 2002). Steg, Vlek and Slotegraaf (2001) have outlined data collection methods that allow observation of the drivers' priorities and concerns but conceal the purpose of the study, thereby minimising self-presentation concerns. Further comparisons of measures 
obtained using Steg et al.'s methods with more widely used self-report measures would be informative.

The key research priority for this area is the development and rigorous evaluation of driving reduction interventions, whether these are based on cognition change or habit breaking (Bartholomew et al., 2006. Such research has the potential to show experimentally how to engineer behaviour change as a direct result of theorised psychological change, using mediation analyses (Michie \& Abraham, 2004).

\subsection{Conclusion}

The studies reported in this thesis have used qualitative and quantitative, inductive and deductive approaches to identify the cognitive antecedents of driving that might be modified as a route to reducing driving. Significant misperceptions and cognitive biases underpinning drivers' beliefs emerged through use of qualitative methods, but for predictive purposes at least, the evidence most strongly favoured the deductive explanation of behaviour derived from the TPB. We showed that the predictive utility of this model could be significantly enhanced through augmentation with cognitions relating to alternative transport modes, descriptive and moral norms, and pro-environment beliefs. Additionally, we showed that, for commuting at least, mode choice was often more strongly determined by habit than by deliberation. These insights are likely to provide important targets for evidence-based interventions to reduce unnecessary car use. 


\section{References}

Studies prefixed with an asterisk (*) were included in the meta-analysis for study 3 (chapter 4). Studies prefixed with superscript 'id' were eligible for meta-analysis but were not entered due to insufficient information.

Aarts, H., \& Dijksterhuis, A. (1999) How often did I do it? Experienced ease of retrieval and frequency estimates of past behavior. Acta Psychologica, 103, 77-89.

Aarts, H., \& Dijksterhuis, A. (2000a) The automatic activation of goal-directed behaviour: The case of travel habit. Journal of Environmental Psychology, 20, 75-82.

Aarts, H., \& Dijksterhuis, A. (2000b) Habits as knowledge structures: Automaticity in goal-directed behavior. Journal of Personality and Social Psychology, 78, 53-63.

Aarts, H., Verplanken, B., \& Van Knippenberg, A. (1997) Habit and information use in travel mode choices. Acta Psychologica, 96, 1-14.

Aarts, H., Verplanken, B., \& Van Knippenberg, A. (1998) Predicting behavior from actions in the past: Repeated decision making or a matter of habit? Journal of Applied Social Psychology, 28, 1355-1374.

Abraham, C. \& Sheeran, P. (2003). Implications of goal theories for the theories of reasoned action and planned behaviour. Current Psychology, 22, 264-280.

Aiken, L.S., \& West, S.G. (1991) Multiple regression: Testing and interpreting interactions. London: Sage.

Ajzen, I. (1988) Attitudes, personality and behavior. Chicago: Open University Press. Ajzen, I. (1991) A theory of planned behavior. Organizational Behaviour and Human Decision Processes, 50, 179-211. 
Ajzen, I. (2002a) Residual effects of past on later behavior: Habituation and reasoned action perspectives. Personality and Social Psychology Review, 6, 107-122.

Ajzen, I. (2002b) Perceived behavioral control, self-efficacy, locus of control, and the Theory of Planned Behavior. Journal of Applied Social Psychology, 32, 665-683.

Ajzen, I. (2006) Constructing a TPB questionnaire: Conceptual and methodological considerations. Accessed $11^{\text {th }}$ January 2007 from http://www.people.umass.edu/aizen/pdf/tpb.measurement.pdf.

Ajzen, I., \& Fishbein, M. (1980) Understanding attitudes and predicting social behavior. New York: Plenum Press.

Ajzen, I., \& Fishbein, M. (2005). The influence of attitudes on behavior. In D. Albarracín, B.T. Johnson, \& M.P. Zanna (Eds.) The handbook of attitudes (pp. 173221). Mahwah: Erlbaum.

Ampt, E. (1999) Grass routes: from travel blending to living neighbourhoods. . a vision for the future. Papers of the 23rd Australasian Transport Research Forum (pp. 579589)

Ampt, E., \& Rooney, A. (1998) Reducing the impact of the car - a sustainable approach: TravelSmart Adelaide. Papers of the $22^{\text {nd }}$ Australasian Transport Research Forum, 805-822.

Anable, J., \& Gatersleben, B. (2005) All work and no play? The role of instrumental and affective factors in work and leisure journeys by different travel modes.

Transportation Research Part A, 39, 163-181.

Arkes, H. R., \& Blumer, C. (1985) The psychology of sunk cost. Organizational Behavior and Human Decision Processes, 35, 124-140.

* Baldassare, M., \& Katz, C. (1992) The personal threat of environmental problems as predictor of environmental practices. Environment and Behavior, 24, 602-616. 
Bamberg, S. (2000) The promotion of new behavior by forming an implementation intention: Results of a field experiment in the domain of travel mode choice. Journal of Applied Social Psychology, 30, 1903-1922.

${ }^{\text {id }}$ Bamberg, S., Ajzen, I., \& Schmidt, P. (2003) Choice of travel mode in the theory of planned behavior: The roles of past behavior, habit, and reasoned action. Basic and Applied Social Psychology, 25, 175-187.

Bamberg, S., Rölle, D., \& Weber, C. (2003) Does habitual car use not lead to more resistance to change of travel mode? Transportation, 30, 97-108.

Bamberg, S., \& Schmidt, P. (1998) Changing travel mode choice as rational choice: Results from a longitudinal intervention study. Rationality and Society, 10, 223-252.

Bamberg, S., \& Schmidt, P. (1999) Regulating transport: Behavioural changes in the field. Journal of Consumer Policy, 22, 479-509.

Bamberg, S., \& Schmidt, P. (2001) Theory-driven subgroup-specific evaluation of an intervention to reduce private car use. Journal of Applied Social Psychology, 31, 13001329.

${ }^{\text {id }}$ Bamberg, S., \& Schmidt, P. (2003) Incentives, morality or habit? Predicting students' car use for university routes with the models of Ajzen, Schwartz and Triandis. Environment and Behavior, 35, 264-285.

Bandura, A. (1997) Self-efficacy: The exercise of control. New York: Freeman.

Bargh, J.A. (1994) The four horsemen of automaticity: Awareness, intention, efficiency, and control in social cognition. In R.S. Wyer \& T.K. Srull (Eds), Handbook of social cognition (Vol. 1, pp1-40). Hillsdale: Lawrence Erlbaum. 
Bargh, J.A. (1996) Automaticity in social psychology. In E.T. Higgins \& A.W. Kruglanski (Eds.) Social psychology: Handbook of basic principles (pp169-183). New York: Guilford.

Bartholomew L. K., Parcel G. S., Kok G., \& Gottlieb N. H. (2006) Intervention mapping: Designing theory and evidence-based health promotion programs. San Francisco: Jossey-Bass.

Bates, J. (1982) Stated preference technique for the analysis of transportation behavior. Proceedings of World Conference of Transportation Research (pp. 252-265). Hamburg.

BBC News Online (2007, $21^{\text {st }}$ February) PM denies road toll 'stealth tax'. Accessed $29^{\text {th }}$ June from http://news.bbc.co.uk/1/hi/uk_politics/6381153.stm.

Beale, J.R., \& Bonsall, P.W. (2007) Marketing in the bus industry: A psychological interpretation of some attitudinal and behavioural outcomes. Transportation Research Part F, 10, 271-287.

Bem, D.J. (1967) Self-perception: An alternative interpretation of cognitive dissonance phenomena. Psychological Review, 74, 183-200.

Bentler, P.M. (2004) EQS 6.0 Structural Equations Program Manual. Enrico, CA: Multivariate Software Inc.

Berntsen, T. (2004) Klimaeffekter av utslipp fra transport [The effect of transport emissions on the climate]. Cicerone, 4, 8-9. English translation available online, accessed $21^{\text {st }}$ January 2006 from http://www.cicero.uio.no/fulltext.asp?id=3032\&lang=en.

id Black, C., Collins, A., \& Snell, M. (2001) Encouraging walking: The case of journeyto-school trips in compact urban areas. Urban Studies, 38, 1121-1141.

Brehm, J. (1966) A theory of psychological reactance. New York: Academic Press. 
Brög, W. (1998) Individualized marketing: implications for transportation demand management. Transportation Research Record, 1618, 116-121.

Brown, B. B., Werner, C. M., \& Kim, N. (2003) Personal and contextual factors supporting the switch to transit use: evaluating a natural transit intervention. Analysis of Social Issues and Public Policy ASAP, 3, 139-160.

Carplus (2004) Add Up Your Travel Costs Calculator. Retrieved 25 ${ }^{\text {th }}$ June 2006 from http://www.carplus.org.uk/excel/Add_up_your_travel_costs.xls.

Ciaburro, T., Jones, P., \& Haigh, D. (1994) Raising public awareness as a means of influencing travel choices. Transportation Planning Systems, 2, 5-21.

Cialdini, R.B., Kallgren, C.A., \& Reno, R.R. (1991) A focus theory of normative conduct. In M.P. Zanna (Ed.) Advances in Experimental Social Psychology (Vol. 24, pp. 201-234). San Diego: Academic Press.

Cohen, J. (1988) Statistical power analysis for the behavioral sciences $\left(2^{\text {nd }}\right.$ ed.). Hillsdale: Erlsbaum.

Cohen, J. (1992) A power primer. Psychological Bulletin, 112, 155-159.

Cohen, J., Cohen, P., West, S.G., \& Aiken, L.S. (2003) Applied multiple regression/correlation analysis for the behavioral sciences $\left(3^{\text {rd }}\right.$ ed.). Mahwah: Lawrence Erlbaum Associates.

${ }^{\text {id }}$ Collins, C.M., \& Chambers, S.M. (2005) Psychological and situational influences on commuter-transport-mode choice. Environment and Behavior, 37, 640-661.

Commission for Integrated Transport (2002) The CfIT Report 2002: Public attitudes to transport in England. London: CfIT. Accessed $27^{\text {th }}$ February 2006 from www.cfit.gov.uk/docs/2002/mori2002. 
Commuter Challenge (2007). Retrieved $3^{\text {rd }}$ April 2007 from http://www.commuterchallenge.ca/english/index.aro.

Conner, M., \& Sparks, P. (1996) The theory of planned behaviour and health behaviours. In M. Conner \& P. Norman (Eds.) Predicting health behaviour: Research and practice with social cognition models (pp. 121-162). Buckingham: Open University Press.

Conner, M., \& Sparks, P. (2005) The theory of planned behaviour and health behaviours. In M. Conner \& P. Norman (Eds.) Predicting health behaviour: Research and practice with social cognition models (2 ${ }^{\text {nd }} e d$. . pp.170-222). Maidenhead: Open University Press.

Cronbach, L.J. (1951) Coefficient alpha and the internal structure of tests. Psychometrika, 16, 297-334.

Curtis, C., \& Headicar, P. (1997) Targeting travel awareness campaigns: Which individuals are more likely to switch from car to other transport for the journey to work? Transport Policy, 4, 57-65.

Dawes, R. M. (1980) Social dilemmas. Annual Review of Psychology, 31, 169-193.

Department for Transport (2005a) Transport 2010: meeting the local transport challenge. London: DfT.

Department for Transport (2005b) Transport statistics Great Britain 2005 (31st ed.) London: The Stationery Office.

Department for Transport (2006a) Transport statistics for Great Britain: 2006 edition. London: The Stationery Office. Available online, accessed $28^{\text {th }}$ June 2007 from http://www.dft.gov.uk/pgr/statistics/datatablespublications/tsgb/2006edition/. 
Department for Transport (2006b) Transport Trends: 2006 edition. Accessed 5th June 2007 from

www.dft.gov.uk/162259/221412/190425/220778/Trends_2006_FINAL_v5.pdf.

Department of the Environment, Transport and the Regions (2000) National travel survey: $1997 / 99$ update. London: The Stationery Office.

Department of Health (1998) The quantification of the effects of air pollution on health in the United Kingdom. London: The Stationery Office.

Eagly, A.H., \& Chaiken, S. (1993) The psychology of attitudes. Fort Worth: Harcourt Brace.

Ellaway, A., Macintyre, S., Hiscock, R., \& Kearns, A. (2003) In the driving seat: psychosocial benefits from private motor vehicle transport compared to public transport. Transportation Research Part F, 6, 217-231.

Emmerink, R. H. M., Nijkamp, P., \& Rietveld, P. (1995) Is congestion pricing a firstbest strategy in transport policy? A critical review of arguments. Environment and Planning B, 22, 581-602.

Faul, F., \& Erdfelder, E. (1992) GPOWER: A priori, post-hoc, and compromise power analyses for MS-DOS [Computer programme]. Bonn, FRG: Bonn University, Department of Psychology. Available online, accessed $4^{\text {th }}$ October 2006 from http://www.psycho.uni-duesseldorf.de/aap/projects/gpower/.

Field, A. (2005) Discovering statistics using SPSS for Windows (2 ${ }^{\text {nd }}$ ed.). London: Sage.

Field, A.P., \& Wright, D.B. (2006) A bluffer's guide to effect sizes. Psypag Quarterly, $58,9-23$.

Fishbein, M., \& Ajzen, I. (1975) Belief, attitude, intention, and behavior: an introduction to theory and research. Reading: Addison-Wesley. 
Fishbein, M., Triandis, H.C., Kanfer, F.H., Becker, M.H., Middlestadt, S.E., \& Eichler, A. (2001) Factors influencing behaviour and behaviour change. In A. Baum, T.R. Revenson, \& J.E. Singer (Eds.), Handbook of health psychology (pp.3-17). Mahwah: Laurence Erlbaum Associates.

Forward, S. (1998a) Behavioural factors affecting modal choice. Linköping: Swedish National Road and Transport Research Institute.

Forward, S. (1998b) Modes of transport on short journeys: Attitudes and behaviour of the inhabitants of Gothenburg. Linköping: Swedish National Road and Transport Research Institute.

* Forward, S. (2004) The prediction of travel behaviour using the theory of planned behaviour. In T. Rothengatter \& R.D. Huguenin (Eds.) Traffic and Transport Psychology (pp.481-492). Amsterdam: Elsevier.

Fujii, S., \& Gärling, T. (2003a) Application of attitude theory for improved predictive accuracy of stated preference methods in travel demand analysis. Transportation Research Part A, 37, 389-402.

Fujii, S., \& Garling, T. (2003b) Development of script-based travel mode choice after forced change. Transportation Research Part F, 6, 117-124.

Fujii, S., \& Gärling, T. (2005) Temporary structural change: a strategy to break car-use habit and promote public transport. In G. Underwood (Ed.), Traffic and transport psychology (pp. 585-592) Amsterdam: Elsevier.

Fujii, S., Gärling, T., \& Kitamura, R. (2001) Changes in drivers' perceptions and use of public transport during a freeway closure: Effects of temporary structural change on cooperation in a real-life social dilemma. Environment and Behavior, 33, 796-808.

Fujii, S., \& Kitamura, R. (2003) What does a one-month free bus ticket do to habitual drivers? An experimental analysis of habit and attitude change. Transportation, 30, 8195. 
Fujii, S., \& Taniguchi, A. (2005a) Reducing family car-use by providing travel advice or requesting behavioral plans: An experimental analysis of travel feedback programs. Transportation Research Part D, 10, 385-393.

Fujii, S., \& Taniguchi, A. (2005b) Travel feedback programs: Communicative mobility management measures for changing travel behavior. Proceedings of the Eastern Asia Society for Transportation Studies, 5, 2320-2329. Available online: accessed $22^{\text {nd }}$ February 2006 from http://www.easts.info/on-line/proceedings_05/2320.pdf.

Gärling, T., Boe, O., \& Golledge, R.G. (2000) Determinants of distance thresholds for driving. Transportation Research Record, 1718, 68-72.

* Gärling, T., Fujii, S., \& Boe, O. (2001) Empirical tests of a model of determinants of script-based driving choice. Transportation Research Part F, 4, 89-102.

Gärling, T., Gillholm, R., \& Gärling, A. (1998) Reintroducing attitude theory in travel behavior research: The validity of an interactive interview procedure to predict car use. Transportation, 25, 129-146.

Gärling, T., \& Sandberg, L. (1997) A commons dilemma approach to households' intentions to change their travel behaviour. In P. R. Stopher, \& M.L. Gosselin (Eds.) Understanding travel behavior in an era of change (pp107-122). Pergamon Press.

Gärling, T., \& Schuitema, G. (2007) Travel demand management targeting reduced private car use: Effectiveness, public acceptability and political feasibility. Journal of Social Issues, 63, 139-153.

* Garvill, J. (1999) Choice of transportation mode: Factors influencing drivers' willingness to reduce personal car use and support car regulations. In M. Foddy, M. Smithson, S. Schneider, \& M. Hogg (Eds.) Resolving social dilemmas: Dynamic, structural, and intergroup aspects (pp.263-279). Hove: Psychology Press. 
* Garvill, J., Marell, A., \& Nordlund, A. (2003) Effects of increased awareness on choice of travel mode. Transportation, 30, 63-79.

Gibbons, F.X., Gerrard, M., Blanton, H., \& Russell, D.W. (1998a) Reasoned action and social reaction: Willingness and intention as independent predictors of health risk. Journal of Personality and Social Psychology, 74, 1164-1180.

Gibbons, F.X., Gerrard, M., Blanton, H., \& Russell, D.W. (1998b) Cognitive antecedents to adolescent health risk: Discriminating between behavioral intention and behavioral willingness. Psychology \& Health, 13, 319-339.

Gibbons, F.X., Gerrard, M., Ouellette, J.A., \& Burzette, R. (2000) Discrimination between behavioural intention and behavioural willingness. In P. Norman, C. Abraham \& M. Conner (Eds.) Understanding and changing health behaviour: From health beliefs to self-regulation (pp. 137-161). Amsterdam: Harwood.

Glaser, B., \& Strauss, A. L. (1967) The discovery of grounded theory: strategies for qualitative research. Chicago: Aldine.

Going for Green (1999) Sustainable communities project: Final report. Wigan: Tidy Britain Group.

Gollwitzer, P.M. (1999) Implementation intentions: Strong effects of simple plans. American Psychologist, 54, 493-503.

Goodwin, P.B. (1997) Mobility and car dependence. In T. Rothengatter \& E. Carbonell Vaya (Eds.) Traffic and transport psychology (pp. 449-464). Oxford: Pergamon Press.

Graham, J.M., Guthrie, A.C., \& Thompson, B. (2003) Consequences of not interpreting structure coefficients in published CFA research: a reminder. Structural Equation Modeling, 10, 142-153.

Green, E., \& Stone, V. (2004) Public attitudes to road pricing: a qualitative study. London: BMRB Social Research. 
Greenwald, A.G. (1975) Consequences of prejudice against the null hypothesis. Psychological Bulletin, 82, 1-20.

Guiver, J.W. (2007) Modal talk: Discourse analysis of how people talk about bus and car travel. Transportation Research Part A, 41, 233-248.

Hampshire County Council (1993) HeadStart. UK.

Hardin, G. (1968) The tragedy of the commons. Science, 162, 1243-1248.

* Harland, P., Staats, H., \& Wilke, H.A.M. (1999) Explaining proenvironmental intention and behavior by personal norms and the theory of planned behavior. Journal of Applied Social Psychology, 29, 2505-2528.

Heath, Y., \& Gifford, R. (2002) Extending the theory of planned behavior: Predicting the use of public transportation. Journal of Applied Social Psychology, 32, 2154-2189.

Heckhausen, H. (1991) Motivation and action. New York: Springer.

Hedges, L.V., \& Olkin, I. (1985) Statistical methods for meta-analysis. Orlando: Academic Press,

Hensher, D. (1994) Stated preference analysis of travel choices: The state of practice. Transportation, 21, 107-133.

Hensher, D.A., \& Reyes, A.J. (2000) Trip chaining as a barrier to the propensity to use public transport. Transportation, 27, 341-361.

Hertfordshire County Council (1993) TravelWise. UK.

Hiscock, R., Macintyre, S., Ellaway, A., \& Kearns, A. (2002) Means of transport and ontological security: do cars provide psychosocial benefits to their users? Transportation Research Part D, 7, 119-135. 
Hunecke, M., Blöbaum, A., Matthies, E., \& Höger, R. (2001) Responsibility and environment: Ecological norm orientation and external factors in the domain of travel mode choice behavior. Environment and Behavior, 33, 830-852.

Hunter, J.E., \& Schmidt, F.L. (1990) Methods of meta-analysis: Correcting error and bias in research findings. London: Sage.

Hunter, J.E., \& Schmidt, F.L. (2004) Methods of meta-analysis: Correcting error and bias in research findings ( $\left.2^{\text {nd }} e d.\right)$. London: Sage.

Hunter, J.E., Schmidt, F.L., \& Jackson, G.B. (1982) Meta-analysis: Cumulating research findings across studies. London: Sage.

Institution of Civil Engineers (2005) The state of the nation 2005. An assessment of the UK's infrastructure by the Institution of Civil Engineers. London: ICE. Available online, accessed $18^{\text {th }}$ January 2006 from http://www.ice.org.uk/downloads/state_of_the_nation_2005.pdf.

Jakobsson, C., Fujii, S., \& Gärling, T. (2002) Effects of economic disincentives on private car use. Transportation, 29, 349-370.

James, B. (1998) Changing travel behaviour through individualised marketing: application and lessons from South Perth. Papers of the $22^{\text {nd }}$ Australasian Transport Research Forum, 635-647.

Johnston, G., \& Abraham, C. (2000) Managing awareness: negotiating and coping with a terminal prognosis. International Journal of Palliative Nursing, 6, 485-494.

* Joireman, J.A., Van Lange, P.A.M., Kuhlman, D.M., Van Vugt, M., \& Shelley, G.P. (1997) An interdependence analysis of commuting decisions. European Journal of Social Psychology, 27, 441-463. 
* Kaiser, F.G., \& Gutscher, H. (2003) The proposition of a general version of the theory of planned behavior: Predicting ecological behavior. Journal of Applied Social Psychology, 33, 586-603.

Kingham, S., Dickinson, J., \& Copsey, S. (2001) Travelling to work: will people move out of their cars. Transport Policy, 8, 151-160.

Klöckner, C. A., \& Matthies, E. (2004) How habits interfere with norm-directed behaviour: a normative decision-making model for travel mode choice. Journal of Environmental Psychology, 24, 319-327.

Klöckner, C.A., Matthies, E., \& Hunecke, M. (2003) Problems of operationalizing habits and integrating habits in normative decision-making models. Journal of Applied Social Psychology, 33, 396-417.

Koppelman, F.S. (1980) Consumer analysis of travel choice behavior. Journal of Advanced Transportation, 14, 133-159.

Koslowsky, M., \& Krausz, M. (1994) On the relationship between commuting, stress symptoms, and attitudinal measures: a LISREL application. Journal of Applied Behavioural Science, 29, 485-492.

Kurz, T., Donaghue, N., Rapley, M., \& Walker, I. (2005) The ways that people talk about natural resources: Discursive strategies as barriers to environmentally sustainable practices. British Journal of Social Psychology, 44, 603-620.

Lajunen, T., \& Summala, H. (2003) Can we trust self-reports of driving? Effects of impression management on driver behaviour questionnaire responses. Transportation Research Part F, 6, 97-107.

Loewenstein, G. (1996) Out of control: Visceral influences on behavior. Organizational Behavior and Human Decision Processes, 65, 272-292. 
* Loukoupolos, P., \& Gärling, T. (2005) Are car users too lazy to walk? The relationship of distance thresholds for driving to the perceived effort of walking. Transportation Research Record, 1926, 205-211.

Macintyre, S., Hiscock, R., Kearns, A., \& Ellaway, A. (2001) Housing tenure and car access: further exploration of the nature of their relationships with health in a UK setting. Journal of Epidemiology and Community Health, 55, 330-331.

Mackett, R.L. (2003) Why do people use their cars for short trips? Transportation, 30, 329-349.

Mann, E. (2004) Cognitive and affective antecedents of commuter transport mode choice. Unpublished doctoral thesis, University of Sussex, Brighton, UK.

Mann, E., \& Abraham, C. (2006) The role of affect in UK commuters' travel mode choices: an interpretative phenomenological analysis. British Journal of Psychology, 97, $155-176$.

* Matthies, E., Klockner, C.A., \& Preißner, C.L. (2006) Applying a modified moral decision making model to change habitual car use: How can commitment be effective? Applied Psychology: An International Review, 55, 91-106.

Matthies, E., Kuhn, S., \& Klockner, C.A. (2002) Travel mode choice of women: The result of limitation, ecological norm, or weak habit? Environment and Behavior, 34, 163-177.

${ }^{\text {id }}$ McKenzie-Mohr, D., Nemiroff, L.S., Beers, L., \& Desmarais, S. (1995) Determinants of responsible environmental behavior. Journal of Social Issues, 51, 139-156.

Meng, X.-L, Rosenthal, R., \& Rubin, D.B. (1992) Comparing correlated correlation coefficients. Psychological Bulletin, 111, 172-175. 
Meyer, M. D. (1999) Demand management as an element of transportation policy: using carrots and sticks to influence travel behavior. Transportation Research Part A, 33, $575-599$.

Michie, S., \& Abraham, C. (2004) Identifying techniques that promote health behaviour change: Evidence-based or evidence-inspired? Psychology and Health, 19, 29-49.

Ministerie van Verkeer en Waterstaat [Ministry of Transport, Public Works and Water Management] (2004) Passenger transport in the Netherlands: Key figures 2004. Available online, accessed $27^{\text {th }}$ May 2007 from http://www.rwsavv.nl/pls/portal30/docs/10197.PDF.

Mittal, B. (1988) Achieving higher seat belt usage: The role of habit in bridging the attitude-behavior gap. Journal of Applied Social Psychology, 18, 993-1016.

Møller, B. T., \& Thøgersen, J. (2003) Car-use habits: An obstacle to the use of public transportation? TRIP Research Conference: The Economic and Environmental Consequences of Regulating Traffic. Hillerød, Denmark, February $2^{\text {nd }} 2003$.

* Nilsson, M., \& Küller, R. (2000) Travel behaviour and environmental concern. Transportation Research Part D, 5, 211-234.

* Nordlund, A.M., \& Garvill, J. (2003) Effects of values, problem awareness, and personal norm on willingness to reduce personal car use. Journal of Environmental Psychology, 23, 339-347.

Nunnally, J.M. (1978) Psychometric Theory: New York: McGraw Hill.

Ory, D. T., \& Mokhtarian, P. L. (2005) When is getting there half the fun? Modeling the liking for travel. Transportation Research Part A, 39, 97-123.

Oskamp, S. (2000) A sustainable future for humanity? How can psychology help? American Psychologist, 55, 496-508. 
Ouellette, J.A., \& Wood, W. (1998) Habit and intention in everyday life: The multiple processes by which past behavior predicts future behavior. Psychological Bulletin, 124, 54-74.

Parkhurst, G. (2000) Influence of bus-based park and ride facilities on users' car traffic. Transport Policy, 7, 159-172.

Paulhus, D. L. (1986) Self-deception and impression management in test responses. In A. Angleitner \& J. S. Wiggins (Eds.), Personality assessment via questionnaires: Current issues in theory and measurement (pp. 143-165) New York: Springer.

Peters, A., \& Pope, C.A. (2002) Cardiopulmonary mortality and air pollution. The Lancet, 360, 1184-1185.

Peters, A., von Klot, S., Heier, M., Trentinaglia, I., Hörmann, A., Wichmann, H.E., \& Löwel, H. (2004) Exposure to traffic and the onset of myocardial infection. The New England Journal of Medicine, 351, 1721-1730.

* Polk, M. (2003) Are women potentially more accommodating than men to a sustainable transportation system in Sweden? Transportation Research Part D, 8, 7595.

* Polk, M. (2004) The influence of gender on daily car use and on willingness to reduce car use in Sweden. Journal of Transport Geography, 12, 185-195.

RAC (2004) RAC report on motoring 2004: counting the cost, cutting congestion. Feltham: RAC.

Reibstein, D. J., Lovelock, C. H., \& Dobson, R. (1980) The direction of causality between perceptions, affect and behavior: an application to travel behavior. Journal of Consumer Research, 6, 370-376. 
Reis, H. T., Sheldon, K. M., Gable, S. L., Roscoe, J., \& Ryan, R. M. (2000) Daily wellbeing: the role of autonomy, competence and relatedness. Personality and Social Psychology Bulletin, 26, 419-435.

Ronis, D.L., Yates, J.F., \& Kirscht, J.P. (1989) Attitudes, decisions, and habits as determinants of repeated behavior. In A.R. Pratkanis, S.J. Breckler, \& A.G. Greenwald (Eds.), Attitude structure and function (pp213-239). Hillsdale: Lawrence Erlbaum.

Rose, G., \& Ampt, E. (2001) Travel blending: an Australian travel awareness initiative. Transportation Research Part D, 6, 95-110.

Rosenthal, R. (1979) The 'file drawer problem' and tolerance for null results. Psychological Bulletin, 86, 638-641.

Rosenthal, R. (1984) Meta-analytic procedures for social research. London: Sage.

Saleh, W. (2007) Success and failure of travel demand management: Is congestion charging the way forward? Transportation Research Part A, 41, 611-614.

Saleh, W., Nelson, J.D., \& Bell, M.G.H. (1998) Modelling vehicle emissions using the TEMIS program. Part 1: enhance of the TEMIS framework. Proceedings of the Institution of Mechanical Engineers, Part A: Journal of Power and Energy, 212, 197 204.

Schade, J., \& Schlag, B. (2003) Acceptability of urban transport pricing strategies. Transportation Research Part F, 6, 45-61.

Schwartz, S. H. (1977) Normative influences on altruism. In L. Berkowitz (Ed.), Advances in experimental social psychology (Vol. 10, pp. 221-279) San Diego: Academic Press.

Schwarzer, R. (1989a) Meta-analysis v5.3. Downloaded $7^{\text {th }}$ November 2006 from http://userpage.fu-berlin.de/ health/meta_e.htm. 
Schwarzer, R. (1989b) Meta-analysis v5.3 manual. Downloaded $7^{\text {th }}$ November 2006 from http://userpage.fu-berlin.de/ health/meta_e.htm.

Sheeran, P. (2002) Intention-behavior relations: A conceptual and empirical review. In W. Stroebe \& M. Hewstone (Eds.) European review of social psychology, Vol 12 (pp.136). Chichester: Wiley.

Sheldon, K. M., Reis, H. T., \& Ryan, R. (1996) What makes for a good day? Competence and autonomy in the day and in the person. Personality and Social Psychology Bulletin, 22, 1270-1279.

Sheppard, B. H., Hartwick, J., \& Warshaw, P. R. (1988). The theory of reasoned action: a meta-analysis of past research with recommendations for modifications and future research. Journal of Consumer Research, 15, 325-343.

Sherrard, C. (1998) Strategies for well-being in later life: a qualitative analysis. British Journal of Medical Psychology, 71, 253-263.

Smith, J., \& Harding, S. (1997) Mortality of women and men using alternative social classifications. In F. Drever \& M. Whitehead (Eds.), Health inequalities (pp. 168-183) London: Office for National Statistics.

* Staats, H., Harland, P., \& Wilke, H.A.M. (2004) Effecting durable change: A team approach to improve environmental behavior in the household. Environment and Behavior, 36, 341-367.

Steg, L. (2003) Can public transport compete the private car? IATSS Research, 27, 2735.

* Steg, L. (2004) Car use: lust and must. In T. Rothengatter \& R.D. Huguenin (Eds.) Traffic and transport psychology (pp. 443-452). Amsterdam: Elsevier.

* Steg, L. (2005) Car use: lust and must. Instrumental, symbolic and affective motives for car use. Transportation Research Part A, 39, 147-162. 
${ }^{\text {id }}$ Steg, L., Geurs, K., \& Ras, M. (2001) The effects of motivational factors on car use: A multidisciplinary modelling approach. Transportation Research Part A, 35, 789-806.

* Steg, L., \& Sievers, I. (2000) Cultural theory and individual perceptions of environmental risks. Environment and Behavior, 32, 248-267.

${ }^{\text {id }}$ Steg, L., \& Vlek, C. (1997) The role of problem awareness in willingness-to-change car use and in evaluating relevant policy measures. In T. Rothengatter \& E. Carbonell Vaya (Eds) Traffic and Transport Psychology: Theory and Application (pp465-475). Oxford: Pergamon.

Steg, L., Vlek, C., \& Slotegraaf, G. (2001) Instrumental-reasoned and symbolicaffective motives for using a motor car. Transportation Research Part F, 4, 151-169.

Stern, P. C. (1992) Psychological dimensions of global environmental change. Annual Review of Psychology, 43, 269-302.

Stradling, S. G., Meadows, M. L., \& Beatty, S. (1998) Psychological benefits and disbenefits of driving. In G. B. Grayson (Ed.), Behavioural research in road safety VIII (pp. 138-151) Crowthorne: Transport Research Laboratory.

Stradling, S.G., Meadows, M.L., \& Beatty, S. (2000) Helping drivers out of their cars: Integrating transport policy and social psychology for sustainable change. Transport Policy, 7, 207-215.

Stradling, S. G., Meadows, M. L., \& Beatty, S. (2001) Identity and independence: two dimensions of driver autonomy. In G. B. Grayson (Ed.), Behavioural research in road safety X (pp. 7-19) Crowthorne: Transport Research Laboratory.

Strauss, A. L., \& Corbin, J. M. (1990) Basics of qualitative research: techniques and procedures for developing grounded theory. London: Sage. 
Strauss, A. L., \& Corbin, J. M. (1998) Basics of qualitative research: techniques and procedures for developing grounded theory (2nd ed.). London: Sage.

Sutton, S. (1994) The past predicts the future: Interpreting behaviour-behaviour relationships in social psychological models of health behaviour. In D.R. Rutter \& L. Quine (Eds.) Social psychology and health: European perspectives (pp.71-88). Aldershot: Avebury.

Tajfel, H. (1981) Human groups and social categories. Cambridge: Cambridge University Press.

Taniguchi, A., Hara, F., Takano, S., Kagaya, S., \& Fujii, S. (2003) Psychological and behavioral effects of travel feedback programs for travel behavior modification. Transportation Research Record, 1839, 182-190.

* Tanner, C. (1999) Constraints on environmental behaviour. Journal of Environmental Psychology, 19, 145-157.

Taylor, M.A.P., \& Ampt, E.S. (2003) Travelling smarter down under: policies for voluntary travel behaviour change in Australia. Transport Policy, 10, 165-177.

Taylor, S., \& Todd, P. (1997) Understanding the determinants of consumer composting behavior. Journal of Applied Social Psychology, 27, 602-628.

Tertoolen, G., van Kreveld, D., \& Verstraten, B. (1998) Psychological resistance against attempts to reduce private car use. Transportation Research Part A, 3, 171-181.

Thøgersen, J. (2006) Understanding repetitive travel mode choices in a stable context: A panel study approach. Transportation Research Part A, 40, 621-638.

Thornton, B., Gibbons, F.X., \& Gerrard, M. (2002) Risk perceptions and prototype perception: Independent processes predicting risk behavior. Personality and Social Psychology Bulletin, 28, 986-999. 
Thorpe, N., Hills, P., \& Jaensirisak, S. (2000) Public attitudes to TDM measures: a comparative study. Transport Policy, 7, 243-257.

Tisato, P., \& Robinson, T. (1999) A cost benefit analysis of travel blending. Papers of the $23^{\text {rd }}$ Australasian Transport Research Forum, 687-702.

Trafimow, D., Sheeran, P., Conner, M., \& Finlay, K. A. (2002). Evidence that perceived behavioural control is a multidimensional construct: Perceived control and perceived difficulty. British Journal of Social Psychology, 41, 101-122.

Transport for London (2007) Central London congestion charging. Impacts monitoring - Fifth annual report, July 2007. London: TfL.

Triandis, H. C. (1977) Interpersonal behavior. Monterey: Brooks/Cole.

Turner, J. C. (1985) Social categorization and the self-concept: a social cognitive theory of group behaviour. In E. J. Lawler (Ed.) Advances in group processes: Theory and research (Vol. 2, pp. 518-538) Greenwich, CT: JAI Press.

Tweed, A. E., \& Salter, D. P. (2000) A conflict of responsibilities: a grounded theory study of clinical psychologists' experiences of client non-attendance within the British National Health Service. British Journal of Medical Psychology, 73, 465-481.

UK National Air Quality Information Archive (undated) Air pollution. Retrieved 15th August 2004 from www.airquality.co.uk/archive/what_causes.

van Lange, P.A.M., van Vugt, M., \& de Cremer, D. (2000) Choosing between personal comfort and the environment: Solutions to the transportation dilemma. In M. van Vugt, M. Snyder, T.R. Tyler \& A. Biel (Eds.) Cooperation in modern society (pp45-63). London: Routledge.

* van Lange, P.A.M., van Vugt, M., Meertens, R.M., \& Ruiter, R.A.C. (1998) A social dilemma analysis of commuting preferences: The roles of social value orientation and trust. Journal of Applied Social Psychology, 28, 796-820. 
van Vugt, M., Meertens, R.M., \& van Lange, P.A.M. (1994) Commuting by car or by public transportation? An interdependence theoretical approach. In U. Schulz, W. Albers, \& U. Muller (Eds.) Social dilemmas and cooperation. Berlin: Springer-Verlag.

* van Vugt, M., Meertens, R.M., \& van Lange, P.A.M. (1995) Car versus public transportation? The role of social value orientations in a real-life social dilemma. Journal of Applied Social Psychology, 25, 258-278.

* van Vugt, M., van Lange, P.A.M., \& Meertens, R.M. (1996) Commuting by car or public transportation? A social dilemma analysis of travel mode judgements. European Journal of Social Psychology, 26, 373-395.

van Vugt, M., van Lange, P.A.M., Meertens, R.M., \& Joireman, J.A. (1996) How a structural solution to a real-world social dilemma failed: A field experiment on the first carpool lane in Europe. Social Psychology Quarterly, 59, 364-374.

Verplanken, B. (2006) Beyond frequency: Habit as mental construct. British Journal of Social Psychology, 45, 639-656.

Verplanken, B., \& Aarts, H. (1999) Habit, attitude, and planned behaviour: Is habit an empty construct or an interesting case of goal-directed automaticity? European Review of Social Psychology, 10, 101-134.

Verplanken, B., Aarts, H., \& van Knippenberg, A. (1997) Habit, information acquisition, and the process of making travel mode choices. European Journal of Social Psychology, 27, 539-560.

* Verplanken, B., Aarts, H., van Knippenberg, A., \& Moonen, A. (1998) Habit versus planned behaviour: A field experiment. British Journal of Social Psychology, 37, 111128. 
* Verplanken, B., Aarts, H., van Knippenberg, A., \& van Knippenberg, C. (1994) Attitude versus general habit: Antecedents of travel mode choice. Journal of Applied Social Psychology, 24, 285-300.

Verplanken, B., \& Faes, S. (1999) Good intentions, bad habits, and effects of forming implementation intentions on healthy eating. European Journal of Social Psychology, 29, 591-604.

Verplanken, B., Myrbakk, B., \& Rudi, E. (2005) The measurement of habit. In T. Betsch \& S. Haberstroh (Eds.), The routines of decision making (pp231-247). Mahwah: Erlbaum.

Verplanken, B., \& Orbell, S. (2003) Reflections on past behaviour: A self-report index of habit strength. Journal of Applied Social Psychology, 33, 1313-1330.

Vredin Johansson, M., Heldt, T., \& Johansson, P. (2006) The effects of attitudes and personality traits on mode choice. Transportation Research Part A, 40, 507-525.

Wardman, M., Hine, J., \& Stradling, S. G. (2001) Interchange and travel choice. Edinburgh: Scottish Executive Central Research Unit.

Wegner, D. (2002) The illusion of conscious will. Cambridge, MA: MIT Press.

Whitelegg, J. (2003) The state of world transport. World Transport Policy and Practice, 9, 4-5. Retrieved 15th August 2004 from www.eco-logica.co.uk/WTTPhome.html.

Wicherts, J.M., Borsboom, D., Kats, J., \& Molenaar, D. (2006) The poor availability of psychological research data for reanalysis. American Psychologist, 61, 726-728.

Willig, C. (2001) Introducing qualitative research in psychology: adventures in theory and method. Milton Keynes: Open University Press.

Winterton, B., \& Sheate, W. (2003) Sustainability and road user charging in UK cities. World Transport Policy \& Practice, 9(4), 5-20. 
Wood, W., Quinn, J.M., \& Kashy, D.A. (2002) Habits in everyday life: Thought, emotion, and action. Journal of Personality and Social Psychology, 83, 1281-1297.

Yamagishi, T. (1986) The structural goal/expectation theory of cooperation in social dilemmas. In E. Lawler (Ed.) Advances in group processes, Volume 3 (pp. 51-87). Greenwich: JAI.

* Yang-Wallentin, F., Schmidt, P., Davidov, E., \& Bamberg, S. (2004) Is there any interaction effect between intention and perceived behavioral control? Methods of Psychological Research Online, 8, 127-157. 
Appendices 
Dear $[\ldots]$,

I am a Professor of Psychology at the University of Sussex, and am working with Ben Gardner, who is a doctoral student funded by the Economic and Social Research Council. We are working on a series of ground-breaking studies into potentially modifiable psychological determinants of private car use.

We obtained your details through Mandy Jameson, who is working with David Parker of Brighton and Hove Council in developing travel plans with local employers. We understand that you are the person at [...] that deals with traffic and transport issues.

I am writing to you to ask for assistance on an interview-based project that we are currently running, from which we aim to develop a general theory of drivers' motives. Although research has previously been conducted in this area, there is as yet no unifying psychological theory of why people choose to drive.

Developing such a theory is crucial for identifying psychological constructs that can be targeted to ensure a reduction in levels of private car use. Furthermore, previous studies have focused mainly on undergraduates that drive to their university campus. However, the major area of concern for researchers in this field is reducing private car use amongst the general population and, in particular, commuters. Thus we aim to recruit from major companies based in Brighton and Hove a small sample of employees that regularly commute to and from work by private car.

We are seeking to interview 2 - 3 regular car commuters from organizations based in Brighton and Hove. We have piloted our interview carefully, and it typically lasts around forty minutes in duration. We are able to offer you a summary of our research findings indicating how a sample of your employees think and feel about traffic and transport issues. We would be happy to discuss how our research might be used as a basis from which to develop an effective 'green' travel plan for your company, should this be of interest to you. We can send you a copy of the interview schedule if desired. Furthermore, we would be able to integrate any traffic and transport-related questions that you may wish to be asked of your employees into this schedule.

Would you be able to help us ask your staff if they would be willing to be interviewed?

Thank you for your help in this matter.

Yours sincerely, Charles Abraham 


\section{A.2.2. Study 1 interview schedule}

- Model of car

- Is it owned or rented?

- Would you consider using an alternative form of transport to get to work?

\section{Typical car use}

- How long have you had your current car?

- What journeys do you undertake in your car?

\section{$\underline{\text { Costs }}$}

- How much would you say that running or keeping your car costs you per month in total, all costs included?

- Prompt: i.e. including road tax, insurance, MOT, petrol etc?

- How much would you say that running or keeping your car costs you per year in total, all costs included?

- Do you know what proportion of your income is spent on running your car?

\section{Ownership of car}

- What is important to you about having a car?

- Prompt: why do you have a car?

- Why did you buy/rent your particular model of car?

- How do you feel about your car in particular?

- Prompts: What is important to you about your (model of) car? Do you like your car?

- How much care do you put into maintaining your car? (Do you have a garage?)

- Do you think your car expresses you (e.g. your personality, traits and/or identity) in any way? (If so, how?)

- What image do you think your car projects to other people who do not know you?

- Do you think other drivers respond to or view you on the basis of your model of car?

\section{Reactions to driving}

- Why do you drive to work?

- Prompt: Why do you not, for example, come by bus?

- How do you feel about driving?

- How do you feel about driving in Brighton and Hove more specifically?

If obstacles are mentioned... Imagine you were in a situation where you knew in advance that there would be certain obstacles on your route, such as roadworks, or traffic jams, but there was no alternative routes available. How would you feel in this situation?

- How does driving make you feel?

- How does driving your particular model of car make you feel? 


\section{In-car experience}

- Have you changed the interior of your car since having bought it? How?

- What's your most memorable experience of driving? What happened?

- Do you give other people lifts in your car? Who? How does this make you feel?

\section{Views on alternative transportation modes}

- If your car was unavailable for whatever reason, and you had to use an alternative form of transport to make your regular journey, which would you choose and why?

- What are your views on the idea of car-sharing? (i.e. several people travelling together to work each day in one car.)

- Have you ever participated in a car-sharing scheme? (If so, how did you find that experience?)

- Have you heard of 'car clubs', e.g. the Hanover car club? What are your thoughts on the idea of a car club?

- Would you be willing to join a car club?

- How often do you use public transport (for any journeys)?

- When did you last use public transport? What happened?

- What's your most memorable experience of using public transport?

- If positive....What is the worst experience you've had of public transport?

- If negative... What is the best experience you've had of public transport?

- What kind of experiences and feelings come to mind when you think of public transport?

- Does this apply to all forms of PT, or just e.g. bus?

- What are your views on the idea of congestion charging?

- Have you experienced the congestion charge in London?

- If yes... How did you find that experience?

\section{$\underline{T D M}$ policy views}

- What do you think of (the idea) of bus lanes?

- How would you feel if they introduced more bus lanes in Brighton and Hove?

- What is your opinion on speed cameras?

- Possible follow-up - What if speed were still monitored, but using a different method, such as helicopter monitoring, in-car 'chip' systems, or in 'cats' eyes'?

- How would you feel about speed limits being lowered to $20 \mathrm{mph}$ in residential streets?

- How would you feel about the idea of some parts of Brighton and Hove being made pedestrian-only?

- In the past few years, Western Road has been closed off for private car users (during daytimes).

- What are your feelings on the idea of Western Road being closed off to private car users?

- Has this particular closure affected you? 
- How would you feel about this being extended to other city centre areas, e.g. North Road, Queens Road, West Street?

- What if the council was to seal off all of the centre of Brighton? How would you feel about this?

- How do you find (the experience of) parking in the city centre?

- i.e. cost, availability of spaces, time taken

- How do you find (the experience of) parking at work?

- What do you think of the idea of public transport having priority over private cars at traffic lights (i.e. buses wait less time at traffic lights)?

- If they were to introduce this here, how would you feel about it?

- How would you feel if the council were to introduce the congestion charge here?

- Possible follow-up: What about if it were less expensive than $£ 5$ (as in London) - e.g. £2 (Edinburgh congestion charge)?

- What do you think of the idea of toll roads?

- What do you think of 'pay as you go' schemes?

- If cost comes up... A recent committee stated that it shouldn't result in paying more (on average) for road use.

- What do you think of 'In Town Without My Car' day?

\section{Close of interview:}

- Considering everything that has been said, would you still be (un)willing to switch from using your car to an alternative form of transport?

- If so... What would it take for you to make the switch?

- If not... If the council were to introduce a set charge for car users, how much would you be willing to pay on top of your current costs to keep using your car? 


\section{A.2.3. Debrief for study 1}

\section{US \\ University of Sussex}

\section{Car use interviews}

Many thanks for taking part in our research. The interview is to be analysed as part of a research project being undertaken by Professor Charles Abraham and myself. The aim of the research is to understand why people use their private cars, and the psychological barriers that prevent regular car commuters from using alternative forms of transport. We are conducting a number of interviews for this purpose.

The final report will be included in my PhD thesis, and may also be submitted to an academic psychology journal for publication.

Both you and your employer will be completely anonymous in the transcript and the final report. Only Professor Abraham, myself, and possibly examiners marking my thesis will have access to the transcript. In the final report, excerpts from your interview may be used but these will be attributed to, e.g., 'Interviewee 4'. Please note too that you retain the right to withdraw your interview from the study at any time.

Neither Professor Abraham nor I are affiliated with any political party, the council, or the automobile industry.

Should you wish to have a transcript of the interview and/or the final report, or if you require any further information, please do not hesitate to contact me at B.D.Gardner@sussex.ac.uk.

Thanks,

Benjamin Gardner

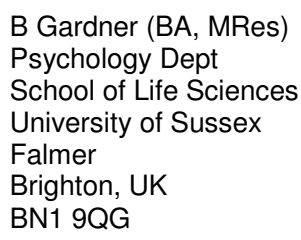




\section{Car use questionnaire}

Please answer the following questions honestly. This is not a test of any sort - it is just about what you think and do. All responses are confidential and anonymous.

\section{Please read very carefully:}

Throughout this questionnaire, you are asked about your experiences of 'commuting'. The term 'commuting' refers specifically to travelling to and from your workplace. Some questions ask you about your experiences of using public transport to commute. If you have never used public transport to commute, please imagine what commuting by public transport would be like.

Are you: female or male (tick one) What is your age? years (write in)

Roughly how far do you have to travel to get to work? miles (write in)

How often do you commute by car?

All the time Most of the time Quite often Sometimes Hardly ever

$\underline{\text { I am willing to commute using public transport instead of my car }}$

$\begin{array}{llllllllll}\text { Strongly disagree } & \mathbf{3} & \mathbf{2} & \mathbf{1} & \mathbf{0} & \mathbf{1} & \mathbf{2} & \mathbf{3} & \text { Strongly agree }\end{array}$

When I commute by public transport, I rarely encounter delays or obstacles $\begin{array}{llllllllll}\text { Strongly agree } & \mathbf{3} & \mathbf{2} & \mathbf{1} & \mathbf{0} & \mathbf{1} & \mathbf{2} & \mathbf{3} & \text { Strongly disagree }\end{array}$

For me, using public transport to commute requires greater effort than driving $\begin{array}{llllllllll}\text { Strongly agree } & \mathbf{3} & \mathbf{2} & \mathbf{1} & \mathbf{0} & \mathbf{1} & \mathbf{2} & \mathbf{3} & \text { Strongly disagree }\end{array}$

Public transport provides the quickest way of getting to and from work $\begin{array}{llllllllll}\text { Strongly disagree } & \mathbf{3} & \mathbf{2} & \mathbf{1} & \mathbf{0} & \mathbf{1} & \mathbf{2} & \mathbf{3} & \text { Strongly agree }\end{array}$

I would be willing to commute by public transport if I used a personal stereo $\begin{array}{llllllllll}\text { Strongly disagree } & \mathbf{3} & \mathbf{2} & \mathbf{1} & \mathbf{0} & \mathbf{1} & \mathbf{2} & \mathbf{3} & \text { Strongly agree }\end{array}$ 
Other people on public transport make me feel:

Threatened

\begin{tabular}{llllllllll}
\hline Strongly agree & $\mathbf{3}$ & $\mathbf{2}$ & $\mathbf{1}$ & $\mathbf{0}$ & $\mathbf{1}$ & $\mathbf{2}$ & $\mathbf{3}$ & Strongly disagree
\end{tabular}

$\underline{\text { Intimidated }}$

$\begin{array}{llllllllll}\text { Strongly agree } & \mathbf{3} & \mathbf{2} & \mathbf{1} & \mathbf{0} & \mathbf{1} & \mathbf{2} & \mathbf{3} & \text { Strongly disagree }\end{array}$

$\underline{\text { Anxious }}$

$\begin{array}{lllllllll}\text { Strongly agree } & \mathbf{3} & \mathbf{2} & \mathbf{1} & \mathbf{0} & \mathbf{1} & \mathbf{2} & \mathbf{3} & \text { Strongly disagree }\end{array}$

$\underline{\text { I find using public transport to commute to and from work: }}$

\begin{tabular}{|c|c|c|c|c|c|c|c|c|}
\hline Very unpleasant & 3 & 2 & 1 & $\mathbf{0}$ & 1 & 2 & 3 & Very pleasant \\
\hline Very enjoyable & 3 & 2 & 1 & $\mathbf{0}$ & $\mathbf{1}$ & 2 & 3 & Very unenjoyable \\
\hline Very unsatisfying & 3 & 2 & 1 & $\mathbf{0}$ & 1 & 2 & 3 & Very satisfying \\
\hline Very frustrating & 3 & 2 & 1 & $\mathbf{0}$ & 1 & 2 & 3 & $\begin{array}{l}\text { Not at all } \\
\text { frustrating }\end{array}$ \\
\hline Very productive & 3 & 2 & 1 & $\mathbf{0}$ & 1 & 2 & 3 & $\begin{array}{l}\text { Not at all } \\
\text { productive }\end{array}$ \\
\hline Very unsafe & 3 & 2 & 1 & $\mathbf{0}$ & 1 & 2 & 3 & Very safe \\
\hline Very slow & 3 & 2 & 1 & $\mathbf{0}$ & 1 & 2 & 3 & Very fast \\
\hline Very reliable & 3 & 2 & 1 & $\mathbf{0}$ & 1 & 2 & 3 & Very unreliable \\
\hline
\end{tabular}

Commuting by car involves subjecting myself to the behaviour of unpleasant people

$\begin{array}{lllllllll}\text { Strongly agree } & \mathbf{3} & \mathbf{2} & \mathbf{1} & \mathbf{0} & \mathbf{1} & \mathbf{2} & \mathbf{3} & \text { Strongly disagree }\end{array}$

For me, commuting by public transport provides protection from other people

$\begin{array}{llllllllll}\text { Strongly disagree } & \mathbf{3} & \mathbf{2} & \mathbf{1} & \mathbf{0} & \mathbf{1} & \mathbf{2} & \mathbf{3} & \text { Stronglyagree }\end{array}$

How much control do you have over the progression of your journey when commuting by public transport?

$\begin{array}{llllllllll}\text { Complete control } & 3 & 2 & 1 & \mathbf{0} & \mathbf{1} & \mathbf{2} & \mathbf{3} & \text { No control }\end{array}$

My priority when commuting is to reach my destination as quickly as possible

$\begin{array}{llllllllll}\text { Strongly agree } & \mathbf{3} & \mathbf{2} & \mathbf{1} & \mathbf{0} & \mathbf{1} & \mathbf{2} & \mathbf{3} & \text { Strongly disagree }\end{array}$

$\underline{\text { I am able to relax when I use public transport to travel home from work }}$

$\begin{array}{llllllllll}\text { Strongly agree } & \mathbf{3} & \mathbf{2} & \mathbf{1} & \mathbf{0} & \mathbf{1} & \mathbf{2} & \mathbf{3} & \text { Strongly disagree }\end{array}$

I would be willing to commute by public transport if public transport were half its current price

$\begin{array}{llllllllll}\text { Strongly disagree } & \mathbf{3} & \mathbf{2} & \mathbf{1} & \mathbf{0} & \mathbf{1} & \mathbf{2} & \mathbf{3} & \text { Strongly agree }\end{array}$ 
Time spent driving to and from work is wasted time

$\begin{array}{llllllllll}\text { Strongly disagree } & \mathbf{3} & \mathbf{2} & \mathbf{1} & \mathbf{0} & \mathbf{1} & \mathbf{2} & \mathbf{3} & \text { Strongly agree }\end{array}$

For me, driving is a simpler option than using public transport

$\begin{array}{llllllllll}\text { Strongly agree } & \mathbf{3} & \mathbf{2} & \mathbf{1} & \mathbf{0} & \mathbf{1} & \mathbf{2} & \mathbf{3} & \text { Strongly disagree }\end{array}$

$\underline{\text { I would be willing to use public transport to commute if using public transport involved less }}$ effort

$\begin{array}{llllllllll}\text { Strongly agree } & \mathbf{3} & \mathbf{2} & \mathbf{1} & \mathbf{0} & \mathbf{1} & \mathbf{2} & \mathbf{3} & \text { Strongly disagree }\end{array}$

$\underline{\text { I use my car mostly for commuting }}$

$\begin{array}{llllllllll}\text { Strongly agree } & \mathbf{3} & \mathbf{2} & \mathbf{1} & \mathbf{0} & \mathbf{1} & \mathbf{2} & \mathbf{3} & \text { Strongly disagree }\end{array}$

My car provides the quickest way of getting to and from work

$\begin{array}{llllllllll}\text { Strongly disagree } & \mathbf{3} & \mathbf{2} & \mathbf{1} & \mathbf{0} & \mathbf{1} & \mathbf{2} & \mathbf{3} & \text { Strongly agree }\end{array}$

I like the sense of control when I commute by car

$\begin{array}{llllllllll}\text { Strongly disagree } & \mathbf{3} & \mathbf{2} & \mathbf{1} & \mathbf{0} & \mathbf{1} & \mathbf{2} & \mathbf{3} & \text { Strongly agree }\end{array}$

I feel safe when commuting by car

$\begin{array}{llllllllll}\text { Strongly agree } & \mathbf{3} & \mathbf{2} & \mathbf{1} & \mathbf{0} & \mathbf{1} & \mathbf{2} & \mathbf{3} & \text { Strongly disagree }\end{array}$

When I use public transport, I feel confident that I will reach my destination within the planned time

$\begin{array}{lllllllll}\text { Strongly agree } & \mathbf{3} & \mathbf{2} & \mathbf{1} & \mathbf{0} & \mathbf{1} & \mathbf{2} & \mathbf{3} & \text { Strongly disagree }\end{array}$

$\underline{\text { I achieve the level of control over my journeys that I require when I use public transport to }}$ commute

$\begin{array}{llllllllll}\text { Strongly disagree } & \mathbf{3} & \mathbf{2} & \mathbf{1} & \mathbf{0} & \mathbf{1} & \mathbf{2} & \mathbf{3} & \text { Strongly agree }\end{array}$

Driving to and from work gives me more free time than does using public transport

$\begin{array}{lllllllll}\text { Strongly agree } & \mathbf{3} & \mathbf{2} & \mathbf{1} & \mathbf{0} & \mathbf{1} & \mathbf{2} & \mathbf{3} & \text { Strongly disagree }\end{array}$

$\underline{\text { I feel free to behave as I wish when commuting by public transport }}$

$\begin{array}{llllllllll}\text { Strongly disagree } & \mathbf{3} & \mathbf{2} & \mathbf{1} & \mathbf{0} & \mathbf{1} & \mathbf{2} & \mathbf{3} & \text { Strongly agree }\end{array}$

$\underline{\text { I feel safe when commuting by public transport }}$

$\begin{array}{llllllllll}\text { Strongly agree } & \mathbf{3} & \mathbf{2} & \mathbf{1} & \mathbf{0} & \mathbf{1} & \mathbf{2} & \mathbf{3} & \text { Strongly disagree }\end{array}$ 
I could get to work on time when commuting by public transport without having to get up $\underline{\text { earlier }}$

$\begin{array}{lllllllll}\text { Strongly agree } & \mathbf{3} & \mathbf{2} & \mathbf{1} & \mathbf{0} & \mathbf{1} & \mathbf{2} & \mathbf{3} & \text { Strongly disagree }\end{array}$

I like to have complete control over the progression of my journey

$\begin{array}{llllllllll}\text { Strongly disagree } & \mathbf{3} & \mathbf{2} & \mathbf{1} & \mathbf{0} & \mathbf{1} & \mathbf{2} & \mathbf{3} & \text { Stronglyagree }\end{array}$

Commuting by public transport allows me to do other things (e.g. read or work) but driving to and from work does not

$\begin{array}{lllllllll}\text { Strongly agree } & \mathbf{3} & \mathbf{2} & \mathbf{1} & \mathbf{0} & \mathbf{1} & \mathbf{2} & \mathbf{3} & \text { Strongly disagree }\end{array}$

$\underline{\text { I am not willing to expend more effort than I already do in commuting to work }}$

$\begin{array}{llllllllll}\text { Strongly disagree } & \mathbf{3} & \mathbf{2} & \mathbf{1} & \mathbf{0} & \mathbf{1} & \mathbf{2} & \mathbf{3} & \text { Strongly agree }\end{array}$

$\underline{\text { Time spent on public transport to and from work is wasted time }}$

$\begin{array}{llllllllll}\text { Strongly disagree } & \mathbf{3} & \mathbf{2} & \mathbf{1} & \mathbf{0} & \mathbf{1} & \mathbf{2} & \mathbf{3} & \text { Strongly agree }\end{array}$

If I use my car to commute, I need to plan my journey in advance

$\begin{array}{llllllllll}\text { Strongly agree } & \mathbf{3} & \mathbf{2} & \mathbf{1} & \mathbf{0} & \mathbf{1} & \mathbf{2} & \mathbf{3} & \text { Strongly disagree }\end{array}$

How effortful is it for you to use public transport to commute?

$\begin{array}{cccccccccc}\begin{array}{c}\text { Completely } \\ \text { effortless }\end{array} & \mathbf{3} & \mathbf{2} & \mathbf{1} & \mathbf{0} & \mathbf{1} & \mathbf{2} & \mathbf{3} & \text { Highly effortful } \\ & & & & & & & & & \end{array}$

I would be willing to use public transport to commute if I felt more in control of my journey when using public transport

$\begin{array}{llllllllll}\text { Strongly disagree } & \mathbf{3} & \mathbf{2} & \mathbf{1} & \mathbf{0} & \mathbf{1} & \mathbf{2} & \mathbf{3} & \text { Strongly agree }\end{array}$

When I drive, I feel confident that I will reach my destination within the planned time

$\begin{array}{llllllllll}\text { Strongly disagree } & \mathbf{3} & \mathbf{2} & \mathbf{1} & \mathbf{0} & \mathbf{1} & \mathbf{2} & \mathbf{3} & \text { Strongly agree }\end{array}$

$\underline{\text { I feel vulnerable when I commute using public transport }}$

$\begin{array}{llllllllll}\text { Strongly agree } & \mathbf{3} & \mathbf{2} & \mathbf{1} & \mathbf{0} & \mathbf{1} & \mathbf{2} & \mathbf{3} & \text { Strongly disagree }\end{array}$

$\underline{\text { To get value for money, I feel I should use my car for most journeys }}$

$\begin{array}{lllllllll}\text { Strongly agree } & \mathbf{3} & \mathbf{2} & \mathbf{1} & \mathbf{0} & \mathbf{1} & \mathbf{2} & \mathbf{3} & \text { Strongly disagree }\end{array}$

I would be willing to use public transport to commute if public transport were quicker

$\begin{array}{llllllllll}\text { Strongly disagree } & \mathbf{3} & \mathbf{2} & \mathbf{1} & \mathbf{0} & \mathbf{1} & \mathbf{2} & \mathbf{3} & \text { Strongly agree }\end{array}$ 
$\underline{\text { I am able to relax when I use my car to travel home from work }}$

$\begin{array}{llllllllll}\text { Strongly agree } & \mathbf{3} & \mathbf{2} & \mathbf{1} & \mathbf{0} & \mathbf{1} & \mathbf{2} & \mathbf{3} & \text { Strongly disagree }\end{array}$

Commuting by public transport involves subjecting myself to the behaviour of unpleasant people

$\begin{array}{lllllllll}\text { Strongly agree } & \mathbf{3} & \mathbf{2} & \mathbf{1} & \mathbf{0} & \mathbf{1} & \mathbf{2} & \mathbf{3} & \text { Strongly disagree }\end{array}$

When I commute by public transport, I am able to overcome potential obstacles arising during the journey

$\begin{array}{llllllllll}\text { Strongly disagree } & \mathbf{3} & \mathbf{2} & \mathbf{1} & \mathbf{0} & \mathbf{1} & \mathbf{2} & \mathbf{3} & \text { Strongly agree }\end{array}$

$\underline{\text { I would be willing to use public transport to commute if I were guaranteed a seat on public }}$ $\underline{\text { transport }}$

$\begin{array}{llllllllll}\text { Strongly disagree } & \mathbf{3} & \mathbf{2} & \mathbf{1} & \mathbf{0} & \mathbf{1} & \mathbf{2} & \mathbf{3} & \text { Strongly agree }\end{array}$

If I were to use public transport to get home from work, I would get home at roughly the same time as if I drove

$\begin{array}{llllllllll}\text { Strongly agree } & \mathbf{3} & \mathbf{2} & \mathbf{1} & \mathbf{0} & \mathbf{1} & \mathbf{2} & \mathbf{3} & \text { Strongly disagree }\end{array}$

$\underline{\text { When I commute by car, I rarely encounter delays or obstacles }}$

$\begin{array}{llllllllll}\text { Strongly disagree } & \mathbf{3} & \mathbf{2} & \mathbf{1} & \mathbf{0} & \mathbf{1} & \mathbf{2} & \mathbf{3} & \text { Strongly agree }\end{array}$

$\underline{\text { I like to be able to initiate my commuting journey when and where I wish }}$

$\begin{array}{llllllllll}\text { Strongly agree } & \mathbf{3} & \mathbf{2} & \mathbf{1} & \mathbf{0} & \mathbf{1} & \mathbf{2} & \mathbf{3} & \text { Strongly disagree }\end{array}$

For me, commuting by public transport is easy

$\begin{array}{llllllllll}\text { Strongly agree } & \mathbf{3} & \mathbf{2} & \mathbf{1} & \mathbf{0} & \mathbf{1} & \mathbf{2} & \mathbf{3} & \text { Strongly disagree }\end{array}$

For me, using public transport to commute is expensive

$\begin{array}{llllllllll}\text { Strongly agree } & \mathbf{3} & \mathbf{2} & \mathbf{1} & \mathbf{0} & \mathbf{1} & \mathbf{2} & \mathbf{3} & \text { Strongly disagree }\end{array}$

$\underline{\text { I like to think over my day when commuting by car home from work }}$

$\begin{array}{lllllllll}\text { Strongly agree } & \mathbf{3} & \mathbf{2} & \mathbf{1} & \mathbf{0} & \mathbf{1} & \mathbf{2} & \mathbf{3} & \text { Strongly disagree }\end{array}$

$\underline{\text { I feel free to behave as I wish when commuting by car }}$

$\begin{array}{llllllllll}\text { Strongly disagree } & \mathbf{3} & \mathbf{2} & \mathbf{1} & \mathbf{0} & \mathbf{1} & \mathbf{2} & \mathbf{3} & \text { Strongly agree }\end{array}$

$\underline{\text { I do not have enough time to commute by public transport }}$

$\begin{array}{lllllllll}\text { Strongly agree } & \mathbf{3} & \mathbf{2} & \mathbf{1} & \mathbf{0} & \mathbf{1} & \mathbf{2} & \mathbf{3} & \text { Strongly disagree }\end{array}$ 
When I commute by car, I am able to overcome potential obstacles arising during the journey

$\begin{array}{llllllllll}\text { Strongly disagree } & \mathbf{3} & \mathbf{2} & \mathbf{1} & \mathbf{0} & \mathbf{1} & \mathbf{2} & \mathbf{3} & \text { Strongly agree }\end{array}$

$\underline{\text { For me, driving to work is easier than using public transport }}$

$\begin{array}{llllllllll}\text { Strongly agree } & \mathbf{3} & \mathbf{2} & \mathbf{1} & \mathbf{0} & \mathbf{1} & \mathbf{2} & \mathbf{3} & \text { Strongly disagree }\end{array}$

When I commute, it is NOT important to me to feel free to behave as I wish

$\begin{array}{lllllllll}\text { Strongly agree } & \mathbf{3} & \mathbf{2} & \mathbf{1} & \mathbf{0} & \mathbf{1} & \mathbf{2} & \mathbf{3} & \text { Strongly disagree }\end{array}$

I would be willing to commute by public transport if public transport were free

$\begin{array}{llllllllll}\text { Strongly disagree } & \mathbf{3} & \mathbf{2} & \mathbf{1} & \mathbf{0} & \mathbf{1} & \mathbf{2} & \mathbf{3} & \text { Strongly agree }\end{array}$

How effortful is it for you to use your car to commute?

$\begin{array}{cccccccccc}\begin{array}{c}\text { Completely } \\ \text { effortless }\end{array} & \mathbf{3} & \mathbf{2} & \mathbf{1} & \mathbf{0} & \mathbf{1} & \mathbf{2} & \mathbf{3} & \text { Highly effortful } \\ & & & & & & & & & \end{array}$

If I use public transport to commute, I need to plan my journey in advance

$\begin{array}{llllllllll}\text { Strongly agree } & \mathbf{3} & \mathbf{2} & \mathbf{1} & \mathbf{0} & \mathbf{1} & \mathbf{2} & \mathbf{3} & \text { Strongly disagree }\end{array}$

I find using my car to commute to and from work:

$\begin{array}{lllllllll}\text { Very unpleasant } & \mathbf{3} & \mathbf{2} & \mathbf{1} & \mathbf{0} & \mathbf{1} & \mathbf{2} & \mathbf{3} & \text { Very pleasant } \\ \text { Very enjoyable } & \mathbf{3} & \mathbf{2} & \mathbf{1} & \mathbf{0} & \mathbf{1} & \mathbf{2} & \mathbf{3} & \text { Very unenjoyable } \\ \text { Very unsatisfying } & \mathbf{3} & \mathbf{2} & \mathbf{1} & \mathbf{0} & \mathbf{1} & \mathbf{2} & \mathbf{3} & \text { Very satisfying } \\ \text { Very frustrating } & \mathbf{3} & \mathbf{2} & \mathbf{1} & \mathbf{0} & \mathbf{1} & \mathbf{2} & \mathbf{3} & \text { Not at all } \\ & & & & & & & & \text { frustrating } \\ \text { Very productive } & \mathbf{3} & \mathbf{2} & \mathbf{1} & \mathbf{0} & \mathbf{1} & \mathbf{2} & \mathbf{3} & \begin{array}{c}\text { Not all } \\ \text { productive }\end{array} \\ & & & & & & & & \text { Very safe } \\ \text { Very unsafe } & \mathbf{3} & \mathbf{2} & \mathbf{1} & \mathbf{0} & \mathbf{1} & \mathbf{2} & \mathbf{3} & \text { Very fast } \\ \text { Very slow } & \mathbf{3} & \mathbf{2} & \mathbf{1} & \mathbf{0} & \mathbf{1} & \mathbf{2} & \mathbf{3} & \text { Very unreliable } \\ \text { Very reliable } & \mathbf{3} & \mathbf{2} & \mathbf{1} & \mathbf{0} & \mathbf{1} & \mathbf{2} & \mathbf{3} & \text { Very }\end{array}$

I would be willing to commute by public transport if the annual road tax charge for my car were to increase by:

$\underline{B y} £ 50$ ?

\begin{tabular}{llllllllll}
\hline Strongly disagree & $\mathbf{3}$ & $\mathbf{2}$ & $\mathbf{1}$ & $\mathbf{0}$ & $\mathbf{1}$ & $\mathbf{2}$ & $\mathbf{3}$ & Strongly agree
\end{tabular}

By $\mathbf{1 1 0 0 ?}$

\begin{tabular}{llllllllll}
\hline Strongly disagree & $\mathbf{3}$ & $\mathbf{2}$ & $\mathbf{1}$ & $\mathbf{0}$ & $\mathbf{1}$ & $\mathbf{2}$ & $\mathbf{3}$ & Strongly agree
\end{tabular}

By £200?

$\begin{array}{lllllllll}\text { Strongly disagree } & \mathbf{3} & \mathbf{2} & \mathbf{1} & \mathbf{0} & \mathbf{1} & \mathbf{2} & \mathbf{3} & \text { Strongly agree }\end{array}$

By £500?

$\begin{array}{llllllllll}\text { Strongly disagree } & \mathbf{3} & \mathbf{2} & \mathbf{1} & \mathbf{0} & \mathbf{1} & \mathbf{2} & \mathbf{3} & \text { Strongly agree }\end{array}$ 
$\underline{\text { I feel in control when I commute by public transport }}$

$\begin{array}{lllllllll}\text { Strongly disagree } & \mathbf{3} & \mathbf{2} & \mathbf{1} & \mathbf{0} & \mathbf{1} & \mathbf{2} & \mathbf{3} & \text { Strongly agree }\end{array}$

For me, commuting by car is less hassle than commuting by public transport

$\begin{array}{llllllllll}\text { Strongly agree } & \mathbf{3} & \mathbf{2} & \mathbf{1} & \mathbf{0} & \mathbf{1} & \mathbf{2} & \mathbf{3} & \text { Strongly disagree }\end{array}$

It is fun to meet other people when commuting by public transport

$\begin{array}{llllllllll}\text { Strongly agree } & \mathbf{3} & \mathbf{2} & \mathbf{1} & \mathbf{0} & \mathbf{1} & \mathbf{2} & \mathbf{3} & \text { Strongly disagree }\end{array}$

For me, commuting by public transport is a sociable activity

$\begin{array}{llllllllll}\text { Strongly agree } & \mathbf{3} & \mathbf{2} & \mathbf{1} & \mathbf{0} & \mathbf{1} & \mathbf{2} & \mathbf{3} & \text { Strongly disagree }\end{array}$

I feel unsafe when I wait at a bus stop or train station when commuting to or from work

$\begin{array}{llllllllll}\text { Strongly agree } & \mathbf{3} & \mathbf{2} & \mathbf{1} & \mathbf{0} & \mathbf{1} & \mathbf{2} & \mathbf{3} & \text { Strongly disagree }\end{array}$

$\underline{\text { I would be willing to commute by public transport if I took a good book to read }}$

$\begin{array}{llllllllll}\text { Strongly disagree } & \mathbf{3} & \mathbf{2} & \mathbf{1} & \mathbf{0} & \mathbf{1} & \mathbf{2} & \mathbf{3} & \text { Strongly agree }\end{array}$

When I use public transport to commute, I have to catch more than one bus or train on one leg of my journey

$\begin{array}{llllllllll}\text { Strongly agree } & \mathbf{3} & \mathbf{2} & \mathbf{1} & \mathbf{0} & \mathbf{1} & \mathbf{2} & \mathbf{3} & \text { Strongly disagree }\end{array}$

$\underline{\text { I like to think over my day when commuting by public transport home from work }}$

$\begin{array}{llllllllll}\text { Strongly agree } & \mathbf{3} & \mathbf{2} & \mathbf{1} & \mathbf{0} & \mathbf{1} & \mathbf{2} & \mathbf{3} & \text { Strongly disagree }\end{array}$

$\underline{\text { If I commuted by public transport I would not need a car }}$

$\begin{array}{lllllllll}\text { Strongly agree } & \mathbf{3} & \mathbf{2} & \mathbf{1} & \mathbf{0} & \mathbf{1} & \mathbf{2} & \mathbf{3} & \text { Strongly disagree }\end{array}$

$\underline{\text { I would be willing to commute by public transport if trains and buses were not so crowded }}$

$\begin{array}{llllllllll}\text { Strongly disagree } & \mathbf{3} & \mathbf{2} & \mathbf{1} & \mathbf{0} & \mathbf{1} & \mathbf{2} & \mathbf{3} & \text { Strongly agree }\end{array}$

$\underline{\text { I would keep a car even if I reverted to using public transport to commute }}$

$\begin{array}{lllllllll}\text { Strongly agree } & \mathbf{3} & \mathbf{2} & \mathbf{1} & \mathbf{0} & \mathbf{1} & \mathbf{2} & \mathbf{3} & \text { Strongly disagree }\end{array}$

How much control do you have over the progression of your journey when using your car to commute?

$\begin{array}{llllllllll}\text { No control } & \mathbf{3} & \mathbf{2} & \mathbf{1} & \mathbf{0} & \mathbf{1} & \mathbf{2} & \mathbf{3} & \text { Complete control }\end{array}$ 
For me, using my car to commute is expensive

$\begin{array}{llllllllll}\text { Strongly agree } & \mathbf{3} & \mathbf{2} & \mathbf{1} & \mathbf{0} & \mathbf{1} & \mathbf{2} & \mathbf{3} & \text { Strongly disagree }\end{array}$ Minimising the amount of money I spend on commuting is NOT important to me

$\begin{array}{lllllllll}\text { Strongly disagree } & \mathbf{3} & \mathbf{2} & \mathbf{1} & \mathbf{0} & \mathbf{1} & \mathbf{2} & \mathbf{3} & \text { Strongly agree }\end{array}$

$\underline{\text { I feel in control when I commute by car }}$

$\begin{array}{lllllllll}\text { Strongly disagree } & \mathbf{3} & \mathbf{2} & \mathbf{1} & \mathbf{0} & \mathbf{1} & \mathbf{2} & \mathbf{3} & \text { Strongly agree }\end{array}$

$\underline{\text { I like the sense of control when I commute by public transport }}$

$\begin{array}{llllllllll}\text { Strongly disagree } & \mathbf{3} & \mathbf{2} & \mathbf{1} & \mathbf{0} & \mathbf{1} & \mathbf{2} & \mathbf{3} & \text { Strongly agree }\end{array}$

$\underline{\text { I feel vulnerable when I commute using my car }}$

$\begin{array}{llllllllll}\text { Strongly agree } & \mathbf{3} & \mathbf{2} & \mathbf{1} & \mathbf{0} & \mathbf{1} & \mathbf{2} & \mathbf{3} & \text { Strongly disagree }\end{array}$

For me, commuting by car is easy

$\begin{array}{llllllllll}\text { Strongly agree } & \mathbf{3} & \mathbf{2} & \mathbf{1} & \mathbf{0} & \mathbf{1} & \mathbf{2} & \mathbf{3} & \text { Strongly disagree }\end{array}$

For me, commuting by car to work is cheaper than using public transport

$\begin{array}{llllllllll}\text { Strongly disagree } & \mathbf{3} & \mathbf{2} & \mathbf{1} & \mathbf{0} & \mathbf{1} & \mathbf{2} & \mathbf{3} & \text { Strongly agree }\end{array}$

My car provides protection from other people

$\begin{array}{llllllllll}\text { Strongly disagree } & \mathbf{3} & \mathbf{2} & \mathbf{1} & \mathbf{0} & \mathbf{1} & \mathbf{2} & \mathbf{3} & \text { Stronglyagree }\end{array}$

Thanks for your help with this study. Please return it in the enclosed envelope. 
A.3.2. Study 2 main study recruitment email sent to employers

Dear $[\ldots]$

\section{Re: Why do more commuters not use public transport?}

I am a social psychologist working at the University of Sussex, and collaborating with Ben Gardner, who is a doctoral student funded by the Economic and Social Research Council. We are working on a series of studies into potentially modifiable psychological determinants of private car use amongst commuters. I am writing to ask you to be involved in these studies.

We wish to explore predictors of transport mode choice, amongst a largish sample of regular car commuters. This will involve regular car commuters completing a questionnaire about their transport-related beliefs, attitudes and intentions. Then, two weeks later, we will contact participants again to measure their commuting behaviour over the previous two weeks. This design will allow us to address several key questions:

1) How prevalent are particular concerns and beliefs?

2) To what extent does holding these concerns and beliefs predict actual commuting behaviour over the two weeks following completion of the first questionnaire?

3) Which concerns and beliefs are most important in predicting willingness to switch to public transport, and actual commuting behaviour?

We aim to recruit a total sample of at least 300 regular car commuters employed in Brighton and Hove. The questionnaire will be distributed electronically, via a weblink to be circulated in an email to participants. (Where electronic distribution is not possible, paper copies will be made available.) Participants who complete the questionnaire will be asked to provide their email addresses, and will then be contacted two weeks later via email with a further link to our second brief questionnaire. Email addresses will then be destroyed. We have piloted our questionnaires carefully amongst persons with varying computer literacy skills, and the first questionnaire typically takes 15 minutes while the second takes about 1 minute to complete.

Participants will be offered a place in a prize draw ( $£ 100$ first prize, $£ 50$ second prize, £25 third prize) as an incentive for participation in both parts of the study.

In return for your assistance, we are happy to offer a presentation of our research to representatives of your organization, and discuss how our research might be used as a basis from which to develop an effective 'green' travel plan for your company. We will of course also provide you with a summary of our research findings.

We enclose a copy of the first questionnaire ('Transport questionnaire') and the follow-up measures ('Follow-up questionnaire') for your inspection. Would you be able to help us by distributing the email below within the Brighton and Hove offices of your organization? 
Thank you for your help in this matter. If you have any questions, please contact B.D.Gardner@sussex.ac.uk.

Yours sincerely,

Prof Charles Abraham 
A.3.3. Study 2 main study recruitment email sent to employees

\section{REGULAR CAR COMMUTERS - win £100!}

If you drive to work regularly, please read on for a chance to win $£ 100$ !

We have been contacted by researchers at the University of Sussex, who are conducting research into why people choose to drive to work. They are looking for people employed in central Brighton and Hove who drive to work regularly (i.e. for most of the working week) to complete a questionnaire, and another very short questionnaire two weeks later.

If you drive to work regularly, please complete the questionnaire via the link below. Everybody who completes both questionnaires will be entered into a prize draw, with the chance to win one of three CASH prizes: $£ 100$ first prize, $£ 50$ second prize, and £25 third prize.

The first questionnaire takes around 15 minutes to complete. The second questionnaire will take around 1 minute.

Please note that your responses will only be available to researchers at the University of Sussex, and NOT anybody within your organisation. Also, although you will be asked to provide your email address so that the researchers can contact you for the second part of the study, your responses will not be stored with your email address. Your email address will be deleted from their records as soon as the draw has taken place.

To access the first questionnaire, please click below: http://www.sussex.ac.uk/Units/socpsy/webq/beng/index.htm

If you have any further questions, please contact the main researcher at B.D.Gardner@sussex.ac.uk.

Thanks!

B. Gardner 


\section{Transport questionnaire}

Please answer the following questions honestly. This is not a test of any sort - it is just about what you think and do. All responses are confidential and anonymous.

Do you drive to and from work regularly (i.e. the majority of your working week)?

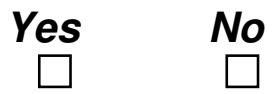

Are you going to be available in two weeks' time to complete a very short, four-question questionnaire online?

Yes No

$\square \quad \square$

$\underline{\text { Please click here to continue }}$

Are you: $\quad$ Female $\square \quad$ Male

What is your age? ___ years

How long have you been driving for? years or months (please indicate in years OR months)

Do you work:

Full-time Part-time 
Roughly how far do you have to travel to get to work? miles

How often do you drive to work?

All the time Most of the time Quite often Sometimes Hardly ever

On how many days in the last two weeks did you commute to and from work by public transport? days

On how many days in the last two weeks did you drive to and from work? days

\section{Please read very carefully:}

Throughout this questionnaire, you are asked about your experiences of 'commuting'.

The term 'commuting' refers specifically to travelling to and from your workplace.

Some questions ask you about your experiences of using public transport to commute.

If you have never used public transport to commute, please imagine what commuting to your workplace by public transport would be like. 
I am willing to commute regularly using public transport instead of my car.

$\begin{array}{llllllllll}\text { Strongly disagree } & \mathbf{3} & \mathbf{2} & \mathbf{1} & \mathbf{0} & \mathbf{1} & \mathbf{2} & \mathbf{3} & \text { Strongly agree }\end{array}$

I have:

$\begin{array}{lllllllllll}\text { No control } & 3 & 2 & 1 & \mathbf{0} & \mathbf{1} & \mathbf{2} & \mathbf{3} & \text { Complete control }\end{array}$ over whether I commute by public transport on at least two days over the next two weeks.

I find driving to and from work:

$\begin{array}{lllllllll}\text { Very unpleasant } & \mathbf{3} & \mathbf{2} & \mathbf{1} & \mathbf{0} & \mathbf{1} & \mathbf{2} & \mathbf{3} & \text { Very pleasant } \\ \text { Very difficult } & \mathbf{3} & \mathbf{2} & \mathbf{1} & \mathbf{0} & \mathbf{1} & \mathbf{2} & \mathbf{3} & \text { Very easy } \\ \text { Completely safe } & \mathbf{3} & \mathbf{2} & \mathbf{1} & \mathbf{0} & \mathbf{1} & \mathbf{2} & \mathbf{3} & \text { Completely unsafe } \\ \text { Very enjoyable } & \mathbf{3} & \mathbf{2} & \mathbf{1} & \mathbf{0} & \mathbf{1} & \mathbf{2} & \mathbf{3} & \text { Very unenjoyable } \\ \text { Highly effortful } & \mathbf{3} & \mathbf{2} & \mathbf{1} & \mathbf{0} & \mathbf{1} & \mathbf{2} & \mathbf{3} & \begin{array}{l}\text { Completely } \\ \text { effortless }\end{array} \\ & & & & & & & & \text { Very satisfying } \\ \text { Very unsatisfying } & \mathbf{3} & \mathbf{2} & \mathbf{1} & \mathbf{0} & \mathbf{1} & \mathbf{2} & \mathbf{3} & \text { Very unreliable } \\ \text { Very reliable } & \mathbf{3} & \mathbf{2} & \mathbf{1} & \mathbf{0} & \mathbf{1} & \mathbf{2} & \mathbf{3} & \text { Very } \\ \text { Very slow } & \mathbf{3} & \mathbf{2} & \mathbf{1} & \mathbf{0} & \mathbf{1} & \mathbf{2} & \mathbf{3} & \text { Very fast } \\ \text { Very expensive } & \mathbf{3} & \mathbf{2} & \mathbf{1} & \mathbf{0} & \mathbf{1} & \mathbf{2} & \mathbf{3} & \text { Very inexpensive }\end{array}$

If I were to use public transport to get home from work, I would get home at roughly the same time as if I drove

$\begin{array}{lllllllll}\text { Strongly agree } & \mathbf{3} & \mathbf{2} & \mathbf{1} & \mathbf{0} & \mathbf{1} & \mathbf{2} & \mathbf{3} & \text { Strongly disagree }\end{array}$

For me, commuting by car is a simpler option than commuting by public transport

$\begin{array}{lllllllll}\text { Strongly agree } & \mathbf{3} & \mathbf{2} & \mathbf{1} & \mathbf{0} & \mathbf{1} & \mathbf{2} & \mathbf{3} & \text { Strongly disagree }\end{array}$

Minimising the amount of money I spend on commuting is:

$\begin{array}{ccccccccccc}\text { Highly important } & \mathbf{3} & \mathbf{2} & \mathbf{1} & \mathbf{0} & \mathbf{1} & \mathbf{2} & \mathbf{3} & \begin{array}{c}\text { Not at all } \\ \text { important }\end{array}\end{array}$

to me. 
For me, driving provides the quickest way of getting to work.

$\begin{array}{lllllllll}\text { Strongly disagree } & \mathbf{3} & \mathbf{2} & \mathbf{1} & \mathbf{0} & \mathbf{1} & \mathbf{2} & \mathbf{3} & \text { Strongly agree }\end{array}$

I am able to control whether I use public transport to commute on at least two days over the next two weeks .

$\begin{array}{lllllllll}\text { Strongly agree } & \mathbf{3} & \mathbf{2} & \mathbf{1} & \mathbf{0} & \mathbf{1} & \mathbf{2} & \mathbf{3} & \text { Strongly disagree }\end{array}$

I would be willing to commute regularly by public transport if public transport were half its current price.

$\begin{array}{lllllllll}\text { Strongly agree } & \mathbf{3} & \mathbf{2} & \mathbf{1} & \mathbf{0} & \mathbf{1} & \mathbf{2} & \mathbf{3} & \text { Strongly disagree }\end{array}$

I feel safe when commuting by car.

$\begin{array}{lllllllll}\text { Strongly disagree } & \mathbf{3} & \mathbf{2} & \mathbf{1} & \mathbf{0} & \mathbf{1} & \mathbf{2} & \mathbf{3} & \text { Strongly agree }\end{array}$

Please click here to continue

I feel safe when commuting by public transport.

$\begin{array}{lllllllll}\text { Strongly disagree } & \mathbf{3} & \mathbf{2} & \mathbf{1} & \mathbf{0} & \mathbf{1} & \mathbf{2} & \mathbf{3} & \text { Strongly agree }\end{array}$

I have enough personal space when I commute by car.

$\begin{array}{lllllllll}\text { Strongly agree } & \mathbf{3} & \mathbf{2} & \mathbf{1} & \mathbf{0} & \mathbf{1} & \mathbf{2} & \mathbf{3} & \text { Strongly disagree }\end{array}$

Minimising the time I spend on commuting to and from work is:

$\begin{array}{lllllllll}\text { Highly important } & \mathbf{3} & \mathbf{2} & \mathbf{1} & \mathbf{0} & \mathbf{1} & \mathbf{2} & \mathbf{3} & \text { Not at all }\end{array}$ important

to me. 
When I commute by public transport, I have enough room to myself.

$\begin{array}{llllllllll}\text { Strongly disagree } & \mathbf{3} & \mathbf{2} & \mathbf{1} & \mathbf{0} & \mathbf{1} & \mathbf{2} & \mathbf{3} & \text { Strongly agree }\end{array}$

How much control do you have over the progression of your journey when driving to and from work?

$\begin{array}{llllllllll}\text { Complete control } & 3 & 2 & 1 & \mathbf{0} & \mathbf{1} & \mathbf{2} & \mathbf{3} & \text { No control }\end{array}$

I feel secure when I commute by public transport.

$\begin{array}{llllllllll}\text { Strongly disagree } & \mathbf{3} & \mathbf{2} & \mathbf{1} & \mathbf{0} & \mathbf{1} & \mathbf{2} & \mathbf{3} & \text { Strongly agree }\end{array}$

I feel vulnerable when I commute by public transport.

$\begin{array}{llllllllll}\text { Strongly agree } & \mathbf{3} & \mathbf{2} & \mathbf{1} & \mathbf{0} & \mathbf{1} & \mathbf{2} & \mathbf{3} & \text { Strongly disagree }\end{array}$

For me, commuting by car is affordable.

$\begin{array}{llllllllll}\text { Strongly agree } & \mathbf{3} & \mathbf{2} & \mathbf{1} & \mathbf{0} & \mathbf{1} & \mathbf{2} & \mathbf{3} & \text { Strongly disagree }\end{array}$

I value the time I spend commuting by public transport, irrespective of its use for getting to work.

$\begin{array}{lllllllll}\text { Strongly agree } & \mathbf{3} & \mathbf{2} & \mathbf{1} & \mathbf{0} & \mathbf{1} & \mathbf{2} & \mathbf{3} & \text { Strongly disagree }\end{array}$

Using public transport to commute on at least two days over the next two weeks would be:

$\begin{array}{lllllllll}\text { Beneficial } & \mathbf{3} & \mathbf{2} & \mathbf{1} & \mathbf{0} & \mathbf{1} & \mathbf{2} & \mathbf{3} & \text { Harmful } \\ \text { Foolish } & \mathbf{3} & \mathbf{2} & \mathbf{1} & \mathbf{0} & \mathbf{1} & \mathbf{2} & \mathbf{3} & \text { Wise } \\ \text { Bad } & \mathbf{3} & \mathbf{2} & \mathbf{1} & \mathbf{0} & \mathbf{1} & \mathbf{2} & \mathbf{3} & \text { Good }\end{array}$


For me, driving to work is easier than using public transport.

$\begin{array}{llllllllll}\text { Strongly agree } & \mathbf{3} & \mathbf{2} & \mathbf{1} & \mathbf{0} & \mathbf{1} & \mathbf{2} & \mathbf{3} & \text { Strongly disagree }\end{array}$

For me, public transport provides the quickest way of getting to work.

$\begin{array}{lllllllll}\text { Strongly agree } & \mathbf{3} & \mathbf{2} & \mathbf{1} & \mathbf{0} & \mathbf{1} & \mathbf{2} & \mathbf{3} & \text { Strongly disagree }\end{array}$

I feel in control when I commute by public transport.

$\begin{array}{lllllllll}\text { Strongly disagree } & \mathbf{3} & \mathbf{2} & \mathbf{1} & \mathbf{0} & \mathbf{1} & \mathbf{2} & \mathbf{3} & \text { Strongly agree }\end{array}$

I feel vulnerable when I commute by car.

$\begin{array}{lllllllll}\text { Strongly agree } & \mathbf{3} & \mathbf{2} & \mathbf{1} & \mathbf{0} & \mathbf{1} & \mathbf{2} & \mathbf{3} & \text { Strongly disagree }\end{array}$

Commuting by public transport seems expensive to me.

$\begin{array}{llllllllll}\text { Strongly disagree } & \mathbf{3} & \mathbf{2} & \mathbf{1} & \mathbf{0} & \mathbf{1} & \mathbf{2} & \mathbf{3} & \text { Strongly agree }\end{array}$

I have little control over the progression of my journey when I commute by car.

$\begin{array}{llllllllll}\text { Strongly agree } & \mathbf{3} & \mathbf{2} & \mathbf{1} & \mathbf{0} & \mathbf{1} & \mathbf{2} & \mathbf{3} & \text { Strongly disagree }\end{array}$

It is:

$\begin{array}{llllllllll}\begin{array}{c}\text { Not at all } \\ \text { important }\end{array} & \mathbf{3} & \mathbf{2} & \mathbf{1} & \mathbf{0} & \mathbf{1} & \mathbf{2} & \mathbf{3} & \text { Highly important } \\ \end{array}$

to me to feel in control of my commuting journey. 
When I drive to work, I am able to overcome potential obstacles during the journey.

$\begin{array}{lllllllll}\text { Strongly agree } & \mathbf{3} & \mathbf{2} & \mathbf{1} & \mathbf{0} & \mathbf{1} & \mathbf{2} & \mathbf{3} & \text { Strongly disagree }\end{array}$

I have enough personal space when I commute by public transport.

$\begin{array}{llllllllll}\text { Strongly disagree } & \mathbf{3} & \mathbf{2} & \mathbf{1} & \mathbf{0} & \mathbf{1} & \mathbf{2} & \mathbf{3} & \text { Strongly agree }\end{array}$

When I commute by public transport, I feel:

$\begin{array}{llllllllll}\text { Highly confident } & \mathbf{3} & \mathbf{2} & \mathbf{1} & \mathbf{0} & \mathbf{1} & \mathbf{2} & \mathbf{3} & \text { Not at all confident }\end{array}$

that I will reach my destination within the planned time.

If I commuted by public transport I would not need a car.

$\begin{array}{llllllllll}\text { Strongly disagree } & \mathbf{3} & \mathbf{2} & \mathbf{1} & \mathbf{0} & \mathbf{1} & \mathbf{2} & \mathbf{3} & \text { Strongly agree }\end{array}$

I plan to use public transport to commute to work on at least two days over the next two weeks.

$\begin{array}{llllllllll}\text { Strongly agree } & \mathbf{3} & \mathbf{2} & \mathbf{1} & \mathbf{0} & \mathbf{1} & \mathbf{2} & \mathbf{3} & \text { Strongly disagree }\end{array}$

I can foresee myself commuting regularly by public transport instead of my car in the future.

$\begin{array}{llllllllll}\text { Strongly disagree } & \mathbf{3} & \mathbf{2} & \mathbf{1} & \mathbf{0} & \mathbf{1} & \mathbf{2} & \mathbf{3} & \text { Strongly agree }\end{array}$

I would keep a car even if I reverted to using public transport to commute.

$\begin{array}{llllllllll}\text { Strongly disagree } & \mathbf{3} & \mathbf{2} & \mathbf{1} & \mathbf{0} & \mathbf{1} & \mathbf{2} & \mathbf{3} & \text { Strongly agree }\end{array}$

I do not have enough time to commute by public transport.

$\begin{array}{llllllllll}\text { Strongly agree } & \mathbf{3} & \mathbf{2} & \mathbf{1} & \mathbf{0} & \mathbf{1} & \mathbf{2} & \mathbf{3} & \text { Strongly disagree }\end{array}$ 
I intend to use public transport to commute to work on at least two days over the next two weeks.

$\begin{array}{llllllllll}\text { Strongly agree } & \mathbf{3} & \mathbf{2} & \mathbf{1} & \mathbf{0} & \mathbf{1} & \mathbf{2} & \mathbf{3} & \text { Strongly disagree }\end{array}$

For me, commuting by public transport is a sociable activity.

$\begin{array}{llllllllll}\text { Strongly disagree } & \mathbf{3} & \mathbf{2} & \mathbf{1} & \mathbf{0} & \mathbf{1} & \mathbf{2} & \mathbf{3} & \text { Strongly agree }\end{array}$

Please click here to continue

For me, commuting by car is less hassle than using public transport.

$\begin{array}{lllllllll}\text { Strongly agree } & \mathbf{3} & \mathbf{2} & \mathbf{1} & \mathbf{0} & \mathbf{1} & \mathbf{2} & \mathbf{3} & \text { Strongly disagree }\end{array}$

When I commute by public transport, I get to my destination on time:

$\begin{array}{lllllllll}\text { Very often } & \mathbf{3} & \mathbf{2} & \mathbf{1} & \mathbf{0} & \mathbf{1} & \mathbf{2} & \mathbf{3} & \text { Very rarely }\end{array}$

When I drive to and from work, I feel:

$\begin{array}{lllllllll}\text { Highly confident } & \mathbf{3} & \mathbf{2} & \mathbf{1} & \mathbf{0} & \mathbf{1} & \mathbf{2} & \mathbf{3} & \text { Not at all confident }\end{array}$ that I will reach my destination within the planned time.

Commuting by car seems expensive to me.

$\begin{array}{lllllllll}\text { Strongly agree } & \mathbf{3} & \mathbf{2} & \mathbf{1} & \mathbf{0} & \mathbf{1} & \mathbf{2} & \mathbf{3} & \text { Strongly disagree }\end{array}$

I feel in control when I drive to and from work.

$\begin{array}{llllllllll}\text { Strongly disagree } & \mathbf{3} & \mathbf{2} & \mathbf{1} & \mathbf{0} & \mathbf{1} & \mathbf{2} & \mathbf{3} & \text { Strongly agree }\end{array}$ 
Most people who are important to me will commute by public transport on at least two days over the next two weeks.

$\begin{array}{lllllllll}\text { Strongly agree } & \mathbf{3} & \mathbf{2} & \mathbf{1} & \mathbf{0} & \mathbf{1} & \mathbf{2} & \mathbf{3} & \text { Strongly disagree }\end{array}$

For me, commuting by public transport requires very little effort.

$\begin{array}{lllllllll}\text { Strongly disagree } & \mathbf{3} & \mathbf{2} & \mathbf{1} & \mathbf{0} & \mathbf{1} & \mathbf{2} & \mathbf{3} & \text { Strongly agree }\end{array}$

It is:

$\begin{array}{llllllllll}\text { Highly important } & \mathbf{3} & \mathbf{2} & \mathbf{1} & \mathbf{0} & \mathbf{1} & \mathbf{2} & \mathbf{3} & \text { Not at all }\end{array}$

important

to me to expend as little effort as possible commuting to and from work .

$\underline{\text { Please click here to continue }}$

Most people who are important to me would want me to commute by public transport on at least two days over the next two weeks.

$\begin{array}{llllllllll}\text { Strongly agree } & \mathbf{3} & \mathbf{2} & \mathbf{1} & \mathbf{0} & \mathbf{1} & \mathbf{2} & \mathbf{3} & \text { Strongly disagree }\end{array}$

I value the time I spend commuting by car, irrespective of its use for getting me to work

$\begin{array}{llllllllll}\text { Strongly disagree } & \mathbf{3} & \mathbf{2} & \mathbf{1} & \mathbf{0} & \mathbf{1} & \mathbf{2} & \mathbf{3} & \text { Strongly agree }\end{array}$

When I commute by car, I have enough room to myself

$\begin{array}{lllllllll}\text { Strongly agree } & \mathbf{3} & \mathbf{2} & \mathbf{1} & \mathbf{0} & \mathbf{1} & \mathbf{2} & \mathbf{3} & \text { Strongly disagree }\end{array}$

I would be willing to commute by public transport regularly if the cost of my road tax increased to $£ 300$ per year.

$\begin{array}{llllllllll}\text { Strongly agree } & \mathbf{3} & \mathbf{2} & \mathbf{1} & \mathbf{0} & \mathbf{1} & \mathbf{2} & \mathbf{3} & \text { Strongly disagree }\end{array}$ 
For me, using public transport to commute is affordable.

$\begin{array}{lllllllll}\text { Strongly disagree } & \mathbf{3} & \mathbf{2} & \mathbf{1} & \mathbf{0} & \mathbf{1} & \mathbf{2} & \mathbf{3} & \text { Strongly agree }\end{array}$

For me, commuting by car requires very little effort.

$\begin{array}{llllllllll}\text { Strongly disagree } & \mathbf{3} & \mathbf{2} & \mathbf{1} & \mathbf{0} & \mathbf{1} & \mathbf{2} & \mathbf{3} & \text { Strongly agree }\end{array}$

How much control do you have over the progression of your journey when commuting by public transport?

$\begin{array}{llllllllll}\text { Complete control } & 3 & 2 & 1 & \mathbf{0} & \mathbf{1} & \mathbf{2} & \mathbf{3} & \text { No control }\end{array}$

To get value for money, I feel I should use my car for most journeys.

$\begin{array}{llllllllll}\text { Strongly agree } & \mathbf{3} & \mathbf{2} & \mathbf{1} & \mathbf{0} & \mathbf{1} & \mathbf{2} & \mathbf{3} & \text { Strongly disagree }\end{array}$

When I drive to and from work, I can do other things (e.g. work, listen to music) at the same time.

$\begin{array}{llllllllll}\text { Strongly agree } & \mathbf{3} & \mathbf{2} & \mathbf{1} & \mathbf{0} & \mathbf{1} & \mathbf{2} & \mathbf{3} & \text { Strongly disagree }\end{array}$

I find commuting by public transport:

$\begin{array}{lllllllll}\text { Very unpleasant } & \mathbf{3} & \mathbf{2} & \mathbf{1} & \mathbf{0} & \mathbf{1} & \mathbf{2} & \mathbf{3} & \text { Very pleasant } \\ \text { Very difficult } & \mathbf{3} & \mathbf{2} & \mathbf{1} & \mathbf{0} & \mathbf{1} & \mathbf{2} & \mathbf{3} & \text { Very easy } \\ \text { Completely safe } & \mathbf{3} & \mathbf{2} & \mathbf{1} & \mathbf{0} & \mathbf{1} & \mathbf{2} & \mathbf{3} & \text { Completely unsafe } \\ \text { Very enjoyable } & \mathbf{3} & \mathbf{2} & \mathbf{1} & \mathbf{0} & \mathbf{1} & \mathbf{2} & \mathbf{3} & \text { Very unenjoyable } \\ \text { Highly effortful } & \mathbf{3} & \mathbf{2} & \mathbf{1} & \mathbf{0} & \mathbf{1} & \mathbf{2} & \mathbf{3} & \begin{array}{l}\text { Completely } \\ \text { effortless }\end{array} \\ & & & & & & & & \text { Very satisfying } \\ \text { Very unsatisfying } & \mathbf{3} & \mathbf{2} & \mathbf{1} & \mathbf{0} & \mathbf{1} & \mathbf{2} & \mathbf{3} & \text { Very unreliable } \\ \text { Very reliable } & \mathbf{3} & \mathbf{2} & \mathbf{1} & \mathbf{0} & \mathbf{1} & \mathbf{2} & \mathbf{3} & \text { Very } \\ \text { Very slow } & \mathbf{3} & \mathbf{2} & \mathbf{1} & \mathbf{0} & \mathbf{1} & \mathbf{2} & \mathbf{3} & \text { Very fast } \\ \text { Very expensive } & \mathbf{3} & \mathbf{2} & \mathbf{1} & \mathbf{0} & \mathbf{1} & \mathbf{2} & \mathbf{3} & \text { Very inexpensive }\end{array}$


I have little control over the progression of my journey when I commute by public transport.

$\begin{array}{llllllllll}\text { Strongly disagree } & \mathbf{3} & \mathbf{2} & \mathbf{1} & \mathbf{0} & \mathbf{1} & \mathbf{2} & \mathbf{3} & \text { Strongly agree }\end{array}$

I like to think over my day when commuting home from work.

$\begin{array}{lllllllll}\text { Strongly disagree } & \mathbf{3} & \mathbf{2} & \mathbf{1} & \mathbf{0} & \mathbf{1} & \mathbf{2} & \mathbf{3} & \text { Strongly agree }\end{array}$

I would be willing to commute by public transport regularly if public transport were free.

$\begin{array}{llllllllll}\text { Strongly agree } & \mathbf{3} & \mathbf{2} & \mathbf{1} & \mathbf{0} & \mathbf{1} & \mathbf{2} & \mathbf{3} & \text { Strongly disagree }\end{array}$

When I commute by car, I get to my destination on time.

$\begin{array}{lllllllll}\text { Very often } & \mathbf{3} & \mathbf{2} & \mathbf{1} & \mathbf{0} & \mathbf{1} & \mathbf{2} & \mathbf{3} & \text { Very rarely }\end{array}$

I could get to work on time when commuting by public transport without having to get up earlier.

$\begin{array}{llllllllll}\text { Strongly disagree } & \mathbf{3} & \mathbf{2} & \mathbf{1} & \mathbf{0} & \mathbf{1} & \mathbf{2} & \mathbf{3} & \text { Strongly agree }\end{array}$

When I commute by public transport, I am able to overcome potential obstacles during the journey.

$\begin{array}{lllllllll}\text { Strongly disagree } & \mathbf{3} & \mathbf{2} & \mathbf{1} & \mathbf{0} & \mathbf{1} & \mathbf{2} & \mathbf{3} & \text { Strongly agree }\end{array}$

I feel secure when I commute by car.

$\begin{array}{lllllllll}\text { Stronglyagree } & \mathbf{3} & \mathbf{2} & \mathbf{1} & \mathbf{0} & \mathbf{1} & \mathbf{2} & \mathbf{3} & \text { Strongly disagree }\end{array}$

When I commute by public transport, I can do other things (e.g. work, listen to music) at the same time

$\begin{array}{llllllllll}\text { Strongly disagree } & \mathbf{3} & \mathbf{2} & \mathbf{1} & \mathbf{0} & \mathbf{1} & \mathbf{2} & \mathbf{3} & \text { Strongly agree }\end{array}$ 
Thank you for completing this questionnaire. Please click here to finish.

We now need you to provide your email address.

This will allow us to contact you in two weeks' time to complete the very short, four-question questionnaire. It will also enable us to enter you into the prize draw.

Please note that after winners have been drawn, all email addresses will be deleted from our database. Your email address will not be shared with any other person or party.

My email address is:

Please now click below:

SUBMIT 
A.3.5. Study 2 main study Time 2 recruitment email

Dear participant,

You will recall that you completed a transport questionnaire two weeks ago.

Please could you now complete the second, very short part of the questionnaire. This questionnaire should take a maximum of 1 minute to complete.

\section{PLEASE COMPLETE THE QUESTIONNAIRE WITH REGARDS TO THE TIME PERIOD XX/XX/05 to XX/XX/05}

*** NB - You MUST complete this questionnaire to be entered into the prize draw to win one of three cash prizes (£100, £50, or £25).

Please give the same email address that you provided in the first questionnaire (i.e. the address to which this email has been sent) to allow us to enter you into the prize draw.

Click below to complete the questionnaire:

http://www.sussex.ac.uk/Units/socpsy/webq/beng/followup.htm

(If the link does not work, please cut and paste the address into your URL browser.)

If you have any further queries, please contact me at

B.D.Gardner@sussex.ac.uk. We will contact prize draw winners when the draw has been conducted, which depends upon when our quota of participants is fulfilled.

Many thanks - and good luck in the prize draw!

B. Gardner 
A.3.6. Study 2 main study Time 2 reminder email

Dear participant,

I recently emailed you to invite you to participate in the second, very short part of our transport questionnaire. However, our records show that you have not completed the second questionnaire. If you do not wish or are unable to complete the questionnaire, please ignore this message. However, you MUST complete the second questionnaire to be entered into the prize draw to win one of three cash prizes (£100, £50 or £25).

When you complete the second questionnaire, you will find questions about your transport use 'over the last two weeks'. It is crucial that you complete the second questionnaire with reference to the two-week period immediately following your completion of the first questionnaire. Please therefore answer questions relating to 'the last two weeks' with reference to the time period $\mathrm{XX} / \mathrm{XX} / 05$ to $\mathrm{XX} / \mathrm{XX} / 05$.

(If you are unable to recount your transport behaviour over this period, please do not complete the questionnaire.)

Click below to access the second questionnaire:

http://www.sussex.ac.uk/Units/socpsy/webq/beng/followup.htm

(If the link does not work, please cut and paste the address into your URL browser.)

Thanks for your help.

Best wishes,

B. Gardner 


\section{Transport questionnaire Part 2}

Please answer the following questions honestly. All responses are confidential and anonymous.

\section{Please read very carefully:}

Throughout this questionnaire, you are asked about your experiences of 'commuting'.

The term 'commuting' refers specifically to travelling to and from your workplace.

On how many days in the last two weeks did you commute to and from work by public transport?

days

On how many days in the last two weeks did you drive to and from work? days

I am willing to commute regularly using public transport instead of my car. $\begin{array}{llllllllll}\text { Strongly disagree } & \mathbf{3} & \mathbf{2} & \mathbf{1} & \mathbf{0} & \mathbf{1} & \mathbf{2} & \mathbf{3} & \text { Stronglyagree }\end{array}$

I can foresee myself commuting regularly by public transport instead of my car in the future.

$\begin{array}{llllllllll}\text { Strongly disagree } & \mathbf{3} & \mathbf{2} & \mathbf{1} & \mathbf{0} & \mathbf{1} & \mathbf{2} & \mathbf{3} & \text { Strongly agree }\end{array}$ 
Please provide your email address below. This will allow us to match the responses you give here with your responses from the previous questionnaire, and will also enable us to enter you into the prize draw.

My email address is:

Please now click below:

SUBMIT 


\section{A.3.8. Debrief for study 2 main study}

Thank you for your participation. This study is being conducted as part of a programme of research examining what predicts private car use amongst commuters.

My previous research has highlighted several key motives underlying continued car commuting. For example, drivers wish to minimise the amount of money they spend on commuting, and travelling by car is seen to be less expensive than using public transport. The questionnaires that you have completed are designed to measure the extent to which each motive applies to you. Having two questionnaires allows us to examine if motives expressed in the first questionnaire predict transport choices over the following two weeks, as measured in the second questionnaire. We are also interested in how strongly related motives are to willingness to switch to public transport: for example, are people who think driving gives them personal space more willing to use public transport than are people who think that driving is cheap?

If you have any questions regarding the research, please contact me at B.D.Gardner@sussex.ac.uk.

\section{The prize draw}

The draw will be conducted as soon as we have reached our quota of participants (around 300 in total), which may take some time. Winners of the prize draw will be notified by email as soon as the draw has taken place. 
A.4.1. Online search details for study 3

\section{Search strings used}

1) car use

2) transport mode*

3) travel mode*

4) commut* AND (motiv* OR correlat* OR influence* OR antecedent* OR determinant* OR reason* OR predict*)

5) driv $^{\star}$ AND motiv* AND (transport ${ }^{\star}$ OR travel ${ }^{\star}$ OR commut*)

6) driv* AND correlat* AND (transport* OR travel* OR commut*)

7) driv* AND influence* AND (transport* OR travel* OR commut*)

8) driv* AND antecedent* AND (transport* OR travel* OR commut*)

9) driv* AND determinant* AND (transport* OR travel ${ }^{\star}$ OR commut ${ }^{\star}$ )

10) driv* AND reason* AND (transport* OR travel* OR commut*)

11) driv* AND predict* AND (transport* OR travel* OR commut*)

12) (environment* OR conservation* OR ecolog*) NEAR (behavio* OR conduct OR practice* OR action* OR psychology) AND (motiv* OR correlate* OR influence* OR antecedent ${ }^{*}$ OR determinant* OR reason* OR predict ${ }^{\star}$ )

\section{$\underline{\text { Notes }}$}

ScienceDirect searches were performed using Decision Sciences, Environmental Science, Psychology, and Social Sciences, searching only Journals, Book Series, Handbooks. 
A.4.2. Data extraction form and author request form for study 3

This is a summary of all the information that we could extract from your publication. Could you please provide the missing information (highlighted in the red cells)? A summary of the necessary information is included at the end of this document. Sending us the full correlation matrix will allow us to include your publication in the meta-analysis. The rest of the information will improve the methodological quality of the meta-analysis, so we would very much appreciate it if you could also find the time to supply that.

\section{Publication}

Name (date) Reference title. Journal/source, volume, pagination.

\section{NOTES TO AUTHORS}

$\bullet$

\section{Study summary}

Country of data collection:

Study design:

Data collection method:

Number of variables of interest:

$\mathbf{N}=$

Variables of interest:

- Dependent variable 1

- Dependent variable 2

- Independent variable 1

- Independent variable 2

- Independent variable 3 etc. 


\begin{tabular}{|c|c|c|}
\hline \multicolumn{3}{|l|}{ Measurements } \\
\hline Variable & Items, with Cronbach's a for scales & $\begin{array}{l}N, \text { Mean }(M) \text {, Standard Deviation (SD), \& } \\
\text { effect } r \text { (or different) for correlation with } \\
\text { behaviour, intention and/or willingness }\end{array}$ \\
\hline \multirow[t]{3}{*}{ (Dependent variable 1) } & XX-item averaged scale, $\alpha=? ?$ & $\begin{array}{l}\mathrm{N}, \text { Mean, SD, and effect size for dependent variable } \\
1\end{array}$ \\
\hline & $\begin{array}{l}\text { Wording of first item used to measure dependent } \\
\text { variable } 1\end{array}$ & \\
\hline & $\begin{array}{l}\text { Wording of second item used to measure dependent } \\
\text { variable } 1 \text { etc. }\end{array}$ & \\
\hline \multirow[t]{3}{*}{$\begin{array}{l}\text { (Dependent variable } 2 \\
\text { etc) }\end{array}$} & XX-item averaged scale, $\alpha=? ?$ & $\begin{array}{l}\text { N, Mean, SD, and effect size for dependent variable } \\
2\end{array}$ \\
\hline & $\begin{array}{l}\text { Wording of first item used to measure dependent } \\
\text { variable } 2 \text { etc. }\end{array}$ & \\
\hline & $\begin{array}{l}\text { Wording of second item used to measure dependent } \\
\text { variable } 2 \text { etc. }\end{array}$ & \\
\hline \multirow[t]{3}{*}{ (Independent variable 1) } & XX-item averaged scale, $\alpha=? ?$ & $\begin{array}{l}\mathrm{N}, \text { Mean, } \mathrm{SD} \text {, and effect size for independent } \\
\text { variable } 1\end{array}$ \\
\hline & $\begin{array}{l}\text { Wording of first item used to measure independent } \\
\text { variable } 1\end{array}$ & \\
\hline & $\begin{array}{l}\text { Wording of second item used to measure independent } \\
\text { variable } 1 \text { etc. }\end{array}$ & \\
\hline
\end{tabular}




\begin{tabular}{|l|l|l|}
\hline (Independent variable 2) & XX-item averaged scale, $\alpha=? ?$ & $\begin{array}{l}\text { N, Mean, SD, and effect size for independent } \\
\text { variable 2 }\end{array}$ \\
\hline & $\begin{array}{l}\text { Wording of first item used to measure independent } \\
\text { variable 2 }\end{array}$ & \\
\hline & $\begin{array}{l}\text { Wording of second item used to measure independent } \\
\text { variable 2 etc. }\end{array}$ & \\
\hline $\begin{array}{l}\text { (Independent variable 3 } \\
\text { etc) }\end{array}$ & XX-item averaged scale, $\alpha=? ?$ & $\begin{array}{l}\text { N, Mean, SD, and effect size for independent } \\
\text { variable 3 }\end{array}$ \\
\hline & $\begin{array}{l}\text { Wording of first item used to measure independent } \\
\text { variable 3 }\end{array}$ & \\
\hline & $\begin{array}{l}\text { Wording of second item used to measure independent } \\
\text { variable 3 etc. }\end{array}$ & \\
\hline
\end{tabular}

\section{Summary of requested actions for authors}

- Please send a correlation matrix containing the variables listed above

- Please provide missing Cronbach's alpha coefficients (where appropriate) for scales

- Please check the information above for any errors

When you have completed this form, please return (using your preferred method) together with the correlation matrix to:

Postal address
Benjamin Gardner
Psychology Department
University of Sussex
Falmer
Brighton, UK
BN1 9QG

\section{Email address $\quad \underline{\text { Fax }}$}

B.D.Gardner@sussex.ac.uk

OR benjamingardner@gmail.com

$+441273678058$

(Please mark 'FAO Benjamin Gardner')

Many thanks for helping! 
A.4.3. Study characteristics and effect sizes for studies and variables entered into study 3 meta-analysis

Study details

Baldassare \& Katz (1992); USA; $\mathrm{N}=1017$; age $18-65+$ years;

general population
Dependent variable $(s)^{32} \quad$ Design

Frequency of limiting driving to $\quad$ Cross-sectional ${ }^{36}$ reduce air pollution

(recoded)

Forward $(2004)^{38}$; Study $1 \mathrm{a}^{39}=$ Netherlands, Intention to drive to $\mathrm{N}=135$; Study $1 \mathrm{~b}=$ Spain, $\mathrm{N}=100$;

Study $1 \mathrm{c}=$ Denmark, $\mathrm{N}=119$; Study $1 \mathrm{a}-\mathrm{c}$ awa

183 males +171 females; Study $2=\quad($ Study 1a alpha $=.91)$

Sweden, $\mathrm{N}=188,105$ males +83 females;

age 21-69 years; general population destination $2.5 \mathrm{~km}$
Cross-sectional
$($ Study $1 \mathrm{~b}$ alpha $=.89)$
Independent variable $\left(s^{33} \mathrm{~N}\right.$

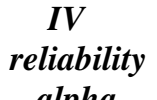

Effect size

alpha

\author{
Perceived personal \\ environmental problem
}

1017

$\mathrm{SI}^{37}$

Attitude to car use
(Study 1a)

135

.54

PBC over car use

135

.83

(Study 1a)

$\begin{array}{lll}\text { Subjective norm towards } & 135 \quad .84\end{array}$

car use (Study 1a)

Attitude to car use

100

${ }^{32}$ Reliabilities are given in parentheses, unless indicated by SI (single-item measure) or N/A (reliability not applicable).

${ }^{33}$ Independent variables examined in only one study with an unreported and statistically non-significant effect at $p<.05$ are not cited.

${ }^{34}$ Effect sizes are not given for interaction terms, and do not apply to qualitative or associational designs.

${ }^{35}$ Rosenthal (1995) recommends reporting both effect sizes and significance levels. However, in correlational designs, effect sizes are partially a function of sample size, such that an effect size $r$ of a particular value could be statistically significant with a large sample but non-significant with a smaller sample. As such, significance levels are not central in illustrating the magnitude of an effect, and are not reported here.

${ }^{36}$ Strictly speaking, the small temporal lapse between completing independent and dependent variable measures in some studies results in all studies being

retrospective or prospective. However, in the absence of intervention travel mode choice is a relatively stable behaviour (e.g. Mann, 2004; Thøgersen, 2006), and hence these lapses are unlikely to be significant (Bamberg et al., 2003), and hence designs are treated as cross-sectional where dependent and independent variable measures were taken in a single data collection session.

${ }^{37} \mathrm{SI}=$ Single-item measure.

${ }^{38}$ Forward (2004) purports to offer a measure of car use habit, but this is measured via past behavioural frequency, which is conceptually distinct from habit (see Verplanken, 2006, for more on this distinction).

${ }^{39}$ Although Forward (2004, Study 1) combines three different datasets into one, these are treated as separate datasets here and labelled Study 1a-1c. We thank Sonja Forward for providing the necessary additional information. 
$($ Study $1 \mathrm{c}$ alpha $=.94)$

(Study 2 alpha $=.92)$

\section{Gärling, Fujii \& Boe (2001, Studies 1} and 2); Sweden; Study $1 \mathrm{~N}=60$,

30 males +30 females; age 20-49 years, undergraduates with driving licence; Study $2 \mathrm{~N}=48,24$ males +24 females; age $18-36$ years, undergraduates with driving licence

Garvill (1999); Sweden; N = 1562; 1093 males + 469 females; age 20-65
Self-reported car use over previous month (Study 1)

(SI)

Percentage of stated preferences

for driving in series of

hypothetical scenarios (Study 2)

(N/A)

Willingness to reduce car use (DM)
(Study 1b)

PBC over car use

100

(Study 1b)

Subjective norm towards 100

83

car use (Study 1b)

Attitude to car use

(Study 1c)

(Study 1c)

Subjective norm towards 119

car use (Study 1c)

Attitude to car use $\quad 188$

(Study 2)

PBC over car use

(Study 2)

Subjective norm towards 188

90

car use (Study 2)

\section{Retrospective}

Cross-sectional

Attitude to car use

Car use habit

Attitude to car use

Car use habit

Cross-sectional 
years; general population, car owners

$\begin{array}{lcc}\begin{array}{l}\text { Perceived threat to } \\ \text { biosphere }\end{array} & 1474 & \text { SI } \\ \begin{array}{l}\text { Perception of car as } \\ \text { cause of environmental } \\ \text { problems }\end{array} & 1474 & \text { SI } \\ \end{array}$

Perceived degree of

$1474 \quad$ SI

seriousness of

environmental problems

Self-reported car use over 7 days Prospective

Sweden; $N=120$; mean age 43.7 years

general population, car access and driving

licence

Harland, Staats \& Wilke (1999);

Netherlands; $N=305 ; 65$ males +240

females; mean age 47 years; individuals

enrolled on pro-environment behaviour

change programme, car owners

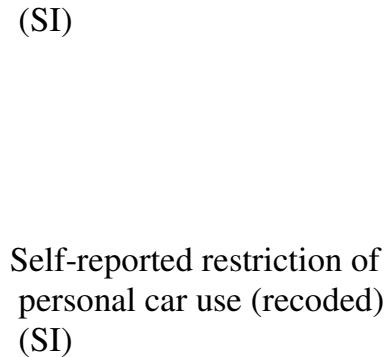
(SI)

Self-reported restriction of personal car use (recoded)

Intention to restrict personal car use (recoded)

(SI)

\section{Car use habit}

(baseline only)

Attitude to car use

(baseline only)

\section{Retrospective}


Joireman, Van Lange, Kuhlman, Van Vugt, \& Shelley (1997); Netherlands; $\mathrm{N}=102 ; 63$ males +38 females +1

unspecified; mean age 33 years 2 months; commuters

Kaiser \& Gutscher (2003); Switzerland $\mathrm{N}=875 ; 401$ males +490 females +4 unspecified; age 18-79 years; general population

Loukopoulos \& Gärling (2005); Sweden; $\mathrm{N}=155 ; 80$ males +70 females +5 unspecified; age 18-65; university employees with driving licence and car
Self-reported weekly driving frequency
Self-reported restriction of personal car use in city centre ('downtown') (recoded)

(SI)

\section{Self-reported intention to restrict personal car use in city centre ('downtown')} $($ recoded $) \quad($ alpha $=.88)$

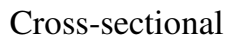

Cross-sectional over PT in series of hypothetical commuting scenarios

(N/A)

Self-reported intention to
restrict personal car use in
city centre ('downtown')
(recoded) (alpha $=.88$ )

Cross-sectional

Cros

$\begin{array}{lcc}\text { Travel time concerns } & 84 & \text { SI } \\ \text { Flexibility concerns } & 84 & \text { SI } \\ \text { Environment concerns } & 84 & \text { SI } \\ \text { Public health concerns } & 84 & \text { SI }\end{array}$

Intention

867

.88

Attitude to non-car use $\quad 883 \quad .79$

Subjective norm for

871

SI

non-car use

Descriptive norm ${ }^{40}$

886

SI

$874 \quad .90$

PBC over non-car use

$883 \quad .79$

Attitude to non-car use

$871 \quad$ SI

Subjective norm for

non-car use

Descriptive norm

$886 \quad$ SI

PBC over non-car use

Problem awareness

\footnotetext{
${ }^{40}$ Although Kaiser and Gutscher (2003) treat it as a subjective norm measure, the item "Most people who are important to me drive their car to or in the city" represents descriptive rather than subjective social norms (Cialdini, Kallgren \& Reno, 1991).
} 
access

Matthies, Klöckner \& Preißner (2006);

Germany; baseline only; $\mathrm{N}=297$;

185 males +112 females; mean age

45 years; commuters with driving licence,

car access and no PT pass
Reported sole use of car vs.

using non-car mode at least once

over 2-week period

(SI)
Retrospective year

245 females; mean age 40 years;

general population

Nordlund \& Garvill (2003); Sweden; $\mathrm{N}=1467 ; 1012$ males +455 females; median age 43 years; car owners
Self-reported willingness

to reduce car use

$($ alpha $=.81)$
Problem awareness

Retrospective

Perceived degree of

seriousness of carinduced problems
Personal / moral norm

Subjective norm for

car use

Car use habit

Environmental concern 
Polk (2003); Sweden; N = 1180; age $18-80$ years; 590 males +590 females; general population

Self-reported typical frequency Cross-sectional
of driving a car ${ }^{41}$ to work
and for errands $\quad$ (SI)

and for errands (SI)

\section{Self-reported willingness to}

reduce car use (SI)
Perception of car traffic as cause of problems

\section{Perceived threat}

Perceived threat

to biosphere

Self-transcendent

values

\section{Environmental \\ concern}

Awareness of car traffic

as cause of

environmental problems

Awareness of car traffic

as cause of

environmental problems

Self-transcendent values
Self-reported willingness

Polk (2004); Sweden; N = 1180;

590 males +590 females; age $18-80$ years; to reduce car use (SI)

individuals with car access and licence

\footnotetext{
${ }^{41}$ Polk (2003) terms this variable 'habitual car use', but this variable represents behavioural frequency only (see Footnote 7).
} 
Staats, Harland \& Wilke (2004);

Netherlands; $\mathrm{N}=150 ; 22$ males +128

females; mean age 52 years; individuals

enrolled on pro-environment behaviour

change programme, car owners

Steg $(2004 ; 2005$, Study 2)

Netherlands; $\mathrm{N}=113 ; 82$ males +31

females; mean age 42 years; commuters

Steg \& Sievers (2000); Netherlands

$\mathrm{N}=413$; age $18+$ years; general

population, individuals who had regularly

driven a car in previous year

Tanner (1999); Switzerland; N = 153;

102 males + 51 females; mean age 46

years; general population, car owners
Self-reported intention to use

non-car modes over next 6

months for short distances

$(<5 \mathrm{~km})$ (recoded)

of car commuting (SI)

Cross-sectional

Descriptive norms

\section{Self-reported typical annual \\ mileage driven + proportion}

Cross-sectiona

of car use relative to other modes

(DM)

\section{Self-reported typical driving}

frequency
Cross-sectiona

(SI)
Problem awareness

Perceived responsibility

for general problems

\section{Perceived persona}

threat from

environmental problem

Perceived responsibility

for reducing

environmental problem

Various perceived

behavioural barriers to

reducing car use

Perceived efficacy for

reducing environmental

problem
$\mathrm{DM}$

62

$.79-.32[-.26,-.37]^{42}$

$.60 \quad-.06[-.03,-.08]$

134

.86

\footnotetext{
${ }^{42}$ Values in parentheses relate to correlations with annual driving mileage and proportion of car use to use of other modes, respectively.
} 
Van Lange, Van Vugt, Meertens \& Ruiter (1998, Study 1); Netherlands;

$\mathrm{N}=140 ; 105$ males +34 females + 1 unspecified; age 19-62 years;

commuters

Van Vugt, Meertens, \& Van Lange (1995); Netherlands; $N=56 ; 25$ males

+ 31 females; mean age 32 years; regular car commuters

Van Vugt, Van Lange, \& Meertens (1996); Netherlands; $N=192 ; 104$ males

+88 females; mean age 35 years

8 months; regular car commuters

Verplanken, Aarts, Van Knippenberg, \& Moonen (1998); Netherlands; $\mathrm{N}=200$;

96 males + 104 females; age 20-70 years;

villagers with driving licence and

car access

Stated preference for car vs. PT in hypothetical

commuting scenario

(N/A)

Stated preference for car

vs. PT in hypothetical

commuting scenario
Cross-sectional

$$
\text { (Pro-)social value }
$$

orientation

140

N/A

Cross-sectional

(Pro-)social value

50

N/A

orientation

Importance of:

- environment

- travel flexibility

- public health

- travel time

(Pro-)social value

orientation

182

N/A

vs. PTin hypothetical

commuting scenario

(N/A)

Percentage of self-reported car trips outside of village over 7 days (N/A) (N/A)

Prospective

Intention

Attitude to car use

DM SI

Subjective norm for

DM $\quad .84$

car use

DM SI

PBC over car use

$\mathrm{DM} \quad \mathrm{SI}$

Car use habit ${ }^{43}$

\footnotetext{
${ }^{43}$ Verplanken et al. (1998) include two habit measures: the response-frequency measure (see Verplanken et al., 1994), and a measure of past behavioural frequency as
} an alternative, proxy habit measure. In the present analysis, we treat only the former of these as an indicator of habit (see Verplanken, 2006). 
Intention to use car for

trips outside of village

Verplanken, Aarts, Van Knippenberg, \&

Van Knippenberg (1994); Netherlands;

$\mathrm{N}=199 ; 92$ males +107 females; age

19-65 years; villagers with driving licence

and car access

Self-reported frequency of car use over previous 2 months

Percentage of car vs. public

transport use for journey on day

Yang-Wallentin, Schmidt, Davidov, \& Bamberg (2004); Germany; N = 1328; 624 males +704 females; mean age

44.3 years; general population reporting having made a journey on day of questionnaire completion
(SI)

Retrospective

Cross-sectional

of questionnaire completion

(N/A)

Cross-sectional

\section{Attitude to car use \\ Subjective norm for car use}

PBC over car use

Car use habit

Attitude to car use

Attitude to non-car use

Car use habit

Deliberation

\section{PBC over non-car use}

\section{DM}

.85

Intention

DM $\quad .94$ 
A.4.4. Study characteristics and effect sizes from studies excluded from study 3 meta-analysis ${ }^{44}$

Study details

\# Bamberg, Ajzen \& Schmidt (2003);

Germany; Wave 1 only; $\mathrm{N}=1036$;

435 males + 601 females;

age 20-37 years; students

\section{Dependent variable(s) ${ }^{45}$ \\ $\operatorname{Design}^{46}$}

Whether car used for commute

on day of questionnaire

completion

(SI)

Intention to use car
for next commute $\left(\mathrm{DM}^{49}\right)$

for next commute $\left(\mathrm{DM}^{49}\right)$

Cross-sectiona

$\begin{array}{lccr}\text { Independent variable(s) }{ }^{47} & \boldsymbol{N} & \begin{array}{c}\text { IV } \\ \text { reliability } \\ \text { alpha }\end{array} & \begin{array}{r}\text { Effect size } \\ \text { Intention }\end{array} \\ \text { Attitude } & \mathrm{DM} & \mathrm{DM} & \mathrm{DM} \\ \text { Subjective norm } & \mathrm{DM} & \mathrm{DM} & \mathrm{DM} \\ \text { PBC } & \mathrm{DM} & \mathrm{DM} & \mathrm{DM} \\ \text { Attitude } & \mathrm{DM} & \mathrm{DM} & \mathrm{DM} \\ \text { Subjective norm } & \mathrm{DM} & \mathrm{DM} & \mathrm{DM} \\ \text { PBC } & \mathrm{DM} & \mathrm{DM} & \mathrm{DM} \\ & \mathrm{DM} & \mathrm{DM} & \mathrm{DM} \\ \text { Intention } & & & \mathrm{DM} \\ \text { Attitude } & \mathrm{DM} & \mathrm{DM} & \mathrm{DM} \\ \text { Subjective norm } & \mathrm{DM} & \mathrm{DM} & \mathrm{DM} \\ \text { PBC } & \mathrm{DM} & \mathrm{DM} & \mathrm{DM}\end{array}$

\# Bamberg \& Schmidt (2003); Germany; $\mathrm{N}=321$; mean age 24.5 years; students

Whether car used for commute on day of Time 2 data collection (SI)

Prospective

\footnotetext{
${ }^{44}$ Studies and/or independent variables prefixed '\#' were excluded due to insufficient information. Independent variables marked with '\#\#' represent either correlations that were not assessed in or available from other studies (i.e. $k=1$ ), or correlation coefficients for which there was insufficient information.

${ }_{45}^{45}$ Reliabilities for dependent variables are given in parentheses, unless indicated by SI (single-item measure) or N/A (reliability not applicable).

${ }^{46}$ All studies involved questionnaire designs unless otherwise specified.

${ }^{47}$ Correlations examined in or available from only one study $(k=1)$ which yielded a statistically non-significant effect at $p<.05$ are not included in this table.

${ }^{48} \mathrm{PBC}=$ Perceived behavioural control.

${ }^{49} \mathrm{DM}=$ Data missing.
} 
Intention to use car

for next commute (DM)

Cross-sectional

(2001); UK

$\mathrm{N}=4214$; age $<26-41+$ years;

parents/guardians with responsibility

for taking child(ren) to school

\# Collins \& Chambers (2005); Australia $\mathrm{N}=204 ; 102$ males +100 females +3 unspecified; age 18-58 years; students

Whether car or $\mathrm{PT}^{50}$ frequently used for commuting (DM)

Preference for car vs. PT (SI)
Probability of self-reporting

usually using a car vs. walking

for journey-to-school trips (SI)
Cross-sectional

Cross-sectional

Cross-sectional
Attitude

Subjective norm

PBC

Perceived responsibilit

for environmental

problem

General environmental

2006 DM

problem awareness

Pro-automobile values

2006 DM

Preference for car vs. PT 204

Biospheric values

$\mathrm{DM} \quad .84$

Social values

$\mathrm{DM} \quad .72$

Egoistic values

$\mathrm{DM} \quad .70$

Social value orientation

DM DM

$203 \quad .86$

Consideration of

future consequences

Social beliefs

$\mathrm{DM} \quad .53$

Egoistic beliefs

$\mathrm{DM} \quad .76$

Biospheric beliefs

$\mathrm{DM} \quad .57$
$\mathrm{DM}$

DM

DM

DM

DM

$\mathrm{DM}$

DM

DM

DM

DM

$\mathrm{DM}$

$\mathrm{DM}$

DM

${ }^{50} \mathrm{PT}=$ Public transport. 
Fujii, Gärling \& Kitamura (2001); Japan; $\mathrm{N}=335 ; 302$ male +33 female;

mean age 42.1 years; commuters

+ 62 females; $16-49$ years;

undergraduates with driving licence

Gärling, Gillholm \& Gärling (1998,

Expt 2); Sweden; $N=130$ households;

general population, car users; control

group only

Garvill (1999); Sweden; N = 1562;

1093 males + 469 females; age 20-65

years; general population, car owners

\section{Self-reported weekly car trip}

frequency

Prospective

trip frequency
\#\# Expected weekly car
Self-reported frequency of automobile commuting prior to

motorway closure

(SI)

Cross-sectional

\section{\#\# Discrepancy between} expected and actual

commuting times by PT

(baseline only)

Self-reported driving frequency Retrospective over previous month

(SI)

$\mathrm{N} / \mathrm{A}^{51}$

\#\# Distance threshold

for walking vs. driving

$111 \quad$ SI

SI

\section{Willingness to reduce car use} (DM)

\author{
\#\# Perceived personal $1474 \quad$ SI \\ threat from environmental \\ problem
}

environmental problems

\footnotetext{
${ }^{51}$ Reliability is not applicable to measures that represent the sum of scores on each item (e.g. the response-frequency habit measure; Verplanken et al., 1994). Where authors have reported an alpha for such scales, this is reported for information but was not entered as an indicator of reliability in the meta-analysis.
} 
Cross-sectional

Stated preference for car over PT in hypothetical

commuting scenario

Vugt, \& Shelley (1997); Netherlands;

$\mathrm{N}=102 ; 63$ males +38 females +1

unspecified; mean age 33 years 2 months;

(N/A)

commuters

Loukopoulos \& Gärling (2005); Sweden;

unspecified; age 18-65; university

Retrospective using non-car mode at least once
$\mathrm{N}=155 ; 80$ males +70 females +5

employees with driving licence and car

access

Matthies, Klöckner \& Preißner (2006);

Germany; baseline only; $\mathrm{N}=297$;

185 males +112 females; mean age

Reported sole use of car vs. over 2-week period

Self-reported weekly driving frequency

45 years; commuters with driving licence, car access and no PT pass
\#\# Descriptive norm

\#\# Perceived personal moral obligation to

reduce car use

\#\# Perceived moral

obligation of all

commuters to reduce

car use

\#\# Misc proself

travel consequences

\#\# Misc prosocial

travel consequences

\#\# Comfort concerns

1474 SI

1474 SI

\#\# Perceived effort of

walking

\#\# Various perceived

365

67

Car use habit 
\# McKenzie-Mohr, Nemiroff, Beers \& Desmarais (1995); Canada; $\mathrm{N}=140$;

77 males +63 females; general

population
Use of car vs. non-car modes over previous year

(DM)
Retrospective;

structured interview
Perceived personal
threat of environmental
problem

DM

Environmental concern

Perceived skill

Attitudes

Perceived moral

responsibility

Efficacy

Knowledge

Retrospective

\section{Driving distance over previous}

year

(SI)

Nordlund \& Garvill (2003); Sweden; $\mathrm{N}=1467 ; 1012$ males +455 females

Self-reported willingness median age 43 years; car owners

\begin{tabular}{|c|c|c|c|}
\hline \#\# Attitude to $\mathrm{PT}^{52}$ & 352 & .48 & -.03 \\
\hline $\begin{array}{l}\text { \#\# Perceived } \\
\text { environmental threat of } \\
\text { traffic and personal } \\
\text { efficacy for reducing } \\
\text { environmental threat }\end{array}$ & 407 & .63 & -.02 \\
\hline $\begin{array}{l}\text { \#\# Personal health \& } \\
\text { environmental concern }\end{array}$ & 378 & .35 & -.01 \\
\hline \#\# Affection for car & 302 & .63 & .46 \\
\hline \#\# Personal / moral norm & 1461 & SI & .44 \\
\hline \#\# Ecocentric values & 1466 & .73 & .23 \\
\hline
\end{tabular}

${ }^{52}$ This variable represented generalised, non-behaviour-specific views towards public transport. Hence, we did not treat this as an attitude towards non-car $u s e$, and thus this variable was not entered into analysis. 
Polk (2003); Sweden; N = 1180; age $18-80$ years; 590 males +590 females; general population

\section{Self-reported typical frequency of driving a car $^{53}$ to work and for errands \\ (SI)}

Self-reported willingness to reduce car use (SI)
Self-reporting typically

driving a car daily

590 males +590 females; age $18-80$ years; individuals who drive a car

\section{Self-reported willingness} to reduce car use (SI)

Staats, Harland \& Wilke (2004); Netherlands; $\mathrm{N}=150 ; 22$ males +128 females; mean age 52 years; individuals enrolled on pro-environment behaviour change programme, car owners
Self-reported intention to use non-car modes over next 6 months for short distances $(<5 \mathrm{~km})$ (recoded)
Cross-sectional

\section{\#\# Attitudes towards}

automobility

1103

.63

$.27[.20, .33]^{54}$

\#\# Environmental

1094

.87

concern

\#\# Positive attitude

towards car use

\#\# Negative attitude

1103

.63

towards car use

Cross-sectional

\#\# Perception of car

838

as status object

\#\# Pleasure from driving

838

\#\# Egoistic values

990

Cross-sectional

\#\# Non-car use habit

\section{5}

.91

\footnotetext{
${ }^{53}$ Polk (2003) terms this variable 'habitual car use', but this variable represents behavioural frequency only (see Footnote 7).

${ }^{54}$ Polk (2003) reports $r$ values for pro- and anti-automobility attitudes separately. Values in parentheses represent pro- and anti-automobility attitudes respectively, the latter of which was recoded to enable conflation.
} 
Steg (2003); Netherlands; N = 1803;

1010 males +793 females; mean age

46 years; general population
Self-reported typical frequency

Steg (2004; 2005, Study 2);

Netherlands; $\mathrm{N}=113 ; 82$ males +31

females; mean age 42 years; commuters of car use (SI)

Cross-sectional

Self-reported typical frequency

of car commuting

(SI)
\#\# Perceived

1802

$\mathrm{DM}$

$-.22$

disadvantages of car use

Perceived opportunities

when driving for:

\#\# - independence

\#\# - fun

\#\# - feelings of control

1802 DM

1802 DM

1802 DM

\#\# - status

1802 DM

09

Perceived opportunities

when using PT for:

\#\# - independence

\#\# - fun

\#\# - feelings of control

1802 DM

1802 DM

1802 DM

1802 DM

\#\# - status

$\begin{array}{ll}636 & .71\end{array}$

Importance of:

\#\# - transportation

$553 \quad .81$

\# - travelling by car

$611 \quad .75$

\#\# Concern for misc

$1802 \quad .73$

problems arising from

car use

\#\# Various instrumental
motives

\#\# Social comparison \&

DM

.64

self-presentation

motives

\#\# Social norms -

DM

SI

colleagues

DM SI

\#\# Social norms -

family
.26 


\begin{tabular}{|c|c|c|c|c|c|c|}
\hline & & & $\begin{array}{l}\text { \#\# Social norms - } \\
\text { friends }\end{array}$ & DM & SI & .06 \\
\hline & & & \#\# Pleasure & DM & .81 & -.23 \\
\hline & & & \#\# Arousal & DM & .70 & -.23 \\
\hline & & & \#\# Control & DM & .69 & .25 \\
\hline \multirow{3}{*}{$\begin{array}{l}\text { Steg (2005, Study } 1) \text {; Netherlands; } \\
\mathrm{N}=185 ; 113 \text { males }+82 \text { females; } \\
\text { mean age } 41 \text { years; general population, } \\
\text { individuals with driving licence }\end{array}$} & \multirow[t]{3}{*}{$\begin{array}{l}\text { Self-reported typical annual } \\
\text { mileage driven (SI) }\end{array}$} & \multirow[t]{3}{*}{ Cross-sectional } & $\begin{array}{l}\text { \#\# Misc symbolic and } \\
\text { affective motives }\end{array}$ & 171 & .90 & .20 \\
\hline & & & $\begin{array}{l}\text { \#\# Misc independence } \\
\text { motives }\end{array}$ & 176 & .72 & .21 \\
\hline & & & $\begin{array}{l}\text { \#\# Misc instrumental } \\
\text { motives }\end{array}$ & DM & .80 & DM \\
\hline $\begin{array}{l}\text { \# Steg, Geurs \& Ras (2001); Netherlands; } \\
\mathrm{N}=1432 ; \text { age } 15-70+\text { years; } \\
\text { general population }\end{array}$ & $\begin{array}{l}\text { Self-reported typical weekly } \\
\text { mileage driven (SI) }\end{array}$ & Cross-sectional & $\begin{array}{l}\text { General problem } \\
\text { awareness }\end{array}$ & DM & DM & DM \\
\hline $\begin{array}{l}\text { Steg \& Sievers (2000); Netherlands; } \\
\mathrm{N}=413 \text {; age } 18+\text { years; general } \\
\text { population, individuals who had regularly } \\
\text { driven a car in previous year }\end{array}$ & $\begin{array}{l}\text { Self-reported typical annual } \\
\text { mileage driven + proportion } \\
\text { of car use relative to other modes } \\
\text { (DM) }\end{array}$ & Cross-sectional & $\begin{array}{l}\text { \#\# Perceived value of } \\
\text { car use reduction }\end{array}$ & 269 & .62 & $-.14[-.08,-.20]^{55}$ \\
\hline
\end{tabular}

${ }^{55}$ Values in parentheses relate to correlations with annual driving mileage and proportion of car use to use of other modes, respectively. 
\# Steg \& Vlek (1997, Study 1);

Netherlands; $\mathrm{N}=539 ; 323$ males +216

females; age $22-87$ years; car drivers

\# Steg \& Vlek (1997, Study 2);

Netherlands; $\mathrm{N}=336 ; 232$ males +104

females; age 18-82 years; car drivers

Tanner (1999); Switzerland; $N=153$;

102 males +51 females; mean age 46 years; general population, car owners

Van Vugt, Meertens, \& Van Lange (1995); Netherlands; $\mathrm{N}=56 ; 25$ males

+ 31 females; mean age 32 years; regular car commuters

Vredin Johansson, Heldt \& Johansson, (2006); Sweden; N = 1708; 1144 males + 564 females; mean age 43 years; commuters
Self-reported mileage driven over past year + percentage of journeys travelled by car over 4 days (DM)

Self-reported mileage driven over past yea

Self-reported typical driving frequency

Stated preference for car vs. PT in hypothetical commuting scenario

Probability of self-reporting typically commuting by car

vs. bus
Retrospective

trospective; focus group
General problem

awareness

Perceived responsibility

for environmental

problems from car use

General problem

awareness

Perceived responsibility

for environmental

problems from car use

\#\# Perceived social and

biospheric threat from

environmental problem

\section{Importance of:}

\#\# - convenience

\#\# - travel costs

\#\# - weather

$56 \quad$ SI

\#\# Preference for comfort $406 \quad .76$

\#\# Preference for $\quad 406 \quad .73$

flexibility

\#\# Preference for

406

.76

convenience

$\mathrm{DM}$

$\mathrm{DM}$

$\mathrm{DM}$

DM 
A.5.1. Recruitment letter sent to participants in study 4 postal group

\section{US \\ University of Sussex \\ CAR DRIVERS - win $£ 50$ !}

Dear Resident,

We are enclosing a questionnaire about your car use, and your views and opinions on driving, as part of a study being conducted by researchers at the University of Sussex. We would be grateful if you could complete this questionnaire and return it to us in the envelope provided.

This questionnaire is being given to residents in your area as part of research into drivers' beliefs, attitudes, and behaviour. Please note that the answers that you give will be completely confidential and anonymous, and will not be linked to you personally. The questionnaire is about what you think and do - there are no 'right' or 'wrong' answers, so please answer the questions honestly. The questionnaire should take no more than 15 minutes to complete.

It is important that only one person completes the questionnaire - please do not let anybody else answer any of the questions for you.

\section{Everybody who returns a completed questionnaire together with their} name and address will be entered into a prize draw to win one of four $£ 50 \mathrm{CASH}$ prizes. Your personal details will not be stored with the responses you give to the questions, so your responses will remain anonymous. As soon as the prize draw has taken place and winners have been contacted, we will delete your name and address from our database. So, no information about you will be stored once all the questionnaires have been collected and the draw has taken place. Winners will be notified by post as soon as the draw has been made.

This questionnaire is being conducted by researchers at the University of Sussex, NOT Brighton and Hove Council.

When you have completed the questionnaire, please return it in the stamped addressed envelope.

If you have any questions about this study or our research, please contact the main researcher at B.D.Gardner@sussex.ac.uk, or by post at the above address.

Thanks! 
A.5.2. Recruitment email sent to participants in study 4 online group

We're looking for CAR DRIVERS WHO LIVE IN BRIGHTON AND HOVE to complete a short online questionnaire. If this is you, click on the link below to complete the questionnaire and you'll be entered into a prize draw to win $£ 50$ in cash.

EVEN IF YOU DON'T MEET THESE CRITERIA, YOU CAN STILL EARN $£ 25$ ! Just forward this email to as many other car drivers living in Brighton and Hove as you can. At the end of the questionnaire, they'll be asked to give your email address. That way, we'll be able to see how many people you've recruited to complete the questionnaire. The two people who recruit the most drivers will win $£ 25$ each!

Don't worry if you don't know many other drivers - you might end up winning $£ 25$ for forwarding this email to just two other people!

Here's the link:

http://www.sussex.ac.uk/Units/socpsy/webq/beng/index.htm

Good luck! 
A.5.3. Study 4 questionnaire

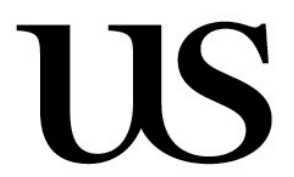

University of Sussex

\section{Car use questionnaire}

Please answer the following questions honestly. All responses are confidential and anonymous.

\section{Do you drive?}

Yes No

Are you: $\quad$ Female $\square \quad$ Male $\square$

What is your age? years

In the last week, how many of your journeys within Brighton and Hove were made using:

A car (including taxis)?

All journeys Most journeys Some journeys Few journeys No journeys

Other transport modes (e.g. bus, train, bike, walking)?

All journeys Most journeys Some journeys Few journeys No journeys 
In an average week, how many of your journeys within Brighton and Hove are made using:

\section{A car (including taxis)?}

All journeys Most journeys Some journeys Few journeys No journeys

\begin{tabular}{ccccc}
$\square$ & $\square$ & $\square$ & $\square$ \\
\hline Other transport modes (e.g. bus, train, bike, walking)? \\
All journeys & Most journeys & Some journeys & Few journeys & No journeys \\
$\square$ & $\square$ & $\square$ & $\square$ & $\square$
\end{tabular}

Imagine yourself travelling to work. What would be your preferred way of getting there?

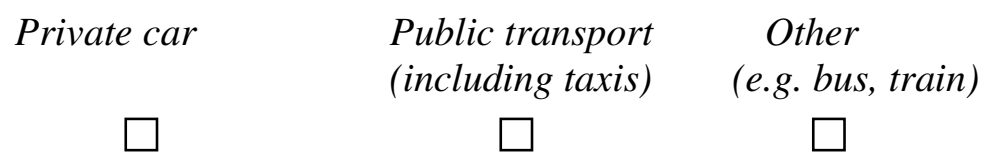

What is your main reason for choosing this type of transport for this journey?

Imagine yourself travelling to another city to visit a friend. What would be your preferred way of getting there?

$\begin{array}{ccc}\text { Private car } & \begin{array}{c}\text { Public transport } \\ \text { (including taxis) }\end{array} & \begin{array}{c}\text { Other } \\ \text { (e.g. bus, train) }\end{array} \\ \square & \square & \square\end{array}$

What is your main reason for choosing this type of transport for this journey?

For each of the statements below, please circle one number in each row.

For example, if you strongly agree with the statement, circle the number next to 'strongly agree'. 
$\underline{\text { I am willing to reduce my car use for journeys within Brighton and Hove }}$

$\begin{array}{llllllllll}\text { Strongly disagree } & \mathbf{3} & \mathbf{2} & \mathbf{1} & \mathbf{0} & \mathbf{1} & \mathbf{2} & \mathbf{3} & \text { Strongly agree }\end{array}$

If I make most of my journeys within Brighton and Hove in the next week WITHOUT using a car, most people who are important to me would approve

$\begin{array}{llllllllll}\text { Strongly disagree } & \mathbf{3} & \mathbf{2} & \mathbf{1} & \mathbf{0} & \mathbf{1} & \mathbf{2} & \mathbf{3} & \text { Strongly agree }\end{array}$

Next week, I intend to make most of my journeys within Brighton and Hove WITHOUT using a car

$\begin{array}{llllllllll}\text { Strongly disagree } & \mathbf{3} & \mathbf{2} & \mathbf{1} & \mathbf{0} & \mathbf{1} & \mathbf{2} & \mathbf{3} & \text { Strongly agree }\end{array}$

$\underline{\text { I am concerned about problems such as air pollution, noise and energy use }}$

$\begin{array}{llllllllll}\text { Strongly disagree } & \mathbf{3} & \mathbf{2} & \mathbf{1} & \mathbf{0} & \mathbf{1} & \mathbf{2} & \mathbf{3} & \text { Strongly agree }\end{array}$

Making most of my journeys within Brighton and Hove next week by car would be: (please circle one number in each row)

\begin{tabular}{|c|c|c|c|c|c|c|c|c|}
\hline Very bad & 3 & 2 & 1 & $\mathbf{0}$ & 1 & 2 & 3 & Very good \\
\hline Very unattractive & 3 & 2 & 1 & $\mathbf{0}$ & 1 & 2 & 3 & Very attractive \\
\hline Very pleasant & 3 & 2 & 1 & $\mathbf{0}$ & 1 & 2 & 3 & Very unpleasant \\
\hline Very satisfying & 3 & 2 & 1 & $\mathbf{0}$ & $\mathbf{1}$ & 2 & 3 & $\begin{array}{l}\text { Very } \\
\text { unsatisfying }\end{array}$ \\
\hline Very unenjoyable & 3 & 2 & 1 & $\mathbf{0}$ & 1 & 2 & 3 & Very enjoyable \\
\hline Very stressful & 3 & 2 & 1 & $\mathbf{0}$ & 1 & 2 & 3 & Very relaxing \\
\hline Very convenient & 3 & 2 & 1 & $\mathbf{0}$ & 1 & 2 & 3 & $\begin{array}{l}\text { Very } \\
\text { inconvenient }\end{array}$ \\
\hline Very slow & 3 & 2 & 1 & $\mathbf{0}$ & 1 & 2 & 3 & Very fast \\
\hline Very expensive & 3 & 2 & 1 & $\mathbf{0}$ & 1 & 2 & 3 & Very inexpensive \\
\hline Very comfortable & 3 & 2 & 1 & $\mathbf{0}$ & $\mathbf{1}$ & 2 & 3 & $\begin{array}{l}\text { Very } \\
\text { uncomfortable }\end{array}$ \\
\hline
\end{tabular}

$\underline{\text { Car use causes environmental problems }}$

$\begin{array}{llllllllll}\text { Strongly disagree } & \mathbf{3} & \mathbf{2} & \mathbf{1} & \mathbf{0} & \mathbf{1} & \mathbf{2} & \mathbf{3} & \text { Stronglyagree }\end{array}$

No matter what other people do, I feel it is right to use my car as little as possible

$\begin{array}{llllllllll}\text { Strongly disagree } & \mathbf{3} & \mathbf{2} & \mathbf{1} & \mathbf{0} & \mathbf{1} & \mathbf{2} & \mathbf{3} & \text { Stronglyagree }\end{array}$

$\underline{\text { I do not feel obliged to use environmentally friendly modes of transport (e.g. bike, bus, }}$ $\underline{\text { train, walk) }}$

$\begin{array}{llllllllll}\text { Strongly disagree } & \mathbf{3} & \mathbf{2} & \mathbf{1} & \mathbf{0} & \mathbf{1} & \mathbf{2} & \mathbf{3} & \text { Strongly agree }\end{array}$ 
I plan to make most of my journeys within Brighton and Hove next week WITHOUT using a car

$\begin{array}{llllllllll}\text { Strongly disagree } & \mathbf{3} & \mathbf{2} & \mathbf{1} & \mathbf{0} & \mathbf{1} & \mathbf{2} & \mathbf{3} & \text { Strongly agree }\end{array}$

Cars are bad for the environment

$\begin{array}{llllllllll}\text { Strongly disagree } & \mathbf{3} & \mathbf{2} & \mathbf{1} & \mathbf{0} & \mathbf{1} & \mathbf{2} & \mathbf{3} & \text { Stronglyagree }\end{array}$

$\underline{\text { I feel obliged to use a car as seldom as possible }}$

$\begin{array}{lllllllll}\text { Strongly disagree } & \mathbf{3} & \mathbf{2} & \mathbf{1} & \mathbf{0} & \mathbf{1} & \mathbf{2} & \mathbf{3} & \text { Strongly agree }\end{array}$

Making most of my journeys within Brighton and Hove next week WITHOUT using a car would be:

$\begin{array}{llllllllll}\text { Very bad } & \mathbf{3} & \mathbf{2} & \mathbf{1} & \mathbf{0} & \mathbf{1} & \mathbf{2} & \mathbf{3} & \text { Very good }\end{array}$

$\begin{array}{lllllllll}\text { Very unattractive } & \mathbf{3} & \mathbf{2} & \mathbf{1} & \mathbf{0} & \mathbf{1} & \mathbf{2} & \mathbf{3} & \text { Very attractive }\end{array}$

$\begin{array}{lllllllll}\text { Very pleasant } & \mathbf{3} & \mathbf{2} & \mathbf{1} & \mathbf{0} & \mathbf{1} & \mathbf{2} & \mathbf{3} & \text { Very unpleasant }\end{array}$

$\begin{array}{lllllllll}\text { Very satisfying } & \mathbf{3} & \mathbf{2} & \mathbf{1} & \mathbf{0} & \mathbf{1} & \mathbf{2} & \mathbf{3} & \text { Very }\end{array}$

$\begin{array}{llllllllll}\text { Very unenjoyable } & \mathbf{3} & \mathbf{2} & \mathbf{1} & \mathbf{0} & \mathbf{1} & \mathbf{2} & \mathbf{3} & \text { Very enjoyable }\end{array}$

$\begin{array}{lllllllll}\text { Very stressful } & \mathbf{3} & \mathbf{2} & \mathbf{1} & \mathbf{0} & \mathbf{1} & \mathbf{2} & \mathbf{3} & \text { Very relaxing }\end{array}$

$\begin{array}{lllllllll}\text { Very convenient } & 3 & 2 & \mathbf{1} & \mathbf{0} & \mathbf{1} & \mathbf{2} & \mathbf{3} & \text { Very }\end{array}$

$\begin{array}{lllllllll}\text { Very expensive } & \mathbf{3} & \mathbf{2} & \mathbf{1} & \mathbf{0} & \mathbf{1} & \mathbf{2} & \mathbf{3} & \text { Very inexpensive }\end{array}$

$\begin{array}{lllllllll}\text { Very comfortable } & 3 & 2 & 1 & \mathbf{0} & \mathbf{1} & \mathbf{2} & \mathbf{3} & \text { Very }\end{array}$

uncomfortable

$\underline{\text { I am worried about environmental problems such as air pollution, noise and energy use }}$

$\begin{array}{llllllllll}\text { Strongly disagree } & \mathbf{3} & \mathbf{2} & \mathbf{1} & \mathbf{0} & \mathbf{1} & \mathbf{2} & \mathbf{3} & \text { Strongly agree }\end{array}$

Through my transport decisions, I can make a difference to the environment

$\begin{array}{llllllllll}\text { Strongly disagree } & \mathbf{3} & \mathbf{2} & \mathbf{1} & \mathbf{0} & \mathbf{1} & \mathbf{2} & \mathbf{3} & \text { Stronglyagree }\end{array}$

Most people who are important to me use a car for most of their journeys within the city

$\begin{array}{llllllllll}\text { Strongly disagree } & \mathbf{3} & \mathbf{2} & \mathbf{1} & \mathbf{0} & \mathbf{1} & \mathbf{2} & \mathbf{3} & \text { Stronglyagree }\end{array}$

Next week, I intend to use a car for most of my journeys within Brighton and Hove

$\begin{array}{llllllllll}\text { Strongly disagree } & \mathbf{3} & \mathbf{2} & \mathbf{1} & \mathbf{0} & \mathbf{1} & \mathbf{2} & \mathbf{3} & \text { Stronglyagree }\end{array}$ 
How important are the following to you:

(please circle one number in each row)

\begin{tabular}{|c|c|c|c|c|c|c|c|c|}
\hline \multicolumn{9}{|c|}{ Honesty } \\
\hline Very important & 3 & 2 & 1 & $\mathbf{0}$ & 1 & 2 & 3 & $\begin{array}{l}\text { Not very } \\
\text { important }\end{array}$ \\
\hline \multicolumn{9}{|c|}{ Equality } \\
\hline Very important & 3 & 2 & 1 & $\mathbf{0}$ & 1 & 2 & 3 & $\begin{array}{l}\text { Not very } \\
\text { important }\end{array}$ \\
\hline \multicolumn{9}{|c|}{ Not judging others } \\
\hline Very important & 3 & 2 & 1 & $\mathbf{0}$ & 1 & 2 & 3 & $\begin{array}{l}\text { Not very } \\
\text { important }\end{array}$ \\
\hline \multicolumn{9}{|c|}{ Forgiving others } \\
\hline Very important & 3 & 2 & 1 & $\mathbf{0}$ & 1 & 2 & 3 & $\begin{array}{l}\text { Not very } \\
\text { important }\end{array}$ \\
\hline \multicolumn{9}{|c|}{ Helpfulness } \\
\hline Very important & 3 & 2 & 1 & $\mathbf{0}$ & 1 & 2 & 3 & $\begin{array}{l}\text { Not very } \\
\text { important }\end{array}$ \\
\hline
\end{tabular}

$\underline{\text { I am able to control whether I use a car for most of my journeys in Brighton and Hove }}$ next week

$\begin{array}{lllllllll}\text { Strongly disagree } & \mathbf{3} & \mathbf{2} & \mathbf{1} & \mathbf{0} & \mathbf{1} & \mathbf{2} & \mathbf{3} & \text { Strongly agree }\end{array}$

Most people who are important to me think I should make most of my journeys within Brighton and Hove in the next week WITHOUT using a car

$\begin{array}{llllllllll}\text { Strongly disagree } & \mathbf{3} & \mathbf{2} & \mathbf{1} & \mathbf{0} & \mathbf{1} & \mathbf{2} & \mathbf{3} & \text { Strongly agree }\end{array}$

How do the people that are important to you make most of their journeys within the city?

$\begin{array}{llllllllll}\text { Others always } & 3 & 2 & 1 & 0 & 1 & 2 & 3 & \text { Others never }\end{array}$ use a car use a car

Using a car is something I do automatically, without really thinking

$\begin{array}{llllllllll}\text { Strongly disagree } & \mathbf{3} & \mathbf{2} & \mathbf{1} & \mathbf{0} & \mathbf{1} & \mathbf{2} & \mathbf{3} & \text { Stronglyagree }\end{array}$

Most people who are important to me think I should use a car for most of my journeys within Brighton and Hove in the next week

$\begin{array}{llllllllll}\text { Strongly disagree } & \mathbf{3} & \mathbf{2} & \mathbf{1} & \mathbf{0} & \mathbf{1} & \mathbf{2} & \mathbf{3} & \text { Strongly agree }\end{array}$ 
I have no control over whether I make most of my journeys in Brighton and Hove next week WITHOUT using a car

$\begin{array}{llllllllll}\text { Strongly disagree } & \mathbf{3} & \mathbf{2} & \mathbf{1} & \mathbf{0} & \mathbf{1} & \mathbf{2} & \mathbf{3} & \text { Strongly agree }\end{array}$

$\underline{\text { Is using a car something you do out of habit? }}$

$\begin{array}{llllllllll}\text { Definitely yes } & \mathbf{3} & \mathbf{2} & \mathbf{1} & \mathbf{0} & \mathbf{1} & \mathbf{2} & \mathbf{3} & \text { Definitely } n o\end{array}$

I plan to use a car to make most of my journeys within Brighton and Hove next week

$\begin{array}{lllllllll}\text { Strongly disagree } & \mathbf{3} & \mathbf{2} & \mathbf{1} & \mathbf{0} & \mathbf{1} & \mathbf{2} & \mathbf{3} & \text { Strongly agree }\end{array}$

I have no control over whether I use a car for most of my journeys in Brighton and Hove next week

$\begin{array}{lllllllll}\text { Strongly disagree } & \mathbf{3} & \mathbf{2} & \mathbf{1} & \mathbf{0} & \mathbf{1} & \mathbf{2} & \mathbf{3} & \text { Strongly agree }\end{array}$

$\underline{\text { I would voluntarily reduce my car use for journeys within Brighton and Hove }}$

$\begin{array}{llllllllll}\text { Strongly disagree } & \mathbf{3} & \mathbf{2} & \mathbf{1} & \mathbf{0} & \mathbf{1} & \mathbf{2} & \mathbf{3} & \text { Strongly agree }\end{array}$

If I use a car for most of my journeys within Brighton and Hove in the next week, most people who are important to me would approve

$\begin{array}{llllllllll}\text { Strongly disagree } & \mathbf{3} & \mathbf{2} & \mathbf{1} & \mathbf{0} & \mathbf{1} & \mathbf{2} & \mathbf{3} & \text { Strongly agree }\end{array}$

How I choose to travel does not affect the environment

$\begin{array}{llllllllll}\text { Strongly disagree } & \mathbf{3} & \mathbf{2} & \mathbf{1} & \mathbf{0} & \mathbf{1} & \mathbf{2} & \mathbf{3} & \text { Stronglyagree }\end{array}$

$\underline{\text { I am able to control whether I make most of my journeys in Brighton and Hove next }}$ week WITHOUT using a car

$\begin{array}{llllllllll}\text { Strongly disagree } & \mathbf{3} & \mathbf{2} & \mathbf{1} & \mathbf{0} & \mathbf{1} & \mathbf{2} & \mathbf{3} & \text { Strongly agree }\end{array}$

Thank you for completing this questionnaire. If you wish to be entered in the prize draw to win one of four £50 CASH prizes, please fill in the slip on the next page.

Please note that after winners have been drawn, your details will be deleted from our database. We will be in touch with prize draw winners as soon as the draw has taken place. We estimate that the draw will take place by the end of November 2006. 
A.5.4. Debrieffor study 4 online participants

Many thanks for completing the questionnaire.

\section{Do you know any other car drivers living in Brighton and Hove? If so, you could earn $£ 25$ by telling them about this questionnaire! Just copy the following text and paste it into a blank email.}

$\mathrm{Hi}$,

I've just completed a short online questionnaire being run by the University of Sussex. They need as many CAR DRIVERS WHO LIVE IN BRIGHTON AND HOVE as possible to fill in their questionnaire, and everyone who completes the questionnaire will be entered into a prize draw to win $£ 50$ in cash. (The link to the questionnaire is below.)

What's more, they're promising to give $£ 25$ each to the two people who recruit the most drivers to do their questionnaire, so by filling it in you could help me win $£ 25$.

In fact, you could win $£ 25$ too, just by forwarding this email to as many drivers in Brighton and Hove as you can.

So if you're a car driver living in Brighton and Hove, click on the link below to access the survey questionnaire. It takes about 10 minutes to complete. Forward this email to other Brighton and Hove car drivers, and you could win $£ 25$ !

Click here for the questionnaire:

http://www.sussex.ac.uk/Units/socpsy/webq/beng/index.htm

Thanks! 
A.6.1. Study 5 recruitment email

Subject: New questionnaire for car drivers, November 2006

Do you drive a car to campus?

I'm looking for PEOPLE WHO DRIVE A CAR TO CAMPUS to complete a NEW very short (5-10 mins) online questionnaire. If this is you, click on the link below to complete the questionnaire and receive $15 \mathrm{mins}$ ' course credits or an entry into a prize draw to win £25.

THIS IS A COMPLETELY NEW QUESTIONNAIRE for November, and you CAN participate if you completed my previous transport questionnaire in September or October.

Please note that you are NOT eligible to take part in this study if you LIVE ON CAMPUS.

Click here for the questionnaire:

https://www.surveymonkey.com/s.asp? u=921652795972

Thanks!

B. Gardner

B.D.Gardner@sussex.ac.uk 


\section{Transport questionnaire}

\section{November 2006}

Please answer the following questions honestly.

All responses are anonymous and confidential.

What is your age? years

Are you:

Female

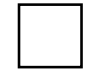

Male

Do you drive?

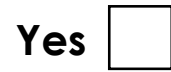

No

Do you have access to a car for commuting to university?

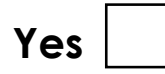

No

Do you live on campus?

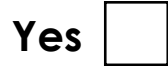

No

In the past week, on how many days did you travel to the university campus? days

In the past week, on how many days did you USE A CAR to commute to the university campus? 
In the past week, on how many days did you USE PUBLIC TRANSPORT

(e.g. bus, train) to commute to the university campus?

In the past week, on how many days did you travel to the university campus by WALKING OR CYCLING?

Many of the questions in this questionnaire are similar. This is intentional.

In all cases, please complete each question without thinking about how you may have completed previous questions.

\section{For each of the statements below, please select one number in each row.}

When I need to travel, I often think about whether it is best to drive or use public transport.

$\begin{array}{llllllllll}\text { Strongly disagree } & \mathbf{3} & \mathbf{2} & \mathbf{1} & \mathbf{0} & \mathbf{1} & \mathbf{2} & \mathbf{3} & \text { Strongly agree }\end{array}$

I carefully consider all available transport options before choosing which type of transport to use.

$\begin{array}{cccccccccc}\text { Strongly agree } & \mathbf{3} & \mathbf{2} & \mathbf{1} & \mathbf{0} & \mathbf{1} & \mathbf{2} & \mathbf{3} & \begin{array}{c}\text { Strongly } \\ \text { disagree }\end{array}\end{array}$

I hardly ever think about using public transport when I need to go somewhere.

$\begin{array}{lllllllll}\text { Strongly agree } & \mathbf{3} & \mathbf{2} & \mathbf{1} & \mathbf{0} & \mathbf{1} & \mathbf{2} & \mathbf{3} & \text { Strongly }\end{array}$

disagree 
When I need to travel, choosing to drive is something I do automatically, without really thinking.

$\begin{array}{llllllllll}\text { Strongly disagree } & \mathbf{3} & \mathbf{2} & \mathbf{1} & \mathbf{0} & \mathbf{1} & \mathbf{2} & \mathbf{3} & \text { Strongly agree }\end{array}$

It takes something unusual for me to consider public transport when I want to get somewhere.

$\begin{array}{lllllllll}\text { Strongly disagree } & \mathbf{3} & \mathbf{2} & \mathbf{1} & \mathbf{0} & \mathbf{1} & \mathbf{2} & \mathbf{3} & \text { Strongly agree }\end{array}$

Using public transport to commute to the university campus on at least two days over the next week would be:

(Please tick one box in each row)

$\begin{array}{lllllllll}\text { Very beneficial } & \mathbf{3} & \mathbf{2} & \mathbf{1} & \mathbf{0} & \mathbf{1} & \mathbf{2} & \mathbf{3} & \text { Very harmful } \\ \text { Very foolish } & \mathbf{3} & \mathbf{2} & \mathbf{1} & \mathbf{0} & \mathbf{1} & \mathbf{2} & \mathbf{3} & \text { Very wise } \\ \text { Very good } & \mathbf{3} & \mathbf{2} & \mathbf{1} & \mathbf{0} & \mathbf{1} & \mathbf{2} & \mathbf{3} & \text { Very bad }\end{array}$

When you need to make a journey, is choosing to drive something you do automatically, without thinking?

$\begin{array}{lllllllll}\text { Definitely yes } & \mathbf{3} & \mathbf{2} & \mathbf{1} & \mathbf{0} & \mathbf{1} & \mathbf{2} & \mathbf{3} & \text { Definitely no }\end{array}$

I plan to use public transport to commute to the university campus on at least two days over the next week.

$\begin{array}{llllllllll}\text { Strongly disagree } & \mathbf{3} & \mathbf{2} & \mathbf{1} & \mathbf{0} & \mathbf{1} & \mathbf{2} & \mathbf{3} & \text { Stronglyagree }\end{array}$

When I have to make a journey, I tend NOT to think about the modes of transport available to me

$\begin{array}{llllllllll}\text { Strongly disagree } & \mathbf{3} & \mathbf{2} & \mathbf{1} & \mathbf{0} & \mathbf{1} & \mathbf{2} & \mathbf{3} & \text { Strongly agree }\end{array}$

When planning a journey, I am not usually aware of making a decision about what mode of transport (e.g., car, bus, train, etc.) I should use.

$\begin{array}{cccccccccc}\text { Stronglyagree } & \mathbf{3} & \mathbf{2} & \mathbf{1} & \mathbf{0} & \mathbf{1} & \mathbf{2} & \mathbf{3} & \begin{array}{c}\text { Strongly } \\ \text { disagree }\end{array}\end{array}$


I intend to use a car to commute on every day I go to the university campus over the next week.

$\begin{array}{llllllllll}\text { Stronglyagree } & \mathbf{3} & \mathbf{2} & \mathbf{1} & \mathbf{0} & \mathbf{1} & \mathbf{2} & \mathbf{3} & \begin{array}{c}\text { Strongly } \\ \text { disagree }\end{array}\end{array}$

When you need to make a journey, do you consider all the available transport options before deciding which transport mode you will use?

$\begin{array}{llllllllll}\text { Definitely do not } & 3 & 2 & 1 & 0 & 1 & 2 & 3 & \text { Definitely do }\end{array}$

When I need to go somewhere I automatically think about driving there.

$\begin{array}{llllllllll}\text { Strongly disagree } & \mathbf{3} & \mathbf{2} & \mathbf{1} & \mathbf{0} & \mathbf{1} & \mathbf{2} & \mathbf{3} & \text { Strongly agree }\end{array}$

Using a car on every day that I go to the university campus over the next week would be:

(Please tick one box in each row)

$\begin{array}{lllllllll}\text { Very beneficial } & \mathbf{3} & \mathbf{2} & \mathbf{1} & \mathbf{0} & \mathbf{1} & \mathbf{2} & \mathbf{3} & \text { Very harmful } \\ \text { Very foolish } & \mathbf{3} & \mathbf{2} & \mathbf{1} & \mathbf{0} & \mathbf{1} & \mathbf{2} & \mathbf{3} & \text { Very wise } \\ \text { Very good } & \mathbf{3} & \mathbf{2} & \mathbf{1} & \mathbf{0} & \mathbf{1} & \mathbf{2} & \mathbf{3} & \text { Very bad }\end{array}$

When I need to make a journey, I DO NOT consider all available transport options before I choose to drive

$\begin{array}{lllllllll}\text { Strongly disagree } & \mathbf{3} & \mathbf{2} & \mathbf{1} & \mathbf{0} & \mathbf{1} & \mathbf{2} & \mathbf{3} & \text { Strongly agree }\end{array}$

When I need to get somewhere, I would find it difficult to stop myself from driving there.

$\begin{array}{llllllllll}\text { Stronglyagree } & \mathbf{3} & \mathbf{2} & \mathbf{1} & \mathbf{0} & \mathbf{1} & \mathbf{2} & \mathbf{3} & \begin{array}{c}\text { Strongly } \\ \text { disagree }\end{array}\end{array}$

When I have to go somewhere, I tend to think about the different modes of transport (e.g., car, bus, train, etc.) available to me.

$\begin{array}{lllllllll}\text { Definitely do } & \mathbf{3} & \mathbf{2} & \mathbf{1} & \mathbf{0} & \mathbf{1} & \mathbf{2} & \mathbf{3} & \text { Definitely do not }\end{array}$

I could easily make more of my journeys by public transport, instead of driving.

$\begin{array}{lllllllll}\text { Strongly disagree } & \mathbf{3} & \mathbf{2} & \mathbf{1} & \mathbf{0} & \mathbf{1} & \mathbf{2} & \mathbf{3} & \text { Stronglyagree }\end{array}$ 
When I have to make a journey, I often use a car without really thinking about the possibility of using other transport modes

$\begin{array}{lllllllll}\text { Definitely do not } & \mathbf{3} & \mathbf{2} & \mathbf{1} & \mathbf{0} & \mathbf{1} & \mathbf{2} & \mathbf{3} & \text { Definitely } d o\end{array}$

I intend to use public transport to commute to the university campus on at least two days over the next week.

$\begin{array}{lllllllll}\text { Strongly agree } & \mathbf{3} & \mathbf{2} & \mathbf{1} & \mathbf{0} & \mathbf{1} & \mathbf{2} & \mathbf{3} & \text { Strongly }\end{array}$ disagree

When I have to make a journey, deciding to drive is something I do automatically

$\begin{array}{llllllllll}\text { Strongly disagree } & \mathbf{3} & \mathbf{2} & \mathbf{1} & \mathbf{0} & \mathbf{1} & \mathbf{2} & \mathbf{3} & \text { Strongly agree }\end{array}$

I plan to use a car to commute on every day that I go to the university campus over the next week.

$\begin{array}{llllllllll}\text { Stronglyagree } & \mathbf{3} & \mathbf{2} & \mathbf{1} & \mathbf{0} & \mathbf{1} & \mathbf{2} & \mathbf{3} & \text { Strongly }\end{array}$ disagree

I automatically choose to use a car when I have to make a journey $\begin{array}{llllllllll}\text { Strongly disagree } & \mathbf{3} & \mathbf{2} & \mathbf{1} & \mathbf{0} & \mathbf{1} & \mathbf{2} & \mathbf{3} & \text { Strongly agree }\end{array}$

I consider all transport options when I have to make a journey

$\begin{array}{lllllllll}\text { Strongly agree } & \mathbf{3} & \mathbf{2} & \mathbf{1} & \mathbf{0} & \mathbf{1} & \mathbf{2} & \mathbf{3} & \text { Strongly }\end{array}$ disagree 
Thank you for completing this questionnaire.

Please enter your email address below and indicate whether you would like to receive course credits or an entry into a £25 prize draw.

Email:

I would like to receive:

Course credit

Entry into the $\mathbf{2} 25$ prize draw

Please now click below to submit your answers. 
A.6.3. Study 5 debrief

Thank you for completing this questionnaire. The questionnaire was designed to enable me to develop reliable measures of some of the psychological variables that have been linked with people's transport choices.

If you have indicated that you wish to receive course credits, I will be in touch with you soon to take details of your name and year of study. By asking for this information separately from the questionnaire, I can assure you that your personal details will not be stored with your questionnaire responses.

If you know of any other car drivers at University of Sussex who may be interested in participating in this study, please forward the following link to them:

(https://www.surveymonkey.com/s.asp?u=921652795972)

If you have any questions regarding this study, please contact me at B.D.Gardner@sussex.ac.uk.

Thanks! 
A.6.4. Study 6 recruitment email

Subject: DRIVERS NEEDED for PAID questionnaire study - $£ 5$ for $20-25$ minutes' work!

I'm running a BRAND NEW questionnaire study. To take part, you must:

- be a CURRENT STUDENT OR STAFF MEMBER at University of SUssex

- LIVE OFF-CAMPUS

- DRIVE A CAR/HOLD A DRIVING LICENCE

- have ACCESS TO A CAR FOR COMMUTING TO CAMPUS (regardless of whether you actually use the car for this purpose).

The questionnaire has to be completed in a lab, and takes about 15-20 minutes. One week later, you will be contacted and asked to answer a few short questions via email. When I receive your responses, you will either receive 30 minutes' course credit or be paid $£ 5$.

(Please note - you CAN participate in this study even if you completed either of my questionnaires last term.)

I will be running participants from Monday of Week 2 (15 th Jan). Time slots are available on the hour and on the half-hour (i.e. 9am, 9.30am, 10am, 10.30am etc.). If you are interested, please email me with a list of your available times, and I will arrange a time for you to participate.

Thanks!

Ben Gardner

PS - Please forward this email to any other Sussex-based staff or students who may be interested in participating. 
A.6.5. Study 6 recruitment poster

\section{CAR DRIVERS NEEDED for PAID questionnaire study}

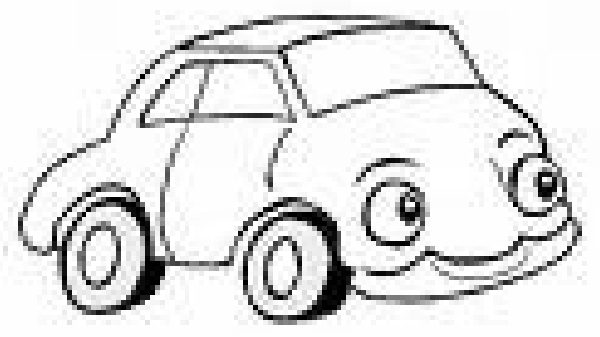

\section{£5 for 15-20 minutes' work!}

Do you DRIVE A CAR?

Do you LIVE OFF-CAMPUS? Do you have ACCESS TO A CAR FOR COMMUTING TO

CAMPUS (regardless of whether you actually use the car for this purpose)?

If so, you are eligible to participate in my questionnaire study.

All you are required to do is come into the lab for 15 minutes, then one week later answer a few short questions via email. You will then be paid $\mathrm{f5}$. 
If interested please email

B.D.Gardner@sussex.ac.uk 


\section{Transport questionnaire}

1. Today's date:

2. What is your age?

3. Are you:

Male

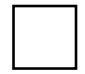

Female

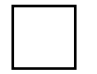

4. If you drive to campus, how do you pay for your parking?

I have an annual permit

I 'pay as I go'

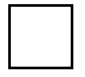

5. How many journeys did you make to the university campus over the last week? journeys

6. How many journeys to the university campus did you make by CAR over the last week?

journeys

7. How many journeys to the university campus did you make by PUBLIC TRANSPORT (e.g. bus, train) over the last week?

journeys

8. How many journeys to the university campus did you make by any other form of transport (e.g. WALKING, CYCLING, MOTORBIKE) over the last week?

journeys

Please answer the following questions honestly.

All responses are anonymous and confidential.

Many of the questions are similar. This is intentional. In all cases, please complete each question without thinking about how you may have completed previous questions.

THERE IS NO TIME LIMIT FOR RESPONDING TO THESE QUESTIONS; please take as long as you require. 
When you need to make a journey, is choosing to drive something you do automatically, without really thinking?

$\begin{array}{llllllllll}\text { Definitely no } & \mathbf{3} & \mathbf{2} & \mathbf{1} & \mathbf{0} & \mathbf{1} & \mathbf{2} & \mathbf{3} & \text { Definitely yes }\end{array}$

When I have to make a journey, I tend NOT to think about the modes of transport available to me

$\begin{array}{llllllllll}\text { Strongly disagree } & \mathbf{3} & \mathbf{2} & \mathbf{1} & \mathbf{0} & \mathbf{1} & \mathbf{2} & \mathbf{3} & \text { Strongly agree }\end{array}$

When I have to make a journey, I often drive without really thinking about the possibility of using other transport modes

$\begin{array}{llllllllll}\text { Definitely do not } & \mathbf{3} & \mathbf{2} & \mathbf{1} & \mathbf{0} & \mathbf{1} & \mathbf{2} & \mathbf{3} & \text { Definitely do }\end{array}$

When I have to make a journey, deciding to drive is something I do automatically

$\begin{array}{llllllllll}\text { Strongly disagree } & \mathbf{3} & \mathbf{2} & \mathbf{1} & \mathbf{0} & \mathbf{1} & \mathbf{2} & \mathbf{3} & \text { Strongly agree }\end{array}$

I automatically choose to drive when I have to make a journey

$\begin{array}{llllllllll}\text { Strongly disagree } & \mathbf{3} & \mathbf{2} & \mathbf{1} & \mathbf{0} & \mathbf{1} & \mathbf{2} & \mathbf{3} & \text { Strongly agree }\end{array}$

When I need to make a journey, I DO NOT consider all available transport options before I choose to drive

$\begin{array}{lllllllll}\text { Strongly disagree } & \mathbf{3} & \mathbf{2} & \mathbf{1} & \mathbf{0} & \mathbf{1} & \mathbf{2} & \mathbf{3} & \text { Stronglyagree }\end{array}$

When planning a journey, I am not usually aware of making a decision about what mode of transport (e.g. car, bus, train, etc) I should use

$\begin{array}{llllllllll}\text { Strongly disagree } & \mathbf{3} & \mathbf{2} & \mathbf{1} & \mathbf{0} & \mathbf{1} & \mathbf{2} & \mathbf{3} & \text { Strongly agree }\end{array}$

When I need to go somewhere I automatically think about driving there

$\begin{array}{lllllllll}\text { Strongly disagree } & \mathbf{3} & \mathbf{2} & \mathbf{1} & \mathbf{0} & \mathbf{1} & \mathbf{2} & \mathbf{3} & \text { Strongly agree }\end{array}$

When I need to travel, choosing to drive is something I do automatically, without really thinking

$\begin{array}{llllllllll}\text { Strongly disagree } & \mathbf{3} & \mathbf{2} & \mathbf{1} & \mathbf{0} & \mathbf{1} & \mathbf{2} & \mathbf{3} & \text { Stronglyagree }\end{array}$ 
Using a car to commute to campus is something I do frequently

$\begin{array}{llllllllll}\text { Strongly disagree } & \mathbf{3} & \mathbf{2} & \mathbf{1} & \mathbf{0} & \mathbf{1} & \mathbf{2} & \mathbf{3} & \text { Stronglyagree }\end{array}$

Using a car to commute to campus is something I do automatically

$\begin{array}{lllllllll}\text { Strongly disagree } & \mathbf{3} & \mathbf{2} & \mathbf{1} & \mathbf{0} & \mathbf{1} & \mathbf{2} & \mathbf{3} & \text { Strongly agree }\end{array}$

Using a car to commute to campus is something I do without having to consciously remember

$\begin{array}{llllllllll}\text { Strongly disagree } & \mathbf{3} & \mathbf{2} & \mathbf{1} & \mathbf{0} & \mathbf{1} & \mathbf{2} & \mathbf{3} & \text { Strongly agree }\end{array}$

Using a car to commute to campus is something that makes me feel weird if I do not do it

$\begin{array}{lllllllll}\text { Strongly disagree } & \mathbf{3} & \mathbf{2} & \mathbf{1} & \mathbf{0} & \mathbf{1} & \mathbf{2} & \mathbf{3} & \text { Strongly agree }\end{array}$

Using a car to commute to campus is something I do without thinking

$\begin{array}{lllllllll}\text { Strongly disagree } & \mathbf{3} & \mathbf{2} & \mathbf{1} & \mathbf{0} & \mathbf{1} & \mathbf{2} & \mathbf{3} & \text { Strongly agree }\end{array}$

Using a car to commute to campus is something that would require effort not to do

$\begin{array}{llllllllll}\text { Strongly disagree } & \mathbf{3} & \mathbf{2} & \mathbf{1} & \mathbf{0} & \mathbf{1} & \mathbf{2} & \mathbf{3} & \text { Strongly agree }\end{array}$

Using a car to commute to campus is something that belongs to my daily routine

$\begin{array}{lllllllll}\text { Strongly disagree } & \mathbf{3} & \mathbf{2} & \mathbf{1} & \mathbf{0} & \mathbf{1} & \mathbf{2} & \mathbf{3} & \text { Strongly agree }\end{array}$

Using a car to commute to campus is something I start doing before I realize I'm doing it

$\begin{array}{lllllllll}\text { Strongly disagree } & \mathbf{3} & \mathbf{2} & \mathbf{1} & \mathbf{0} & \mathbf{1} & \mathbf{2} & \mathbf{3} & \text { Strongly agree }\end{array}$

Using a car to commute to campus is something I would find hard not to do

$\begin{array}{llllllllll}\text { Strongly disagree } & \mathbf{3} & \mathbf{2} & \mathbf{1} & \mathbf{0} & \mathbf{1} & \mathbf{2} & \mathbf{3} & \text { Strongly agree }\end{array}$ 
Using a car to commute to campus is something I have no need to think about doing

$\begin{array}{llllllllll}\text { Strongly disagree } & \mathbf{3} & \mathbf{2} & \mathbf{1} & \mathbf{0} & \mathbf{1} & \mathbf{2} & \mathbf{3} & \text { Strongly agree }\end{array}$

Using a car to commute to campus is something that's typically "me"

$\begin{array}{llllllllll}\text { Strongly disagree } & \mathbf{3} & \mathbf{2} & \mathbf{1} & \mathbf{0} & \mathbf{1} & \mathbf{2} & \mathbf{3} & \text { Stronglyagree }\end{array}$

Using a car to commute to campus is something I have been doing for a long time

$\begin{array}{lllllllll}\text { Strongly disagree } & \mathbf{3} & \mathbf{2} & \mathbf{1} & \mathbf{0} & \mathbf{1} & \mathbf{2} & \mathbf{3} & \text { Strongly agree }\end{array}$

I intend to use a car for most of my journeys to the university campus over the next week

$\begin{array}{lllllllll}\text { Strongly disagree } & \mathbf{3} & \mathbf{2} & \mathbf{1} & \mathbf{0} & \mathbf{1} & \mathbf{2} & \mathbf{3} & \text { Strongly agree }\end{array}$

I will try to use a car for most of my journeys to the university campus over the next week

$\begin{array}{lllllllll}\text { Strongly disagree } & \mathbf{3} & \mathbf{2} & \mathbf{1} & \mathbf{0} & \mathbf{1} & \mathbf{2} & \mathbf{3} & \text { Strongly agree }\end{array}$

I plan to use a car for most of my journeys to the university campus over the next week

$\begin{array}{lllllllll}\text { Strongly disagree } & \mathbf{3} & \mathbf{2} & \mathbf{1} & \mathbf{0} & \mathbf{1} & \mathbf{2} & \mathbf{3} & \text { Strongly agree }\end{array}$

I aim to use a car for most of my journeys to the university campus over the next week

$\begin{array}{llllllllll}\text { Strongly disagree } & \mathbf{3} & \mathbf{2} & \mathbf{1} & \mathbf{0} & \mathbf{1} & \mathbf{2} & \mathbf{3} & \text { Strongly agree }\end{array}$

Using a car for most of my journeys to the university campus over the next week would be:

$\begin{array}{lllllllll}\text { Harmful } & \mathbf{3} & \mathbf{2} & \mathbf{1} & \mathbf{0} & \mathbf{1} & \mathbf{2} & \mathbf{3} & \text { Beneficial } \\ \text { Pleasant } & \mathbf{3} & \mathbf{2} & \mathbf{1} & \mathbf{0} & \mathbf{1} & \mathbf{2} & \mathbf{3} & \text { Unpleasant } \\ \text { Good } & \mathbf{3} & \mathbf{2} & \mathbf{1} & \mathbf{0} & \mathbf{1} & \mathbf{2} & \mathbf{3} & \text { Bad } \\ \text { Enjoyable } & \mathbf{3} & \mathbf{2} & \mathbf{1} & \mathbf{0} & \mathbf{1} & \mathbf{2} & \mathbf{3} & \text { Unenjoyable } \\ \text { Wise } & \mathbf{3} & \mathbf{2} & \mathbf{1} & \mathbf{0} & \mathbf{1} & \mathbf{2} & \mathbf{3} & \text { Foolish }\end{array}$


Making most of my journeys to the university campus over the next week WITHOUT using a car would be:

$\begin{array}{lllllllll}\text { Harmful } & \mathbf{3} & \mathbf{2} & \mathbf{1} & \mathbf{0} & \mathbf{1} & \mathbf{2} & \mathbf{3} & \text { Beneficial } \\ \text { Pleasant } & \mathbf{3} & \mathbf{2} & \mathbf{1} & \mathbf{0} & \mathbf{1} & \mathbf{2} & \mathbf{3} & \text { Unpleasant } \\ \text { Good } & \mathbf{3} & \mathbf{2} & \mathbf{1} & \mathbf{0} & \mathbf{1} & \mathbf{2} & \mathbf{3} & \text { Bad } \\ \text { Enjoyable } & \mathbf{3} & \mathbf{2} & \mathbf{1} & \mathbf{0} & \mathbf{1} & \mathbf{2} & \mathbf{3} & \text { Unenjoyable } \\ \text { Wise } & \mathbf{3} & \mathbf{2} & \mathbf{1} & \mathbf{0} & \mathbf{1} & \mathbf{2} & \mathbf{3} & \text { Foolish }\end{array}$

Most people who are important to me think that I should use a car for most of my journeys to the university campus over the next week

$\begin{array}{lllllllll}\text { Strongly disagree } & \mathbf{3} & \mathbf{2} & \mathbf{1} & \mathbf{0} & \mathbf{1} & \mathbf{2} & \mathbf{3} & \text { Strongly agree }\end{array}$

People who are important to me expect me to use a car for most of my journeys to the university campus over the next week

$\begin{array}{llllllllll}\text { Strongly disagree } & \mathbf{3} & \mathbf{2} & \mathbf{1} & \mathbf{0} & \mathbf{1} & \mathbf{2} & \mathbf{3} & \text { Strongly agree }\end{array}$

If I use a car for most of my journeys to the university campus over the next week, people who are important to me would approve

$\begin{array}{llllllllll}\text { Strongly disagree } & \mathbf{3} & \mathbf{2} & \mathbf{1} & \mathbf{0} & \mathbf{1} & \mathbf{2} & \mathbf{3} & \text { Stronglyagree }\end{array}$

Most people who are important to me think that I should make most of my journeys to the university campus over the next week WITHOUT using a car

$\begin{array}{llllllllll}\text { Strongly disagree } & \mathbf{3} & \mathbf{2} & \mathbf{1} & \mathbf{0} & \mathbf{1} & \mathbf{2} & \mathbf{3} & \text { Stronglyagree }\end{array}$

People who are important to me expect me to make most of my journeys to the university campus over the next week WITHOUT using a car

$\begin{array}{llllllllll}\text { Strongly disagree } & \mathbf{3} & \mathbf{2} & \mathbf{1} & \mathbf{0} & \mathbf{1} & \mathbf{2} & \mathbf{3} & \text { Strongly agree }\end{array}$

If I made most of my journeys to the university campus over the next week WITHOUT using a car, people who are important to me would approve

$\begin{array}{llllllllll}\text { Strongly disagree } & \mathbf{3} & \mathbf{2} & \mathbf{1} & \mathbf{0} & \mathbf{1} & \mathbf{2} & \mathbf{3} & \text { Strongly agree }\end{array}$ 
If I wanted to, I could use a car for most of my journeys to the university campus over the next week

$\begin{array}{lllllllll}\text { Strongly disagree } & \mathbf{3} & \mathbf{2} & \mathbf{1} & \mathbf{0} & \mathbf{1} & \mathbf{2} & \mathbf{3} & \text { Strongly agree }\end{array}$

How much control do you have over using a car for most of your journeys to the university campus over the next week?

$\begin{array}{llllllllll}\text { No control } & \mathbf{3} & \mathbf{2} & \mathbf{1} & \mathbf{0} & \mathbf{1} & \mathbf{2} & \mathbf{3} & \text { Complete }\end{array}$ control

It is mostly up to me whether or not I use a car for most of my journeys to the university campus over the next week

$\begin{array}{llllllllll}\text { Strongly disagree } & \mathbf{3} & \mathbf{2} & \mathbf{1} & \mathbf{0} & \mathbf{1} & \mathbf{2} & \mathbf{3} & \text { Stronglyagree }\end{array}$

I am able to control whether I use a car for most of my journeys to the university campus over the next week

$\begin{array}{llllllllll}\text { Strongly disagree } & \mathbf{3} & \mathbf{2} & \mathbf{1} & \mathbf{0} & \mathbf{1} & \mathbf{2} & \mathbf{3} & \text { Stronglyagree }\end{array}$

If I wanted to, I could make most of my journeys to the university campus over the next week WITHOUT using a car

$\begin{array}{llllllllll}\text { Strongly disagree } & \mathbf{3} & \mathbf{2} & \mathbf{1} & \mathbf{0} & \mathbf{1} & \mathbf{2} & \mathbf{3} & \text { Strongly agree }\end{array}$

How much control do you have over making most of your journeys to the university campus over the next week WITHOUT using a car?

$\begin{array}{llllllllll}\text { No control } & 3 & 2 & \mathbf{1} & \mathbf{0} & \mathbf{1} & \mathbf{2} & \mathbf{3} & \text { Complete }\end{array}$ control

It is mostly up to me whether or not I make most of my journeys to the university campus over the next week WITHOUT using a car

$\begin{array}{llllllllll}\text { Strongly disagree } & \mathbf{3} & \mathbf{2} & \mathbf{1} & \mathbf{0} & \mathbf{1} & \mathbf{2} & \mathbf{3} & \text { Strongly agree }\end{array}$

I am able to control whether I make most of my journeys to the university campus over the next week WITHOUT using a car

$\begin{array}{llllllllll}\text { Strongly disagree } & \mathbf{3} & \mathbf{2} & \mathbf{1} & \mathbf{0} & \mathbf{1} & \mathbf{2} & \mathbf{3} & \text { Strongly agree }\end{array}$ 
The following is a leisure activity that you may often perform. Assume that you would like to spontaneously engage in this activity. Which mode of transportation would you be most likely to use?

Press:

C for car

B for bus

T for train

O for other (e.g. taxi, cycle, walk)

When presented with each activity, please indicate AS QUICKLY AS POSSIBLE which mode of transport you would use to make the journey, by pressing the appropriate keys.

Practice trials

Going for a drink with friends

Going to the countryside

Going to the library

Visiting your parents

Going to the beach with friends

Experimental trials

Visiting a friend

Going to a concert

Playing sports

Taking a trip on a nice day

Routine grocery shopping

Going to the movies

Going on a date

Going out for dinner

Shopping after work

Going shopping for clothes 
A.6.7. Study 6 Time 2 email and questionnaire

Subject: Transport questionnaire part 2

Hi there,

Following your participation in my questionnaire study last week, I now need you to email me your responses to the following questions.

Please reply to this email AS SOON AS POSSIBLE and write your responses where indicated.

Thanks,

Ben

\section{TRANSPORT QUESTIONNAIRE PART 2}

1) How many journeys did you make to the university campus over the last week? JOURNEYS

2) How many journeys to the university campus did you make by CAR over the last week? JOURNEYS

3) How many journeys to the university campus did you make by PUBLIC TRANSPORT (e.g. bus, train) over the last week? JOURNEYS

4) How many journeys to the university campus did you make by any other form of transport (e.g. WALKING, CYCLING, MOTORBIKE) over the last week? JOURNEYS

*** Please only answer the following question if you did not make all of your journeys to the university campus by car. ${ }^{* * *}$

5) You may have intended to make one or more journeys over the last week by car but were unable to because a car was not available to you (e.g. your car had broken down, or was being used by a family member).

Was a car available to you for all of the journeys you made to the university campus over the last week? YES / NO

If no, for how many journeys to the university campus was your car unavailable? JOURNEYS 
A.6.8. Study 6 Time 2 reminder email

Subject: REMINDER: Transport questionnaire part 2

Hi there,

I have not yet received your responses to the second part of my driving questionnaire. This in itself is not a problem, but when you do respond, please complete the questionnaire AS YOU WOULD HAVE DONE on XXXDAY XX XXXUary. So, your responses should relate to the week preceding $X X X$ day $X X$.

Upon receiving your responses to the second part of the questionnaire, I will email you to arrange a time for you to collect your five pounds or course credits.

Many thanks,

Ben 
A.6.9. Study 6 debrief

Hi there,

Thank you for your email, and for participating in my study. The questionnaire was designed to explore whether people choose to drive because they have formed a habit and so do so automatically, or whether they deliberate over the pros and cons of driving before deciding which transport mode to use.

To measure habit, I used a brief scale comprising 4 items that I have devised. To ensure that this scale is appropriate, it was necessary to compare my scale with existing measures of habit, and so I also had to include around 20 items from other habit measures, and the reaction time task. This is why there were so many similar questions in the questionnaire.

Many thanks for participating,

Ben 


\section{PARTICIPANTS \\ NEEDED for PAID questionnaire study}

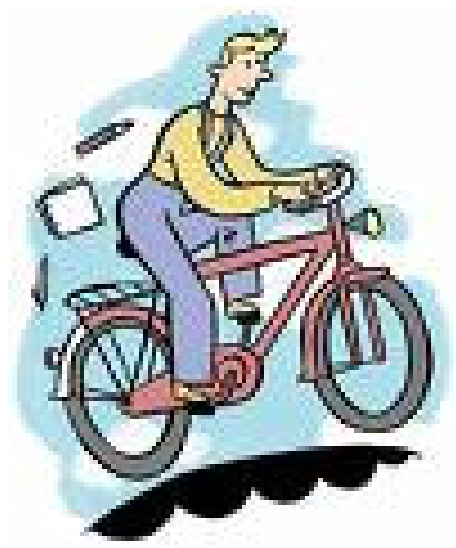

\section{0,5 proefpersoon punten (or $€ 5 \mathrm{CASH}$ ) for $15-20$ minutes!}

\section{Do you have A BICYCLE? \\ Do you SPEAK ENGLISH?}

If so, you can participate in my questionnaire study. All you are required to do is come into the lab for 15 minutes, then one week later spend 1-2 minutes answering a few short questions via email.

You will then be given two proefpersoon punten or $€ 5$ in CASH.

\section{Please email}

R.Ruiter@psychology.unimaas.nl 


\section{Transport questionnaire}

1. Your email address:

2. What is your age?

3. Are you:

Male

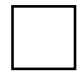

Female

4. How many journeys did you make to the university over the last week? journeys

5. How many journeys to the university did you make by BICYCLE over the last week? journeys

6. How many journeys to the university did you make by CAR over the last week? journeys

7. How many journeys to the university did you make by any other form of transport (e.g. MOTORBIKE, BUS, TRAIN, WALKING) over the last week?

journeys

Please answer the following questions honestly.

All responses are anonymous and confidential.

Many of the questions are similar. This is intentional. In all cases, please complete each question without thinking about how you may have completed previous questions.

THERE IS NO TIME LIMIT FOR RESPONDING TO THESE QUESTIONS; please take as long as you require. 
When you need to make a journey, is choosing to use a bicycle something you do automatically, without really thinking?

$\begin{array}{llllllllll}\text { Definitely no } & 3 & 2 & 1 & 0 & 1 & 2 & 3 & \text { Definitely yes }\end{array}$

When I have to make a journey, I tend NOT to think about the modes of transport available to me

$\begin{array}{llllllllll}\text { Strongly disagree } & \mathbf{3} & \mathbf{2} & \mathbf{1} & \mathbf{0} & \mathbf{1} & \mathbf{2} & \mathbf{3} & \text { Strongly agree }\end{array}$

When I have to make a journey, I offen use a bicycle without really thinking about the possibility of using other transport modes

$\begin{array}{llllllllll}\text { Definitely do not } & \mathbf{3} & \mathbf{2} & \mathbf{1} & \mathbf{0} & \mathbf{1} & \mathbf{2} & \mathbf{3} & \text { Definitely } d o\end{array}$

When I have to make a journey, deciding to use a bicycle is something I do automatically

$\begin{array}{llllllllll}\text { Strongly disagree } & \mathbf{3} & \mathbf{2} & \mathbf{1} & \mathbf{0} & \mathbf{1} & \mathbf{2} & \mathbf{3} & \text { Strongly agree }\end{array}$

I automatically choose to use a bicycle when I have to make a journey

$\begin{array}{llllllllll}\text { Strongly disagree } & \mathbf{3} & \mathbf{2} & \mathbf{1} & \mathbf{0} & \mathbf{1} & \mathbf{2} & \mathbf{3} & \text { Strongly agree }\end{array}$

When I need to make a journey, I DO NOT consider all available transport options before I choose to use a bicycle

$\begin{array}{llllllllll}\text { Strongly disagree } & \mathbf{3} & \mathbf{2} & \mathbf{1} & \mathbf{0} & \mathbf{1} & \mathbf{2} & \mathbf{3} & \text { Strongly agree }\end{array}$

When planning a journey, I am not usually aware of making a decision about what mode of transport (e.g. bicycle, bus, train, etc) I should use

$\begin{array}{llllllllll}\text { Strongly disagree } & \mathbf{3} & \mathbf{2} & \mathbf{1} & \mathbf{0} & \mathbf{1} & \mathbf{2} & \mathbf{3} & \text { Strongly agree }\end{array}$

When I need to go somewhere I automatically think about using a bicycle to get there

$\begin{array}{llllllllll}\text { Strongly disagree } & \mathbf{3} & \mathbf{2} & \mathbf{1} & \mathbf{0} & \mathbf{1} & \mathbf{2} & \mathbf{3} & \text { Strongly agree }\end{array}$

When I need to travel, choosing to use a bicycle is something I do automatically, without really thinking

$\begin{array}{llllllllll}\text { Strongly disagree } & \mathbf{3} & \mathbf{2} & \mathbf{1} & \mathbf{0} & \mathbf{1} & \mathbf{2} & \mathbf{3} & \text { Stronglyagree }\end{array}$ 
Using a bicycle to commute to campus is something I do frequently

$\begin{array}{lllllllll}\text { Strongly disagree } & \mathbf{3} & \mathbf{2} & \mathbf{1} & \mathbf{0} & \mathbf{1} & \mathbf{2} & \mathbf{3} & \text { Strongly agree }\end{array}$

Using a bicycle to commute to campus is something I do automatically

$\begin{array}{lllllllll}\text { Strongly disagree } & \mathbf{3} & \mathbf{2} & \mathbf{1} & \mathbf{0} & \mathbf{1} & \mathbf{2} & \mathbf{3} & \text { Strongly agree }\end{array}$

Using a bicycle to commute to campus is something I do without having to consciously remember

$\begin{array}{llllllllll}\text { Strongly disagree } & \mathbf{3} & \mathbf{2} & \mathbf{1} & \mathbf{0} & \mathbf{1} & \mathbf{2} & \mathbf{3} & \text { Strongly agree }\end{array}$

Using a bicycle to commute to campus is something that makes me feel weird if I do not do it

$\begin{array}{lllllllll}\text { Strongly disagree } & \mathbf{3} & \mathbf{2} & \mathbf{1} & \mathbf{0} & \mathbf{1} & \mathbf{2} & \mathbf{3} & \text { Strongly agree }\end{array}$

Using a bicycle to commute to campus is something I do without thinking

$\begin{array}{llllllllll}\text { Strongly disagree } & \mathbf{3} & \mathbf{2} & \mathbf{1} & \mathbf{0} & \mathbf{1} & \mathbf{2} & \mathbf{3} & \text { Strongly agree }\end{array}$

Using a bicycle to commute to campus is something that would require effort not to do

$\begin{array}{llllllllll}\text { Strongly disagree } & \mathbf{3} & \mathbf{2} & \mathbf{1} & \mathbf{0} & \mathbf{1} & \mathbf{2} & \mathbf{3} & \text { Strongly agree }\end{array}$

Using a bicycle to commute to campus is something that belongs to my daily routine

$\begin{array}{llllllllll}\text { Strongly disagree } & \mathbf{3} & \mathbf{2} & \mathbf{1} & \mathbf{0} & \mathbf{1} & \mathbf{2} & \mathbf{3} & \text { Strongly agree }\end{array}$

Using a bicycle to commute to campus is something I start doing before I realize I'm doing it

$\begin{array}{lllllllll}\text { Strongly disagree } & \mathbf{3} & \mathbf{2} & \mathbf{1} & \mathbf{0} & \mathbf{1} & \mathbf{2} & \mathbf{3} & \text { Stronglyagree }\end{array}$

Using a bicycle to commute to campus is something I would find hard not to do

$\begin{array}{llllllllll}\text { Strongly disagree } & \mathbf{3} & \mathbf{2} & \mathbf{1} & \mathbf{0} & \mathbf{1} & \mathbf{2} & \mathbf{3} & \text { Strongly agree }\end{array}$ 
Using a bicycle to commute to campus is something I have no need to think about doing

$\begin{array}{lllllllll}\text { Strongly disagree } & \mathbf{3} & \mathbf{2} & \mathbf{1} & \mathbf{0} & \mathbf{1} & \mathbf{2} & \mathbf{3} & \text { Strongly agree }\end{array}$

Using a bicycle to commute to campus is something that's typically "me"

$\begin{array}{llllllllll}\text { Strongly disagree } & \mathbf{3} & \mathbf{2} & \mathbf{1} & \mathbf{0} & \mathbf{1} & \mathbf{2} & \mathbf{3} & \text { Strongly agree }\end{array}$

Using a bicycle to commute to campus is something I have been doing for a long time

$\begin{array}{llllllllll}\text { Strongly disagree } & \mathbf{3} & \mathbf{2} & \mathbf{1} & \mathbf{0} & \mathbf{1} & \mathbf{2} & \mathbf{3} & \text { Strongly agree }\end{array}$

I intend to use a bicycle for most of my journeys to the university campus over the next week

$\begin{array}{llllllllll}\text { Strongly disagree } & \mathbf{3} & \mathbf{2} & \mathbf{1} & \mathbf{0} & \mathbf{1} & \mathbf{2} & \mathbf{3} & \text { Strongly agree }\end{array}$

I will try to use a bicycle for most of my journeys to the university campus over the next week

$\begin{array}{llllllllll}\text { Strongly disagree } & \mathbf{3} & \mathbf{2} & \mathbf{1} & \mathbf{0} & \mathbf{1} & \mathbf{2} & \mathbf{3} & \text { Stronglyagree }\end{array}$

I plan to use a bicycle for most of my journeys to the university campus over the next week

$\begin{array}{llllllllll}\text { Strongly disagree } & \mathbf{3} & \mathbf{2} & \mathbf{1} & \mathbf{0} & \mathbf{1} & \mathbf{2} & \mathbf{3} & \text { Strongly agree }\end{array}$

I aim to use a bicycle for most of my journeys to the university campus over the next week

$\begin{array}{llllllllll}\text { Strongly disagree } & \mathbf{3} & \mathbf{2} & \mathbf{1} & \mathbf{0} & \mathbf{1} & \mathbf{2} & \mathbf{3} & \text { Strongly agree }\end{array}$ 
Using a bicycle for most of my journeys to the university campus over the next week would be:

$\begin{array}{lllllllll}\text { Harmful } & \mathbf{3} & \mathbf{2} & \mathbf{1} & \mathbf{0} & \mathbf{1} & \mathbf{2} & \mathbf{3} & \text { Beneficial } \\ \text { Pleasant } & \mathbf{3} & \mathbf{2} & \mathbf{1} & \mathbf{0} & \mathbf{1} & \mathbf{2} & \mathbf{3} & \text { Unpleasant } \\ \text { Good } & \mathbf{3} & \mathbf{2} & \mathbf{1} & \mathbf{0} & \mathbf{1} & \mathbf{2} & \mathbf{3} & \text { Bad } \\ \text { Enjoyable } & \mathbf{3} & \mathbf{2} & \mathbf{1} & \mathbf{0} & \mathbf{1} & \mathbf{2} & \mathbf{3} & \text { Unenjoyable } \\ \text { Wise } & \mathbf{3} & \mathbf{2} & \mathbf{1} & \mathbf{0} & \mathbf{1} & \mathbf{2} & \mathbf{3} & \text { Foolish }\end{array}$

Making most of my journeys to the university campus over the next week WITHOUT using a bicycle would be:

$\begin{array}{lllllllll}\text { Harmful } & \mathbf{3} & \mathbf{2} & \mathbf{1} & \mathbf{0} & \mathbf{1} & \mathbf{2} & \mathbf{3} & \text { Beneficial } \\ \text { Pleasant } & \mathbf{3} & \mathbf{2} & \mathbf{1} & \mathbf{0} & \mathbf{1} & \mathbf{2} & \mathbf{3} & \text { Unpleasant } \\ \text { Good } & \mathbf{3} & \mathbf{2} & \mathbf{1} & \mathbf{0} & \mathbf{1} & \mathbf{2} & \mathbf{3} & \text { Bad } \\ \text { Enjoyable } & \mathbf{3} & \mathbf{2} & \mathbf{1} & \mathbf{0} & \mathbf{1} & \mathbf{2} & \mathbf{3} & \text { Unenjoyable } \\ \text { Wise } & \mathbf{3} & \mathbf{2} & \mathbf{1} & \mathbf{0} & \mathbf{1} & \mathbf{2} & \mathbf{3} & \text { Foolish }\end{array}$

Most people who are important to me think that I should use a bicycle for most of my journeys to the university campus over the next week

$\begin{array}{llllllllll}\text { Strongly disagree } & \mathbf{3} & \mathbf{2} & \mathbf{1} & \mathbf{0} & \mathbf{1} & \mathbf{2} & \mathbf{3} & \text { Stronglyagree }\end{array}$

People who are important to me expect me to use a bicycle for most of my journeys to the university campus over the next week

$\begin{array}{llllllllll}\text { Strongly disagree } & \mathbf{3} & \mathbf{2} & \mathbf{1} & \mathbf{0} & \mathbf{1} & \mathbf{2} & \mathbf{3} & \text { Stronglyagree }\end{array}$

If I use a bicycle for most of my journeys to the university campus over the next week, people who are important to me would approve

$\begin{array}{llllllllll}\text { Strongly disagree } & \mathbf{3} & \mathbf{2} & \mathbf{1} & \mathbf{0} & \mathbf{1} & \mathbf{2} & \mathbf{3} & \text { Stronglyagree }\end{array}$

Most people who are important to me think that I should make most of my journeys to the university campus over the next week WITHOUT using a bicycle

$\begin{array}{llllllllll}\text { Strongly disagree } & \mathbf{3} & \mathbf{2} & \mathbf{1} & \mathbf{0} & \mathbf{1} & \mathbf{2} & \mathbf{3} & \text { Strongly agree }\end{array}$

People who are important to me expect me to make most of my journeys to the university campus over the next week WITHOUT using a bicycle

$\begin{array}{llllllllll}\text { Strongly disagree } & \mathbf{3} & \mathbf{2} & \mathbf{1} & \mathbf{0} & \mathbf{1} & \mathbf{2} & \mathbf{3} & \text { Strongly agree }\end{array}$ 
If I made most of my journeys to the university campus over the next week WITHOUT using a bicycle, people who are important to me would approve

$\begin{array}{llllllllll}\text { Strongly disagree } & \mathbf{3} & \mathbf{2} & \mathbf{1} & \mathbf{0} & \mathbf{1} & \mathbf{2} & \mathbf{3} & \text { Strongly agree }\end{array}$

If I wanted to, I could use a bicycle for most of my journeys to the university campus over the next week

$\begin{array}{llllllllll}\text { Strongly disagree } & \mathbf{3} & \mathbf{2} & \mathbf{1} & \mathbf{0} & \mathbf{1} & \mathbf{2} & \mathbf{3} & \text { Strongly agree }\end{array}$

How much control do you have over using a bicycle for most of your journeys to the university campus over the next week?

$\begin{array}{llllllllll}\text { No control } & \mathbf{3} & \mathbf{2} & \mathbf{1} & \mathbf{0} & \mathbf{1} & \mathbf{2} & \mathbf{3} & \text { Complete }\end{array}$ control

It is mostly up to me whether or not I use a bicycle for most of my journeys to the university campus over the next week

$\begin{array}{lllllllll}\text { Strongly disagree } & \mathbf{3} & \mathbf{2} & \mathbf{1} & \mathbf{0} & \mathbf{1} & \mathbf{2} & \mathbf{3} & \text { Strongly agree }\end{array}$

I am able to control whether I use a bicycle for most of my journeys to the university campus over the next week

$\begin{array}{llllllllll}\text { Strongly disagree } & \mathbf{3} & \mathbf{2} & \mathbf{1} & \mathbf{0} & \mathbf{1} & \mathbf{2} & \mathbf{3} & \text { Strongly agree }\end{array}$

If I wanted to, I could make most of my journeys to the university campus over the next week WITHOUT using a bicycle

$\begin{array}{llllllllll}\text { Strongly disagree } & \mathbf{3} & \mathbf{2} & \mathbf{1} & \mathbf{0} & \mathbf{1} & \mathbf{2} & \mathbf{3} & \text { Strongly agree }\end{array}$

How much control do you have over making most of your journeys to the university campus over the next week WITHOUT using a bicycle?

$\begin{array}{llllllllll}\text { No control } & 3 & 2 & \mathbf{1} & \mathbf{0} & \mathbf{1} & \mathbf{2} & \mathbf{3} & \text { Complete }\end{array}$ control

It is mostly up to me whether or not I make most of my journeys to the university campus over the next week WITHOUT using a bicycle

$\begin{array}{llllllllll}\text { Strongly disagree } & \mathbf{3} & \mathbf{2} & \mathbf{1} & \mathbf{0} & \mathbf{1} & \mathbf{2} & \mathbf{3} & \text { Stronglyagree }\end{array}$ 
I am able to control whether I make most of my journeys to the university campus over the next week WITHOUT using a bicycle

$\begin{array}{llllllllll}\text { Strongly disagree } & \mathbf{3} & \mathbf{2} & \mathbf{1} & \mathbf{0} & \mathbf{1} & \mathbf{2} & \mathbf{3} & \text { Strongly agree }\end{array}$

The following is a leisure activity that you may often perform. Assume that you would like to spontaneously engage in this activity. Which mode of transportation would you be most likely to use?

Press:

B for bicycle

C for bus

$\mathbf{T}$ for train

O for other (e.g. taxi, walk)

When presented with each activity, please indicate AS QUICKLY AS POSSIBLE which mode of transport you would use to make the journey, by pressing the appropriate keys.

Practice trials

Going for a drink with friends

Going to the countryside

Going to the library

Visiting your parents

Going to the beach with friends

Experimental trials

Visiting a friend

Going to a concert

Playing sports

Taking a trip on a nice day

Routine grocery shopping

Going to the movies

Going on a date

Going out for dinner

Shopping after work

Going shopping for clothes 
A.6.12. Study 7 Time 2 email and questionnaire

Subject: Transport questionnaire part 2

Hi there,

Following your participation in my questionnaire study last week, I now need you to email me your responses to the following short questions.

Please reply to this email AS SOON AS POSSIBLE and write your responses where indicated.

Thanks,

Ben

TRANSPORT QUESTIONNAIRE PART 2

1) How many journeys did you make to the university over the last week?

JOURNEYS

2) How many journeys to the university did you make by BICYCLE over the last week? JOURNEYS

3) How many journeys to the university did you make by CAR over the last week? JOURNEYS

4) How many journeys to the university did you make by any other form of transport (e.g. MOTORBIKE, BUS, TRAIN, WALKING) over the last week?

_ JOURNEYS

*** Please only answer the following question if you did not make all of your journeys to the university by bicycle. ${ }^{* * *}$

5) You may have intended to make one or more journeys over the last week by bicycle but were unable to because a bicycle was not available to you (e.g. your bicycle was being repaired).

Was a bicycle available to you for all of the journeys you made to the university campus over the last week? YES / NO

If no, for how many journeys to the university was your bicycle unavailable? JOURNEYS 
A.6.13. Study 7 Time 2 reminder email

Subject: REMINDER: Transport questionnaire part 2

Hi there,

I have not yet received your responses to the second part of my driving questionnaire. Please respond as soon as possible, completing the questionnaire AS YOU WOULD HAVE DONE on XXXDAY XX MARCH. So, your responses should relate to the week preceding XX March.

Upon receiving your responses to the second part of the questionnaire, I will email you to arrange a time for you to collect your five Euros or proefpersoon punten.

The questions are given again below for ease of access.

Many thanks,

Ben 
A.6.14. Study 7 debrief

Hi there,

Thank you for your responses, and for participating in my study. The questionnaire was designed to explore whether people use bicycles because they have formed a habit and so do so automatically, or whether they deliberate over the advantages and disadvantages before deciding which transport mode to use.

To measure habit, I used a brief scale comprising 4 items that I have devised. To ensure that this scale is appropriate, it was necessary to compare my scale with existing measures of habit, and so I also had to include around 20 items from other habit measures, and the reaction time task. This is why there were so many similar questions in the questionnaire.

Many thanks for participating,

Ben 